\title{
Characterizing Synergisms between Algae-Mediated Bioenergy Production and Ecosystem Services
}

\author{
A Dissertation submitted to the \\ Faculty of the School of Engineering and Applied Sciences \\ University of Virginia \\ In partial fulfillment of the requirements for the degree \\ Doctor of Philosophy \\ In Civil and Environmental Engineering
}

Eleazer Pangilinan Resurreccion

May 2013 


\section{Approval Sheet}

This dissertation is submitted in partial fulfillment

of the requirements for the degree of

Doctor of Philosophy in Civil and Environmental Engineering

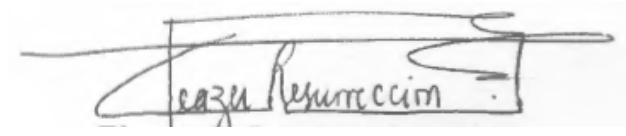

Eleazer P. Resurreccion

(Author)

This dissertation has been read and approved by the examining committee:

Andres F. Clarens, Ph.D. (Co-Advisor)

Lisa M. Colosi, Ph.D. (Co-Advisor)

Teresa B. Culver, Ph.D. (Chairperson)

Wu-Seng Lung, Ph.D.

Mark A. White, Ph.D.

Accepted for the School of Engineering and Applied Sciences

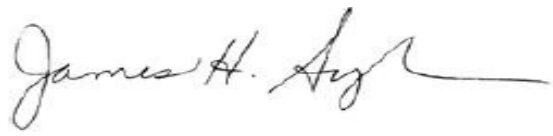

James H. Aylor, Ph.D.

(Dean, School of Engineering and Applied Sciences)

May 2013 


\begin{abstract}
The goal of this work is to understand synergies between municipal wastewater treatment and algae cultivation in terms of energy production, nutrient recycling, and removal of estrogenic endocrine disrupting compounds (eEDCs). Complementary life cycle assessment (LCA) and laboratory experiments were utilized to deliver integrated information about the relative sustainability of various algae-derived energy carriers, compared to each other and to terrestrial biofuels benchmarks. A comprehensive LCA framework was developed to facilitate analysis of proposed algae-to-energy system configurations and between algae-derived energy and relevant benchmarks, using both traditional environmental impacts (land use, energy use, water use, etc.) and also eEDC removal as criteria for comparison. It is expected that inclusion of eEDC removal as a key "ecosystem service" performed by an integrated algae-wastewater system could make these systems environmentally preferable to standalone systems for either process. Using LCA results as a design tool, experimental work was carried out to understand the optimal conditions under which to leverage algae as a wastewater effluent polishing step. Experimental outcomes include: (1) assessment of eEDC removal efficacy and efficiency during algae cultivation; and (2) apportionment among possible algae-mediated estrogen removal reactions (i.e., photolysis, biosorption, and biotransformation). Fate and transport parameters derived from experimental studies were then used to construct an eEDC mass-balance model for the unit operations comprising algae-to-energy system configurations. The proposed dissertation research creates critical knowledge pertaining to improving the overall sustainability of the water-energy nexus.
\end{abstract}




\section{Acknowledgements}

For the greater glory of God.

I wish to extend gratitude to Dr. Andres F. Clarens and Dr. Lisa Colosi for their guidance in the completion of this manuscript. I am also thankful to Dr. Mark A. White for his economic insights and to my committee members Dr. Teresa B. Culver and Dr. Wu-Seng Lung. Finally, I am grateful to Dr. Michael J. Smith for his mentorship and presentation guidance. 


\section{List of Acronyms and Symbols}

\begin{tabular}{|c|c|}
\hline \multicolumn{2}{|l|}{ Acronyms } \\
\hline $\mathrm{AC}$ & Algae cultivation \\
\hline CAN & Acetonitrile \\
\hline $\mathrm{AD}$ & Anaerobic digestion \\
\hline A-D & Anderson-Darling statistics distribution \\
\hline AFDW & Ash-free dry weight \\
\hline ASTM & American Society for Testing and Materials \\
\hline BEV & Battery electric vehicle \\
\hline BioD & Biodiesel \\
\hline BioE & Bioelectricity \\
\hline BNR & Biological nutrients removal \\
\hline BSW & Brackish-to-saline water \\
\hline CAS & Conventional activated sludge \\
\hline $\mathrm{CC}$ & Capital cost \\
\hline $\mathrm{DC}$ & Direct combustion \\
\hline DI & Distilled deionized water \\
\hline DCM & Dichloromethane \\
\hline DOC & Dissolved organic carbon \\
\hline eEDC & Estrogenic endocrine disrupting compounds \\
\hline EEQ & Estrogenic equivalent \\
\hline EUT & Eutrophication potential \\
\hline $\mathrm{EN}$ & Energy use \\
\hline EROI & Energy return on investment \\
\hline FW & Freshwater \\
\hline GCMS & Gas chromatography-mass spectrometry \\
\hline GHG & Greenhouse gas \\
\hline gpm & Gallons per minute \\
\hline GAC & Granulated activated carbon \\
\hline GWP & Global warming potential \\
\hline $\mathrm{HHV}$ & High heating value \\
\hline HPLC & High-performance liquid chromatography \\
\hline HRT & Hydraulic retention time \\
\hline $\mathrm{ICV}$ & Internal combustion vehicle \\
\hline IPAR & Intercepted photosynthetically active radiation \\
\hline ISO & International Organization for Standardization \\
\hline LCA & Life cycle assessment \\
\hline LCC & Life cycle costing \\
\hline LCMS & Liquid chromatography-mass spectrometry \\
\hline LEC & Levelized energy cost \\
\hline LHV & Low heating value \\
\hline LU & Land use \\
\hline MB3N & Modified Bold 3N \\
\hline MEC & Major equipment cost \\
\hline MGD & Million gallons per day \\
\hline MPN & Most probable number \\
\hline MW & Molecular weight \\
\hline NGR & Net greenhouse gas ratio \\
\hline $\mathrm{OP}$ & Open pond \\
\hline
\end{tabular}




$\begin{array}{ll}\text { OZ } & \text { Ozonation } \\ \text { PAR } & \text { Photosynthetically-active radiation } \\ \text { PBR } & \text { Photobioreactor } \\ \text { PE } & \text { Photosynthetic efficiency } \\ \text { PI } & \text { Profitability index } \\ \text { PMMA } & \text { Polymethyl methacrylate } \\ \text { PP } & \text { Polypropylene } \\ \text { ppb } & \text { Parts per billion } \\ \text { ppm } & \text { Parts per million } \\ \text { PT } & \text { Primary treatment } \\ \text { PV } & \text { Present value } \\ \text { PVC } & \text { Polyvinyl chloride } \\ \text { PW } & \text { Paddle wheels } \\ \text { RAS } & \text { Return activated sludge } \\ \text { RH } & \text { Relative humidity } \\ \text { rpm } & \text { Rotations per minutes } \\ \text { RO } & \text { Reverse osmosis } \\ \text { RUE } & \text { Radiation use efficiency } \\ \text { SCFM } & \text { Standard cubic feet per minute } \\ \text { SPE } & \text { Solid-phase extraction } \\ \text { SRT } & \text { Sludge residence time } \\ \text { SSU } & \text { Source-separated urine } \\ \text { ST } & \text { Secondary treatment } \\ \text { SWW } & \text { Synthetic wastewater } \\ \text { TE } & \text { Transfer efficiency } \\ \text { TKN } & \text { Total Kjeldahl nitrogen } \\ \text { TP } & \text { Total phosphorus } \\ \text { TSS } & \text { Total suspended solids } \\ \text { UV } & \text { Ultraviolet } \\ \text { VKT } & \text { Vehicle kilometers traveled } \\ \text { VSS } & \text { Volatile suspended solids } \\ \text { WAS } & \text { Waste activated sludge } \\ \text { WWTP } & \text { Wastewater treatment plant } \\ \text { WU } & \text { Water use } \\ & \end{array}$

\section{Arabic Symbols}

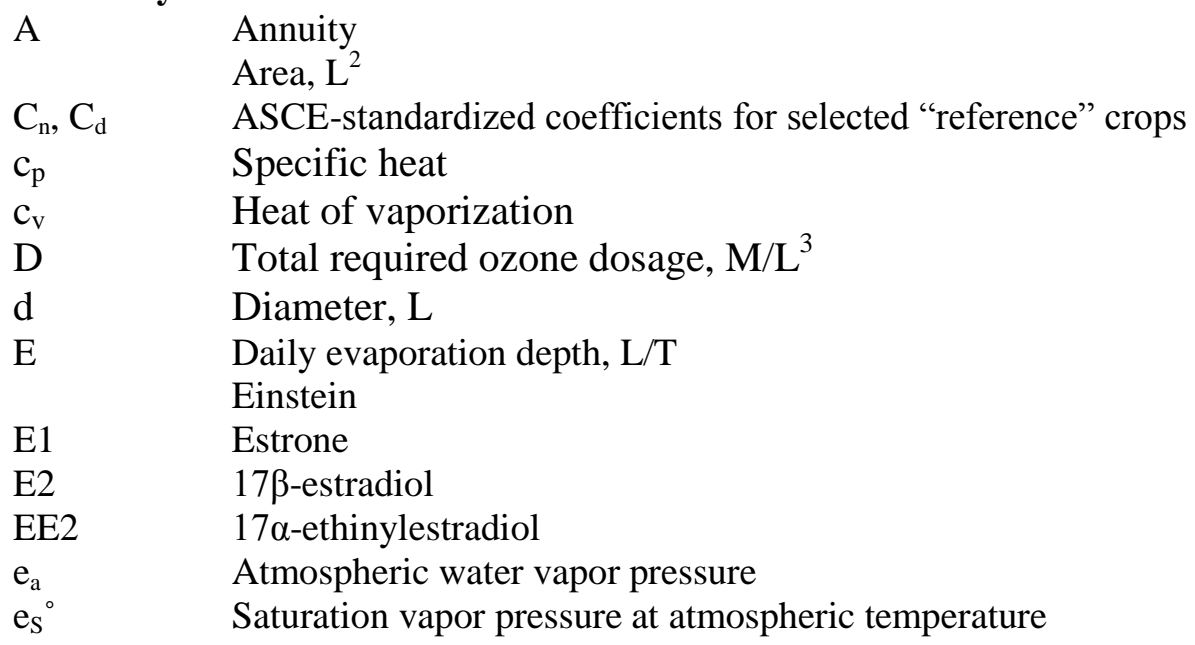




\begin{tabular}{|c|c|}
\hline $\mathrm{f}$ & Darcy-Weisbach friction factor \\
\hline \multirow[t]{2}{*}{ G } & Global solar insolation \\
\hline & Gravitational force \\
\hline $\mathrm{g}$ & Acceleration due to gravity \\
\hline $\mathrm{GkW}$ & Flue gas pump power rating \\
\hline $\mathrm{G}_{\mathrm{S}}$ & Soil heat flux density at the soil surface \\
\hline $\mathrm{H}_{\mathrm{L}}$ & Head loss, L \\
\hline $\mathrm{h}$ & Height, L \\
\hline hp & Horsepower \\
\hline \multirow[t]{2}{*}{ I } & Centrifuge constant \\
\hline & Second moment of inertia \\
\hline K & Elbow constant \\
\hline $\mathrm{K}_{\mathrm{E}}$ & Mass transfer coefficient \\
\hline \multirow[t]{2}{*}{$\mathrm{k}$} & Cohesion constant \\
\hline & Shape parameter \\
\hline $\mathrm{k}_{1}, \mathrm{k}_{2}$ & Centrifuge constants \\
\hline $\mathrm{L}$ & Length \\
\hline $\mathrm{L}_{\mathrm{eff}}$ & Effective length of centrifuge, $\mathrm{L}$ \\
\hline \multirow[t]{2}{*}{$M$} & Mass \\
\hline & Moment of inertia \\
\hline $\mathrm{m}_{\mathrm{ss}}$ & Dry feed rate of slurry to centrifuge, $\mathrm{M} / \mathrm{T}$ \\
\hline $\mathrm{N}$ & Number of microorganisms \\
\hline $\mathrm{n}$ & Number of items or data points \\
\hline $\mathrm{P}$ & Pressure \\
\hline $\mathrm{P}_{\mathrm{acc}}$ & Power to accelerate feed stream \\
\hline $\mathrm{P}_{\text {con }}$ & Power to convey and discharge cake \\
\hline$r_{P}$ & Radius of centrifuge, $\mathrm{L}$ \\
\hline S & Material design stress \\
\hline $\mathrm{SA}_{\mathrm{I}}$ & Irradiated surface area, $\mathrm{L}^{2}$ \\
\hline Q & Flow rate, $\mathrm{L}^{3 /} \mathrm{T}$ \\
\hline $\mathrm{Q}_{\mathrm{DRYING}}$ & Amount of heat required to evaporate a known mass of water \\
\hline $\mathrm{R}_{\mathrm{N}}$ & Net solar radiation \\
\hline $\operatorname{sg}$ & Specific gravity \\
\hline $\mathrm{T}$ & Temperature \\
\hline $\mathrm{t}$ & Time, $\mathrm{T}$ \\
\hline$t_{R}$ & Retention time, $\mathrm{T}$ \\
\hline $\mathrm{U}$ & Utilized/transferred ozone dose, $\mathrm{M} / \mathrm{L}^{3}$ \\
\hline $\mathrm{u}$ & Bulk velocity, $\mathrm{L} / \mathrm{T}$ \\
\hline $\mathrm{V}$ & Volume, $\mathrm{L}^{3}$ \\
\hline$v_{\mathrm{A}}$ & Wind speed, L/T \\
\hline $\mathrm{v}_{\mathrm{H}}$ & Scouring velocity, $\mathrm{L} / \mathrm{T}$ \\
\hline$V_{\text {peak }}$ & Peak flow velocity, $\mathrm{L} / \mathrm{T}$ \\
\hline $\mathrm{W}$ & Work \\
\hline $\mathrm{W}_{\mathrm{c}}$ & Energy of compression \\
\hline
\end{tabular}

\section{Greek Symbols}

$\gamma \quad$ Normalized estrogen equivalency factor

Psychrometric constant

Specific heat ratio

$\Delta \quad$ Differential speed of centrifuge, $\mathrm{L} / \mathrm{T}$ 
Slope of the saturated vapor pressure vs. temperature at daily average air temperature

$\Delta \mathrm{z} \quad$ Elevation difference

$\varepsilon \quad$ Roughness factor

$\sigma \quad$ Bending stress

Standard deviation

$\eta \quad$ Efficiency

$\theta \quad$ Scale parameter

$\lambda_{v} \quad$ Latent heat of vaporization for water

$\mu \quad$ Average value

$\rho \quad$ Density, $\mathrm{M} / \mathrm{L}^{3}$

$\tau \quad$ Residence time, $\mathrm{T}$

$\Omega \quad$ Rotational speed of centrifuge, $1 / \mathrm{T}$ 


\section{List of Figures}

Figure 1.1 Schematic of the overall research work

Figure 2.1 Schematic of system boundaries in modeling algae and three other terrestrial crops (corn, switchgrass, canola)

Figure 2.2 Estimated algae dry yields by month in San Diego, CA

Figure 2.3 Estimated algae dry yields by month in Roanoke, VA

Figure 2.4 Estimated algae dry yields by month in Ames, IA

Figure 2.5 Schematic of algae and water flows through the ponds

Figure 2.6 Land, energy and water use impacts for the production of algae in California (CA), Iowa (IA) and Virginia (VA)

Figure 2.7 Sensitivity tornado plots of energy use and GHG emission for algae cultivation

Figure 3.1 Schematic of a generic algae-to-bioenergy production system

Figure 3.2 Modified schematic of a generic algae-to-bioenergy production system

Figure 3.3 Annual gross VKT per hectare-year for four bioenergy systems

Figure 3.4 Environmental impacts per VKT for four bioenergy systems

Figure 4.1 Top view of a 1-ha OP module and a 1-ha PBR system

Figure 4.2 Total energy input, total energy output and energy return on investment for production of one functional unit in four selected algae cultivation systems

Figure 4.3 Components of total energy inputs and energy outputs in four selected algae cultivation systems

Figure 4.4 Total greenhouse gas emissions, total greenhouse gas offsets and net greenhouse gas for production of one functional unit in four selected algae cultivation systems

Figure 4.5 Tornado plots for assessing the sensitivity of PIs to inputs in four modeled algae cultivations systems

Figure 4.6 PI probability distributions in four selected algae cultivation systems

Figure 4.7 PI probability distributions for two selected algae cultivation systems, OP-BSW and PBR-BSW

Figure 5.1 Schematic of estrogen removal in SWW

Figure 5.2 Schematic of algae cultivation set-up

Figure 5.3 Summary of sample preparation protocols used prior to HPLC analysis

Figure 5.4 Overall process flow for a WWTP employing AC to improve effluent water quality and generate bio-electricity

Figure 5.5 Overall process flow for the benchmark systems comprising primary treatment, secondary treatment, and one of four evaluated tertiary treatments

Figure 5.6 Overall process flow for a WWTP employing OZ for tertiary treatment

Figure 5.7 Schematic representation of an ozone contact unit

Figure 5.8 Overall process flow for a WWTP employing UV irradiation for tertiary treatment

Figure 5.9 Schematic representation of a UV irradiation unit

Figure 5.10 Overall process flow for a WWTP employing RO for tertiary treatment

Figure 5.11

Figure 5.12

Figure 5.13

Schematic representation of an RO filtration module

Overall process flow for a WWTP employing GAC for tertiary treatment

Figure 5.14

Schematic representation of a GAC adsorption module

Growth curve for $S$. dimorphus pure culture over 150 hours 
Figure 5.15 Concentrations of $17-\beta$ estradiol (E2) over time during cultivation of $S$. dimorphus exhibiting exponential growth

Figure 5.16 Total energy input, total energy output, and energy return on investment for production of one functional unit in five evaluated WWTP + tertiary treatment systems

Figure 5.17 Total greenhouse gas emissions, total greenhouse gas offsets, and net greenhouse gas ratio for production of one functional unit in five evaluated WWTP + tertiary treatment systems 


\section{List of Tables}

Table 2.1 Summary of parameters used to form distributions of climactic model inputs (PAR, temperature, wind speed, relative humidity, precipitation) and outputs (evaporation and evapotranspiration)

Table 2.2 Summary of Anderson-Darling statistics (goodness-of-fit) for selected climactic input distributions

Table 2.3 Cumulative IPAR and average estimated wet yields for corn production in three geographic locations

Table 2.4 PAR, reported wet switchgrass yields and computed RUE values for switchgrass production in several geographic regions

Table 2.5 PAR and average estimated wet yields for switchgrass growing seasons in three geographic locations

Table 2.6 Summary of PAR, reported winter canola seed yields and computed RUE values for several geographic regions in the US

Table 2.7 Summary of cumulative PAR and average dry yields for winter canola growing seasons in three geographic locations

Table 2.8 Summary of reported and estimated monthly values of RUE for pilot-scale algae production in three different locations

Table 2.9 Summary of cumulative PAR and average estimated dry algae yields for three geographic locations

Table 2.10 Summary of approximate elemental composition and HHV estimates for each of the biomass feedstocks evaluated in this investigation.

Table 2.11 GWP values used to estimate total impacts

Table 2.12 Eutrophication potential values used to estimate the total potential

Table 2.13 Life cycle impacts for canola seed, corn kernel, and grass silage production

Table 2.14 Life cycle impacts for electricity and chemicals used in algae production

Table 2.15 Three types of wastewater effluents with their respective concentrations of total nitrogen and total phosphorus.

Table 2.16 Life cycle impacts for electricity and chemicals used to model offset life cycle burdens associated with avoidance of wastewater treatment

Table 2.17 Five life cycle burdens for production of one functional unit of energy (317 GJ) from algae, corn, canola and switchgrass in Virginia, USA

Table 3.1 RUEs and pertinent biomass characteristics for marine algae

Table 3.2 Monthly PARs and dry yields for algae

Table 3.3

Table 3.4

Table 3.5

Water balance for algae systems corresponding to Cases A-D

Parameters for anaerobic digestion models for both Cases A and B

Table 3.6

Table 3.7

Parameters used to model digestate nutrient bioavailability during accounting for commercial fertilizer production offsets

Parameters used to model transesterification of algae oil into raw biodiesel

Table 3.8 Life cycle impact factors for materials and energy inputs for Scenarios 1-4 (Cases A-D)

Table 4.1

Table 4.2

Table 4.3

Table 4.4

Energy return on investment (EROI) for four algae conversion pathways

RUE and other pertinent biomass characteristics of algae strains in OP-FW

RUE and other pertinent biomass characteristics of algae strains in OP-BSW

RUE and other pertinent biomass characteristics of algae strains in PBR-FW

RUE and other pertinent biomass characteristics of algae strains in PBR-BSW 
Table 4.5 Summary of RUE values, lipid contents, biomass yields, lipid yields and nutrient demands for OP-FW, OP-BSW, PBR-FW and PBR-BSW

Table 4.6 Water balance for algae cultivation, conversion and post-processing

Table 4.7 Flow rates, residence times, capacity volumes, capacity liquid weights and internal tank pressures required to compute tank steel demand for conversion unit operations following all four algae cultivation systems: OP-FW, OP-BSW, PBRFW and PBR-BSW

Table 4.8 Life cycle impact factors for materials and energy inputs used in all four models: OP-FW, OP-BSW, PBR-FW and PBR-BSW

Table 4.9 Cost data showing initial outlays for OP-FW and OP-BSW delivering 20,000 VKT per year

Table 4.10 Annual cash flows of operations for OP-FW or OP-BSW algae cultivation systems delivering 20,000 VKT per year

Table 4.11 Cost data showing initial outlays for PBR-FW and PBR-BSW delivering 20,000 VKT per year

Table 4.12 Annual cash flows of operations for PBR-FW or PBR-BSW algae cultivation systems delivering 20,000 VKT per year

Table 4.13 Summary of key model inputs and outputs for production of one functional unit in four evaluated algae systems

Table 4.14 Cash flows and profitability indices associated with production of biodiesel and bioelectricity in four evaluated algae-to-bioenergy systems per FU of output

Table 5.1 Representative estrogens and their properties

Table 5.2 Typical water quality parameters for medium-strength wastewater in the U.S.

Table 5.3 Average nutrient concentrations of a typical medium-strength wastewater in the U.S. after secondary treatment secondary treatment via CAS employing BNR

Table 5.4 Stoichiometric $\mathrm{CO}_{2}, \mathrm{~N}$, and $\mathrm{P}$ requirements during algae cultivation in an integrated wastewater treatment + algae cultivation system

Table 5.5 Parameters for anaerobic co-digestion of primary and secondary WWTP sludges with algae biomass

Table 5.6 Parameters used to model digestate nutrient bioavailability, as means to estimate offsets of commercial fertilizer use

Table 5.7 Lamp characteristics corresponding to the UV module

Table 5.8 GAC specifications

Table 5.9 Parameters for anaerobic co-digestion of primary and secondary sludge without algae

Table 5.10 Parameters used to model digestate nutrient in dewatered digestate solids

Table 5.11 Water balance for all modeled cases: OZ, UV, RO, GAC, and Algae

Table 5.12 Mass fractions comprising water, algae, and sludge for systems with conventional tertiary treatment or algae-mediated tertiary treatment

Table 5.13 Empirical estrogenic potency factors for the three eEDCs

Table 5.14 Life cycle impact factors for materials and energy inputs used in LCA models for the selected tertiary treatment methods (algae, OZ, UV, RO, and GAC)

Table 5.15 E2 removal within the first 12 hours of dark and after $24 \mathrm{~h}$ and $48 \mathrm{~h}$

Table 5.16 Summary of key model outputs for treatment of one functional unit in five evaluated WWTP + tertiary treatment systems 


\section{Related Refereed Journal Articles and Conference Presentations}

Several journal papers and conference presentations have been created as a result of this research. These journal papers and conference proceedings are listed below (asterisk indicates presenter):

Resurreccion, E. P., Colosi, L. M., White, M. A., Clarens, A. F. "Comparison of AlgaeCultivation Methods for Bioenergy Production using a Combined Life Cycle Assessment and Life Cycle Costing Approach.” Bioresource Technology 126 (2012): 298 - 306.

Clarens, A. F., Nassau, H., Resurreccion, E. P., White, M. A., Colosi, L. M. "Environmental Impacts of Algae-Derived Biodiesel and Bioelectricity for Transportation." Environmental Science and Technology 45, no. 17 (2011): 7554 - 7560.

Clarens, A. F., Resurreccion, E. P., White, M. A., Colosi, L. M. "Environmental Life Cycle Comparison of Algae to Other Bioenergy Feedstocks." Environmental Science and Technology 44, no. 5 (2010): $1813-1819$.

Resurreccion, E. P.,* Colosi, L. M., White, M. A., Clarens, A. F. "Comparative Life Cycle Assessment and Life Cycle Costing of Algae Cultivation Methods." Life Cycle Assessment (LCA) XI Conference 2011: American Center for Life Cycle Assessment, Navy Pier, Chicago, IL, October 2010.

Clarens, A. F.*, Resurreccion, E. P., Colosi, L. M. "What Can Identifying the Rate-Limiting Steps in Sustainable Algae Production for Bioenergy?" New Environmental Technologies Symposium: $239^{\text {th }}$ National Meeting of the American Chemical Society, San Francisco, CA, March 2010.

Clarens, A. F.*, Resurreccion, E. P., Fry, B., White, M. A., Colosi, L. M.* "What Can Algae Farmers Learn from Environmental Engineers?" The Grand Challenge of Renewable Energy Symposium: Association of Environmental Engineering and Science Professors' Biannual Conference, Iowa City, IA, July 2009. 


\section{Table of Contents}

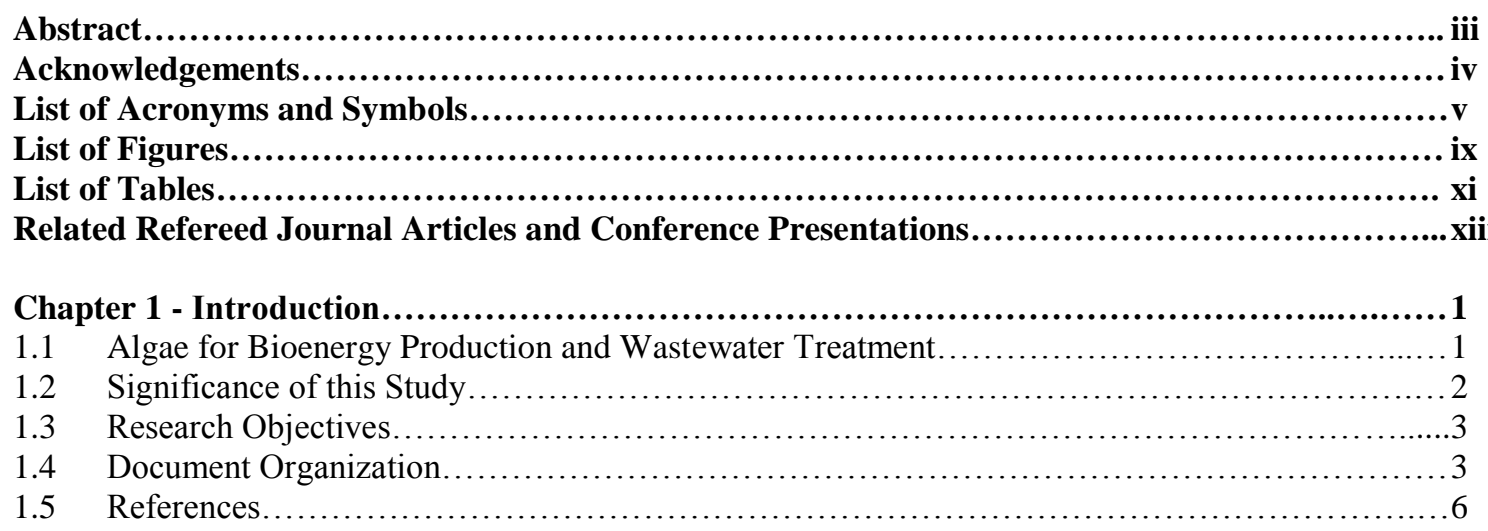

Chapter 2 - Environmental Life Cycle Comparison of Algae to Other Bioenergy Feedstocks..........7

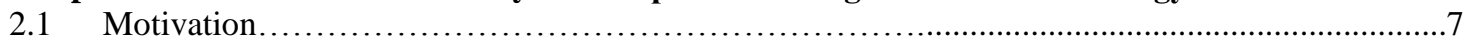

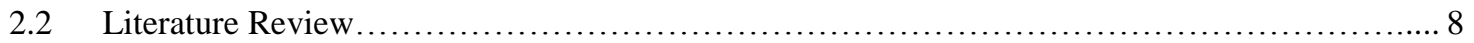

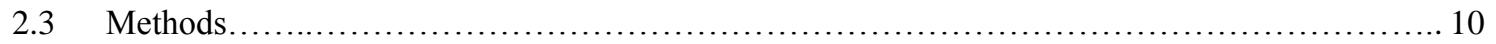

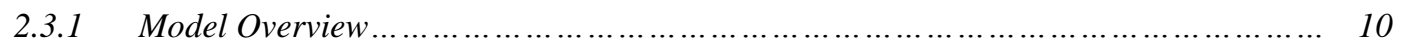

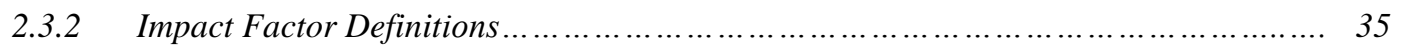

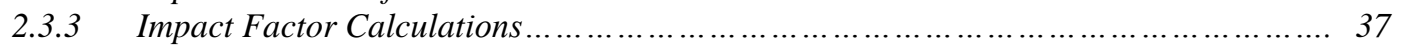

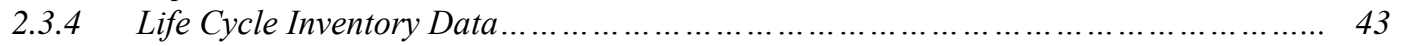

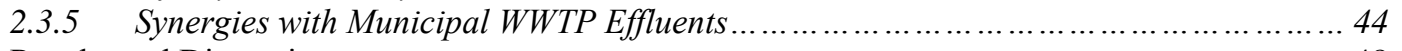

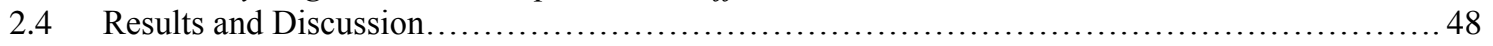

2.4.1 Comparison Among Crops............................................................ 48

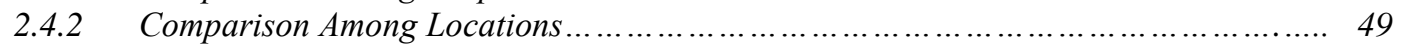

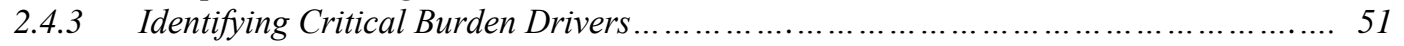

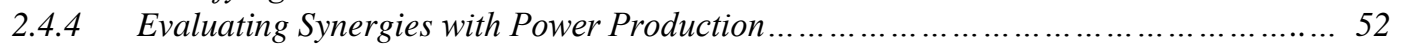

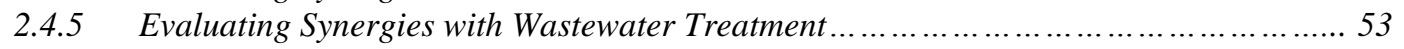

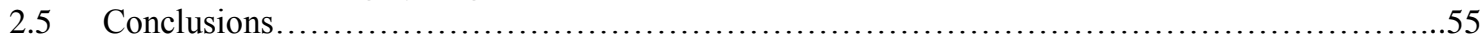

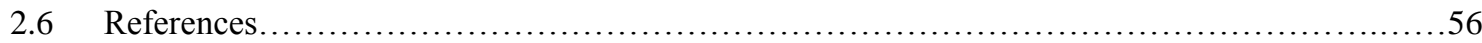

Chapter 3 - Environmental Impacts of Algae-Derived Biodiesel and Bioelectricity..................62

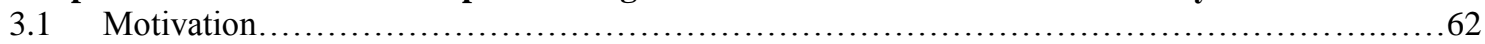

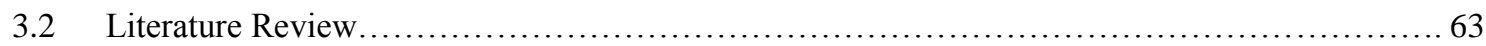

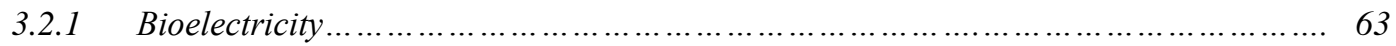

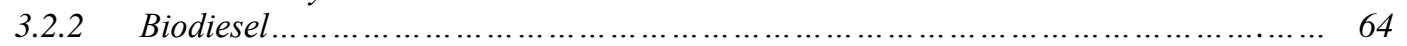

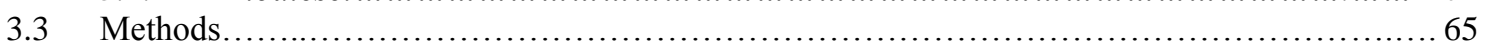

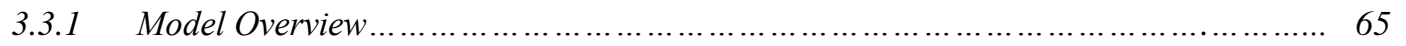

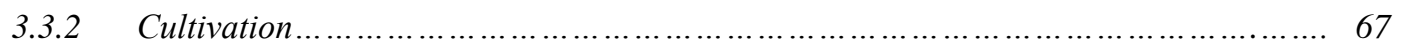

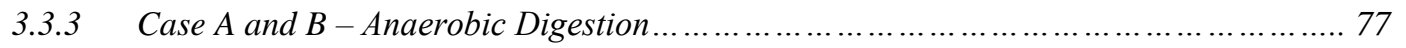

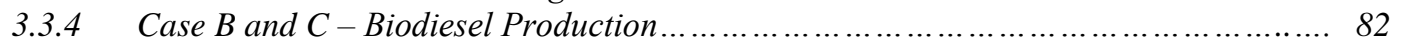

3.3.5 Case C and D - Direct Combustion ............................................. 85

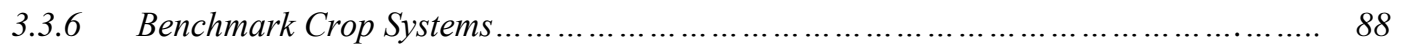

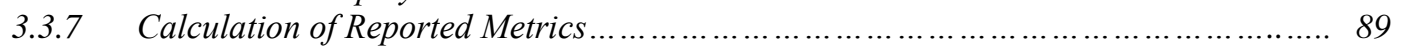

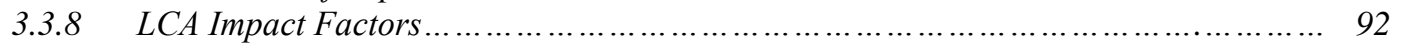

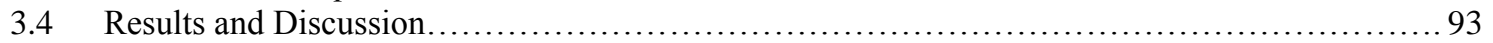

3.4.1 Comparison of EROI Among Algae Systems ................................................. 93

3.4.2 Comparison of Vehicle Kilometers Traveled from Algae vs. Other Crops .................. 97

3.4.3 Comparison of VKT from Two Algae Conversion Systems.................................. 99

3.4.4 Life Cycle Burdens for Transportation Energy from Algae vs. Other Crops.................100

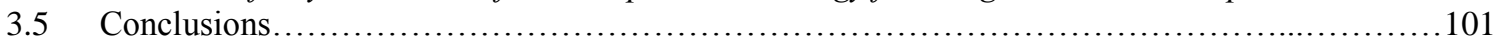

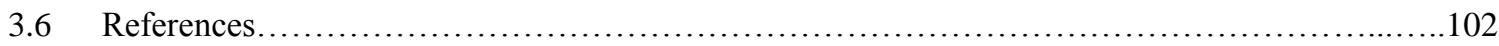


Chapter 4 - Comparison of Algae Cultivation Methods for Bioenergy Production Using a Combined Life Cycle Assessment and Life Cycle Costing Approach............................................ 107

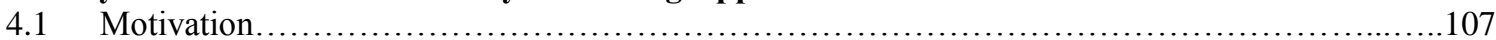

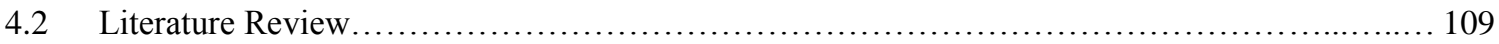

4.2.1 LCA on OP Systems / LCC on OP Systems ........................................... 109

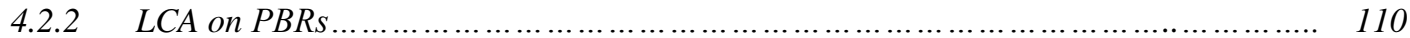

4.2.3 LCA on OP Systems versus PBRs / LCC on OP Systems versus PBRs / Combined LCA and LCC on OP Systems versus PBRs...................................................... 112

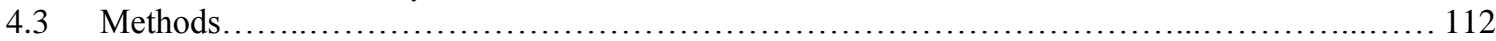

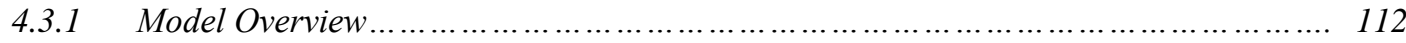

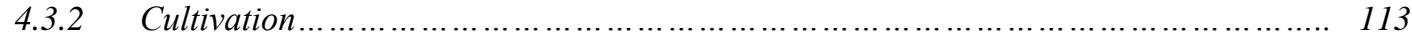

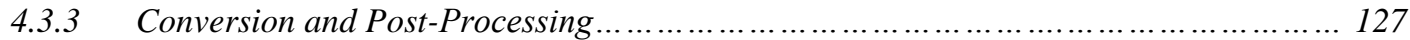

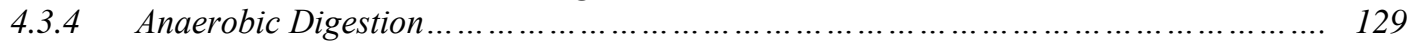

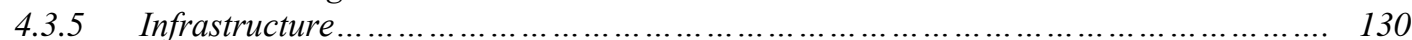

4.3.6 Calculation of Reported LCA Metrics ..................................................... 143

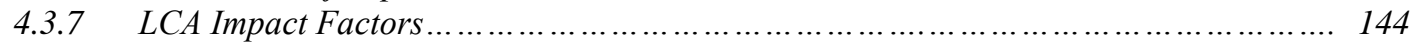

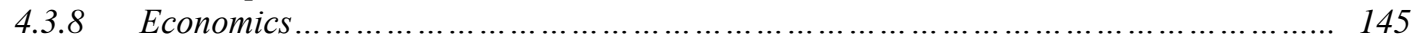

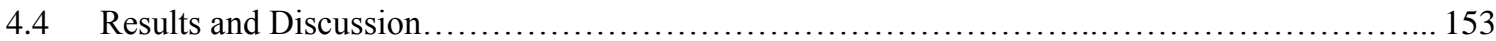

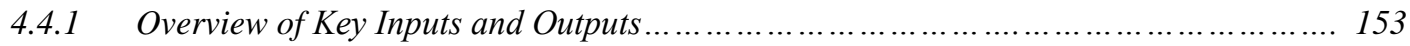

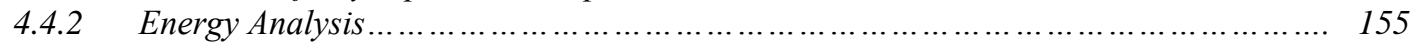

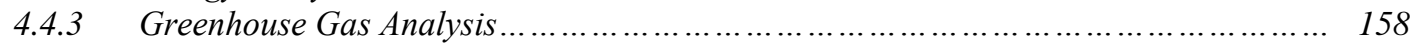

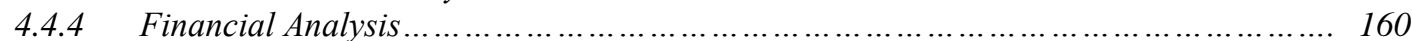

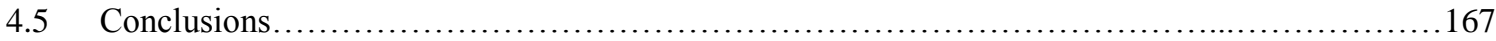

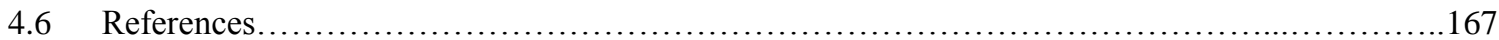

Chapter 5 - Evaluating Estrogenicity Removal and Bioenergy Production in an Integrated WWTP + Algae Cultivation System...........................................................................174

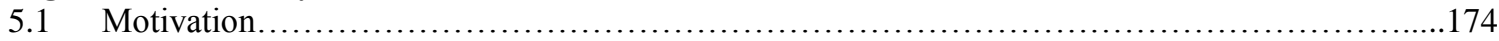

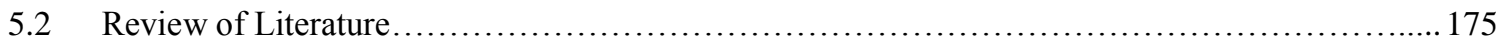

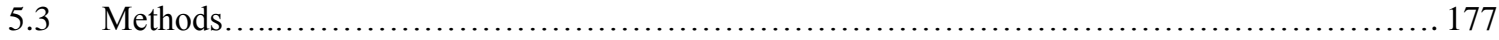

5.3.1 Laboratory Measurement of Algae-Mediated Estrogen Removal .......................... 177

5.3.2 Description of WWTP Unit Processes ...................................................... 182

5.3.3 Analysis of Algae Cultivation System as a Tertiary Treatment Step .......................... 188

5.3.4 Analysis of Conventional Tertiary Treatment Methods ....................................... 199

5.3.5 Mass Balance for All Modeled Systems ..................................................... 220

5.3.6 Calculation of Reported LCA Metrics........................................................ 222

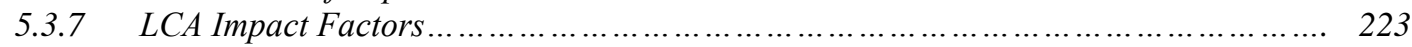

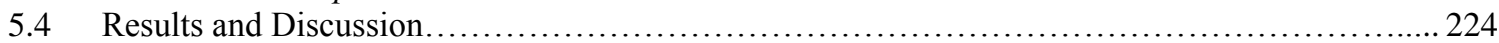

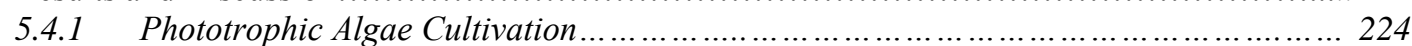

5.4.2 Algae-Mediated E2 Removal in Batch Tests ............................................... 225

5.4.3 Algae Cultivation versus Conventional Tertiary Treatment Method: Moore's Creek WWTP Case Study ............................................................................ 229

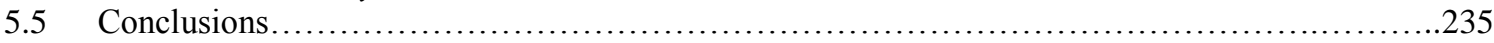

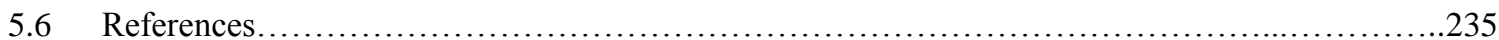

Chapter 6 - Conclusions and Future Work........................................................... 242

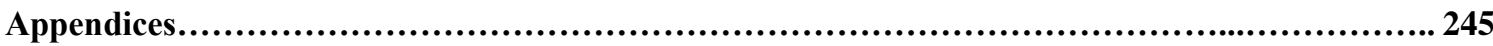




\section{Chapter 1 \\ Introduction}

\subsection{Algae for Bioenergy Production and Wastewater Treatment}

The increasing scarcity and adverse climate impacts of fossil fuels has led to accelerating interest in alternative energy sources. Algae-based fuels are considered by many to be a promising alternative source of fuel that is both renewable and domestically available (Benemann and Oswald, 1996). This attention stems from several of algae's seemingly desirable characteristics that set it apart from other biomass sources. First, algae tend to produce more biomass than terrestrial plants per unit area, and unlike terrestrial plants, they can be cultivated on otherwise marginal land using freshwater or saltwater (Chisti, 2007). A fast-growing aquatic alternative to conventional crops is appealing since most developed nations consume more energy than they could offset using slow-growing terrestrial crops (Hill et al., 2006). Second, algae do not compete directly with food crops (Sheehan et al., 1998). Food versus fuel ethical issues could be avoided by the production of separate crops for food and for fuel (Runge and Senauer, 2007). Lastly, algae has high growth rate that could be cultivated on marginal land and low-quality water to simultaneously produce biomass for energy, uptake anthropogenic $\mathrm{CO}_{2}$ and remove certain water pollutants (Benemann and Oswald, 1996; Powell et al., 2008). In the presence of slightly elevated $\mathrm{CO}_{2}$ and nutrient levels, algae stoichiometrically consume nutrients more readily than terrestrial photosynthetic organisms. Despite these several key characteristics, which would seem to make algae an ideal biofuels feedstock, the environmental impacts of producing nutrient fertilizers to support algae cultivation for bioenergy production have been shown to be quite burdensome. As such, the use of secondary effluent from a conventional activated sludge (CAS) wastewater treatment plant (WWTP) as growth medium for algae cultivation reduces the energy use and

other environmental impacts for large-scale algae cultivation systems. Interestingly, it is hypothesized that the use of WWTP effluent for algae cultivation can significantly reduce energy 
consumption at the WWTP. This duality of benefits could be motivation for WWTPs to partner with algae farming operations. However, the proposed integrated synergy has inherent challenges. The hypothesis of this dissertation is that the benefits of the proposed integrated synergy will outweigh the difficulties. Thus, it is important to address these challenges, not only to improve the system's overall performance but also to prevent impending environmental hazards that would minimize the benefits of the integrated system.

\subsection{Significance of this Study}

To date, there has been no comprehensive systems-level analysis of algae cultivation system and integrated wastewater treatment plus algae farming system. In particular, there has been no full evaluation of the energy production and water quality benefits that could be achieved. As such, this dissertation will explore the evaluation of the environmental burdens associated with energy production from algae and eEDC removal in bench-scale studies. The resulting knowledge will be integrated into a life cycle assessment (LCA) and life cycle costing (LCC) frameworks for improved sustainability decision-making pertaining to algae-derived energy production and wastewater treatment.

Assessment of an algae-wastewater system using LCA can also be challenging for two reasons. First, changes in system boundaries, in general, generate different output results. The results of an LCA model may vary depending upon whether only algae cultivation is considered or conversion processes are added to the scope. Second, uncertainties in input parameters affect the distribution of selected output parameters. It is therefore critical to define input distributions as collected from various sources to generate reliable results. The sustainability of this coupled system can be effectively evaluated only after both of these issues are resolved. 


\subsection{Research Objectives}

The overall objective of this research is to understand the environmental impacts of bioenergy production provided by an algae cultivation system and the ecosystem services (nutrient and eEDC removal to improve water quality) provided by an integrated algae-wastewater system. The sustainability of the proposed algae-wastewater system is to be assessed by comparing it with standalone alternatives for delivery of treated wastewater. The work carried out here includes LCA modeling, LCC modeling, and laboratory experiments, organized into four major tasks. The tasks are listed below and illustrated schematically in Figure 1.1.

Task 1: Compare the environmental life cycle impacts of algae to other bioenergy feedstocks.

Task 2: Compare the environmental life cycle impacts of several promising algae-derived transportation fuels.

Task 3: Compare environmental life cycle impacts and life cycle costs of two prominent algae cultivation methods to each other.

Task 4: Evaluate the environmental life cycle impacts and eEDC removal in a hypothetical integrated system, and then compare this performance to that of conventional, standalone treatment.

\subsection{Document Organization}

This dissertation manuscript is organized by task, according to the specific goals articulated in Section 1.3. Chapter II details the baseline model structure in analyzing the environmental performance of an algae-to-bioenergy cultivation system. As this is an initial attempt to fully quantify life cycle impacts of algae, the results are compared with terrestrial biomass feedstocks as benchmark. Chapter III discusses the expansion of algae's system boundary that includes relevant conversion processes to produce bioenergy-carriers for transportation. Chapter IV presents life cycle assessment and life cycle costing results of two generic algae cultivation 
methods - the open pond (OP) system and horizontal tubular tubular photobioreactor (PBR). Chapter V discusses life cycle assessment and characterization of eEDC removal in a combined algae-wastewater culture system. The results are then compared to various standalone tertiary treatment methods. Finally, Chapter VI summarizes the findings and conclusions of this study, and identifies directions for future related work. 


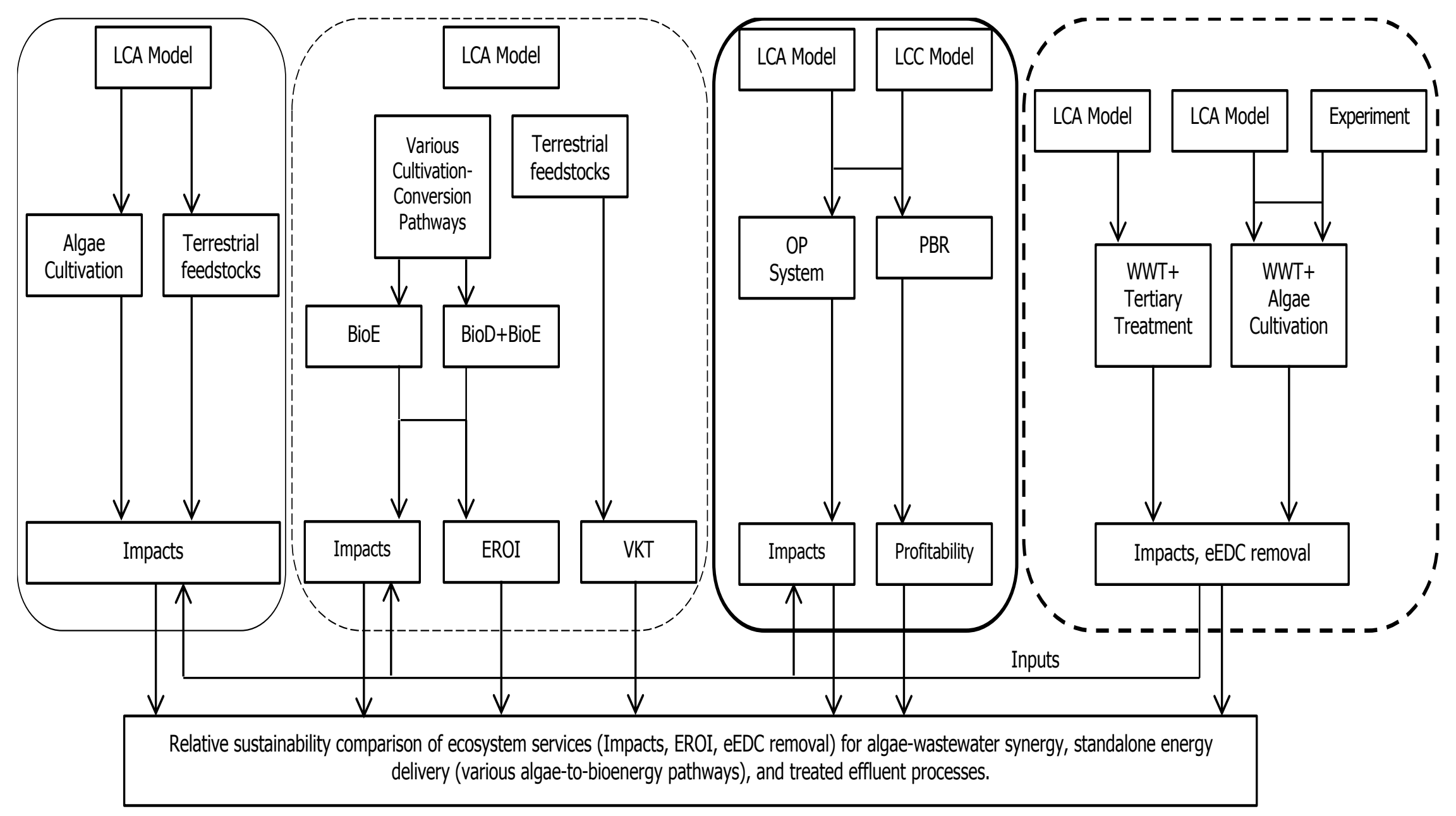

Figure 1.1. Schematic of the overall research reported here. Tasks 1, 2, 3 and 4 are enclosed using a solid, dashed, heavy solid and heavy dashed line. Nomenclature is as follows: $\mathrm{LCA}=$ life cycle assessment, $\mathrm{LCC}=$ life cycle costing, $\mathrm{BioD}=$ biodiesel, $\mathrm{BioE}=\mathrm{bioelectricity}$, $\mathrm{OP}=\mathrm{open}-\mathrm{pond}$, $\mathrm{PBR}=$ photobioreactor, $\mathrm{WWT}=$ wastewater treatment, $\mathrm{EROI}=$ energy return on investment, $\mathrm{VKT}=$ vehicle kilometers traveled and $\mathrm{eEDC}=$ estrogenic endocrine disrupting compounds. 


\subsection{References}

Benemann, J., Oswald, W. "Systems and Economic Analysis of Microalgae Ponds for Conversion of $\mathrm{CO}_{2}$ to Biomass - Final Report." U.S. Department of Energy: Pittsburgh, 1996, 201.

Chisti, Y. “Biodiesel from Microalgae.” Biotechnology Advances 25, no. 3 (2007): 294-306.

Hill, J., Nelson, E., Tilman, D., Polasky, S., Tiffany, D. "Environmental, Economic, and Energetic Costs and Benefits of Biodiesel and Ethanol Biofuels. Proceedings of the National Academy of Sciences of the United States of America 103, no. 30 (2006): 11206-11210.

Powell, N., Shilton, A. N., Pratt, S., Chisti, Y. "Factors Influencing Luxury Uptake of Phosphorus by Microalgae in Waste Stabilization Ponds." Environmental Science and Technology 42, no. 16 (2008): 5958-5962.

Runge, C. F., Senauer, B. "How Biofuels Could Starve the Poor?" Foreign Affairs 2007: May/June.

Sheehan, J., Dunahay, T., Benemann, J., Roessler, P. "A Look Back at the U.S. Department of Energy Aquatic Species Program: Biodiesel from Algae." National Renewable Energy Laboratory: Golden, CO, July 1998, 328. 


\section{Chapter 2 \\ Environmental Life Cycle Comparison of Algae to Other Bioenergy Feedstocks}

\subsection{Motivation}

Diminishing fossil fuel reserves and concerns about anthropogenic carbon dioxide emissions and their impacts on climate have driven significant research into alternative sources of sustainable energy (Sheehan et al., 1998). Solar, wind, and biomass have been the focus of significant private and public sector investment over the past decade (Panwar, Kaushik and Kothari, 2011). Of these, biomass holds a great deal of potential because it most seamlessly enables the production of liquid transportation fuels that can be used in existing vehicles (Antoni, Zverlov and Schwarz, 2007; Li, Xu and Wu, 2007). The focus on bio-based liquid transportation fuels is evident in the rapid deployment of ethanol in the United States. Despite this growth, terrestrial crops are limited in their productivity and it is unlikely that additional capacity is possible causing many to look for alternative feedstocks. Algae are of great interest because of their seemingly desirable characteristics that set them apart from other biomass sources. These characteristics include: (1) algae has higher biomass productivity than terrestrial plants per unit area and it is capable of being cultivated on marginal land using freshwater or saltwater (Chisti, 2007); (2) algae do not compete directly with food crops unlike corn and canola (Hill et al., 2006; Runge and Senauer, 2007; Sheehan et al., 1998); and (3) algae cultivation systems are designed to simultaneously produce biomass for energy production, uptake anthropogenic carbon dioxide $\left(\mathrm{CO}_{2}\right)$, and remove certain water pollutants (Benemann and Oswald, 1996; Powell et al., 2008).

The first part of this dissertation explored algae cultivation processes with the goal of comparing the life cycle burdens of algae-to-energy systems with traditional terrestrial crop-based biofuels. Recognizing that a major limiting factor in algae-to-energy production are the nutrient demands, 
algae cultivation was analyzed in the context of using WWTP effluent to offset nitrogen $(\mathrm{N})$ and phosphorus (P) demands.

\subsection{Literature Review}

Algae have been widely discussed as a possible energy feedstock since the oil crises of the 1970s. Between 1980 and the mid-1990s, research was largely focused on identifying strains exhibiting high lipid content for the purpose of using algae-extracted lipids for liquid fuels generation (Sheehan et al., 1998). More recently, basic research has been focused on genetic modification to enhance lipid production or induce lipid excretion (Rosenberg et al., 2008). Complementary efforts have been made to investigate algae growth rates in the presence of flue gas, optimal growth, and lipid yields under different light fluxes (Ramli et al., 2002), reactor configurations (Godos et al., 2009), or nutrient loads (Powell et al., 2008). Previous pilot scale operations have demonstrated that monoculture systems can be prone to contamination, indicating that cultivation of mixed native communities may result in more robust operation despite the potential decrease in lipid content (Miao and $\mathrm{Wu}, 2006$ ). Finally, economic analyses of growing algae in photobioreactors have indicated that the problem of scale could lead algae growers to use more reasonable and cheaper unlined open ponds (Benemann and Oswald, 1996). Despite these advancements in algae understanding, two critical issues must be addressed: (1) there is no consensus on the most effective and lowest impact means of cultivating algae at large-scale and (2) there are a number of candidate processes for converting algae into biofuels.

There are two general classifications of algae cultivation methods: open-pond (OP) systems and photobioreactor (PBR) systems (Benemann and Oswald, 1996; Chisti, 2007). Each of these configurations has distinct advantages and disadvantages. Currently, there is no consensus as to which cultivation method generates the least environmental impacts. Similarly, there are three broad classifications of biofuel conversion processes: chemical (e.g., lipids-to-biodiesel via 
esterification); biochemical (e.g., corn-to-ethanol via fermentation); or thermochemical (e.g., switchgrass-to-syngas via pyrolysis). Similar to algae cultivation, studies published on each of these conversion process are specific to the nature of the biofuel and do not offer a comprehensive environmental evaluation on a normalized basis (Campbell, 2009; Dominguez et al., 2009; Farrell et al., 2006).

Studies on both algae cultivation and biofuel conversion have utilized LCA as a performance tool in quantifying environmental impacts. Although water demand during algae cultivation for production of biofuels has rarely been directly addressed in the preliminary algae LCA analyses published to date (Aresta, Dibenedetto and Barberio, 2005; Kadam, 2002), it is likely that algae's significant fertilizer requirements render this system to be as water-intensive as terrestrial crops cultivation. These analyses seem to suggest that the environmental burdens of producing energy from biomass could be equal to or greater than those associated with terrestrial crops.

Even though the life cycle burdens of many terrestrial biofuel feedstocks have been investigated in the literature, no work had been carried out on the life cycle burdens of algae cultivation processes when I commenced my dissertation research. A number of studies have focused on the algae fuel production system, although there are several cultivation parameters that have not been extensively studied. For example, conclusive quantification of the influence of regional climate, water availability, nutrient supply and harvesting technology are yet to be explored (Lardon et al., 2009). Kadam (2002), who explored the use of flue gas as a carbon source for producing algae near power plants, effectively identified some of the limiting factors associated with algae production, such as fertilizers (Kadam, 2002). However, the study did not exclude the effects of regional yields, nor did it compare algae with conventional bioenergy crops. Lardon et al. (2009) summarized the life cycle implications of algae-to-fuel conversions without accounting for the cultivation impacts (Lardon et al., 2009). The purpose of this chapter is to integrate data from 
previously published pilot-scale demonstration projects, climactic records and other sources into a stochastic life cycle model of algae cultivation processes (Benemann and Oswald, 1996; Weissman and Tillett, 1990). The resulting environmental burdens are then compared to switchgrass, corn, and canola since these are leading contenders for production of first and second-generation biofuels. For all crops, comparisons were made on the basis of total energy. Biofuel conversion processes were intentionally excluded from the scope of this analysis because this chapter aimed at focusing on cultivation burdens alone and conversion processes impacts have been reported in other papers. It is therefore necessary to focus on algae cultivation because the impacts of conversion processes are not expected to significantly alter the overall impacts of algae-to-bioenergy system.

\subsection{Methods}

This analysis includes processes required for the cultivation of algae biomass. Pertinent modeling input parameters and output data are described hereafter. Methodology is categorized into sections namely: (1) model overview, (2) impact definitions, (3) impact factor calculations, (4) life cycle inventory data and (5) synergies with municipal wastewater treatment.

\subsubsection{Model Overview}

The LCA model in this chapter was developed using Microsoft Excel in conjunction with the Crystal Ball predictive modeling suite plug-in. This plug-in can run Monte Carlo analyses for complex systems by defining statistical distributions for different input parameters. The program then automates sampling from the various input parameters and generates distributions for selected output parameters (i.e., forecasts). The Monte Carlo analysis was conducted using 10,000 trial runs. 


\subsubsection{Functional Unit}

The functional unit (FU) selected for this analysis is $3 \times 10^{8}$ BTU (317 GJ). This is the approximate per capita consumption of total primary energy for one American in one year (EIA, 2008). This value reflects all energy consumed including upstream impacts associated with power production. The results are expressed using an energy functional unit to provide a reasonable comparison between dissimilar biomass feedstocks. It also provides a reasonably intuitive amount of energy that can be used to foster discussion around the "footprint" of energy consumption. The FU was also selected under the assumption that the biomass could be directly burned to produce bioelectricity and not further processed to produce a refined liquid fuel product. This avoids the inefficiency and uncertainty associated with downstream processes of the biomass into liquid fuels, which was outside the scope of this study. Figure 2.1 depicts a schematic of the system boundaries in modeling algae, corn, switchgrass, canola.
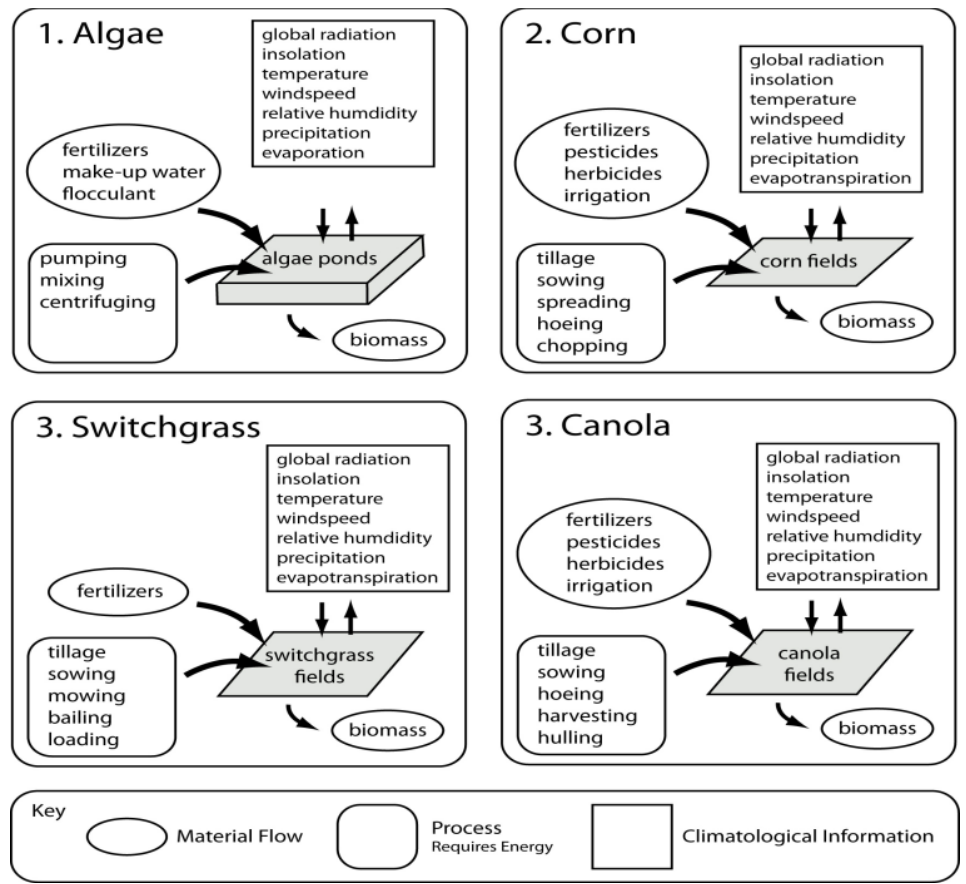

Figure 2.1. Schematic of system boundaries considered in modeling algae and three other terrestrial crops (corn, switchgrass, canola). Model scope includes all burdens upstream of delivered biomass and excludes all conversion processes to liquid or solid fuel. 


\subsubsection{Solar Radiation and Meteorological Data}

\subsection{Insolation}

Thirty years of insolation and selected meteorological data (1961-1990) were downloaded from the National Solar Radiation Database (NSRDB) maintained by the National Renewable Energy Laboratory (NREL) (NREL, 1994). Monthly averages of daily total solar radiation over the global horizontal element $(\mathrm{G})$ were obtained from observation stations in Mason City, Iowa (IA); Roanoke, Virginia (VA); and San Diego, California (CA). All of these locations are in the United States.

The fraction of total solar energy available for plants to use in photosynthesis is referred to as photosynthetically active radiation (PAR) and spans the range of wavelengths between 400 and $700 \mathrm{~nm}$. PAR measurements were computed by multiplying total radiation (G) at each location by 0.46, a fraction appropriate for the range of latitudes investigated in this study (Benemann and Oswald, 1996; NOAA, 2009). Histograms of monthly PAR at each location were constructed in Minitab®. The normal distribution was found to be the best fit for each monthly PAR dataset on the basis of Anderson-Darling statistics computed by the statistical software.

\subsection{Miscellaneous Meteorological Parameters}

Additional meteorological measurements taken from the 1961-1990 NSRDB datasets for the selected locations include: average monthly temperature, average monthly relative humidity, and average monthly wind speed. Histograms of monthly values for these parameters were constructed in Minitab®. The normal distribution was found to be the best fit for each dataset on the basis of Anderson-Darling statistics. 


\subsection{Precipitation}

Thirty years of precipitation data (1979-2008) were downloaded from the National Climatic Data Center (NCDC) maintained by the National Oceanic \& Atmospheric Administration (NOAA) (NOAA, 2009). Annual climatological summaries were downloaded for NOAA observation stations in Ames, Iowa (IA) (5 SE, \#130203/99999); Roanoke, Virginia (VA) (RoanokeWoodrum Airport, \#447285/13741); and San Diego, California (CA) (Lindbergh Field, \#047740/23188). Total precipitation was reported in inches per month. Histograms of monthly precipitation at each location were constructed in Minitab®. The lognormal distribution was found to be the best fit for each monthly precipitation dataset on the basis of Anderson-Darling statistics.

\subsection{Evaporation}

Daily water losses via evaporation from open pond surfaces were computed for each selected geographic location using the Penman Equation, Equation 2.1.

$$
E=\frac{\Delta R_{n}+\gamma \times \lambda_{v} \times \rho_{w} \times K_{E} \times v_{A} \times\left(e_{s}^{\circ}-e_{a}\right)}{\lambda_{v} \times \rho_{w} \times(\Delta+\gamma)} \quad \text { Equation } 2.1
$$

Where $E$ is daily evaporative flux (m/day), $\Delta$ is slope of the saturated vapor pressure vs. temperature relationship at daily average air temperature $\left(\mathrm{kPa} /{ }^{\circ} \mathrm{C}\right) ; R_{N}$ is net solar radiation $\left(\mathrm{MJ} / \mathrm{m}^{2}-\mathrm{d}\right), \gamma$ is psychrometric constant $\left(\approx 0.066 \mathrm{kPa} /{ }^{\circ} \mathrm{C}\right) ; \lambda_{v}$ is latent heat of vaporization for water $(2.45 \mathrm{MH} / \mathrm{kg}) ; \rho_{W}$ is density of water $\left(1000 \mathrm{~kg} / \mathrm{m}^{3}\right) ; K_{E}$ is a mass transfer coefficient $(\approx$ $\left.1.39 \mathrm{E}-8 \mathrm{kPa}^{-1}\right) ; v_{A}$ is wind speed $\left(\mathrm{m} /\right.$ day); $e_{S}{ }^{\circ}$ is saturation vapor pressure at atmospheric temperature $(\mathrm{kPa})$; and $e_{a}$ is atmospheric water vapor pressure $(\mathrm{kPa})$. 
The slope of the saturated vapor pressure vs. temperature curve $\Delta$ is given by the derivative summarized in Equation 2.2. Saturation vapor pressures at various temperatures were taken from Perry's Chemical Engineering Handbook (Perry, 1997). $T$ is average daily temperature as taken from NSRDB.

$$
\Delta=\frac{d e^{0}}{d t}(0.625 \times \exp (0.064 \times T))=0.04 \times \exp (0.064 \times T) \quad \text { Equation } 2.2
$$

Net solar radiation, $R_{N}$, was computed using the formulation given by Equation 2.3. Use of this equation as written required $G$ to be in units of $\mathrm{W} / \mathrm{m}^{2}$. Thus, values of daily global solar radiation, as downloaded from the NSRB, were divided by $24 \mathrm{~h} / \mathrm{d}$ to convert from $\mathrm{Wh} / \mathrm{m}^{2}$.

$$
R_{N}=0.63 \times G-40 \quad \text { Equation } 2.3
$$

The quantity $\left(e_{S}{ }^{\circ}-e_{a}\right)$ was computed using an empirical relationship for saturation vapor pressure $\left(e_{s}{ }^{\circ}\right)$ as a function of average daily temperature $(T)$ (Perry, 1997) and daily measurements of relative humidity $(R H)$ from the NSRB. Note that relative humidity values were expressed as fractions rather than percentages. This formulation is summarized in Equation 2.4.

$$
e_{s}^{0}-e_{a}=0.625 \exp (0.064 \times T)-0.625 \exp (0.064 \times T) \times R H \quad \text { Equation } 2.4
$$

Monthly evaporation was computed via multiplication of the average daily evaporation depths resulting from Equation 2.1 by the number of days in each month. These values were stochastic in so far as they were computed by Crystal Ball via sampling from distributions for monthly insolation, temperature, wind speed, and relative humidity. 


\subsection{Evapotranspiration}

Daily water losses via evapotranspiration from cultivated fields were computed for each selected geographic location using the Penman-Monteith Equation. Specifically, the so-called "standardized" method promulgated by the American Society of Civil Engineers' Environmental \& Water Resources Initiative (ASCE-EWRI) was used to compute evapotranspiration during cultivation of algae (Howell and Evett, 2004). Evapotranspiration values for corn, canola, and switchgrass were all taken from SimaPro (Weidema, 2008). This formulation is Equation 2.5.

$$
E T=\frac{0.408 \Delta \times\left(R_{N}-G_{S}\right)+\gamma \frac{C n}{T+273} \times v_{A} \times\left(e_{s}^{\mathrm{o}}-e_{a}\right)}{\Delta+\gamma\left(1+C_{d} v_{A}\right)} \quad \text { Equation } 2.5
$$

Here, ET is daily evapotranspiration flux (m/day); $G_{S}$ is soil heat flux density at the soil surface $\left(\mathrm{MJ} / \mathrm{m}^{2}\right), C_{n}$ and $C_{d}$ are ASCE-standardized coefficients for selected "reference" crops. Other parameters $\left(\Delta, R_{N}, \gamma, T, v_{A}, e_{s}{ }^{\circ}-e_{a}\right)$ are as defined for use in the Penman Equation (Equation 2.1). Corn, canola, and switchgrass were modeled using standardized coefficients for the "tall" reference $\operatorname{crop}\left(C_{n}=1600, C_{d}=0.38\right)(\mathrm{ASCE}, 2002)$.

Average daily $G_{S}$ values were computed using ASCE-standardized coefficients for daylight and nighttime soil heat fluxes. Daily hours of daylight ( $\left.t_{\mathrm{DAY}}\right)$ and darkness $\left(\mathrm{t}_{\mathrm{NIGHT}}\right)$ over the course of a single year at each selected location were taken from data tabulated by the US Naval Observatory (USNO, 2009). These values were incorporated into computation of $\mathrm{G}_{\mathrm{S}}$ as a function of daily net radiation $\left(R_{N}\right)$ according to Equation 2.6.

$$
G_{S}=\frac{R_{N}}{24} \times\left(0.04 t_{D A Y}-0.2 t_{N I G H T}\right) \quad \text { Equation } 2.6
$$


Monthly evapotranspiration was computed via multiplication of the average daily evapotranspiration depths resulting from Equation 2.6 by the number of days in each month.

\subsection{Summary}

Climactic inputs to the biomass production model include photosynthetically active radiation (PAR), temperature, wind speed, relative humidity, and precipitation. Input distributions for PAR, wind speed, and relative humidity were normally distributed; monthly precipitation was lognormally distributed. Averages $(\mu)$ and standard deviations $(\sigma)$ for distributions are summarized in Table 2.1. Crystal Ball was used to sample from the input climactic distributions for each of the months in one year. Evapotranspiration and evaporation at each location were then computed as model outputs. These two outputs were generally well fit by the gamma distribution for each of the selected geographic locations. Table 2.1 summarizes scale $(\theta)$ and shape (k) factors corresponding to monthly best-fit gamma distributions for evaporation and evapotranspiration in each of the three selected geographic locations. 
Table 2.1. Summary of parameters used to form distributions of climactic model inputs (PAR, temperature, wind speed, relative humidity, precipitation) and outputs (evaporation and evapotranspiration). Tabulated values represent averages $(\mu)$ and standard deviations $(\sigma)$, using $\mu / \sigma$ notation, for normal/lognormal-distributed inputs or scale $(\theta)$ and shape $(\mathrm{k})$ parameters, using $\theta / \mathrm{k}$ notation, for gamma-distributed outputs. It should be noted that evaporation and evapotranspiration for months outside of each crop's respective growing season in a particular location are marked 'NA' for "not applicable".

\begin{tabular}{|c|c|c|c|c|c|c|c|c|c|c|c|c|}
\hline \multicolumn{13}{|c|}{ Average Photosynthetically Active Radiation (PAR) (MJ $/ \mathrm{m}^{2}$-day) } \\
\hline & Jan & Feb & Mar & Apr & May & Jun & Jul & Aug & Sep & Oct & Nov & Dec \\
\hline CA & $5.0 / 0.4$ & $6.3 / 0.5$ & $8.0 / 0.6$ & $9.9 / 0.5$ & $10.1 / 0.8$ & $10.5 / 0.9$ & $11.2 / 0.6$ & $10.6 / 0.5$ & $8.8 / 0.6$ & $7.1 / 0.4$ & $5.5 / 0.3$ & $4.6 / 0.3$ \\
\hline IA & $3.0 / 0.2$ & $4.4 / 0.3$ & $6.0 / 0.5$ & 7.6/0.6 & $9.3 / 0.6$ & $10.3 / 0.6$ & $10.2 / 0.6$ & $8.9 / 0.5$ & $6.9 / 0.6$ & $4.9 / 0.4$ & $3.0 / 0.2$ & $2.5 / 0.2$ \\
\hline \multicolumn{13}{|c|}{ Average Daily Temperature Per Month $\left({ }^{\circ} \mathrm{C}\right)$} \\
\hline VA & $1.4 / 2.7$ & $2.9 / 2.1$ & $8.2 / 1.9$ & $13.1 / 1.5$ & $17.8 / 1.5$ & $22.0 / 1.1$ & $24.2 / 1.0$ & $23.7 / 1.0$ & $19.8 / 1.3$ & $13.6 / 1.8$ & $8.6 / 1.6$ & $3.5 / 2.4$ \\
\hline IA & $-10.4 / 3.8$ & $-7.4 / 3.2$ & $-0.3 / 3.2$ & $8.0 / 2.0$ & $14.8 / 2.0$ & $20.2 / 1.5$ & $22.5 / 1.3$ & 21.0/1.4 & $16.0 / 1.2$ & $9.6 / 2.1$ & $1.1 / 2.1$ & $-7.6 / 3.3$ \\
\hline \multicolumn{13}{|c|}{ Average Daily Wind Speed (m/s) } \\
\hline & Jan & Feb & Mar & Apr & May & Jun & Jul & Aug & Sep & Oct & Nov & Dec \\
\hline \multicolumn{13}{|c|}{ Average Relative Humidity (\%) } \\
\hline & Jan & Feb & Mar & Apr & May & Jun & Jul & Aug & Sep & Oct & Nov & Dec \\
\hline CA & $63 / 6$ & $66 / 6$ & $67 / 4$ & $67 / 4$ & $71 / 3$ & $74 / 3$ & $75 / 3$ & $74 / 3$ & $73 / 4$ & $69 / 6$ & $66 / 7$ & $64 / 7$ \\
\hline VA & $61 / 5$ & $60 / 7$ & $57 / 7$ & $57 / 7$ & $66 / 4$ & $69 / 5$ & $71 / 5$ & $73 / 4$ & $74 / 5$ & $68 / 6$ & $65 / 7$ & $64 / 5$ \\
\hline IA & $74 / 7$ & $77 / 6$ & $76 / 6$ & $68 / 6$ & $65 / 6$ & $67 / 5$ & $73 / 5$ & $76 / 4$ & $76 / 6$ & $72 / 6$ & $78 / 5$ & $79 / 5$ \\
\hline \multicolumn{13}{|c|}{ Average Monthly Precipitation (cm/month) } \\
\hline & Jan & Feb & Mar & Apr & May & Jun & Jul & Aug & Sep & Oct & Nov & Dec \\
\hline$C A$ & $5.7 / 5.9$ & $5.8 / 4.7$ & $5.1 / 4.9$ & $1.9 / 1.9$ & $0.4 / 0.6$ & $0.2 / 0.5$ & $0.1 / 0.2$ & $0.1 / 0.2$ & $0.4 / 0.7$ & $1.3 / 2.4$ & $2.5 / 2.7$ & $3.7 / 3.0$ \\
\hline VA & $7.6 / 4.9$ & $7.5 / 4.4$ & $8.9 / 4.6$ & $9.0 / 5.6$ & $9.7 / 5.1$ & $9.9 / 6.7$ & $10.1 / 5.1$ & $8.8 / 5.4$ & $9.9 / 8.4$ & $7.5 / 5.7$ & $8.2 / 5.7$ & $6.7 / 3.1$ \\
\hline
\end{tabular}




\begin{tabular}{|c|c|c|c|c|c|c|c|c|c|c|c|c|}
\hline IA & $0.9 / 0.5$ & $0.3 / 0.6$ & $2.2 / 1.5$ & $3.3 / 1.9$ & $4.7 / 2.4$ & $5.0 / 3.1$ & $4.8 / 3.1$ & $4.7 / 3.1$ & $3.1 / 1.5$ & $2.5 / 1.6$ & $2.3 / 1.6$ & $1.2 / 0.8$ \\
\hline \multicolumn{13}{|c|}{ Average Monthly Evaporation (mm/month) } \\
\hline & Jan & Feb & Mar & Apr & May & Jun & Jul & Aug & Sep & Oct & Nov & Dec \\
\hline CA & $1.1 / 41.8$ & $1.1 / 42.3$ & $1.2 / 47.4$ & $0.9 / 78.8$ & $1.4 / 50.3$ & $1.7 / 48.1$ & $1.1 / 68.9$ & $0.9 / 73.2$ & $1.3 / 49.9$ & $1.0 / 59.4$ & $1.0 / 45.8$ & $1.1 / 34.7$ \\
\hline VA & $1.2 / 27.7$ & $1.3 / 30.4$ & $1.6 / 36.3$ & $1.8 / 43.4$ & $1.2 / 56.2$ & $1.2 / 62.5$ & $1.5 / 52.6$ & $0.9 / 67.1$ & $1.3 / 42.1$ & $1.2 / 42.8$ & $1.2 / 37.4$ & $1.0 / 29.8$ \\
\hline IA & NA & NA & NA & $1.8 / 36.5$ & $1.8 / 47.2$ & $1.5 / 58.7$ & $1.3 / 60.7$ & $1.2 / 56.3$ & $1.4 / 41.1$ & $1.4 / 33.5$ & $0.8 / 31.4$ & NA \\
\hline \multicolumn{13}{|c|}{ Average Monthly Evapotranspiration (mm/month) } \\
\hline & Jan & Feb & Mar & Apr & May & Jun & Jul & Aug & Sep & Oct & Nov & Dec \\
\hline CA & NA & NA & NA & $1.9 / 56.9$ & $1.7 / 54.5$ & $1.9 / 47.3$ & $1.7 / 58.2$ & $1.5 / 64.1$ & 2.1/48.7 & NA & NA & NA \\
\hline VA & NA & NA & NA & NA & $2.5 / 46.3$ & $2.4 / 49.3$ & 2.7/49.6 & $1.9 / 54.6$ & $2.2 / 41.5$ & NA & NA & NA \\
\hline IA & NA & NA & NA & NA & $3.9 / 35.8$ & $3.4 / 42.2$ & $3.1 / 42.2$ & $2.5 / 41.3$ & $3.0 / 35.5$ & NA & NA & NA \\
\hline
\end{tabular}


Anderson-Darling (A-D) statistics for the distributions referenced in Table 2.1 are summarized in Table 2.2. These values indicate the extent to which each climactic input is well fit by the selected statistical distribution. Recall that PAR, temperature, wind speed, and relative humidity were fit to normal distributions. Precipitation was fit to the lognormal distribution. Lower values of the A-D statistic indicate better fits. In general, and for the normal distribution in particular, A$\mathrm{D}$ values less than 1.5 are said to be indicative of a reasonably well-fit distribution as shown by $\operatorname{Minitab}^{\circledR}$ 
Table 2.2. Summary of Anderson-Darling statistics (goodness-of-fit) for selected climactic input distributions. All parameters were fit to the normal distribution except monthly precipitation, which was fit to the lognormal distribution. Asterisks (**) indicate distributions for which an Anderson-Darling statistic could not be computed.

\begin{tabular}{|c|c|c|c|c|c|c|c|c|c|c|c|c|}
\hline \multicolumn{13}{|c|}{ Average Photosynthetically Active Radiation (PAR) - Normal Distribution } \\
\hline $\mathrm{CA}$ & 0.76 & 0.33 & 0.67 & 0.46 & 0.25 & 0.52 & 0.84 & 0.65 & 0.81 & 0.24 & 0.24 & 0.22 \\
\hline IA & 0.23 & 0.36 & 0.41 & 0.21 & 0.48 & 0.16 & 0.21 & 0.25 & 0.20 & 0.19 & 0.63 & 0.34 \\
\hline \multicolumn{13}{|c|}{ Average Daily Temperature Per Month - Normal Distribution } \\
\hline VA & 0.31 & 0.76 & 0.48 & 0.18 & 0.30 & 0.40 & 0.59 & 1.34 & 0.34 & 0.20 & 0.29 & 0.24 \\
\hline IA & 0.22 & 0.56 & 0.43 & 0.22 & 0.45 & 0.65 & 0.22 & 0.34 & 0.20 & 0.27 & 0.49 & 0.23 \\
\hline \multicolumn{13}{|c|}{ Average Daily Wind Speed - Normal Distribution } \\
\hline & Jan & Feb & Mar & Apr & May & Jun & Jul & Aug & Sep & Oct & Nov & Dec \\
\hline \multicolumn{13}{|c|}{ Average Relative Humidity - Normal Distribution } \\
\hline & Jan & Feb & Mar & Apr & May & Jun & Jul & Aug & Sep & Oct & Nov & Dec \\
\hline$C A$ & 0.40 & 0.63 & 0.21 & 0.50 & 0.55 & 0.51 & 0.36 & 1.10 & 1.18 & 0.25 & 0.39 & 0.49 \\
\hline VA & 0.36 & 0.57 & 0.25 & 0.46 & 0.27 & 0.23 & 0.55 & 0.25 & 0.36 & 0.33 & 0.36 & 0.40 \\
\hline IA & 0.44 & 0.47 & 1.04 & 0.30 & 0.23 & 0.25 & 0.40 & 0.44 & 0.21 & 0.26 & 0.36 & 0.37 \\
\hline \multicolumn{13}{|c|}{ Average Monthly Precipitation (cm/month) - Lognormal Distribution } \\
\hline & Jan & Feb & Mar & Apr & May & Jun & Jul & Aug & Sep & Oct & Nov & Dec \\
\hline $\mathrm{CA}$ & 0.40 & 0.52 & $* *$ & $* *$ & $* *$ & $* *$ & $* *$ & $* *$ & $* *$ & $* *$ & $* *$ & 1.44 \\
\hline VA & 0.31 & 0.42 & 0.69 & 0.33 & 0.41 & 0.52 & 0.37 & 0.19 & 0.53 & 2.22 & 1.22 & 0.94 \\
\hline
\end{tabular}




\subsubsection{Crop Yield Estimates}

\subsection{Corn}

Silage corn yield estimates were computed on the basis of growing season insolation and empirical estimates of radiation-use efficiency (RUE). RUE is the amount of aboveground crop biomass produced per unit PAR flux. Each location was assumed to have the same annual growing season for corn: 1 May - 15 September. Biomass was assumed to be $35-42 \%$ dry matter at harvest, and this value was modeled using a uniform distribution over the given range (Brann, Abaye and Peterson, 2009).

The methodology of Kiniry et al. (1989) was used to estimate corn yields (Mg/ha) at each location according to Equation 2.7 (Kiniry et al., 2009).

$$
\text { Yield }_{\text {CORN }}=R U E_{C O R N} \times \sum(I P A R)=R U E_{C O R N} \times \sum P A R \times\left(1-e^{-k \times L A I}\right) \quad \text { Equation } 2.7
$$

IPAR is intercepted photosynthetically active radiation. This can be measured directly or computed as a function of extinction coefficient $(\mathrm{k}=0.65)$ and leaf area index (LAI). Values of dimensionless LAI were taken from the literature and found to be normally distributed with average $=4.59$ and standard deviation $=0.43(\mathrm{n}=12)($ Maddonni and Otegui, 1996). Average monthly IPAR values were summed over the growing season to compute cumulative IPAR at each location. Values of $\mathrm{RUE}_{\mathrm{CORN}}$, in units of grams dry biomass per MJ IPAR, were taken from the literature and found to be lognormally distributed with average $=3.46$ and standard deviation $=0.80\left(\mathrm{n}=37\right.$; Anderson-Darling = 1.4) (Kiniry et al., 1989). RUE $\mathrm{CORN}_{\mathrm{C}}$ was multiplied by the cumulative IPAR at each location to estimate annual corn yields at each location. Resulting estimates of annual corn yield at each location were lognormally distributed. Resulting average 
estimates were also compared to literature values and found to be consistent with reported ranges.

Pertinent distribution parameters and distribution goodness-of-fit are summarized in Table 2.3.

Table 2.3. Cumulative intercepted photosynthetically active radiation (IPAR) and average estimated wet yields $(\mu)$ (with standard deviations, $\sigma$ ) for corn production in three geographic locations. Low values of the Anderson-Darling (A-D) statistic indicate that each wet yield distribution is well fit by the lognormal distribution; average estimates are well-aligned with previous measurements as indicated at far right.

\begin{tabular}{|c|c|c|c|c|}
\hline Location & $\begin{array}{l}\text { Average Cumulative } \\
\text { IPAR }\left(\mathrm{MJ} / \mathrm{m}^{2}\right)\end{array}$ & $\begin{array}{l}\text { Estimated Wet Yield } \\
\qquad \mu / \sigma(\mathrm{Mg} / \mathrm{ha})\end{array}$ & $\begin{array}{c}\text { Lognormal Distribution } \\
\text { A-D Statistic }\end{array}$ & $\begin{array}{c}\text { Average Measured Wet } \\
\text { Yield } \\
(\mathrm{Mg} / \mathrm{ha})[\text { Source] }\end{array}$ \\
\hline $\mathrm{CA}$ & 1364 & $47.2 / 11.0$ & 0.14 & $45-68$ (USDA, 2006) \\
\hline VA & 1209 & $45.5 / 10.7$ & 0.55 & $\begin{array}{c}32-56 \text { (Brann and Abaye, } \\
\text { 2009) }\end{array}$ \\
\hline IA & 1228 & $42.5 / 9.9$ & 0.41 & $\begin{array}{c}39-50 \text { (Thoreson and } \\
\text { Lang, 2009) }\end{array}$ \\
\hline
\end{tabular}

\subsection{Switchgrass}

Switchgrass yield estimates for each of the selected locations were computed on the basis of growing season insolation and radiation use efficiency using an empirically derived estimate of

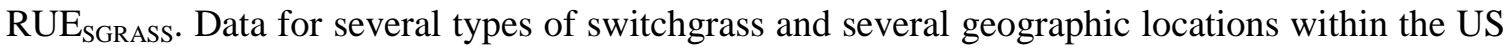
were used to compute an estimate for $\mathrm{RUE}_{\mathrm{SGRASS}}$ in units of grams aboveground dry biomass per MJ PAR. Cultivars included lowland varieties 'Alamo' and 'Kanlow' as well as upland cultivars 'Cave-in-Rock', and 'Shelter'. Yield measurements for these varieties were measured in the following locations: Princeton, KY; Raleigh, NC; State College, PA; Jackson and Knoxville, TN; Roanoke, VA (two test plots); and, Morgantown, WV (Adler et al., 2006; Putnam, 2008). RUE was computed as the ratio between dry switchgrass yield and measurements of PAR as taken from the NSRDB for each of these six locations. Switchgrass growing season was assumed to be 1 May - 1 Aug for each of these locations except State College, PA, where it was 1 June -1 September. Pertinent information is summarized in Table 2.4. 
Table 2.4. Photosynthetically active radiation (PAR) (NREL, 2002), reported wet switchgrass yields and computed radiation use efficiency (RUE) values for switchgrass production in several geographic regions (Lemus, 2004; Adler et al., 2006).

\begin{tabular}{lcccc}
\hline Location & Year & $\begin{array}{c}\text { PAR } \\
\left(\mathrm{MJ} / \mathrm{m}^{2}\right)\end{array}$ & $\begin{array}{c}\text { Yield } \\
(\mathrm{Mg} / \mathrm{ha})\end{array}$ & $\begin{array}{c}\text { RUE } \\
(\mathrm{g} / \mathrm{MJ})\end{array}$ \\
\hline Jackson, TN & 2000 & 920 & 8.8 & 0.96 \\
Knoxville, TN & 2001 & 913 & 10.3 & 1.13 \\
\hline \multirow{2}{*}{ Morgantown, WV } & 2000 & 931 & 15.6 & 1.68 \\
& 2001 & 868 & 18.1 & 2.09 \\
Princeton, KY & 2000 & 847 & 15.1 & 1.78 \\
& 2001 & 866 & 17.8 & 2.06 \\
Raleigh, NC & 2000 & 885 & 12.6 & 1.42 \\
& 2001 & 914 & 13.1 & 1.43 \\
Roanoke, VA & 2000 & 878 & 12.1 & 1.38 \\
& 2001 & 877 & 6.4 & 0.73 \\
& 2000 & 849 & 15.7 & 1.85 \\
& 2000 & 876 & 13.1 & 1.50 \\
State College, PA & 2001 & 852 & 15.6 & 1.83 \\
& 2001 & 869 & 15.4 & 1.77 \\
\hline A. PAR da & 2002 & 904 & 7.9 & 1.06 \\
& 2003 & 802 & 7.0 & 1.02 \\
& 2004 & 800 & 7.0 & 1.07 \\
\hline
\end{tabular}

A. PAR data are from nearest NSRDB station in Evansville, IN.

RUE $_{\text {SGRASS }}$ values in Table 2.4 were fit to the lognormal distribution, using average $=1.46 \mathrm{~g} / \mathrm{MJ}$ and standard deviation $=0.41(\mathrm{n}=17$; Anderson-Darling $=0.42)$. Switchgrass yields in CA, IA, and VA were then estimated by computing cumulative PAR over each area's growing season and multiplying that number by the empirical estimate of RUE $E_{\text {SGRASs. }}$ Growing seasons were assumed to be 1 May - 1 August in Virginia, 1 June - 1 September in Iowa, and 1 April - 16 September in California. Resulting annual switchgrass yields were found to be lognormally distributed in each location, and mean values were benchmarked against published reports. This data is summarized in Table 2.5. 
Table 2.5. Cumulative photosynthetically active radiation (PAR) and average estimated wet yields $(\mu)$ (with standard deviation, $\sigma$ ) for switchgrass growing seasons in three geographic locations. Low values of the Anderson-Darling (A-D) statistic indicate that each wet yield distribution is well fit by the lognormal distribution; estimates are consistent with previous measurements as indicated at far right.

\begin{tabular}{|c|c|c|c|c|}
\hline Location & $\begin{array}{l}\text { Average Cumulative PAR } \\
\qquad\left(\mathrm{MJ} / \mathrm{m}^{2}\right)\end{array}$ & $\begin{array}{l}\text { Estimated Wet Yield } \\
\qquad \mu / \sigma(\mathrm{Mg} / \mathrm{ha})\end{array}$ & $\begin{array}{c}\text { Lognormal Distribution } \\
\text { A-D Statistic }\end{array}$ & $\begin{array}{c}\text { Average } \\
\text { Measured } \\
\text { Wet Yield } \\
\text { (Mg/ha) } \\
\text { [Source] }\end{array}$ \\
\hline CA & 1733 & $25.2 / 7.1$ & 0.21 & $\begin{array}{c}22.5-33.8 \\
\text { (Putnam, } \\
2008)\end{array}$ \\
\hline VA & 890 & $12.9 / 3.7$ & 0.35 & $\begin{array}{c}\text { 4.0 - } 15.0 \\
\text { (Brann and } \\
\text { Abaye, 2009; } \\
\text { Lemus, 2004) }\end{array}$ \\
\hline IA & 900 & $13.1 / 3.8$ & 0.27 & $\begin{array}{c}4.5-14.4 \\
\text { (Gibson and } \\
\text { Bernhart, } \\
\text { 2007) }\end{array}$ \\
\hline
\end{tabular}

\subsection{Canola}

Estimates of canola dry yield were computed for each of the selected locations on the basis of growing season insolation and radiation use efficiency using an empirically derived estimate of

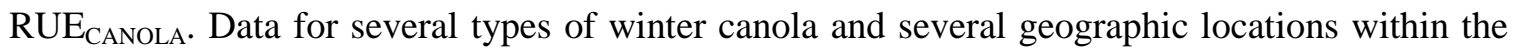
US were used to compute an estimate for $\mathrm{RUE}_{\mathrm{CANOLA}}$ in units of grams aboveground dry biomass per MJ PAR. Cultivars included those utilized in the 2003 National Winter Canola Variety Trial (NWCVT) (Rife, 2003) and others. Yield measurements were taken from selected NWCVT locations plus Corvallis, OR; Marianna, AR; Othello, WA; and Pendleton, OR (Adler et al., 2006; Lemus, 2004). RUE was computed as the ratio between dry seed yield as published in literature reports (Hang et al., 2009; Parsons, 2006) and measured PAR as taken from the NSRDB for each of these locations. Canola growing seasons were taken from the respective literature reports (Hang et al., 2009; Parsons, 2006). Pertinent information is summarized in Table 2.6. 
Table 2.6. Summary of photosynthetically active radiation (PAR) (NREL, 2005), reported winter canola seed yields, and computed radiation use efficiency (RUE) values for several geographic regions in the US.

\begin{tabular}{|c|c|c|c|c|c|}
\hline Location & Year & Growing Season & $\begin{array}{c}\text { PAR } \\
\left(\mathrm{MJ} / \mathrm{m}^{2}\right)\end{array}$ & $\begin{array}{c}\text { Yield } \\
\text { (Mg/ha) }\end{array}$ & $\begin{array}{c}\text { RUE } \\
\text { (g/MJ) }\end{array}$ \\
\hline Belleville, IL & $2002-2003^{*}$ & 25 Sep -25 Jun & 1607 & 3707 & 0.23 \\
\hline Columbia City, IN & 2002-2003* & 12 Sep - 17 Jul & $3852^{\dagger}$ & 1081 & 0.03 \\
\hline Corvallis, OR & 2004-2005 & 1 Sep - 1 Jul & 1481 & 4324 & 0.29 \\
\hline Garden City, KS & 2002-2003* & 6 Sep - 1 Jul & 2077 & 1836 & 0.09 \\
\hline Griffin, GA & $2002-2003 *$ & 3 Oct -6 Jun & 1644 & 1849 & 0.11 \\
\hline Kibler, AR & $2002-2003^{*}$ & 3 Oct - 17 Jun & $1614^{\dagger}$ & 1858 & 0.12 \\
\hline Lexington, $\mathrm{KY}$ & $2002-2003 *$ & 25 Sep - 23 Jun & 1381 & 2570 & 0.19 \\
\hline Lincoln, NE & $2002-2003^{*}$ & 10 Sep - 10 Jul & 1926 & 3285 & 0.17 \\
\hline \multirow{2}{*}{ Marianna, AR } & 2001-2002 & 15 Oct - 15 Jun & $1685^{\dagger}$ & 3131 & 0.25 \\
\hline & 2003-2004 & 15 Oct - 15 Jun & $1534^{\dagger}$ & 4102 & 0.27 \\
\hline Meridianville, AL & $2002-2003^{*}$ & 4 Oct -10 Jun & $1484^{\dagger}$ & 1269 & 0.09 \\
\hline Munday, TX & 2002-2003* & 23 Sep - 4 Jun & $1696^{\dagger}$ & 413 & 0.02 \\
\hline Novelty, MO & 2002-2003* & 2 Sep - 3 Jul & $1786^{\dagger}$ & 2047 & 0.12 \\
\hline Orange, VA & 2002-2003* & 25 Sep - 26 Jun & $1419^{\dagger}$ & 2995 & 0.27 \\
\hline \multirow[t]{2}{*}{ Othello, WA } & 2007-2008 & 10 Sep - 23 Jul & $1802^{\dagger}$ & 5064 & 0.28 \\
\hline & 2001-2002 & 1 Sep - 1 Jul & 1685 & 3131 & 0.17 \\
\hline \multirow[t]{2}{*}{ Pendleton, OR } & $2002-2003$ & 1 Sep - 1 Jul & 1718 & 2706 & 0.16 \\
\hline & 2004-2005 & $1 \mathrm{Sep}-1 \mathrm{Jul}$ & 1698 & 2858 & 0.19 \\
\hline Torrington, WY & 2002-2003* & 26 Aug - 21 Jul & $2296^{\dagger}$ & 1977 & 0.09 \\
\hline \multicolumn{6}{|c|}{$\begin{array}{l}\text { * Indicates investigation conducted as part of } 2003 \text { National Winter Canola Variety Trial (NWCVT). } \\
\text { Indicates location for which PAR data was not directly available from NSRDB so closest observation } \\
\text { station was used instead. Columbia City, IN = Fort Wayne, IN; Griffin, GA = Atlanta, GA; Kibler, AR } \\
\text { = Fort Smith, AR; Marianna, AR = Stuttgart, AR; Meridianville, AL = Hunstville, AL; Munday, TX = } \\
\text { Wichita Falls, TX; Novelty, MO = Kirkville, MO; Orange, VA = Charlottesville, VA; Othello, WA = } \\
\text { Ephrata, WA; Torrington, WY = Scottsbluff, NE. }\end{array}$} \\
\hline
\end{tabular}

$\mathrm{RUE}_{\text {CANOLA }}$ values in Table 2.6 were fit to the lognormal distribution, using average $=0.164 \mathrm{~g} / \mathrm{MJ}$ and standard deviation $=0.084(\mathrm{n}=19$; Anderson-Darling $=0.86)$. Although the normal distribution exhibited a lower Anderson-Darling statistic, and thus a better fit for this data, the lognormal data was used to ensure that sampled values of RUE $\mathrm{CANOLA}_{\text {and }}$ were never less than zero. Winter canola seed yield at each selected geographic location was estimated by computing cumulative PAR over each area's growing season and multiplying that number by RUE CANOLA $_{\text {. }}$ Resulting estimates for wet seed yield were multiplied by 0.92 to account for the fact that canola seeds are roughly $8 \%$ moisture by mass before drying. Dry seed masses were then multiplied by a factor of three to account for the mass of stalks and pods, since canola seeds comprise $1 / 3$ of the 
plant's dry weight while stalks and pods account for the other 2/3 (Thomas, 2003). Growing seasons were assumed to be 1 September- 30 June in Virginia (Rife, 2003; Starner et al., 1996), 15 September - 15 July in Iowa (based on similarity in latitude and weather conditions among Ames, IA; Columbia City, IN; and Lincoln, NE) (Rife, 2004) and 15 October - 30 May in California (Bañuelos, 2002; Schill, 2008). Resulting annual canola yields were found to be lognormally distributed in each location, and mean values were benchmarked against published reports. This data is summarized in Table 2.7.

Table 2.7. Summary of cumulative photosynthetically active radiation (PAR) and average dry yields $(\mu)$ (with standard deviation, $\sigma$ ) for winter canola growing seasons in three geographic locations. Yields represent total biomass; i.e. seeds plus stalks. Low values of the AndersonDarling (A-D) statistic indicate that each dry yield distribution is well fit by the lognormal distribution. Average estimates are well aligned with previously measured dry yields as indicated at far right. Previously reported values for canola seed yield have been multiplied by three to reflect the assumption that seeds account for $1 / 3$ of canola's weight while straw and pods (i.e., stover) account for the other $2 / 3$.

\begin{tabular}{|c|c|c|c|c|}
\hline Location & $\begin{array}{l}\text { Average Cumulative PAR } \\
\qquad\left(\mathrm{MJ} / \mathrm{m}^{2}\right)\end{array}$ & $\begin{array}{l}\text { Estimated Total Dry Yield } \\
\qquad \mu / \sigma(\mathrm{Mg} / \mathrm{ha})\end{array}$ & $\begin{array}{c}\text { Lognormal Distribution } \\
\text { A-D Statistic }\end{array}$ & $\begin{array}{c}\text { Average } \\
\text { Measured Total } \\
\text { Dry Yield (Mg/ha) } \\
\text { [Source] }\end{array}$ \\
\hline CA & 1608 & 7.1/0.7 & 0.23 & $\begin{array}{c}6.4-13.3 \\
\text { (Bañuelos, 2002; } \\
\text { Schill, 2008) }\end{array}$ \\
\hline VA & 1933 & $8.5 / 0.9$ & 0.36 & $\begin{array}{c}6.6-9.0 \text { (Rife, } \\
\text { 2003; Starner, } \\
\text { 1996) }\end{array}$ \\
\hline IA & 1810 & $7.8 / 0.8$ & 0.40 & $\begin{array}{c}3.2-9.8 \text { (Rife, } \\
2003)\end{array}$ \\
\hline
\end{tabular}

\subsection{Algae}

Algae dry yield estimates for each of the selected locations were computed on the basis of growing season insolation and radiation use efficiency using an empirically derived estimate of $\mathrm{RUE}_{\mathrm{ALGAE}}$. This estimate was derived from literature reports of field-scale algae cultivation in open ponds by Benemann and Oswald (1996), Kadam (2001) and Weissmann and Tillet (1992) (Benemann and Oswald, 1996, Kadam, 2001 and Weissmann and Tillet, 1992). Their ponds were operated in Brawley, CA; San Juan, NM; and, Roswell, NM, respectively. Table 2.8 summarizes 
average estimated monthly yields reported by the authors and average monthly PAR values as taken from the NSRDB for stations located closest to each area of interest: San Diego, CA for Brawley, CA; Albuquerque, NM for San Juan, NM; and, Tucumcari, NM for Roswell, NM.

Table 2.8. Summary of reported and estimated monthly values of radiation use efficiency for pilot-scale algae production in three different locations.

\begin{tabular}{|c|c|c|c|c|c|c|c|c|c|c|}
\hline \multirow{2}{*}{ Month } & \multicolumn{3}{|c|}{$\begin{array}{c}\text { Brawley, CA } \\
{[\text { San Diego, CA] }}\end{array}$} & \multicolumn{3}{|c|}{$\begin{array}{c}\text { Roswell, NM } \\
\text { [Tucumcari, NM] }\end{array}$} & \multicolumn{3}{|c|}{$\begin{array}{c}\text { San Juan, NM } \\
\text { [Albuquerque, NM] }\end{array}$} & \multirow{2}{*}{$\begin{array}{c}\text { Mean } \\
\text { RUE } \\
\text { (g/MJ) }\end{array}$} \\
\hline & $\begin{array}{c}\text { Yield } \\
\text { (Mg/ha) }\end{array}$ & $\begin{array}{c}\text { PAR } \\
\left(\mathrm{MJ} / \mathrm{m}^{2}\right)\end{array}$ & $\begin{array}{l}\text { RUE } \\
\text { (g/MJ) }\end{array}$ & $\begin{array}{c}\text { Yield } \\
\text { (Mg/ha) }\end{array}$ & $\begin{array}{c}\text { PAR } \\
\left(\mathrm{MJ} / \mathrm{m}^{2}\right)\end{array}$ & $\begin{array}{c}\text { RUE } \\
\text { (g/MJ) }\end{array}$ & $\begin{array}{c}\text { Yield } \\
\text { (Mg/ha) }\end{array}$ & $\begin{array}{c}\text { PAR } \\
\left(\mathrm{MJ} / \mathrm{m}^{2}\right)\end{array}$ & $\begin{array}{l}\text { RUE } \\
\text { (g/MJ) }\end{array}$ & \\
\hline Jan & 93 & 154 & 0.6 & 90 & 150 & 0.6 & & & & 0.64 \\
\hline Feb & 112 & 176 & 0.6 & 112 & 178 & 0.6 & & & & 0.63 \\
\hline Mar & 217 & 248 & 0.9 & 254 & 255 & 1.0 & & & & 1.13 \\
\hline Apr & 360 & 297 & 1.2 & 111 & 310 & 0.4 & & & & 0.83 \\
\hline May & 527 & 314 & 1.7 & 270 & 351 & 0.8 & 973 & 387 & 2.5 & 1.26 \\
\hline Jun & 600 & 314 & 1.9 & 420 & 362 & 1.2 & 942 & 393 & 2.4 & 1.89 \\
\hline Jul & 620 & 348 & 1.8 & 614 & 361 & 1.7 & 973 & 379 & 2.6 & 1.99 \\
\hline Aug & 620 & 328 & 1.9 & 564 & 32 & 1.7 & 973 & 346 & 2.8 & 2.09 \\
\hline Sep & 690 & 264 & 2.6 & 474 & 267 & 1.8 & 942 & 285 & 3.3 & 2.40 \\
\hline Oct & 682 & 221 & 3.1 & 419 & 225 & 1.9 & 973 & 237 & 4.1 & 2.78 \\
\hline Nov & 90 & 166 & 0.5 & 141 & 158 & 0.9 & & & & 1.85 \\
\hline Dec & 93 & 143 & 0.6 & 71 & 137 & 0.5 & & & & 0.57 \\
\hline
\end{tabular}

Two of the three studies summarized in Table 2.8 reported measured yields for each month of the calendar year. In contrast, Kadam (2002) reported only average photosynthetic efficiency, $4.86 \%$ on PAR basis over one year (Kadam, 2002). He also reported a total pond area of 1000 ha, estimated daily dry yield of $314,300 \mathrm{~kg}$, and 250 operational days per year. These figures were thus used to back-calculate corresponding $\mathrm{RUE}_{\mathrm{ALGAE}}$ values for each month. First, daily yield of $314,300 \mathrm{~kg}$ in a 1000 ha pond corresponds to $31.4 \mathrm{~g} / \mathrm{m}^{2}$-day productivity. This value was multiplied by the number of days per month to yield estimates of monthly yields. These figures are shown in italicized font within Table 2.8. In dividing the estimated monthly yields by measured values of average monthly PAR, it was possible to compute estimates of average

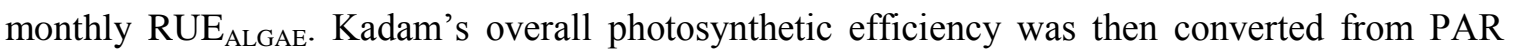
basis to biomass basis by multiplying $4.86 \%$ by the molecular weight of glucose $(180 \mathrm{~g} / \mathrm{mole})$ and 
dividing by its energy content $(2.87 \mathrm{MJ} /$ mole glucose). This yielded an average annual RUE of 3.0 g/MJ. It was then possible to select the 250 -day combination of monthly averages exhibiting this overall RUE average, namely 1 May - 31 Oct. The resulting back-calculated values of RUE $_{\mathrm{ALGAE}}$ in each of these months for Roswell, NM are indicated in Table 2.8.

Taken together with the monthly $\mathrm{RUE}_{\mathrm{ALGAE}}$ values from Brawley, CA and Roswell, NM, the back-calculated values for San Juan, NM were used to formulate triangular distributions for monthly RUE $E_{\text {ALGAE }}$ values during May - October. For months not sampled within the Kadam study (November - April), uniform distributions were assumed to cover the range between values reported by the other two studies (Benemann and Oswald, 1996; Weissman and Tillett, 1990). Annual algae yields at the selected geographic locations were then computed by multiplying each month's PAR value by its associated monthly RUE $\mathrm{ALGAE}_{\mathrm{A}}$ estimate. These products were then summed over an entire year. Algae cultivation was assumed to be impossible in months with an average daily temperature less than $0{ }^{\circ} \mathrm{C}$ (Weissman and Tillett, 1990). As such, Iowa yields for the months of January, February, March, and December were assigned a value of zero. Resulting estimates of annual algae yield in each location were normally distributed. Table 2.9 summarizes annual algae yields at each location.

Table 2.9. Summary of cumulative photosynthetically active radiation (PAR) and average estimated dry algae yields $(\mu)$ (with standard deviation, $\sigma$ ) for three geographic locations. Low values of the Anderson-Darling (A-D) statistic indicate that each yield distribution is well fit by the normal distribution.

\begin{tabular}{lccc} 
Location & Average Cumulative PAR $\left(\mathrm{MJ} / \mathrm{m}^{2}\right)$ & $\begin{array}{c}\text { Estimated Dry Yield } \\
\mu / \sigma(\mathrm{Mg} / \mathrm{ha})\end{array}$ & $\begin{array}{c}\text { Normal Distribution } \\
\text { A-D Statistic }\end{array}$ \\
\hline CA & 1733 & $47.1 / 2.5$ & 0.87 \\
VA & 890 & $40.2 / 2.2$ & 0.35 \\
IA & 900 & $34.5 / 2.1$ & 0.27 \\
\hline
\end{tabular}


Figures $2.2-2.4$ summarize predicted values of algae dry yield for each month of the year in three geographic locations of interest. Yield estimates from previously published sources are also presented in each figure for point of reference.

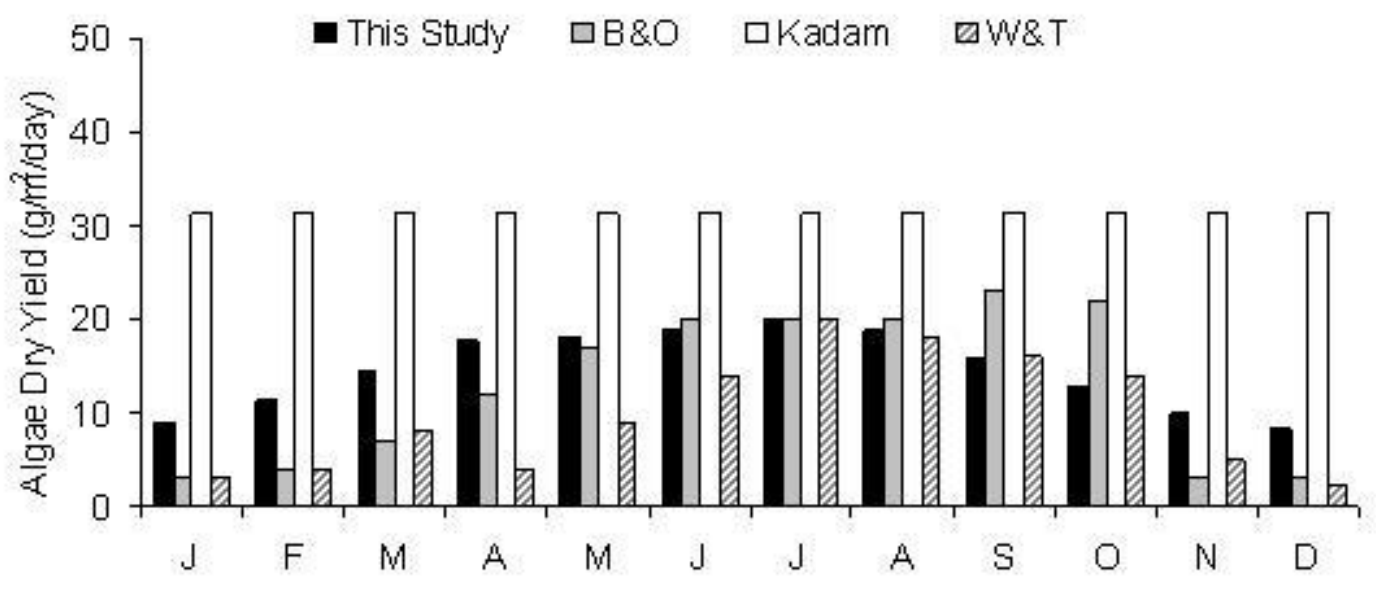

Figure 2.2. Estimated algae dry yields by month in San Diego, CA. Yield estimates reflect reported $\mathrm{RUE}_{\mathrm{ALGAE}}$ values from various sources (B\&O = Benemann and Oswald (1996); Kadam = Kadam (2002); W\&T = Weissman and Tillett (1990)) as multiplied by growing season PAR in San Diego, CA.

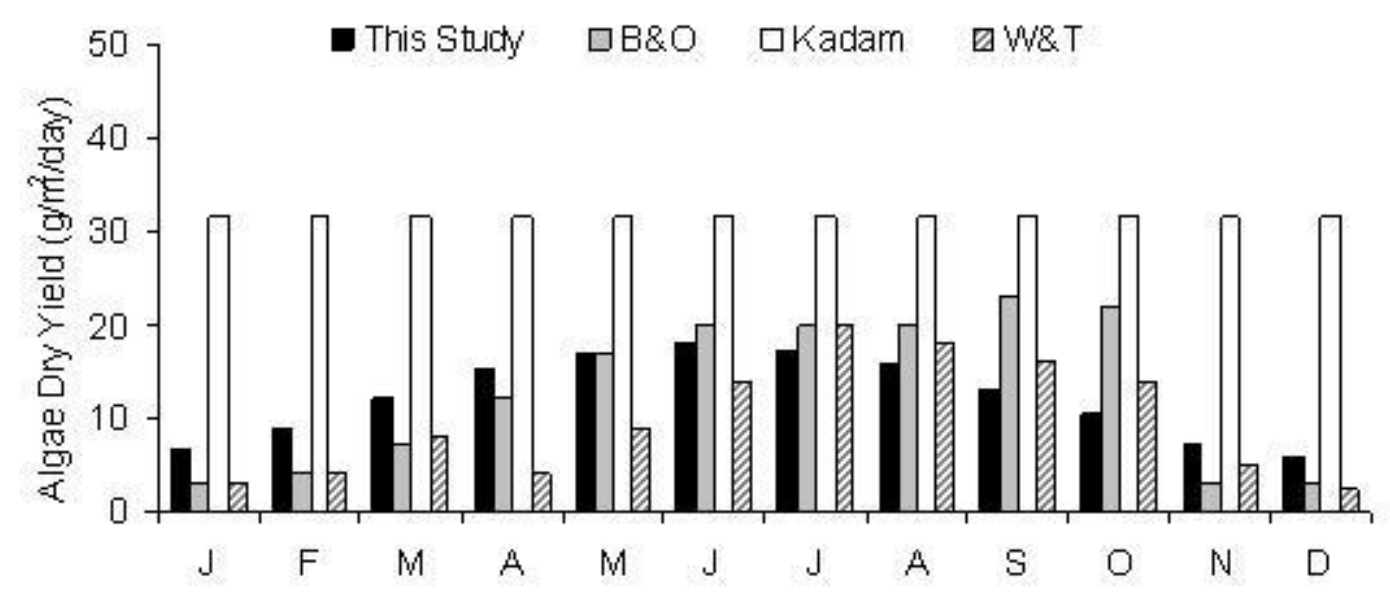

Figure 2.3. Estimated algae dry yields by month in Roanoke, VA. Yield estimates reflect reported RUE $E_{\mathrm{ALGAE}}$ values from various sources $(\mathrm{B} \& \mathrm{O}=$ Benemann and Oswald (1996); Kadam $=$ Kadam (2002); W\&T = Weissman and Tillett (1990)) as multiplied by growing season PAR in Roanoke, VA. 


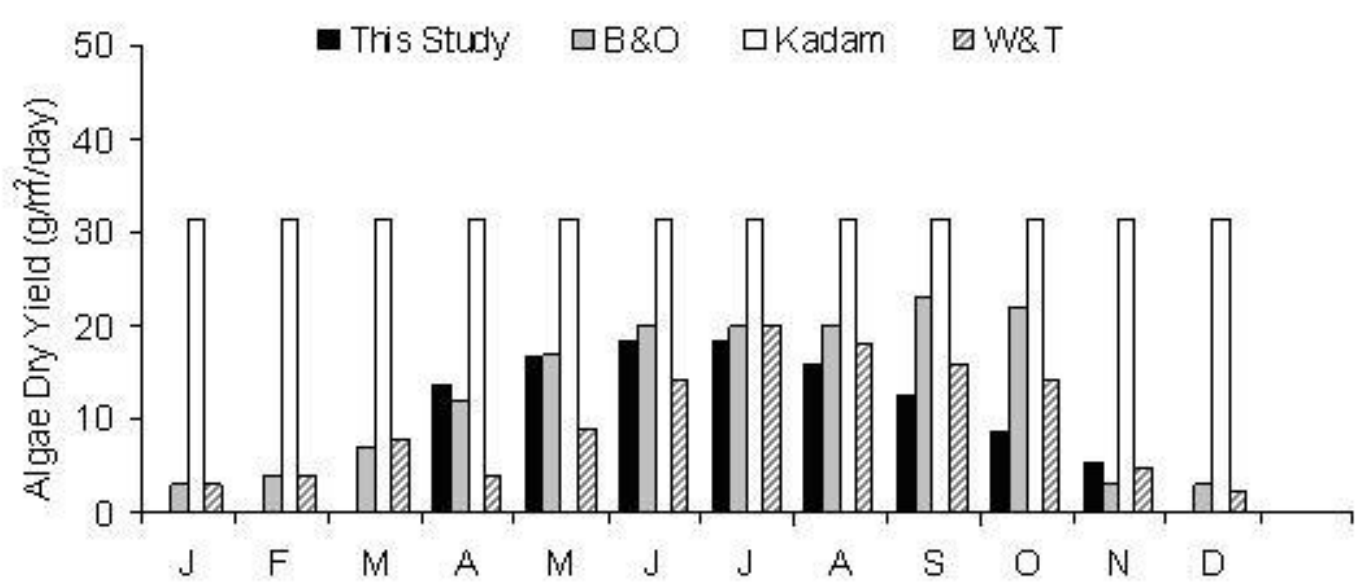

Figure 2.4. Estimated algae dry yields by month in Ames, IA. Yield estimates reflect reported RUE $_{\text {ALGAE }}$ values from various sources $(\mathrm{B} \& \mathrm{O}=$ Benemann and Oswald (1996); Kadam $=$ Kadam (2002); W\&T = Weissman and Tillett (1990)) as multiplied by growing season PAR in Ames, IA.

\subsubsection{Selection of Open Ponds v. Photobioreactors}

The decision to model open ponds in this research is based primarily on the economics of biomass production for fuel and the likelihood that these reactors will be used in the near future. Recent research has focused on photobioreator design for optimal growth rates and in this regard, photobioreactors do offer certain benefits over open ponds: (1) higher cell densities can be obtained and (2) pure cultures of lipid-rich organisms can be grown without risk of contamination by other species (Chisti, 2007). Despite these advantages, the cost of photobioreactors makes them highly unfavorable for energy production applications. Growing algae for fuel will require large-scale operations and the capital cost of photobioreactor projects increases linearly with production much faster than open ponds. One estimate is that cost of producing algae from photobioreactors is an order of magnitude higher than in open ponds (Del Campo et al., 2007). Additionally, the land footprint of photobioreactors is not much better than open ponds. More importantly, the life cycle burdens of photobioreactors are expected to be many times higher than open ponds in terms of greenhouse gas emissions, energy use, and water use. The production of all the required materials (glass, metal, concrete foundations, etc.) for production of a 
photobioreactor is expected make them an unfavorable option relative to open ponds. The primary contributions to the life cycle of algae, e.g., the nutrient use and $\mathrm{CO}_{2}$ consumption, would not be changed regardless of the growing method. For this reason the open pond results reported here could be considered a 'best case' scenario for photobioreactors assuming the impacts from producing and operating the facility were offset by the improved productivity.

\subsubsection{Algae Stoichiometry and Fertilizer Requirements}

\subsection{Algae Stoichiometry}

The molecular composition of algae was used to help define several of the estimates used in this study including the $\mathrm{CO}_{2}$ uptake rate, fertilizer addition rates, etc. The molecular composition of algae is largely consistent between photosynthetic species as demonstrated by Redfield (1958) (Redfield, 1958).

$$
\text { Algae }=C_{106} H_{181} O_{45} N_{15} P(M W=2414)
$$

Production of algae biomass was assumed to proceed via the combination of carbon dioxide + water + urea + phosphate + light. This is shown in Equation 2.8 .

$$
99.5 \mathrm{CO}_{2}+75.5 \mathrm{H}_{2} \mathrm{O}+7.5 \mathrm{CO}\left(\mathrm{NH}_{2}\right)_{2}+1 / 2 \mathrm{P}_{2} \mathrm{O}_{5} \rightarrow \mathrm{C}_{106} \mathrm{H}_{181} \mathrm{O}_{45} \mathrm{~N}_{15} \mathrm{P}+119.75 \mathrm{O}_{2} \quad \text { Equation } 2.8
$$

This stoichiometry was utilized in estimating amounts of various required inputs for algae cultivation.

\subsection{Fertilizer Requirements}

A combination of literature data and algae stoichiometry, as defined in 2.3.1.5.1, were used to determine appropriate mass dosing for nitrogen $(\mathrm{N})$ and phosphorus $(\mathrm{P})$ fertilizers. Triangular 
distributions were used for both $\mathrm{N}$ and $\mathrm{P}$ dosing rates. Minimum, maximum, and most likely nitrogen concentrations were set to 23, 140, and $70 \mathrm{mg} / \mathrm{L}$ as $\mathrm{N}$, respectively (Andersen, 2005). Minimum, maximum, and most likely phosphorus concentrations were set to 10, 102, and 29 $\mathrm{mg} / \mathrm{L}$ as $\mathrm{P}_{2} \mathrm{O}_{5}$, respectively (Andersen, 2005). Use of these distributions led to $\mathrm{N}$ and $\mathrm{P}$ doses that were just less than $2 \times$ the stoichiometric requirements for the average computed algae yield. It was assumed that the excess $\mathrm{N}$ and $\mathrm{P}$ may be diverted to other biochemical reactions (e.g., production of extracellular material, bacterial growth, etc.). Since the water balance was assumed to be at steady-state, dose concentrations were multiplied by the amount of water centrifuged out of the system each month to compute total required masses of each nutrient per month. For all of the modeled scenarios, urea $\left(\left(\mathrm{NH}_{2}\right)_{2} \mathrm{CO}\right)$ was used as $\mathrm{N}$ source and superphosphate $\left(\mathrm{Ca}\left(\mathrm{H}_{2} \mathrm{PO}_{4}\right)_{2}\right)$ was used as P source.

\subsubsection{Higher Heating Values of Biomass Stocks}

Data from the Energy research Centre of the Netherlands ECN was combined with results from this study's literature review to compile a table of biomass compositions and high heating values (HHV) for the four types of biofeedstocks investigated in this study. Literature measurements of algae biomass HHV was confirmed in measurements performed by an algae start-up company located outside Richmond, VA. This firm estimates the HHV of dried algae to be $24,300 \mathrm{~kJ} / \mathrm{kg}$. For biomass samples where HHV was not reported, the relationship between $\mathrm{C}-\mathrm{H}-\mathrm{N}$ embodied by Equation 2.9 was used to formulate an estimate.

$H H V(M J / M g)=35160 \times w t \% C+116225 \times w t \% H-11090 \times w t \% O+6280 \times w t \% N \quad$ Equation 2.9

HHV values taken from the literature or estimated using Equation 2.9 were incorporated into triangular distributions using the minimum, maximum, and most likely values. For corn and canola, two separate triangular distributions were utilized for the grain (kernels or seed) and 
stover/straw. Composite HHV, encapsulating the amount of energy that would be released upon combustion of the entire plant, was then computed using a mass-weighed average of the kernel/seed and stover/straw HHVs for each plant. Each range of values summarized in Table 2.10 was fit to a triangular distribution according to $\mathrm{HHV} \sim$ Triangular (minimum value, likeliest value, and maximum value). HHV values for each type of biomass are summarized in Table 2.10.

Table 2.10. Summary of approximate elemental composition (i.e., weight percentage comprising carbon, hydrogen, oxygen, and nitrogen) and high heating value (HHV) estimates for each of the biomass feedstocks evaluated in this investigation.

\begin{tabular}{|c|c|c|c|c|c|c|}
\hline Feedstock & $\mathrm{C} \%$ & $\mathrm{H} \%$ & O\% & N\% & $\mathrm{HHV}(\mathrm{MJ} / \mathrm{Mg})$ & Source \\
\hline Algae & 52.7 & 7.22 & 28.9 & 8.01 & 23480 & Phyllis, 2009 \\
\hline Algae & 43.9 & 6.86 & 34.5 & 6.54 & 19818 & Hirano et al., 1998 \\
\hline Algae & 54.8 & 6.67 & 23.5 & 6.66 & 26357 & Phyllis, 2009 \\
\hline Algae & 52.7 & 7.22 & 28.9 & 8.01 & *24219 & Ross et al., 2008 \\
\hline \multicolumn{3}{|l|}{ Minimum HHV } & \multicolumn{4}{|c|}{19800} \\
\hline \multicolumn{3}{|l|}{ Maximum HHV } & \multicolumn{4}{|c|}{26400} \\
\hline \multicolumn{3}{|c|}{ Likeliest Value HHV } & \multicolumn{4}{|c|}{24000} \\
\hline Switchgrass & 47.4 & 5.75 & 42.3 & 0.74 & 18641 & Miles et al., 1995 \\
\hline Switchgrass & 47.5 & 5.80 & 43.6 & 0.36 & 18559 & Miles et al., 1995 \\
\hline Switchgrass & 47.8 & 5.76 & 35.1 & 1.17 & 18024 & $\begin{array}{l}\text { Hughes and } \\
\text { Tillman, } 1997\end{array}$ \\
\hline Switchgrass & 42 & 5 & 35 & 0.2 & *16710 & $\begin{array}{l}\text { Sami, Annamalai } \\
\text { and Wooldridge, } \\
2001\end{array}$ \\
\hline \multicolumn{3}{|l|}{ Minimum HHV } & \multicolumn{4}{|c|}{16700} \\
\hline \multicolumn{3}{|c|}{ Maximum HHV } & \multicolumn{4}{|c|}{18650} \\
\hline \multicolumn{3}{|c|}{ Likeliest Value HHV } & \multicolumn{4}{|c|}{18300} \\
\hline Corn kernels & 44.6 & 5.37 & 39.6 & 0.41 & 17690 & Phyllis, 2009 \\
\hline Corn kernels & 44 & 6.4 & 49.2 & 1.1 & *17522 & $\begin{array}{l}\text { Smeenk, Brown } \\
\text { and Eckels, } 1999\end{array}$ \\
\hline Corn kernels & 43.4 & 6.17 & 45.8 & 1.02 & 17359 & D'Jes's et al., 2006 \\
\hline Corn kernels & 42 & 5 & 42 & 0.7 & *15965 & $\begin{array}{c}\text { Sami, Annamalai } \\
\text { and Wooldridge, } \\
2001\end{array}$ \\
\hline \multicolumn{3}{|l|}{ Corn kernels } & \multicolumn{3}{|r|}{15900} & Weidema, 2008 \\
\hline Corn stover & 37.8 & 4.84 & 35 & 0.65 & 14493 & Evans et al., 1988 \\
\hline Corn stover & 46.8 & 5.74 & 41.4 & 0.66 & 18101 & BFIN, 2009 \\
\hline Corn stover & 49.4 & 5.6 & 42.5 & 0.6 & 13344 & Demirbas, 2005 \\
\hline Corn stover & 43.4 & 6.17 & 45.8 & 1.02 & 17359 & D'Jes's et al., 2006 \\
\hline \multicolumn{3}{|c|}{ Minimum HHV - kernels } & \multicolumn{4}{|c|}{15960} \\
\hline \multicolumn{3}{|c|}{ Maximum HHV - kernels } & \multicolumn{4}{|c|}{17690} \\
\hline \multicolumn{3}{|c|}{ Likeliest Value HHV - kernels } & \multicolumn{4}{|c|}{17250} \\
\hline \multicolumn{3}{|c|}{ Minimum HHV - stover } & \multicolumn{4}{|c|}{13340} \\
\hline \multicolumn{3}{|c|}{ Maximum HHV - stover } & \multicolumn{4}{|c|}{18100} \\
\hline \multicolumn{3}{|c|}{ Likeliest Value HHV - stover } & \multicolumn{4}{|c|}{15930} \\
\hline
\end{tabular}




\begin{tabular}{|c|c|c|c|c|c|c|}
\hline Rape seed & 51.1 & 6.4 & 34 & 2.3 & 21604 & ETSU, 1988 \\
\hline Rape seed & 48.1 & 5.9 & 45.2 & 0.8 & 19330 & $\begin{array}{l}\text { Wilen, Moilanen } \\
\text { Kurkela, } 1996\end{array}$ \\
\hline Rape seed & 50.5 & 6.3 & 41.2 & 2.1 & 21547 & $\begin{array}{c}\text { Schmidt, } \\
\text { Zschetzsche and } \\
\text { Hantsch-Linhart, } \\
1993\end{array}$ \\
\hline Rape seed & 50.2 & 6.9 & 37.9 & 5.1 & 22000 & Reisinger, 1997 \\
\hline Rape straw & 37.8 & 4.6 & 56.8 & 0.8 & 19380 & G, 1988 \\
\hline Rape straw & 33.7 & 3.9 & 61.8 & 0.7 & 19740 & ETSU, 1998 \\
\hline Rape straw & 44.6 & 5.1 & 48.8 & 1.4 & 17610 & Reisinger, 1997 \\
\hline Rape straw & 42.8 & 5.3 & 47.4 & 0.6 & 15788 & $\begin{array}{l}\text { Zabaniotou, } \\
\text { loannidou and } \\
\text { Skoulou, } 2008\end{array}$ \\
\hline \multicolumn{5}{|c|}{ Minimum HHV - seed } & \multicolumn{2}{|l|}{19330} \\
\hline \multicolumn{5}{|c|}{ Maximum HHV - seed } & \multicolumn{2}{|l|}{22000} \\
\hline \multicolumn{5}{|c|}{ Likeliest Value HHV - seed } & \multicolumn{2}{|l|}{21575} \\
\hline \multicolumn{5}{|c|}{ Minimum HHV - straw } & \multicolumn{2}{|l|}{15788} \\
\hline \multicolumn{5}{|c|}{ Maximum HHV - straw } & \multicolumn{2}{|l|}{19740} \\
\hline \multicolumn{5}{|c|}{ Likeliest Value HHV - straw } & \multicolumn{2}{|l|}{18495} \\
\hline
\end{tabular}

\subsubsection{Corn versus corn kernel and canola versus canola seed}

In conventional agriculture, corn is generally cultivated for kernels and canola is generally cultivated for seed. The rest of the plant (i.e. stover or straw) may be left in the field or harvested and ground up for use as animal feed (e.g. corn silage). For this study, we wished to utilize the heat content of the entire plant, consistent with the assumption that the most straightforward way to make energy from biomass may be combustion to yield bioelectricity. It was thus desirable to account for the maximum amount of biomass-derived heat that could be grown per unit area, so we computed the composite HHV values summarized in Table 2.10. Still, it was also necessary to account for the "free" biomass generated as stover or straw when either corn or canola are grown for the express purpose of producing bioenergy. In particular, it was necessary to adjust literature values for life cycle impacts (e.g. energy use) associated with the production of some unit mass corn kernel or canola. Thus, we assumed that a canola plant and corn plant comprise $33 \% \mathrm{w} / \mathrm{w}$ as seed (Thomas, 2003) or 50\% w/w as kernel (Myers, 2009) and then divided by the weight fraction comprising seed or kernel to compute life cycle burdens per unit mass whole plant. 


\subsubsection{Impact Factor Definitions}

\subsubsection{Land Use}

Land use represents all the land, direct and indirect that would be required to produce the functional unit of energy. This value is influenced by the productivity of the given crop and the HHV of the biomass source. Indirect land use (i.e. "upstream" land use) is associated with the use of industrial chemicals that require land for production. Land use is expressed as hectares (ha).

\subsubsection{Water Use}

Water use includes direct water usage required to fill algae ponds and irrigate crops. Water use is expressed as $\mathrm{m}^{3}$ of fresh water at the surface. Direct use water streams coming into the systems include precipitation and pumping from surface water reservoirs. Outflows from the agricultural operations include evaporation (algae) and evapotranspiration (corn, canola, and switchgrass) as well as carry-out in the algae biomass. Carry-out includes all the water in the biomass matrix carried with the algae when it is extracted. Indirect water use was included based on the consumption of fertilizers and other inputs, which require water for their production.

\subsubsection{Energy Use}

Energy use represents the total energy consumption associated with the production of one functional unit of energy. Naturally, the higher the energy use value, the lower the efficiency of the bioenergy source. The functional unit was not included in each reported energy use number since it is the same for each crop inherent to the definition of a functional unit. Thus, the total energy use number reported here includes the energy required for cultivation and preliminary transportation of each crop. Indirect energy associated with production of input chemicals is also included. Energy is reported here in terms of megajoules (MJ). 


\subsubsection{Global Warming Potential}

Global warming potential was quantified in terms of kilogram equivalents of $\mathrm{CO}_{2}$ using the global warming potential values adopted by the Intergovernmental Panel on Climate Change (IPCC) (IPCC, 2007). The values for a 100 year time horizon were selected and are summarized in Table 2.11. $\mathrm{CO}_{2}$ sequestered in the biomass was subtracted from the total greenhouse gas emissions for the agricultural process.

Table 2.11. Global warming potential (GWP) values used to estimate total impacts reported in this study.

\begin{tabular}{lc}
\hline \multicolumn{1}{c}{ Gas } & GWP (100 year time horizon) \\
\hline Carbon Dioxide & 1 \\
Methane & 25 \\
Nitrous Oxide & 298 \\
\hline
\end{tabular}

\subsubsection{Eutrophication}

Eutrophication was expressed in terms of $\mathrm{PO}_{4}{ }^{3-}$ mass equivalents. Conversion factors for the four compounds included in this composite impact category are provided in Table 2.12. As with the other impact factors, both direct and indirect contributions were included. Direct contributions were estimated based on a stochastic rate of fugitive emissions (spills) that could be reasonably expected in an algae production facility. Indirect contributions (i.e. "upstream" contributions) arise during upstream processes such as fertilizer production, electricity generation and transmission, etc.

Table 2.12. Eutrophication potential values used to estimate the total potential reported in this study.

\begin{tabular}{|c|c|}
\hline Pollutant Type & $\begin{array}{l}\text { Eutrophication Equivalence } \\
\text { (g } \mathrm{PO}_{4}^{-} \mathrm{eq} / \mathrm{g} \text { substance) }\end{array}$ \\
\hline COD & 0.022 \\
\hline Nitrogen & 0.42 \\
\hline Nitrate & 0.1 \\
\hline Phosphorus & 3.06 \\
\hline
\end{tabular}




\subsubsection{Impact Factor Calculations}

The impacts associated with algae cultivation are described in detail below. The impacts for canola, corn, and switchgrass were used as reported in the Ecoinvent database (Weidema, 2008) and referenced against other published data. Since these are published values, they are not discussed in detail here.

\subsubsection{Land Use}

Land use is reported in hectares (ha) because this is the SI unit of area $\left(1\right.$ ha $=10,000 \mathrm{~m}^{2}=2.47$ acre). It was assumed that not all land dedicated toward the production of a biofuel is used for direct cultivation. Access roads, buildings, and other infrastructure are needed. For corn, canola, and switchgrass, these contributions were included in the Ecoinvent database (Weidema, 2008). For algae, a $25 \%$ increase in land area was included to account for the footprint of support infrastructure.

\subsubsection{Water Use}

Water use was computed using the precipitation and evaporation data presented in Section 2.3.1.2. Overall, indirect contributions from the production of chemicals used in algae cultivation were much greater than the direct use contributions.

\subsubsection{Energy Use}

Energy use includes all the energy inputs that would be required to produce one functional unit. This measure captures the primary energy needed for all the material inputs to the process (e.g., fertilizers) as well as the energy needed to run the farming operation (e.g., mixing, centrifuges). Since energy demands of these processes are driven entirely by movement of water through the ponds, a harvesting model was created to estimate flows as a function of pond productivity. This water and algae balance was performed to determine: (1) the volume of algae solution to be 
separated as a function of productivity (harvesting rate) and (2) the flow of make-up water required to maintain a constant pond volume as a function of productivity and evaporation (makeup rate). This balance, presented in Figure 2.5, shows that the volume entering the centrifuge $\left(\mathrm{Q}_{2}\right)$ is the product of the pond's productivity and the pond area (in L/day). The concentration (factor of 1000x) cancels in the unit conversion between $\mathrm{g} \rightarrow \mathrm{kg} \rightarrow \mathrm{L}$ algae solution. The make-up rate depends very much on evaporation rate and carry out rate $\left(\mathrm{Q}_{1}\right)$.

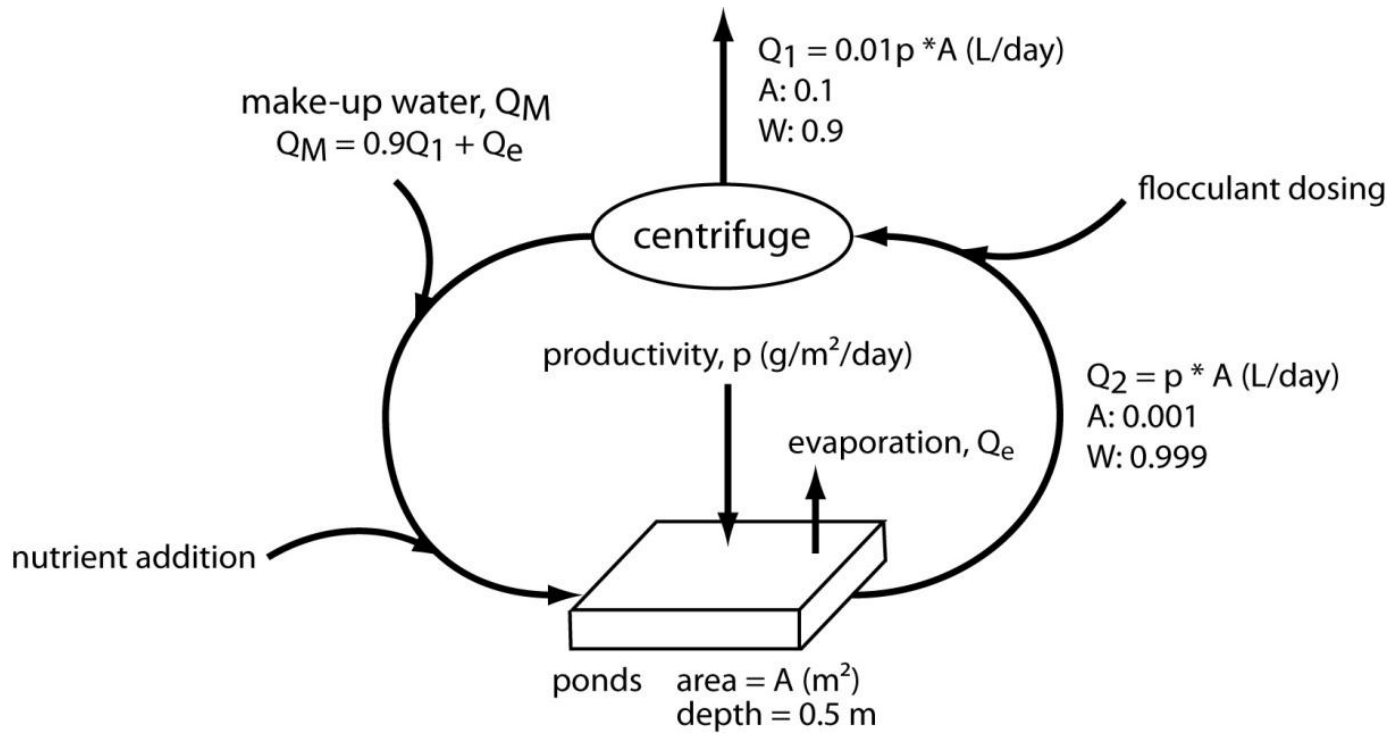

Figure 2.5. Schematic of algae and water flows through the ponds. The equations presented here were used to estimate water and algae flows as a function of pond productivity. These flows were in turn used to estimate the energy demands during algae cultivation.

Demonstration scale studies of algae production have found that energy demands can be divided into several classes: mixing (24.4\%); harvesting/processing (17.4\%); water supply (19.8\%); flue gas supply (34.8\%); and other (3.5\%) (Benemann and Oswald, 1996). For this model, it was assumed that $\mathrm{CO}_{2}$ can be delivered as a pure gas such that flue gas supply was not required. As such, our estimates for the other energy streams were divided up roughly as follows: mixing (25.5\%); harvesting (43.7\%); and water supply (30.8\%). This breakdown is approximately 
proportional to Benemann's allocation (Benemann and Oswald, 1996), and differences could be easily attributed to differences in pond architecture or machinery efficiency.

\subsection{Mixing}

The energy required to operate a paddle wheel depends on its size and rotation speed. The energy required by one paddle wheel was modeled using a triangular distribution over the range 0.0001 $\mathrm{kW}$ to $0.01 \mathrm{~kW}$ (likeliest value $=0.0037 \mathrm{~kW}$ ) (Moulick and Mal, 2009). There are 10 paddle wheels used per hectare (roughly a density of 1 paddle wheel per $1,000 \mathrm{~m}^{2}$ of ponds) operating at 10 RPM. This constitutes an energy demand of approximately $0.01 \mathrm{~W}$ as shown in Equation 2.10 .

$P=0.037 \mathrm{~kW} /$ paddle wheel $\times 10$ paddle wheels $/$ ha $\times 3.15 \times 10^{7} \mathrm{~s} / \mathrm{yr}=11,668 \mathrm{MJ} / \mathrm{ha} \mathrm{yr}$ Equation 2.10

\subsection{Centrifugation}

It was ssumed that a combined flocculation/centrifugation process is used to separate the solids from the medium. Alum was utilized as the flocculent, and dosing was consistent with previous reports by Becker (1994) (Becker, 1994). Algae concentrations entering and exiting the centrifuge were assumed to be $0.1 \%$ mass per volume $(\mathrm{m} / \mathrm{v})$ and $10 \%$, respectively. We assumed the centrifuge to be of the sediment-type configuration. The energy for such a unit can be approximated as the sum of the energy to accelerate the feed stream and the power to discharge the solid cake, $\mathrm{P}_{\text {total }}=\mathrm{P}_{\mathrm{acc}}+\mathrm{P}_{\text {con }}$, where $\mathrm{P}_{\mathrm{acc}}$ is the power to accelerate feed stream from zero speed to full tangential speed at the pool required to achieve sufficient G-force for separation. This is expressed in Equation 2.11.

$$
P_{a c c}=5.984 \times 10^{-10} \times \operatorname{sg} \times Q \times\left(\Omega r_{p}\right)^{2} \quad \text { Equation } 2.11
$$


Here $s g$ is the specific gravity of the mixture ( $1 \mathrm{~kg} / \mathrm{L}), Q$ is the flow rate of mixture (in $\mathrm{gal} / \mathrm{min}$ ), $\Omega$ is the rotational speed of centrifuge $\left(\mathrm{min}^{-1}\right)$ and $r_{p}=$ radius of centrifuge bowl (m).

$P_{c o n}$ is the power to convey and discharge cake and it can be calculated using the relationship in Equation 2.12.

$$
P_{c o n}=1.587 \times 10^{-5} \times \Delta \times T \quad \text { Equation } 2.12
$$

Where $\Delta$ is the differential speed and it can be calculated using Equation 2.13.

$$
\Delta=\sqrt{\left(\frac{k_{1}}{k_{2}}\right)^{2}+\frac{1}{k_{2}} \times m_{s s} \times I \times G \times L_{\text {eff }}-\frac{k_{1}}{2 k_{2}}} \quad \text { Equation } 2.13
$$

Here, $k_{l}$ was assumed to be $80 \mathrm{bar}, k_{2}$ is $5.3 \mathrm{bar}, g_{c}$ is $32.2 \mathrm{lbf}-\mathrm{ft} / \mathrm{lbm}-\mathrm{s}^{2}, I$ is $0.5, \mathrm{~m}_{\mathrm{ss}}$ is the dry feed rate basis $(10 \mathrm{~kg} / \mathrm{sec}), G$ is $770 \mathrm{~g}$, the length to diameter ratio (L/D) is 3, the diameter of the bowl $(D)$ is $690 \mathrm{~mm}, \mathrm{~L}$ is $2070 \mathrm{~mm}$, and the effective length $L_{\text {eff }}$ is $(2 / 3) \mathrm{L}$ so $1380 \mathrm{~mm}(54.33 \mathrm{in})$. The conveyance torque $(T)$ is $\mathrm{T}=\mathrm{k}_{1}+\mathrm{k}_{2} \mathrm{x} \Delta$. This torque value is then plugged back into Equation 2.11 and the $P_{c o n}$ and $P_{a c c}$ values are added together to get the power requirements on the centrifuge. The energy estimates obtained here correspond well with published values for centrifuges with comparable specifications (Perry, 1997).

\subsection{Water Supply}

Energy is required to pump water into and among the ponds as well as to the centrifuges. This energy requirement was estimated by calculating the head through the pump using Equation 2.14. 


$$
h=\frac{P_{2}-P_{1}}{\rho g}
$$

Equation 2.14

Here $P_{2}$ and $P_{1}$ are the pressure at the pump inlet and outlet, respectively. Inlet pressure was assumed to be $0.1 \mathrm{MPa}$, and outlet pressure was assumed to be $0.2 \mathrm{MPa} . g$ is the acceleration of gravity, and $\rho$ is the density of water. Work in the pump is then estimated, using $h$ as derived from Equation 2.14, via Equation 2.15.

$$
W=\frac{h g}{\eta} \quad \text { Equation } 2.15
$$

Where $W$ is the work in $\mathrm{J} / \mathrm{s}, g$ is the acceleration of gravity, and $\eta$ is the pump efficiency (85\%).

\subsection{Infrastructure Manufacturing}

The life cycle impacts associated with manufacture and installation of the pumps, paddle wheels, and centrifuge were estimated using SimaPro and ultimately found to be negligible relative to the magnitude of the impacts associated with other life cycle stages. The total energy draw of the overall system during operation (included in the model) was on the order of $1.1 \mathrm{~kW} / \mathrm{ha}$. This value was used to size the physical components needed to operate the ponds. Based on data from the Ecoinvent database (Weidema, 2008), the impacts associated with building these unit operations was less than $1 \%$ of the total impact for one year (land use $=8.3 \times 10^{-4}$ ha, water use $=$ $847 \mathrm{~m}^{3}$, energy use $=1,870 \mathrm{MJ}, \mathrm{GHG}=121 \mathrm{~kg} \mathrm{CO} 2$ equivalents, EUT $=7 \times 10^{-3} \mathrm{~kg}^{\mathrm{PO}_{4}}$ equivalents). Over the life of a pond, e.g., tens of years, it is reasonable to assume that the "use phase' energy requirements dominate over the production and manufacture energy requirements. 


\subsection{Other}

The $\mathrm{CO}_{2}$ was stored as a liquid and delivered as a gas such that no energy was modeled for $\mathrm{pH}$ mediated on-demand delivery of $\mathrm{CO}_{2}$. There will be an energy draw associated with buildings and other infrastructure serving the algae production process. It was assumed $3 \%$ of the total energy needed to operate the production facility will be required for this purpose, consistent with Benemann (Benemann and Oswald, 2006).

\subsubsection{Global Warming Potential}

Greenhouse gas (GHG) emissions from the production of algae were calculated by adding the emissions associated with all the inputs to the process (e.g., fertilizer, energy, etc.) and subtracting out the rate at which algae take up $\mathrm{CO}_{2}$ when they grow. This rate was estimated based on the stoichiometry of an algal cell and was made stochastic based on the fact that algae bind carbon in biomolecules that are later excreted as algal organic mass. This carbon content is not included in the total biomass produced since it cannot be centrifuged from solution given its dissolved state. Based on stoichiometry, 91 moles of $\mathrm{CO}_{2}$ is consumed for every mole of algae produced. Multiplying through by the molecular weight of each material, the expected sequestration rate is $1.7 \mathrm{~g} \mathrm{CO}_{2} / \mathrm{g}$ algae. Four additional empirical measurements for this ratio, ranging from 0.99 - 1.96 were taken from the literature (Weissman and Tillett, 1990; Kadam, 2002; Becker, 1994). These five values were then fit to a normal distribution with average $(\mu)=$ $1.6 \mathrm{~g} \mathrm{CO}_{2} / \mathrm{g}$ algae and standard deviation $(\sigma)=0.3 \mathrm{~g} \mathrm{CO}_{2} / \mathrm{g}$ algae. The Anderson-Darling statistic for this fit was 0.99 , indicating a reasonable fit for this data.

\subsubsection{Eutrophication}

Eutrophication impacts for the production of algae included contributions from each of the inputs to the process (e.g., fertilizer) and also assumed a small amount of fugitive losses as a function of 
the amount of algae produced. A uniform distribution was used to model these losses over the range reported in the literature, $1 \mathrm{E}-6$ - $1 \mathrm{E}-5 \mathrm{~kg} \mathrm{PO}_{4}$-eq per $\mathrm{kg}$ dry yield algae (Benemann and Oswald, 1996). For a well-managed outdoor pond system, these losses are likely to be much lower than nutrient run off from conventional agricultural operations.

\subsubsection{Life Cycle Inventory Data}

\subsubsection{Canola, Corn, and Switchgrass Production}

Table 2.13. Life cycle impacts for canola seed, corn kernel, and grass silage production as taken from the Ecoinvent database (Weidema, 2008). GHG is greenhouse gas emissions; EUT is eutrophication potential. Impact factors were assigned lognormal distributions using averages $(\mu)$ and standard deviations $(\sigma)$ from the data source. These parameters are presented for each distribution using $\mu / \sigma$ notation.

\begin{tabular}{lcccccc}
\multicolumn{1}{c}{ Item } & Functional Unit & $\begin{array}{c}\text { Land Use } \\
\left(\mathrm{m}^{2}\right)\end{array}$ & $\begin{array}{c}\text { Water Use } \\
\left(\mathrm{m}^{3}\right)\end{array}$ & $\begin{array}{c}\text { Energy Use } \\
(\mathrm{MJ})\end{array}$ & $\begin{array}{c}\text { GHG } \\
\left(\mathrm{CO}_{2} \text {-eq) }\right.\end{array}$ & $\begin{array}{c}\text { EUT } \\
\left(\mathrm{PO}_{4} \text {-eq }\right)\end{array}$ \\
\hline Canola & $1 \mathrm{~kg}$ dry rapeseed & $0.1 / 0.02$ & $1.8 / 1.8$ & $11.9 / 11.6$ & $1.9 / 1.9$ & $5.1 \mathrm{E}-3 / 5 \mathrm{E}-3$ \\
\hline Corn & $1 \mathrm{~kg}$ dry weight & $0.1 / 0.01$ & $0.1 / 0.007$ & $0.4 / 0.1$ & $0.1 / 0.004$ & $1.4 \mathrm{E}-6 / 2 \mathrm{E}-7$ \\
\hline Switchgrass & $1 \mathrm{~kg}$ dry weight & $0.8 / 0.2$ & $0.2 / 0.02$ & $1.4 / 0.2$ & $0.2 / 0.04$ & $4.4 \mathrm{E}-6 / 8 \mathrm{E}-7$ \\
\hline
\end{tabular}

\subsubsection{Algae Production}

Table 2.14. Life cycle impacts for electricity and chemicals used in algae production as extracted from the Ecoinvent database (Weidema, 2008). GHG is greenhouse gas emissions; EUT is eutrophication potential. Impact factors were assigned lognormal distributions using averages $(\mu)$ and standard deviations $(\sigma)$ from the data source. These parameters are presented for each distribution using $\mu / \sigma$ notation.

\begin{tabular}{lcccccc}
\hline \multicolumn{1}{c}{ Item } & $\begin{array}{c}\text { Functional } \\
\text { Unit }\end{array}$ & $\begin{array}{c}\text { Land Use } \\
\left(\mathrm{m}^{2}\right)\end{array}$ & $\begin{array}{c}\text { Water Use } \\
\left(\mathrm{m}^{3}\right)\end{array}$ & $\begin{array}{c}\text { Impact category } \\
\text { Energy Use } \\
(\mathrm{MJ})\end{array}$ & $\begin{array}{c}\mathrm{GHG} \\
\left(\mathrm{CO}_{2} \text {-eq }\right)\end{array}$ & $\begin{array}{c}\text { EUT } \\
\left(\mathrm{PO}_{4} \text {-eq }\right)\end{array}$ \\
\hline $\begin{array}{l}\text { Electricity } \\
\text { (US mix) }\end{array}$ & $1 \mathrm{kWh}$ & $0.005 / 0.006$ & $0.8 / 0.01$ & $2.5 / 2.4$ & $0.2 / 0.01$ & $2.2 \mathrm{E}-6 / 2 \mathrm{E}-6$ \\
$\begin{array}{l}\text { Alum } \\
\text { Super- } \\
\text { phosphate }\end{array}$ & $1 \mathrm{~kg} \mathrm{Al}_{2}\left(\mathrm{SO}_{4}\right)_{3}$ & $0.01 / 0.008$ & $2.5 / 0.5$ & $5.7 / 1.3$ & $0.5 / 0.07$ & $9.0 \mathrm{E}-4 / 8 \mathrm{E}-5$ \\
\hline $\begin{array}{l}\text { Urea } \\
\mathrm{Kg} \mathrm{P}_{2} \mathrm{O}_{5}\end{array}$ & $1 \mathrm{~kg} \mathrm{~N}$ & $0.09 / 0.05$ & $7.2 / 1.1$ & $24.7 / 4.0$ & $2.1 / 0.2$ & $8.4 \mathrm{E}-5 / 8 \mathrm{E}-5$ \\
\hline & $1 \mathrm{~kg}$ & $0.06 / 0.05$ & $4.0 / 1.3$ & $62.1 / 11.8$ & $3.4 / 0.3$ & $1.7 \mathrm{E}-4 / 2 \mathrm{E}-4$ \\
\hline
\end{tabular}


requirements. In contrast, a 3.5\% solution of hydrolyzed urine in water was found to contain an amount of nitrogen almost exactly equivalent, on average, to the algae's $\mathrm{N}$ demand. To avoid introducing more $\mathrm{N}$ than could be directly taken up by the algae, the concentration of the sourceseparated urine was capped at a $3.5 \%$. It was assumed that additional superphosphate would be added to meet the full $\mathrm{P}$ demand. A $3.5 \%$ solution strength is consistent with previous experiments in which a $3 \%$ solution of fermented swine urine was used for bench-scale algae culture (Kim et al., 2007).

\subsubsection{Modeling Burden Offsets}

It was expected that three types of burden reductions would be associated with use of wastewater treatment effluents as nutrient sources during large-scale algae cultivation. These included: (1) offsets associated with reduced need for fertilizer production; (2) offsets associated with reduced need for wastewater treatment (WWT) and its associated material and energy inputs and (3) offsets in freshwater usage since the wastewater effluent is utilized as algae growth medium. Computation of these offsets is summarized in the following paragraphs.

\subsection{Offset Fertilizer Production Burdens}

For computation of the burden offset associated with reduced fertilizer production in each wastewater scenario, $\mathrm{TN}$ and $\mathrm{TP}$ requirements were first computed on the basis of nutrient demand. This computation is outlined in Section 2.3.1.5. These quantities were then multiplied by their respective life cycle impact factors from Ecoinvent ${ }^{\circledR}$ to estimate reductions in each impact area associated with decreased fertilizer usage. Life cycle inventory data for urea and superphosphate, the chemical fertilizers partially supplanted by use of wastewater nutrients, are summarized in Table 2.14 (Section 2.3.4.2). 


\subsection{Offset Wastewater Treatment Burdens}

It was expected that each of the partially-treated wastewaters, if not used as nutrient sources for algae cultivation, would otherwise have to undergo nutrient removal in a municipal wastewater treatment plant (WWTP). The WWTP's fully-treated effluents would then be subject to stringent nutrient standards under Virginia's Pollution Discharge Elimination System (VPDES) Tier 4 Effluent Guidelines (VDEQ, 2007). For this reason, the burdens that would have been accrued during WWT were counted as negative burdens (i.e. offsets) for the algae life cycle. Final effluent concentrations of total $\mathrm{N}$ and total $\mathrm{P}$ were assumed to be $3.0 \mathrm{mg} / \mathrm{L}$ and $0.1 \mathrm{mg} / \mathrm{L}$, respectively.

Life cycle impact data for removal of $1 \mathrm{~kg}$ nitrogen was taken from Maurer, Schwegler and Larsen (2003) (Maurer, Schwegler and Larsen, 2003). N removal was assumed to proceed via nitrification and subsequent denitrification with addition of methanol as external carbon source. A ratio of $3.4 \mathrm{~kg}$ methanol per $1 \mathrm{~kg} \mathrm{~N}$ eliminated (Putschert, Siegrist and Gujer, 1996) was used to compute the mass of methanol required to reduce each wastewater's initial nitrogen concentration down to the VPDES acceptable limit $(3.0 \mathrm{mg} / \mathrm{L})$. This quantity of methanol was then multiplied by Ecoinvent ${ }^{\circledR}$ impact factors for methanol production (e.g., $37.5 \mathrm{MJ}$ per $1 \mathrm{~kg}$ methanol). Electricity consumption for aeration during nitrification was also assessed, using a value of $10 \mathrm{MJ}$ per $1 \mathrm{~kg} \mathrm{~N}$ eliminated.

Life cycle impact data for removal of $1 \mathrm{~kg}$ phosphorus was also taken from Maurer, Schwegler and Larsen (2003) (Maurer, Schwegler and Larsen, 2003). P removal was assumed to proceed via chemical precipitation with ferrous sulfate. A ratio of $1.8 \mathrm{~kg}$ Fe per $1 \mathrm{~kg} P$ removed was used to compute the amount of ferrous sulfate required to reduce each wastewater's initial phosphorus concentration down to the VPDES acceptable limit $(0.1 \mathrm{mg} / \mathrm{L})$. This quantity was then multiplied by Ecoinvent impact factors for iron (II) sulfate production (e.g., $1.95 \mathrm{MJ}$ per $1 \mathrm{~kg} \mathrm{Fe}(\mathrm{III}) \mathrm{SO}_{4}$ ). 
Energy consumption for transportation of the resulting precipitant sludge was estimated to be 2 MJ per kg P eliminated.

\subsection{Offset Freshwater Burdens}

It was assumed that effluent used to deliver nutrients as fertilizer offset could also serve as algae growth medium. Thus, for the BNR and CAS cases, the direct freshwater requirements could be completely eliminated. In contrast, it was assumed that the source-separated urine would need to be diluted to a $3.5 \%$ solution in freshwater to satisfy the algae's nitrogen demand without compromising algal growth. Thus the SSU scenario reflects only a 3.5\% offset in direct water use relative to the VA base case scenario direct water usage.

\subsubsection{Wastewater Treatment Life Cycle Inventory Data}

Impact factors for fertilizer avoidance, as mediated by use of wastewaters as $\mathrm{N}$ and $\mathrm{P}$ source, are summarized in Table 2.14 in Section 2.3.4.2. Additional life cycle data for chemicals utilized in the removal of nutrients from municipal wastewater are summarized in Table 2.16.

Table 2.16. Life cycle impacts for electricity and chemicals used to model offset life cycle burdens associated with avoidance of wastewater treatment (Weidema, 2008). GHG is greenhouse gas emissions; EUT is eutrophication potential. Impact factors were assigned lognormal distributions using averages $(\mu)$ and standard deviations $(\sigma)$ from the Ecoinvent database. These parameters are presented for each distribution using $\mu / \sigma$ notation.

\begin{tabular}{lcccccc}
\hline \multicolumn{1}{c}{ Item } & $\begin{array}{c}\text { Functional } \\
\text { Unit }\end{array}$ & $\begin{array}{c}\text { Land Use } \\
\left(\mathrm{m}^{2}\right)\end{array}$ & $\begin{array}{c}\text { Water Use } \\
\left(\mathrm{m}^{3}\right)\end{array}$ & $\begin{array}{c}\text { Impact category } \\
\text { Energy Use } \\
(\mathrm{MJ})\end{array}$ & $\begin{array}{c}\mathrm{GHG} \\
\left(\mathrm{CO}_{2} \text {-eq) }\right.\end{array}$ & $\begin{array}{c}\text { EUT } \\
\left(\mathrm{PO}_{4} \text {-eq }\right)\end{array}$ \\
\hline $\begin{array}{l}\text { Electricity } \\
\text { (US mix) }\end{array}$ & $1 \mathrm{kWh}$ & $0.005 / 0.006$ & $0.8 / 0.01$ & $2.5 / 2.4$ & $0.2 / 0.01$ & $2.2 \mathrm{E}-6 / 2 \mathrm{E}-6$ \\
$\begin{array}{l}\text { Ferrous } \\
\text { sulfate }\end{array}$ & $1 \mathrm{~kg} \mathrm{Fe}(\mathrm{II}) \mathrm{SO}_{4}$ & $0.02 / 0.02$ & $1.3 / 0.5$ & $2.0 / 1.0$ & $0.2 / 0.07$ & $8.3 \mathrm{E}-6 / 7 \mathrm{E}-6$ \\
$\begin{array}{l}\text { Methanol } \\
1 \mathrm{~kg} \mathrm{CH}\end{array}$ & $0.007 / 0.002$ & $4.3 / 0.1$ & $37.5 / 5.4$ & $1.7 / 0.07$ & $4.2 \mathrm{E}-5 / 4 \mathrm{E}-6$ \\
\hline
\end{tabular}




\subsection{Results and Discussion}

\subsubsection{Comparison Among Crops}

Algae and all other terrestrial crops were evaluated on the basis of five life cycle impact categories. Relative to other terrestrial crops, algae cultivation consumes significantly more energy (Table 2.17). Although all biomass feedstocks has net positive energy (i.e., more energy is produced than consumed), only algae has exhibits a net positive GHG emission. This result suggests that algae require more fossil-based carbon to generate the same amount of energy. With respect to terrestrial crops energy consumption, the results of this study are consistent with published values in literature. Corn, for instance requires $2.4 \times 10^{4}$ and $3.9 \times 10^{4} \mathrm{MJ}$ (PHYLLIS, 2009) while switchgrass consumes between $2.9 \times 10^{4}$ and $4.0 \times 10^{4} \mathrm{MJ}$.

Algae has a distinct advantage over the other three crops is terms of land use. It consumes 3.25 times less land than corn, five times less land than canola and 4.25 less land than switchgrass. Algae's land use efficiency is further enhanced by the fact that unlike corn, algae's entire biomass is harvested for further processing. If corn is to be grown for kernel only, land use disparity against algae will even be more profound. Although previous studies have suggested that only a slight improvement in land use will be offered by algae (Ross et al., 2008), it is apparent from these results that algae has a potential for meeting the United States' future energy needs. Estimates reveal that algae roughly need only $13 \%$ of the US land area to meet the nation's total energy requirement. In contrast, corn requires $41 \%$ while switchgrass and canola would require $56 \%$ and $66 \%$, respectively. Land use changes inherent to large-scale bioenergy implementations has profound implications on climate change and other impacts since cultivation of biomass requires the conversion of arable land into production. This study assumes that all land has already been cultivated removing land use change effects. 
It is important to note that it is highly unlikely that dramatic improvements in corn or switchgrass cultivation will occur in the near future. On the other hand, algae cultivation is a novel technology and all calculations in this study represent "first-generation approach" to algae-farming. Thus, significant improvements in algae cultivation could increase the favorability of energy production from algae over the next several decades. Algae also demonstrate a much lower eutrophication potential compared to terrestrial crops. Eutrophication includes all direct nutrient emissions from the algae pond as well as all upstream impacts associated with the production of fertilizers. Algae's favorable eutrophication performance is attributed to well-engineered ponds that allow better run-off control than terrestrial cultivation. Results of the all impacts the four modeled biomass feedstocks are depicted in Table 2.17.

Table 2.17. Five life cycle burdens for production of one functional unit of energy ( $317 \mathrm{GJ}$ ) from algae, corn, canola and switchgrass in Virginia, U.S.A. The standard deviation of each value is also presented $( \pm)$.

\begin{tabular}{|c|c|c|c|c|c|}
\hline Biomass & $\begin{array}{l}\text { Land } \\
\text { (ha) }\end{array}$ & $\begin{array}{l}\text { Energy } \\
\text { (MJ) }\end{array}$ & $\begin{array}{c}\mathrm{GHG} \\
\left(\mathrm{kg} \mathrm{CO} \mathrm{C}_{2} \text { eq) }\right.\end{array}$ & $\begin{array}{l}\text { Water } \\
\left(\mathrm{m}^{3}\right)\end{array}$ & $\begin{array}{c}\text { Eutrophication } \\
\left(\mathrm{kg} \mathrm{PO}_{4}^{-} \text {eq) }\right.\end{array}$ \\
\hline Algae & $4.1 \mathrm{E}-1 \pm 5.0 \mathrm{E}-2$ & $3.0 \mathrm{E} 5 \pm 6.6 \mathrm{E} 4$ & $1.8 \mathrm{E} 4 \pm 5.8 \mathrm{E} 3$ & $1.2 \mathrm{E} 5 \pm 2.4 \mathrm{E} 4$ & $3.3 \mathrm{E} 0 \pm 8.6 \mathrm{E}-1$ \\
\hline Corn & $1.3 \mathrm{EO} \pm 3.0 \mathrm{E}-1$ & $3.8 \mathrm{E} 4 \pm 3.5 \mathrm{E} 3$ & $-2.6 \mathrm{E} 4 \pm 9.4 \mathrm{E} 2$ & $8.2 \mathrm{E} 3 \pm 1.9 \mathrm{E} 3$ & 2.6E1 $\pm 5.4 \mathrm{E} 0$ \\
\hline Canola & $2.0 \mathrm{EE} \pm 2.0 \mathrm{E}-1$ & $7.0 \mathrm{E} 4 \pm 8.3 \mathrm{E} 3$ & $-1.6 \mathrm{E} 4 \pm 1.0 \mathrm{E} 3$ & $1.0 \mathrm{E} 4 \pm 1.4 \mathrm{E} 3$ & $2.8 \mathrm{E} 1 \pm 5.8 \mathrm{E} 0$ \\
\hline Switchgrass & $1.7 \mathrm{E} 0 \pm 4.9 \mathrm{E}-1$ & $2.9 \mathrm{E} 4 \pm 2.7 \mathrm{E} 3$ & $-2.4 \mathrm{E} 4 \pm 1.8 \mathrm{E} 3$ & $5.7 \mathrm{E} 3 \pm 2.1 \mathrm{E} 3$ & $6.1 \mathrm{EO} \pm 1.7 \mathrm{E} 0$ \\
\hline
\end{tabular}

\subsubsection{Comparison Among Locations}

Sunlight is perceived to be a more important factor than access to abundant water in selecting a suitable location for algae cultivation. As a result, previous project demonstrations were located in Southern California and New Mexico, presumably due to their higher solar flux for most part of the year. This assumption is valid since insolation is linked to photosynthetic activity and yield. However, sufficient water supply is also essential to algae growth since places with sufficient sunlight tend to lose more surface water due to evaporation. Therefore, it is important to evaluate whether sunlight or water availability should be the primary consideration. Both of these factors were integrated in all of the four models in this research using insolation, annual 
precipitation and annual evaporation as surrogates for evaluating geographic access to sunlight and abundant water.

The relative suitability of Virginia, Iowa and Southern California for production of one functional unit from algae is depicted in Figure 2.6. This graph demonstrates interesting insights on the relative effects of geography on algae cultivation. The three locations offer no statistically significant variability in terms of energy and water consumption. Only in land use does Iowa require the highest land area while Virginia requires the least (95\% confidence interval). This difference arises because of the large fraction of the total land use attributed to "upstream" use, i.e., the amount of land necessary to deliver $\mathrm{CO}_{2}$, fertilizers, and electricity at some offsite location. These large magnitudes inundate the differences in land, energy and water use among three sites. Interestingly, if there exists a way to mitigate the need for $\mathrm{CO}_{2}$ and chemical fertilizers, subtle geographical differences in direct energy, water and land use would become more apparent. First, there is an inverse relationship between land use and energy use. In a place such as CA with significantly higher solar flux than VA, algae quality is higher (i.e., higher energy imbedded in biomass per unit area). Consequently, lesser land is required to produce the same amount of energy and lesser direct energy is needed to implement cultivation (i.e., lower centrifuge electricity requirement for denser algae). Second, there is an inverse relationship between land use and water use. For the case of CA (best land use) versus VA (best water use), a $17 \%$ increase in direct land use results into a $112 \%$ decrease in direct water use because average net evaporation is less than zero in Virginia. 

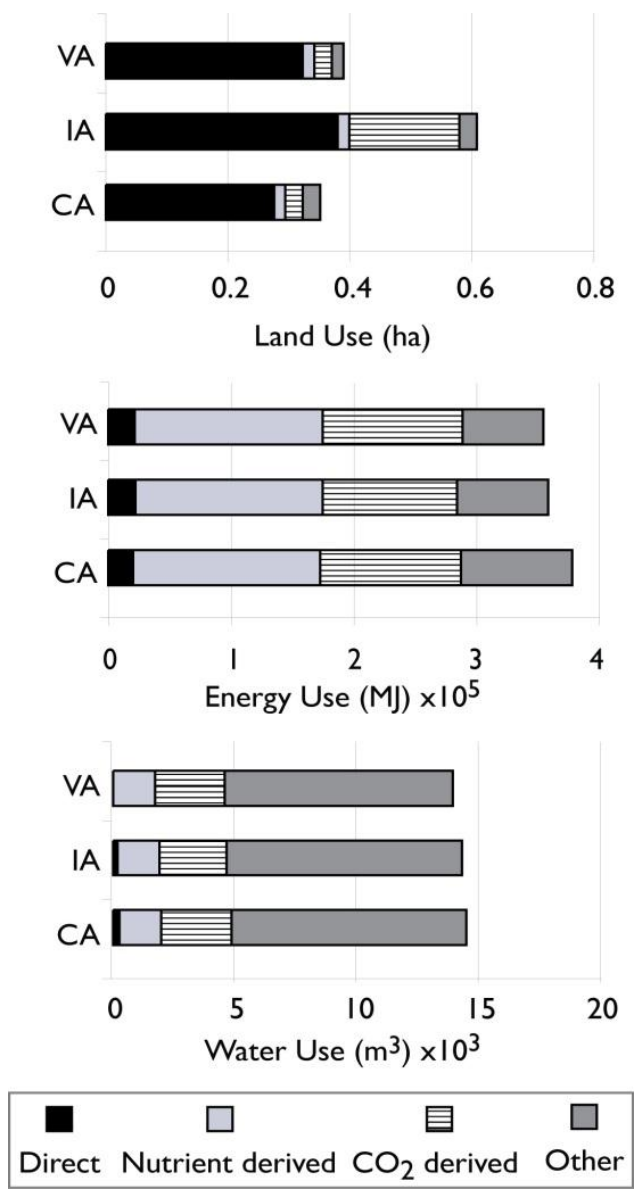

Figure 2.6. Land, energy and water use impacts for the production of algae in three different geographic locations: $\mathrm{CA}=$ California, $\mathrm{IA}=$ Iowa and VA = Virginia .

\subsubsection{Identifying Critical Burden Drivers}

Despite algae's poor performance in three of the five impacts evaluated, a sensitivity analysis was performed to determine the component of the algae's life cycle contribute most to its burdensome footprint. These parameters should be the focus of major research if algae are to be employed as a carbon-neutral replacement for fossil fuels in the near future. These results are presented in Figure 2.7. Each bar represents a change in magnitudes of output parameter (i.e., energy use) as a result of a $10 \%$ change in input parameter from the mean value. Direct and inverse proportionality are reflected in either side of the center line using dark and light shading. 
For example, energy use during algae cultivation is highly dependent upon higher heating value (HHV) (i.e., the energy content embodied by algal biomass and released during combustion), $\mathrm{CO}_{2}$ production/use; and fertilizer requirements. This is consistent with algae research to date utilizing flue gas as a carbon source or increasing HHV by increasing algal lipid content (Miao and Xu, 2006; Brown, 1996). Surprisingly, fertilizer impacts have not been the focus of most recent research despite appearing as drivers for both energy and GHG emissions. For this reason, nutrient delivery represents a significant opportunity for improving the overall sustainability of large-scale algae cultivation.
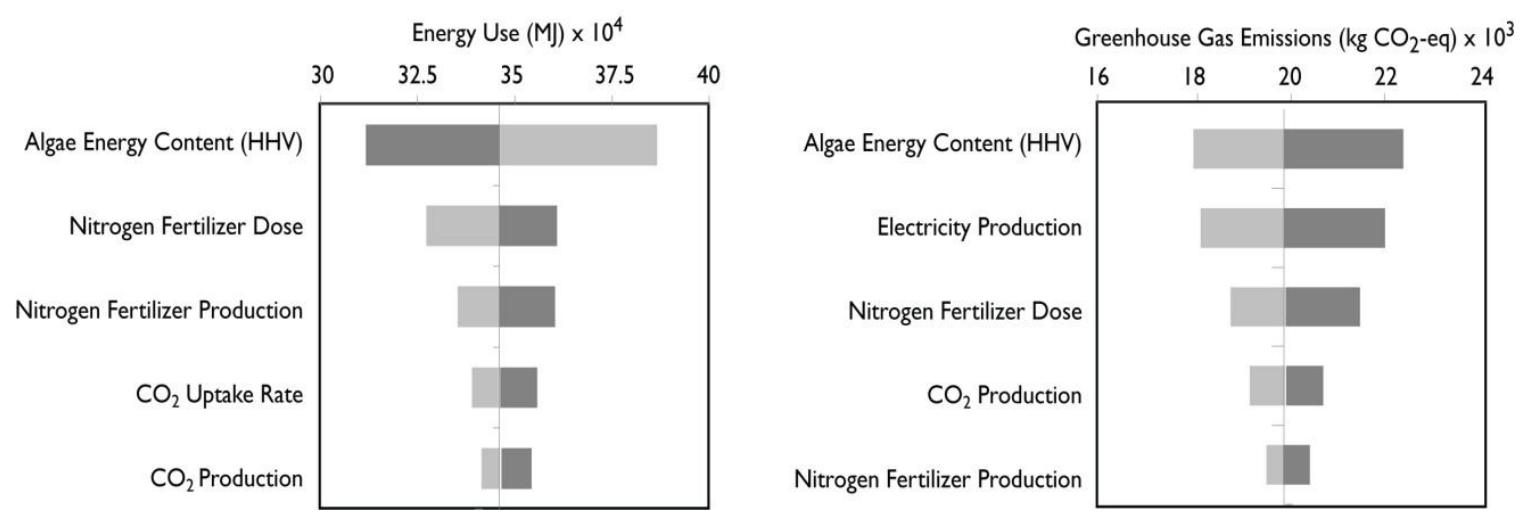

Figure 2.7. Tornado plots reveal the extent to which energy use (left) and greenhouse gas (right) emissions for algae cultivation are sensitive to a $\pm 10 \%$ change in input parameters. The centerline represents the baseline case. The dark and light shaded values indicate direct and inverse relationships, respectively. A $10 \%$ increase in the nitrogen fertilizer requirement, for example, increases the total energy use from $299,559 \mathrm{MJ}$ to $309,894 \mathrm{MJ}$, or $\sim 4 \%$. Tornado plots for the other impact factors can be found in the supporting information.

\subsubsection{Evaluating Synergy with Power Production}

Table 2.17 indicates that first generation algae cultivation release more $\mathrm{CO}_{2}$ to the atmosphere than is taken up by biomass during photosynthesis. In contrast, corn, canola and switchgrass production are carbon negative. However, these results reflect only biomass cultivation and preliminary transportation. The life cycle impacts of the conversion of each crop into usable energy carrier could potentially increase each of these impacts. One way to mitigate these impacts 
is to co-locate ponds for algae production in the immediate vicinity of a coal-fired power plant and use the flue gas as $\mathrm{CO}_{2}$ source to reduce the overall life cycle burden of algae production (Kadam, 2002). This approach will be beneficial to algae farmers since $\mathrm{CO}_{2}$ delivery is a significant driver (Benemann and Oswald, 1996) and it also accounts for roughly $40 \%$ of energy consumption and $30 \%$ of GHG emissions during algae cultivation. This forms the basis for further studies in this dissertation. The benefits for participating WWTPs include: (1) production of local, inexpensive biomass suitable for co-combustion with coal, (2) reduced toxicity of its airborne emissions and (3) reduced financial outlay for carbon tariffs (Kadam, 2002).

It is important to note that co-location of algae cultivation with power production highlights the relationship between carbon and nitrogen. Results of this modeling work indicates that it will be possible to achieve significant energy and GHG reductions for coal-fired power plants only by cultivating very large quantities of biomass. In doing so, significant amounts of nitrogen fertilizer will be required that will cause the principal burden driver (i.e., chemical fertilizer) to increase. When the algae cultivation LCA model was modified to incorporate use of flue gas rather than industrial-grade $\mathrm{CO}_{2}$, the total energy consumption and GHG emissions were still larger than corn, canola, and switchgrass. Thus, the use of algae ponds to grow next generation biofuels or sequester $\mathrm{CO}_{2}$ from power plants co-combusting coal will not be environmentally sustainable until a carbon-neutral, less energy-intensive replacement for chemical fertilizers can be identified.

\subsubsection{Evaluating Synergies with Wastewater Treatment}

Having established that an alternative carbon-neutral nutrient source is required to implement coal-fired power plant-algae cultivation partnership, one obvious mechanism for reducing chemical fertilizer use is coupling algae cultivation with municipal WWT. This idea has been evaluated in the past, although previous work was not driven by life cycle analysis (Kim et al., 2007; Ryther et al., 1972). It is shown in Table 2.17 that around 50\% of energy use and GHG 
emissions are associated with fertilizer production. The algae production life cycle model was therefore expanded to quantify the potential offsets associated with use of algae to perform operations otherwise carried out in municipal wastewater treatment plants. Three specific scenarios were evaluated, each using a different type of partially treated wastewater: (1) secondary effluent from an activated sludge treatment plant with biological nutrient removal for $\mathrm{N}$ and P (BNR); (2) secondary effluent from a conventional activated sludge treatment plant with nitrification (CAS); and, (3) a 3.5\% solution of hydrolyzed source-separated urine (SSU). The first two of these were selected on the basis of availability. The US EPA reports that US WWTPs produce some 16,500 and 14,600 million gallons per day of CAS and BNR effluents, respectively (US EPA, 2004). In contrast, SSU is not generally collected in the US. However, it has very high nutrient density, particularly $\mathrm{N}$ content. While this infrastructure is currently not in place, it may ultimately be desirable from a reuse perspective.

The results of each WWT coupling scenario demonstrate that algae's life cycle burdens can be substantially reduced via use of partially treated wastewater to supplant chemical fertilizers. The energy burden offset associated with use of BNR effluent (3\%) is less extensive than that associated with CAS effluent (22\%) and much less extensive than that associated with SSU (134\%). This is due to dramatic variation among available nutrient concentrations in each wastewater (Maurer, Schwegler and Larsen, 2003; Dodd et al., 2008). For the case of SSU, environmental impacts are reduced well below those of corn, canola, or switchgrass. Importantly, the differences in energy burden offsets between modeled WWT cases reflect not only an avoidance of fertilizer production but also the extremely energy-intensive nature of municipal WWT. Although urine makes up less than $1 \%$ of municipal wastewater flow by volume, it contains a disproportionately large amount of the nutrients ultimately processed at a wastewater treatment plant (WWTP) (e.g., 80\% of $\mathrm{N}$ and $50 \%$ of P) (Dodd et al., 2008). Thus, some 60-80\% of energy consumption during WWT is associated with nutrient removal (Maurer, Schwegler and 
Larsen, 2003) and wastewaters with higher nutrient concentrations (e.g. SSU versus BNR) are more environmentally burdensome to treat at a WWTP. Rerouting a portion of a WWTP's nutrient load to algae cultivation is one way to reduce energy consumption during municipal WWT. Finally, it should be noted that reductions in each life cycle impact associated with avoidance of WWT nutrient removal account for 50-70\% of the total offsets presented in Table 2.17, whereas the avoidance of fertilizer production accounts for only 30-50\%. This is a clear indication that municipal WWTPs will have as much or more incentive than their partnering algae production facilities to couple these two processes.

\subsection{Conclusions}

Algae's life cycle cultivation impacts are highly dependent upon the availability of nutrients and carbon dioxide. This result is in contrast with what algae has been perceived to be sensitive to: algae yield and sunlight. Traditional algae pond cultivation requires supply of these nutrients from fossil-based sources. Processes for the production of hydrocarbons and nitrogen used for cultivation are very energy-intensive. To improve algae's performance relative to terrestrial crops and enhance its sustainability as biofuel source, it is important to supplant these nutrients with those coming from waste streams. The need to minimize the upstream impacts is the first outcome from this modeling work.

The second outcome is that conversion processes downstream to produce usable energy carriers are unlikely to change the results of this LCA given the disparity between cultivation and conversion impacts. While it is reasonable to expect that algae biomass could be co-fired with coal to produce electricity, other conversion processes may be desirable. This analysis has shown that various biomass feedstocks are not equal in terms of imbedded energy per mass of biomass produced. It is therefore reasonable to assume that this comparison could exclude important life cycle stages. If the burdens of converting switchgrass to ethanol are significantly higher than the 
burdens of converting algae to biodiesel, then algae's high cultivation impacts will be reasonable. Nevertheless, the results of this work have clearly shown that at the very least, cultivation impacts will be significant relative to the overall impacts. Apart from upstream nutrients and carbon dioxide impacts, sustainable conversion schemes must be integrated with cultivation to improve algae's overall life cycle performance. This conclusion has raised questions on the favorability of producing biodiesel from algae biomass - a conversion pathway widely associated with algae. Succeeding analyses by the author will evaluate this claim.

\subsection{References}

Adler, P., Sanderson, M., Boateng, A., Weimer, P., Jung, H. "Biomass Yield and Biofuel Quality of Switchgrass Harvested in Fall or Spring.” Agronomy Journal 98 (2006): 1518-1525.

Andersen, R. A. “Algal Culturing Techniques.” Elsevier Academic Press: Amsterdam, 2005.

Antoni, D., Zverlov, V. V., Schwarz, W. H. "Biofuels from Microbes." Applied Microbiology and Biotechnology 77, no. 1 (2007): 23-25.

Aresta, M., Dibenedetto, A., Barberio, G. "Utilization of Macro-algae for Enhanced $\mathrm{CO}_{2}$ Fixation and Biofuels Production: Development of a Computing Software for an LCA Study." Fuel Process Technology 86 (2005): 1679-1693.

ASCE. "The ASCE Standardized Reference Evapotranspiration Equation." In American Society of Civil Engineers, 2002.

Bañuelos, G. "Irrigation of Broccoli and Canola with Boron- and Selenium-Laden Effluent." Journal of Environmental Quality 31 (2002): 1802-1808.

Benemann, J., Oswald, W. "Systems and Economic Analysis of Microalgae Ponds for Conversion of $\mathrm{CO}_{2}$ to Biomass - Final Report." U.S. Department of Energy: Pittsburgh, 1996, 201.

Brown, L. M. "Uptake of Carbon Dioxide from Flue Gas by Microalgae." Energy Conversion and Management 37, no. 6-7 (1996): 1363-1367.

Becker, E. W. "Microalgae: Biotechnology and Microbiology." Cambridge University Press: Cambridge, 1994, vii, 293 p.

BFIN, Bioenergy Feedstock Information Network. In NREL, 2009.

Brann, D., Abaye, A., Peterson, P. "Virginia Agronomy Handbook." Virginia Polytechnic Institute and State University: Blacksburg, VA., 2009. 
Campbell, J. E., Lobell, D. B., Field, C. B. "Greater Transportation Energy and GHG Offsets from Bioelectricity than Ethanol.” Science (2009).

Carey, R., Migliaccio, K. "Contribution of Wastewater Treatment Plant Effluents to Nutrient Dynamics in Aquatic Systems: A Review.” Environmental Management 44, no. 2 (2009): 205217.

Chisti, Y. “Biodiesel from Microalgae.” Biotechnology Advances 25, no. 3 (2007): 294-306.

Del Campo, J., García-González, M., Guerrero, M. "Outdoor Cultivation of Microalgae for Carotenoid Production: Current State and Perspectives." Applied Microbiology and Biotechnology 74, no. 6 (2007): 1163-1174.

D'Jes`s, P., Boukis, N., Kraushaar-Czarnetzki, B., Dinjus, E. "Gasification of Corn and Clover Grass in Supercritical Water." Fuel 85, no. 7-8 (2006): 1032-1038.

Dodd, M. C., Zuleeg, S., Von Gunten, U., Pronk, W. "Ozonation of Source-Separated Urine for Resource Recovery and Waste Minimization: Process Modeling, Reaction Chemistry and Operational Considerations." Environmental Science and Technology 42 no. 24 (2008): 93299337.

Dominguez-Faus, R., Powers, S. E., Burken, J. G., Alvarez, P. J. "The Water Footprint of Biofuels: A Drink or Drive Issue?" Environmental Science and Technology 43, no. 9 (2009): 3005-3010.

EIA, Energy Information Administration. 2008.

Evans, R. J., Knight, R. A., Onischak, M., Babu, S. P. "Development of Biomass Gasification to Produce Substitute Fuels.” Battelle Pacific NW Laboratory: Richland, WA, 1988.

ETSU. “Straw Firing of Industrial Boilers.” ETSU: London, 1988.

Farrell, A. E., Plevin, R. J., Turner, B. T., Jones, A. D., O'Hare, M., Kammen, D. M. "Ethanol Can Contribute to Energy and Environmental Goals. Science 311, no. 5760 (2006): 506-508.

FEC. "Straw Firing of Industrial Boilers." Energy Technology Support Unit: Department of Energy, UK, 1988.

Gibson, L., Bernhart, S. “Switchgrass (AG 200).” Ames, IA, 2007.

Godos, I. D., González, C., Becares, E., García-Encina, P., Muñoz, R. "Simultaneous Nutrients and Carbon Removal During Pretreated Swine Slurry Degradation in a Tubular Biofilm Photobioreactor.” Applied Microbiological Biotechnology 82, no. 1 (2009): 187-194.

Hang, A. N., Collins, H. P., Sowers, K. E. "Irrigated Spring and Winter Canola Production in Washington." Washington State University Extension: Pullman, WA, 2009, 7.

Hill, J., Nelson, E., Tilman, D., Polasky, S., Tiffany, D. "Environmental, Economic, and Energetic Costs and Benefits of Biodiesel and Ethanol Biofuels. Proceedings of the National Academy of Sciences of the United States of America 103, no. 30 (2006): 11206-11210. 
Hirano, A., Hon-Nami, K., Kunito, S., Hada, M., Ogushi, Y. “Temperature Effect on Continuous Gasification of Microalgal Biomass: Theoretical Yield of Methanol Production and its Energy Balance." Catalysis Today 45, no. 1-4 (1998): 399-404.

Howell, T., Evett, S. "The Penman-Monteith Method", Section 3. In Evapotranspiration: Determination of Consumptive Use in Water Rights, Denver, CO, 2004.

Hughes, E., Tillman, D. "FETC/EPRI Biomass Cofiring Cooperative Agreement." Electric Power Research Institute (EPRI), 1997.

IPCC. "Changes in Atmospheric Constituents and in Radiative Forcing." In Fourth Assessment Report (AR4) by Working Group 1 (WG1), 2007.

Kadam, K. L. "Environmental Implications of Power Generation via Coal-Microalgae Cofiring. Energy 27, no. 10 (2002): 905-22.

Kim, M. K., Park, J. W., Park, C. S., Kim, S. J., Jeune, K. H., Chang, M. U., Acreman, J. "Enhanced Production of Scenedesmus spp. (Green Microalgae) using a New Medium Containing Fermented Swine Wastewater." Bioresource Technology 98, no. 11 (2007): 2220-2228.

Kiniry, J., Jones, C., O’Toole, J., Blanche, R., Cabelguenne, M., Spanel, D. "Radiation-Use Efficiency in Biomass Accumulation Prior to Grain-Filling for Five Grain-Crop Species." Crop Research 20 (1989): 51-64.

Lardon, L., Helias, A., Sialve, B., Steyer, J. P., Bernard, O. "Life-Cycle Assessment of Biodiesel Production from Microalgae." Environmental Science and Technology 43, no. 17 (2009): 64756481.

Lemus, R. "Switchgrass As An Energy Crop: Fertilization, Cultivar and Cutting Management." Virginia Polytechnic Institute and State University: Blacksburg, VA, 2004.

Li, X., Xu, H., Wu, Q. "Large-Scale Biodiesel Production from Microalga Chlorella protothecoides through Heterotrophic Cultivation in Bioreactors." Biotechnology and Bioengineering 98, no. 4 (2007): 764-771.

Maddonni, M., Otegui, M. "Leaf Area, Light Interception and Crop Development in Maize." Field Crop Research 48 (1996): 81-87.

Maurer, M., Schwegler, P., Larsen, T. A. "Nutrients in Urine: Energetic Aspects of Removal and Recovery.” Water Science and Technology 48, no. 1 (2003): 37-46.

Miao, X., Wu, Q. "Biodiesel Production from Heterotrophic Microalgal Oil." Bioresource Technology 97, no. 6 (2006): 841-846.

Miles, T. R., Miles, J., Baxter, L., Bryers, R. W., Jenkins, B. M., Oden, L. L. "Alkali Deposits Found in Biomass Power Plants: A Preliminary Investigation of their Extend and Nature." In NREL, 1995, 82.

Moulick, S., Mal, B. C. "Performance Evaluation of Double-Hub Paddle Wheel Aerator." Journal of Environmental Engineering Volume 135 no. 7 (2009): 562-566. 
Myers, D. K. "Harvesting Corn Residue.” Ohio State University Extension: Columbus, 2009.

NOAA, Surface Radiation Network (SURFRAD). In National Oceanic and Atmospheric Administration, 2009.

NREL, National Solar Radiation Database (1961-1990). In National Renewable Energy Laboratory, 1994.

NREL, National Solar Radiation Database Update (1991-2005). In National Renewable Energy Laboratory, 2005.

Panwar, N. L., Kaushik, S. C., Kothari, S. "Role of Renewable Energy Sources in Environmental Protection: A Review.” Renewable and Sustainable Energy Reviews 15 (2011): 1513-1524.

Parsons, C. E. "Canola Yield Data.” University of Arkansas Division of Agriculture, 2006.

Perry, R. H., Green, D. W. "Perry's Chemical Engineers' Handbook." 7th Edition, McGraw-Hill: 1997.

PHYLLIS. "Database for Biomass and Waste. In Energy Research Centre of the Netherlands, 2009.

Powell, N., Shilton, A. N., Pratt, S., Chisti, Y. "Factors Influencing Luxury Uptake of Phosphorus by Microalgae in Waste Stabilization Ponds." Environmental Science and Technology 42, no. 16 (2008): 5958-5962.

Putnam, D. "Switchgrass and Alfalfa as Cellulosic Biofuels: Possibilities and Limitations." In Proceedings of the 2008 California Alfalfa and Forage Symposium and Western Seed Conference, San Diego, CA, 2008.

Purtschert, I., Siegrist, H., Gujer, W. "Enhanced Denitrification with Methanol at WWTP ZürichWerdhölzli." Water Science and Technology 33, no. 12 (1996): 117-126.

Ramli, U. S., Baker, D. S., Quant, P. A., Harwood, J. L. "Control Analysis of Lipid Biosynthesis in Tissue Cultures from Oil Crops Shows that Flux Control is Shared Between Fatty Acid Synthesis and Lipid Assembly.” Biochemistry Journal 364, no. 2 (2002): 393-401.

Redfield, A. C. "The Biological Control of Chemical Factors in the Environment." American Scientist 64 (1958), 205-221.

Reisinger, K. "Energetische Verwertungsmöglichkeiten von Biogenen Reststoffen Verschiedener Industriebranchen Wowie Aus Kommunalen Sammelsystemen.” TU Wien, Wien, 1997.

Rife, C. "National Winter Canola Variety Trial." Kansas State University Agricultural Experiment Station and Cooperative Extension Service: Manhattan, KS, 2003.

Rosenberg, J. N., Oyler, G. A., Wilkinson, L., Betenbaugh, M. J. "A Green Light for Engineered Algae: Redirecting Metabolism to Fuel a Biotechnology Revolution." Current Opinion in Biotechnology 19, no. 5 (2008): 430-436. 
Ross, A. B., Jones, J. M., Kubacki, M. L., Bridgeman, T. "Classification of Macroalgae as Fuel and its Thermochemical Behavior.” Bioresource Technology 99, no. 14 (2008): 6494-6504.

Ryther, J. H., Dunstan, W. M., Tenore, K. R., Huguenin, J. E. "Controlled Eutrophication: Increasing Food Production from the Sea by Recycling Human Wastes." BioScience 22, no. 3 (1972): 144-152.

Runge, C. F., Senauer, B. "How Biofuels Could Starve the Poor?" Foreign Affairs 2007: May/June.

Sami, M., Annamalai, K., Wooldridge, M. "Co-Firing of Coal and Biomass Fuel Blends. Progress in Energy and Combustion Science 27, no. 2 (2001): 171-214.

Sheehan, J., Dunahay, T., Benemann, J., Roessler, P. "A Look Back at the U.S. Department of Energy Aquatic Species Program: Biodiesel from Algae." National Renewable Energy Laboratory: Golden, CO, July 1998, 328.

Schill, S. "Canola Waits in the Wings. Biodiesel Magazine 2008.

Schmidt, A., Zschetzsche, A., Hantsch-Linhart, W. “Analyse Von Biogenen Brennstoffen.” 1993.

Smeenk, J., Brown, R. C., Eckels, D. "Determination of Vapor Phase Alkali Content During Biomass Gasification.” 1999, 961-967.

Starner, D., Bhardwaj, H., Hamama, A., Rangappa, M. "Canola Production in Virginia." In Progress in New Crops, Janick, J., Ed. ASHS Press: Alexandria, VA., 1996, 287-290.

Thomas, P. "Chapter 3: Growth Stages." In Canola Council of Canada's Canola Growers Manual, 2003.

Thoreson, D., Lang, B. “2008 Corn Silage Yield Trial.” Ames, IA, 2009.

U.S. Environmental Protection Agency, "Clean Watersheds Needs Survey - Report to Congress." US EPA: Washington, DC, 2004.

U.S. Department of Agriculture, "California Corn for Silage Acreage, Yield and Production by County." In NASS, C.F.O.S., CA, Ed. US Department of Agriculture, 2006.

USNO, "Astronomical Applications: Complete Sun and Moon Data for One Year." In Observatory, U.N., Ed. 2009.

VDEQ, "Nutrients and the Chesapeake Bay." Virginia Department of Environmental Quality: Richmond, 2007.

Weidema, B. "Ecoinvent Data v2.0." http://www.ecoinvent.org/ (accessed September 2008).

Weissman, J. C., Tillett, D. M. "Design and Operation of an Outdoor Microalgae Test Facility: Large-Scale System Results.” NREP: Golden, CO, 1990.

Wilen, C., Moilanen, A., Kurkela, E. "Biomass Feedstock Analyses." Technical Research Centre of Finland, 1996. 
Zabaniotou, A., Ioannidou, O., Skoulou, V. "Rapeseed Residues Utilization for Energy and 2nd Generation Biofuels. Fuel 87, no. 8-9 (2008): 1492-1502. 


\section{Chapter 3 \\ Environmental Impacts of Algae-Derived Biodiesel and Bioelectricity}

\subsection{Motivation}

In the previous chapter, the sustainability of algae cultivation relative to terrestrial biomass feedstocks was evaluated. The impacts of converting that biomass into usable energy carriers were intentionally excluded from the analysis.

The results of the previous chapter cannot tell whether algae are more or less suitable for production of usable transportation energy than the benchmark crops. This is because some crops are more easily converted into energy carriers than others. This chapter expands on the original model to include conversion of each of the biomass into transportation energy sources (i.e., "wellto-wheel" system boundaries). The functional unit was also modified into two complementary functional units to capture algae's expected tradeoffs between land use and other environmental impacts. These functional units are: (1) usable energy production per unit land area as expressed using "vehicle kilometers traveled" (VKT per ha) and (2) environmental burdens (net energy use, water use, and GHG) per VKT. Since this chapter aims to perform direct comparison among dissimilar conversion systems, energy return on investment (EROI) (i.e., the amount of energy produced per energy consumed to deliver one functional unity) was also assessed for each system. The most sustainable algae systems based on EROI were then compared with benchmark terrestrial biofuels. 


\subsection{Literature Review}

Few studies have focused on the impact assessment of algae-derive bioenergy from different conversion processes relative to other energy sources derived from conventional biomass feedstocks. Campbell, Becker and Field (2009) compared the impacts of generating electricity for battery-powered vehicles by direct combustion of corn and switchgrass biomass to the impacts of converting these feedstocks to biodiesel for internal combustion vehicles (ICVs) (Campbell, Becker and Field, 2009). Sialve, Becker and Bernard (2009) concluded that anaerobic digestion is more suitable than biodiesel production when algae's dry weight contains less than $40 \%$ lipids by mass (Sialve, Becker and Bernard, 2009). They also assessed relative EROIs between these two conversion schemes. Previous research on lipid production without LCA from the same research team focused on improving lipid content to as high as $85 \%$ by weight through starvation of algae cells by nitrogen supply (Becker, 1994). Prior to this study, Sialve, Becker and Bernard (2009) has been perhaps the only instance in the literature that dealt with direct comparison of algae conversion methods (Sialve, Becker and Bernard, 2009). Although both of these studies investigated conversion processes in the context of different biomass feedstocks, their conclusions were similar: bioelectricity through combustion of biomass produced more usable transportation energy and less GHG emissions relative to liquid fuels. Most algae conversion methods presented in the literature considered only one method in isolation. The subsequent sections of this literature review examine two conversion processes utilized in this study: bioelectricity and biodiesel.

\subsubsection{Bioelectricity}

An LCA comparing electricity production from coal against electricity production from coal with algae grown using flue gas as a carbon source was investigated by Kadam (2002). Results from this study suggested that the co-firing scenario yielded better environmental performance in all areas evaluated except for eutrophication potential and depletion of natural resources. Co-firing 
coal with wood has also been found to significantly reduce the overall footprint of a coal-fired power plant (Mann and Spath, 2001). This study revealed that co-firing improved the power plant's overall energy balance and also significantly reduced GHG emissions, solid waste generation and resource depletion potential relative to the base case (i.e., coal-fired only). As a point of reference, Chapter 2 not only excluded conversion from the analysis but also used algae high heating value (HHV) in translating algae yield to energy in determining footprint via the functional unit (317 GJ). This assumption implied that the entire biomass must be combusted.

\subsubsection{Biodiesel}

In contrast to bioelectricity, numerous studies on biodiesel from algae have been published. The findings of Brennan and Owende (2001) and Smith et al. (2009) reinforced assumptions that algae biodiesel could be superior to terrestrial crops biodiesel in terms of greenhouse gas emissions (Brennan and Owende, 2001; Smith et al., 2009). One review indicated that algae lipid production is environmentally preferable than soybean oil production because the diesel produced is carbon-neutral (Williams et al., 2009).

Lardon et al. (2009) compared two cultivation scenarios and two conversion scenarios. The cultivation process compared two nutrient cases: normal and low nitrogen, each of which produced different lipid contents (Lardon et al., 2009). Conversion process compared two extraction cases: dry extraction based on the current industry-accepted method of oil extraction from soybean and wet extraction (Lardon et al., 2009). Their results indicated that low nitrogen cultivation yielded low impacts in all areas evaluated while wet extraction produced low impacts. They also found that wet extraction resulted in an improved energy ratio (Lardon et al., 2009).

The study by Sander and Murthy (2010) revealed results contrary to most studies on algae biodiesel. They excluded the combustion of fuel in a vehicle and the results showed that energy 
ratio is negatively correlated with lipid content. This result was attributed to co-product allocation, assuming that all of the algae residual after lipid extraction, containing mostly carbohydrates, was converted to ethanol (Sander and Murthy, 2010). This demonstrated how unfavorable corn ethanol production is from an energy perspective. It has also established the value of producing algae ethanol rather than algae biodiesel, because it required considerably less energy from thermal drying of the algae biomass (89\% of its total) (Sander and Murthy, 2010).

Brune et al. (2009) modeled an algae cultivation system using flue gas as carbon source and waste paper, municipal sludge or animal manure as nutrient source (Brune et al., 2009). This study showed a significant decrease in GHG emissions relative to conventional process of using virgin fertilizer and commercially-available carbon dioxide.

\subsection{Methods}

\subsubsection{Model Overview}

A modeling framework based on the one developed in Chapter 2 was employed for this analysis. It was found that increasing the number of runs from 10,000 to 100,000 did not significantly alter the final LCA results. All material and energy inputs for all four systems analyzed were obtained using first-principles engineering calculations. Impacts factors used for these inputs for burden calculations were obtained from the ecoinvent database (accessed using SimaPro v. 7.1). These environmental burdens evaluated are: net energy use (MJ), water use $\left(\mathrm{m}^{3}\right)$, and greenhouse gas emissions ( $\left.\mathrm{kg} \mathrm{CO}_{2}-\mathrm{eq}\right)$.

\subsubsection{Functional Units}

In Chapter 2, an energy content FU using HHV to normalize output was used to compare the environmental impacts of algae against terrestrial feedstocks. However, this functional unit is limited to cultivation impacts, disregarding the contributions of converting these crops to usable 
transportation fuels. The delivery of vehicle kilometers traveled (VKT) in a passenger automobile is the ultimate function of this analysis. In order to reflect this modified function, the comparison of algae with two terrestrial biofuels systems was performed using two endpoints: (1) overall transportation energy per unit land area (i.e., VKT/ha) and (2) fuel-cycle impacts incurred per kilometer traveled (i.e., $\mathrm{MJ} / \mathrm{km}, \mathrm{m}^{3} / \mathrm{km}$, and $\mathrm{kg} \mathrm{CO} 2 \mathrm{eq} / \mathrm{km}$ ). The combination of these two provided outputs for the systems and inputs for each system normalized to a per-km basis.

\subsubsection{Overview of Analyses}

There are four cases modeled in this study (Cases A-D), each of which represents a unique pathway for the conversion of algae biomass into usable transportation energy: (A) anaerobic digestion of bulk algae biomass to produce bioelectricity via methane combustion; (B) biodiesel production from lipids with anaerobic digestion of the algae residuals to generate bioelectricity via methane combustion; (C) biodiesel production from lipids with direct combustion of the algae residuals to generate bioelectricity and (D) direct combustion of bulk algae biomass to produce bioelectricity. Each case was evaluated for four different nutrient procurement scenarios. The four nutrient scenarios are detailed in Section 3.3.2.1 while the four conversion cases are outlined in Section 3.3.3 (Cases A and B), Section 3.3.4 (Cases B and C) and Section 3.3.5 (Cases D and D). Schematic of all cases and scenarios are depicted in Figure 3.1. 


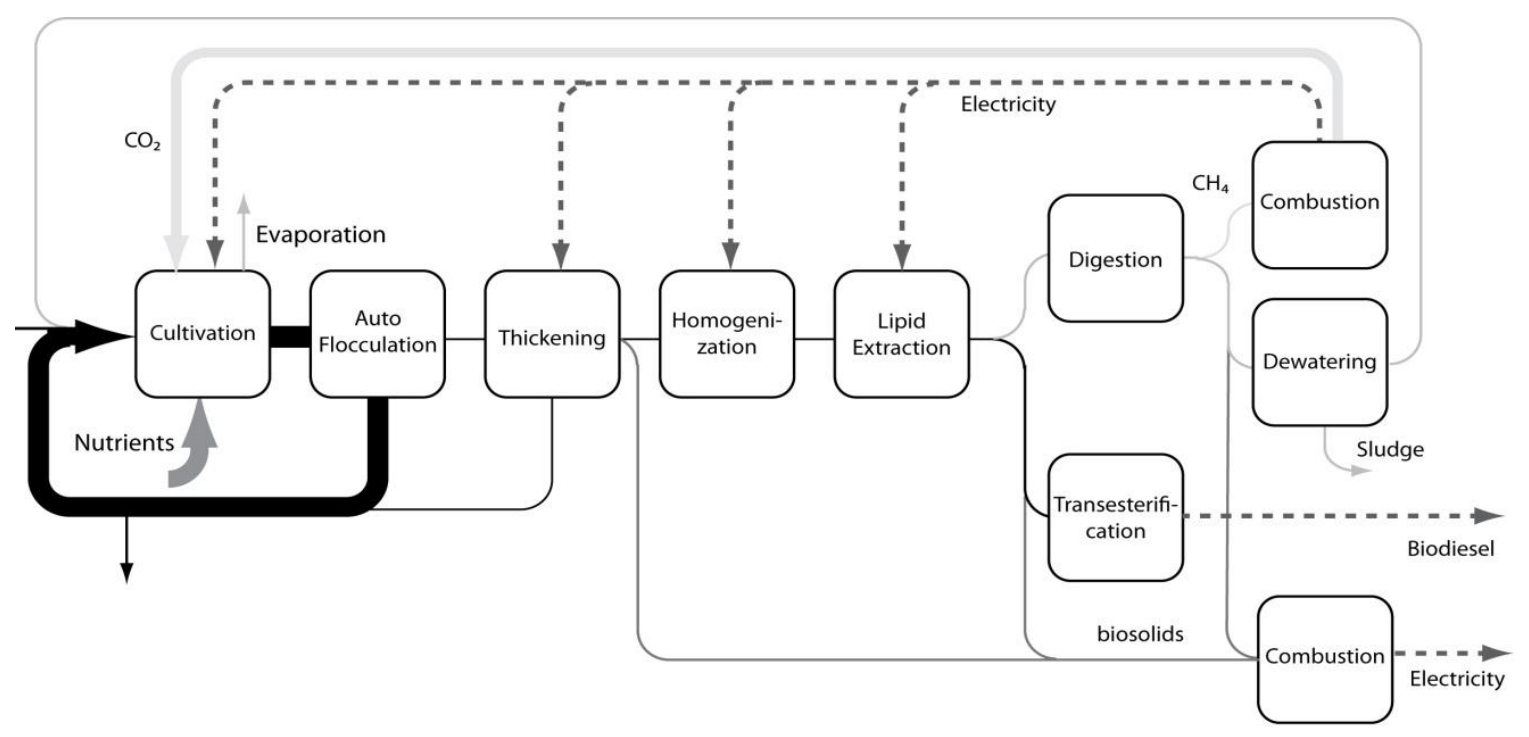

A.

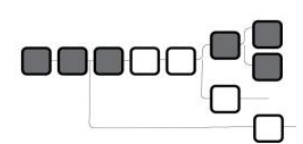

B.

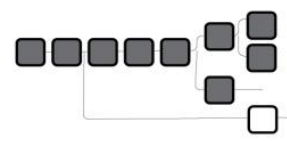

C.

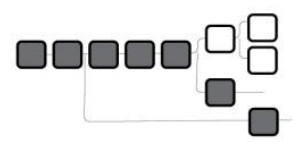

D.

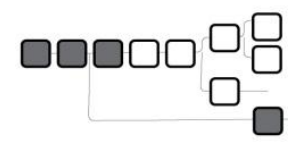

Figure 3.1. Schematic of a generic algae-to-bioenergy production system used in this study. Arrow widths are proportional to mass flows. Energy flows are indicated using dashed lines. Unit operations pertinent to assessment of conversion pathways (Cases) are shaded (gray) in panels A$\mathrm{D}$ at bottom. These pathways are: (A) anaerobic digestion of bulk algae biomass to produce bioelectricity; (B) biodiesel production from algae lipids with anaerobic digestion of algae residuals to generate bioelectricity; (C) biodiesel production from algae lipids with direct combustion of algae residuals to generate bioelectricity; and (D) direct combustion of bulk algae biomass to produce bioelectricity.

\subsubsection{Cultivation}

This study utilized algae grown in raceway open ponds. However, there are distinct differences in cultivation characteristics used in Chapter 2 and in this chapter:

Stoichiometric $\mathrm{CO}_{2}$, nitrogen and phosphorus requirements were calculated using the Redfield ratio $\left(\mathrm{C}_{106} \mathrm{H}_{181} \mathrm{O}_{45} \mathrm{~N}_{15} \mathrm{P}\right)$ (Redfield, 1958) rather than literature values on nutrients demand under various conditions. This method is suitable for generic marine phytoplankton that were grown in readily available brackish to saline groundwater. Both $\mathrm{N}$ and $\mathrm{P}$ requirements were supplied by ammonium phosphate up to the stoichiometric $\mathrm{P}$ demand because the use of a combined $\mathrm{N}$ and $\mathrm{P}$ 
source significantly reduces upstream energy use per quantity of algae biomass produced. Additional fertilizer up to the stoichiometric $\mathrm{N}$ demand was supplied by urea.

Algae dewatering and drying (i.e., centrifugation) prior to conversion was replaced by a series of algae slurry concentration and drying steps outlined in Sections 3.3.3.3 and 3.3.5.1 due to their actual applications in the industry and because centrifugation consumes significant energy.

Brackish to saline groundwater (2-3\% salinity) was used as growth medium instead of freshwater in response to the recommendation made in Chapter 2. This significantly reduced freshwater consumption and utilized the abundant water resource in the southwestern USA (Barclay et al., 1988).

\subsubsection{Nutrient Procurement Scenarios}

Chapter 2 demonstrated the significant upstream impacts of nutrients on overall system sustainability. Thus in order to prove that algae-to-bioenergy systems are more preferable than benchmark terrestrial crops, various nutrient procurement scenarios must be assessed These four nutrient procurement scenarios are summarized below.

Scenario 1. Virgin commercial $\mathrm{CO}_{2}$. This scenario, used in Chapter 2, considered $\mathrm{CO}_{2}$ generated via steam-splitting of methane. The resulting $\mathrm{CO}_{2}$ impact factor obtained from LCA databases used in this analysis was then appropriately multiplied by 0.5 to account for the allocation between $\mathrm{CO}_{2}$ and $\mathrm{H}_{2}$. Nitrogen $(\mathrm{N})$ and phosphorus $(\mathrm{P})$, on the other hand, were assumed to be from virgin commercial fertilizers.

Scenario 2. $\mathrm{CO}_{2}$ from Carbon Capture at a Coal-Fired Power Plant. It has been suggested in Chapter 2 that the environmental performance of algae-to-bioenergy systems could be improved 
using a carbon source from the flue gas emitted during fossil-fueled power production. Although the effects of the other components in a flue gas on algae productivity and operational logistics of algae cultivation are currently unknown (Brown et al., 1996), evaluation of this carbon capture technology was nevertheless performed by Khoo and Tan (2006) (Khoo and Tan, 2006). Their data, used in this study, demonstrated that $\mathrm{CO}_{2}$ procurement increases overall electricity demand for the algae-to-bioenergy system and that $\mathrm{CO}_{2}$ capture and purification is achieved via chemical sorption. The energy demand (i.e., chemisorption energy) used in this study follows a triangular distribution: minimum $=1.18 \mathrm{MJ} / \mathrm{kg} \mathrm{CO}$, likeliest $=1.31 \mathrm{MJ} / \mathrm{kg} \mathrm{CO}_{2}$, and maximum $=1.44$ $\mathrm{MJ} / \mathrm{kg} \mathrm{CO}$. This distribution reflects $\pm 10 \%$ variation around the mean value reported by Khoo and Tan (2006) (Khoo and Tan, 2006).

Carbon capture technology benefits both the power plant and algae cultivation. It is thus appropriate to allocate the entire $\mathrm{CO}_{2}$ production on an energy basis (ISO, 2006) (i.e., $\mathrm{CO}_{2}$ allocated to either coal-fired power plant (CFPP) electricity or algae-derived bioenergy). The allocation is performed by expanding the system boundary to include both the power plant and algae farm. The shared $\mathrm{CO}_{2}$ by both systems, that is $\mathrm{CO}_{2}$ generated by CFPP supplied to the algae farm, can be represented by $\mathrm{C} \mathrm{Mg} \mathrm{CO}$. This supplied $\mathrm{CO}_{2}$ would then produce $\mathrm{B} \mathrm{Mg}$ algae biomass which would then be converted into A MJ of algae-derived energy (either as biodiesel of bioelectricity). The production of $\mathrm{C} \mathrm{Mg} \mathrm{CO}_{2}$ is accompanied by the production of $\mathrm{F}$ MJ fossilfuel electricity from CCFPP, denoted by F MJ. These quantities are related via the impact factor 1 $\mathrm{Mg} \mathrm{CO}_{2} / \mathrm{MWh}$ for a conventional power plant (NREL, 2002). The fraction of $\mathrm{CO}_{2}$ allocated to algae-derived energy $\left(\mathrm{f}_{\mathrm{ALGAE}-\mathrm{CO} 2}\right)$ could be calculated as $\mathrm{A} /(\mathrm{A}+\mathrm{F})$. Values of $\mathrm{f}_{\mathrm{ALGAE}-\mathrm{CO} 2}$ varied from $0.40-0.57$ among Cases A-D.

Scenario 3. $\mathrm{CO}_{2}$ from Compressed Flue Gas. There are certain $\mathrm{CO}_{2}$ sources such as fermentation $\mathrm{CO}_{2}$, anaerobic digestion $\mathrm{CO}_{2}$ and $\mathrm{CO}_{2}$ from methane combustion that are relatively pure 
requiring no additional purification (Hauck, Scierka and Perry, 1996). The $\mathrm{CO}_{2}$ modeled in this scenario came from compressed, unaltered flue gas. The energy of compression per unit mass of flue gas is defined in Equation 3.1.

$$
W_{c}=\frac{C_{p} T_{i}}{\eta}\left[\left(\frac{P_{0}}{P_{i}}\right)^{\left(\frac{\gamma}{\gamma-1}\right)}-1\right] \quad \text { Equation } 3.1
$$

Where $C_{p}$ is the specific heat of the flue gas assumed to be $(1 \mathrm{~J} / \mathrm{kg}-\mathrm{K}) ; T_{i}$ is inlet temperature (300 $\mathrm{K}) ; \eta$ is adiabatic efficiency of the compressor $(0.85) ; P_{\text {OUT }} / P_{I N}$ is ratio of exit to inlet pressure, assuming compression from ambient pressure (1 atm) to 2 atm in order to move the flue gas and $\gamma$ is specific heat ratio (1.4).

Electricity demand for compression was then calculated to be $39 \mathrm{~kJ} / \mathrm{kg}$ flue gas and $0.31 \mathrm{MJ} / \mathrm{kg}$ $\mathrm{CO}_{2}$ since flue gas is approximately $12.5 \% \mathrm{CO}_{2}$ (Laws et al., 1986). This amount was also allocated between CFFP electricity and algae-derived energy. Values of $\mathrm{f}_{\mathrm{ALGAE}-\mathrm{CO} 2}$ for both Scenarios 2 and 3 were similar with their corresponding Cases (A-D) $(0.40-0.57)$.

Scenario 4. $\mathrm{CO}_{2}$ from Compressed Flue Gas Plus Wastewater Effluent $N$ and P. Based on the results of Chapter 2, the use of wastewater stream could be a means of reducing upstream fertilizer burdens. Even with wastewater use, $\mathrm{N}$ and $\mathrm{P}$ demand were still high necessitating the need for additional virgin fertilizer. Regardless, the main advantage of modeling Scenario 3 eliminates the direct use of freshwater as algae medium for cultivation. In all scenarios, brackish to saline groundwater was used instead of freshwater. Additionally, the use of marine algae irrigated with groundwater is more favorable than the use of freshwater algae irrigated with effluent due to three reasons: (1) municipal wastewater in the USA could not fully offset largescale nutrient demands since the volume is too small and the quality is too dilute (very low $\mathrm{N}$ and 
P); (2) marine species were shown in literature to have higher productivity than its freshwater counterpart and (3) locations in the USA suitable for algae cultivation due to high solar flux coincidentally have the most abundant resources of brackish to saline groundwater.

Allocations for $\mathrm{CO}_{2}$ were performed similar to Scenarios 1 and 2 although make-up water for evaporation and salt purge stream came from municipal effluent from conventional activated sludge (CAS) treatment plant. Values of nutrients from CAS effluents are uniformly-distributed and are as follows: $\mathrm{N}$ minimum $=15 \mathrm{mg} / \mathrm{L}, \mathrm{N}$ maximum $=35 \mathrm{mg} / \mathrm{L} ; \mathrm{P}$ minimum $=4 \mathrm{mg} / \mathrm{L}, \mathrm{P}$ maximum $=10 \mathrm{mg} / \mathrm{L}(\mathrm{EPA}, 2007)$.

\subsubsection{Radiation Use Efficiency (RUE)}

RUEs, expressed in units of "Mg algae ash-free dry weight (AFDW) per MJ photosyntheticallyactive radiation (PAR)", were calculated in two ways: (1) obtaining the ratio of algae productivity (in $\mathrm{Mg} \mathrm{AFDW} / \mathrm{m}^{2}$-d) to PAR irradiance (in $\mathrm{MJ} \mathrm{PAR} / \mathrm{m}^{2}$-d) or (2) converting photosynthetic efficiencies (PEs) to RUEs using reported proximate analyses and assuming heat contents of 9.3 $\mathrm{kcal} / \mathrm{g}$ lipid, $4.2 \mathrm{kcal} / \mathrm{g}$ carbohydrate, and $5.7 \mathrm{kcal} / \mathrm{g}$ protein.

RUE values calculated using the first method were applied to data from Goldman et al. (1975), Laws et al. (1986) and Materassi et al. (1984). RUE values calculated using the second method were applied to data from Ansell et al. (1963), Laws et al. (1986), Raymond et al. (1977) and Thomas et al. (1984a, 1984b). All RUE values and their associated algae biomass algae species are presented in Table 3.1. 
Table 3.1. Radiation use efficiencies (RUEs) and pertinent biomass characteristics for marine algae modeled in this study. Last three rows summarize triangular distributions for model inputs.

\begin{tabular}{|c|c|c|c|c|c|c|c|}
\hline Genus & $\begin{array}{l}\text { AFDW } \\
\text { Yield, } \\
\mathrm{g} / \mathrm{m}^{2}-\mathrm{d}^{\mathrm{a}}\end{array}$ & $\begin{array}{c}\text { RUE, } \\
\text { g AFDW/MJ } \\
\text { PAR }^{b}\end{array}$ & $\begin{array}{l}\text { Total } \\
\text { Lipids, } \\
\% \text { AFDW } \\
\text { Basis }^{c}\end{array}$ & $\begin{array}{l}\text { Neutral } \\
\text { Lipids, } \\
\text { \% AFDW } \\
\text { Basis }\end{array}$ & $\begin{array}{l}\text { Energy } \\
\text { Content, } \\
\text { MJ/Mg } \\
\text { AFDW }^{d}\end{array}$ & $\begin{array}{c}\text { Ash, } \\
\%\end{array}$ & Sources \\
\hline $\begin{array}{l}\text { Amphora, } \\
\text { Amphiphora, } \\
\text { Phaeodactylum, }\end{array}$ & 11.4 & 1.8 & & & & & $\begin{array}{l}\text { Goldman } \\
\text { and Ryther } \\
(1975)\end{array}$ \\
\hline Cyclotella & 29.7 & 2.5 & $14.4^{c}$ & 13.1 & & 10.0 & $\begin{array}{l}\text { Laws et al. } \\
(1986) ; \text { DOE } \\
(1986)\end{array}$ \\
\hline Dunaliella & 8.5 & 1.6 & 26.2 & 26.2 & 22,000 & 11.7 & $\begin{array}{l}\text { Thomas, } \\
\text { Sterry and } \\
\text { Patience } \\
\text { (1984) }\end{array}$ \\
\hline Nitzchia & 19.0 & 2.4 & 27 & & & & $\begin{array}{l}\text { Goldman } \\
\text { and Ryther } \\
\text { (1975) }\end{array}$ \\
\hline Phaeodactylum & 14.7 & 2.6 & 23.9 & 23.9 & 23,900 & 14.3 & $\begin{array}{l}\text { Thomas et } \\
\text { al. (1984) }\end{array}$ \\
\hline Phaeodactylum & & 4.2 & 10.7 & 8.1 & 23,600 & 18.6 & $\begin{array}{l}\text { Ansell et al. } \\
(1964 a) ; \\
\text { Ansell et al. } \\
\text { (1964b) }\end{array}$ \\
\hline Phaeodactylum & 34.3 & 5.4 & & & & & $\begin{array}{l}\text { Raymond } \\
(1977)\end{array}$ \\
\hline Tetraselmis & & 1.0 & $20.0^{c}$ & 6.6 & & 9.9 & $\begin{array}{l}\text { Ansell et al. } \\
(1963)\end{array}$ \\
\hline Tetraselmis & 29.0 & 2.3 & & & & & $\begin{array}{l}\text { Materassi et } \\
\text { al. (1983) }\end{array}$ \\
\hline Tetraselmis & 14.3 & 2.6 & 25.9 & 25.9 & 21,900 & 9.8 & $\begin{array}{l}\text { Thomas, } \\
\text { Sterry and } \\
\text { Patience } \\
\text { (1984) }\end{array}$ \\
\hline Tetraselmis & 40.0 & 3.2 & & & 24,300 & & $\begin{array}{l}\text { Laws et al. } \\
(1986)\end{array}$ \\
\hline Tetraselmis & 35.7 & 4.5 & 16 & 5.3 & & 10 & $\begin{array}{l}\text { Laws et al. } \\
\text { (1986) }\end{array}$ \\
\hline Minimum & 8.5 & 1.0 & 10.7 & 5.3 & 21,900 & 9.8 & \\
\hline Maximum & 40.0 & 5.4 & 26.2 & 26.2 & 24,300 & 18.6 & \\
\hline Likeliest & 23.7 & 2.9 & 19.6 & 15.6 & 23,140 & 11.2 & \\
\hline \multicolumn{8}{|c|}{$\begin{array}{l}\text { Ash-free dry weight (AFDW) yield, (in } \mathrm{g} \text { AFDW } / \mathrm{m}^{2} \text {-d) as reported directly in noted sources or as computed using } \\
\text { respective ash contents. } \\
\text { b Radiation use efficiency, in "g algae ash-free dry weight per MJ photosynthetically active radiation." } \\
\text { c Total lipid contents taken from Benemann and Oswald (1996), Table } 6.2 \text {, then converted to AFDW basis using } \\
\text { reported ash content. } \\
\text { d Energy content, (in "MJ per Mg algae ash-free dry weight") as reported directly in noted sources or as computed } \\
\text { using respective ash contents and assumed energy content for proteins (5.7 cal/mg), lipids (9.3 cal/mg), and } \\
\text { carbohydrates ( } 4.2 \mathrm{cal} / \mathrm{mg} \text { ) (Laws et al., 1986). }\end{array}$} \\
\hline
\end{tabular}




\subsubsection{Yield}

All climatic inputs to the revised algae cultivation models, based on thirty years of insolation and selected meteorological data (1961-1990) were obtained from the National Solar Radiation Database (NSRDB) inventory for San Diego, California (CA). These climatic parameters were outlined in Section 2.3.1.2. Evaporation was calculated using the Penman Equation (Equation 2.1).

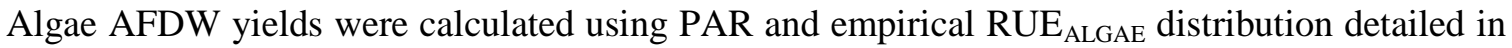
Table 3.1. Dry yields for the benchmark crops, switchgrass and canola, were computed using this approach and RUE values summarized in Tables 2.5 and 2.7, respectively. Table 2.2 summarizes monthly PAR and biomass yields for algae per hectare, for climactic conditions corresponding to the southwestern USA. Switchgrass and canola dry yields were 25.2 and $7.1 \mathrm{Mg}$ Dry solids (DS)/ha*year, respectively. Switchgrass yield accounts for above-ground biomass while canola yield accounts for seeds, pods, and stalks.

Table 3.2. Monthly photosynthetically active radiation (PAR) and dry yields of algae for climatic conditions corresponding to the southwestern USA.

\begin{tabular}{lrr}
\hline \multicolumn{1}{c}{ Month } & Monthly PAR, MJ/m & Algae Yield, Mg AFDW/ha \\
\hline January & 155 & 4.7 \\
February & 176 & 5.4 \\
\hline March & 248 & 7.6 \\
\hline April & 297 & 9.1 \\
May & 313 & 9.6 \\
June & 315 & 9.6 \\
July & 347 & 10.7 \\
August & 329 & 10.0 \\
September & 264 & 8.1 \\
\hline October & 220 & 6.8 \\
November & 165 & 5.1 \\
\hline December & 143 & 4.4 \\
\hline Annual & 2,972 & 91.1 \\
\hline Algae yield is in "Mg ash-free dry weight (AFDW) per hectare". This corresponds to $24.9 \mathrm{~g}$ AFDW/m ${ }^{2}$-d or $27.9 \mathrm{~g}$ \\
gae/m ${ }^{2}$-d (assuming ash content distribution from Table 3.1). & &
\end{tabular}




\subsubsection{Mixing and Pumping}

Mixing and pumping energy demand used in cultivation ponds were described in Sections 2.3.2.3.1 and 2.3.2.3.3. Paddle wheel power consumption follows a triangular distribution: minimum $=10^{-4} \mathrm{~kW}$, likeliest $=10^{-3} \mathrm{~kW}$, maximum $=10^{-2} \mathrm{~kW}$. Overall mixing energy demand was about 1,200 MJ/ha*yr. Overall pumping energy demand was on the order of 41,000 $\mathrm{MJ} / \mathrm{ha}{ }^{*} \mathrm{yr}$.

\subsubsection{Preliminary Dewatering}

Preliminary dewatering of the algae slurry used a thickening approach. Contrary to Chapter 2's use of alum as a chemical flocculent, this analysis assumed an auto-flocculation process requiring no energy input for as long as the medium contains $0.2 \mathrm{mM} \mathrm{PO}_{4}$ in excess of the stoichiometric $\mathrm{P}$ demand. This excess $\mathrm{P}$ was also found to induce auto-flocculation in Phaeodactylum tricornutum and Scenedesmus dimorphus by Spilling, Seppala and Tamminen (2010) and Sukenik and Shelef (1984) (Spilling, Seppala and Tamminen, 2010; Sukenik and Shelef, 1984), respectively. Concentration factors during $\mathrm{PO}_{4}$-induced auto-flocculation follow a triangular distribution: minimum $=5 \times$, likeliest $=10 \times$, maximum $=22 \times($ Spilling, Seppala and Tamminen, 2010 $)$.

Thickening was assumed to further concentrate the algae slurry after auto-flocculation. Energy demand during gravity thickening was computed using an empirical regression equation developed by Soda et al. (2010). This equation is based on sludge dewatering operations at municipal wastewater treatment plants described in Equation 3.2. Here, $y$ is electricity consumption in $\mathrm{kWh} / \mathrm{t}-\mathrm{DS}$ and $x$ is sludge loading rate in t-DS/d.

$$
y=636 x^{1.04} \quad \text { Equation } 3.2
$$


Concentration factors during gravity thickening follow a triangular distribution: minimum $=8 \times$, likeliest $=10 \times$, maximum $=15 \times($ Soda et al., 2010). Thickening energy use was on the order of 74,000 MJ/ha*yr. The estimated concentration of the algae slurry following gravity thickening was approximately $140 \mathrm{~g} / \mathrm{L}$. It was assumed that this concentration is suitable for homogenization and then subsequent anaerobic digestion or lipid extraction without additional concentrating steps (Stephenson et al., 2010; Golueke and Oswald, 1965).

\subsubsection{Generic Flow and Overall Water Balance}

All flows to and from each of the units operations were calculated using a comprehensive mass balance. Systems of equations were developed per unit operation and these equations were simultaneously solved. Results were validated using ASPEN chemical engineering unit operations software. Flow relationships were then established among the unit operations taking into account respective water, algae and salt volume fractions. It has been established in literature that marine algae would not survive in a highly saline environment and as such, make-up freshwater would be required to maintain a suitable salinity level. Table 3.3 summarizes volumetric flow rates and volume fractions comprising water, algae, and salt for the overall water balance depicted in Figure 2.2 (modified version of Figure 2.1). All flows are similar across all cases (A-D). 


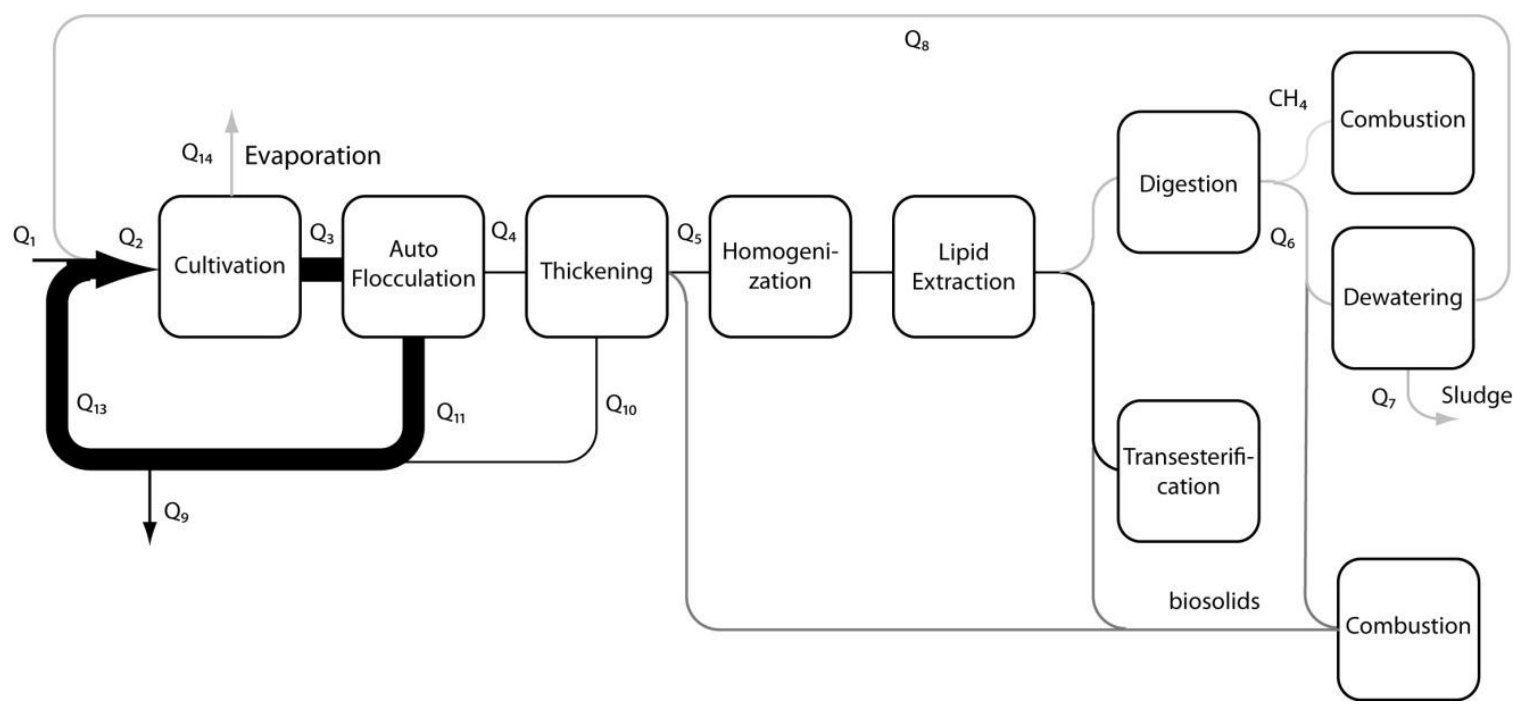

Figure 3.2. A modified version of Figure 3.1 reflecting all four different modeled cases and all volumetric flows with corresponding water, algae and salt compositions.

Table 3.3. Water balance for algae systems corresponding to Cases A-D ${ }^{\mathrm{a}}$. Interior flows among unit conversion processes differed among lettered cases. These magnitudes were computed but were not shown for simplicity. $x_{\text {water }}, x_{\text {algae }}$ and $x_{\text {salt }}$ are mass fractions of water, algae and salt, respectively.

\begin{tabular}{llrrrr}
\hline & \multicolumn{1}{c}{ Stream } & $\mathrm{Q}(\mathrm{L} / \mathrm{ha}$ * yr $)$ & \multicolumn{1}{c}{$x_{\text {water }}$} & \multicolumn{1}{c}{$x_{\text {algae }}$} & $x_{\text {salt }}$ \\
\hline $\mathrm{Q}_{1}$ & Make up flow from groundwater & $11,406,079$ & 0.996 & 0 & 0.004 \\
$\mathrm{Q}_{2}$ & Influent to cultivation & $104,475,181$ & 0.969 & 0.000 & 0.032 \\
$\mathrm{Q}_{3}$ & Effluent from cultivation & $94,461,834$ & 0.964 & 0.001 & 0.035 \\
$\mathrm{Q}_{4}$ & Effluent from auto-flocculation & $6,949,508$ & 0.955 & 0.01 & 0.035 \\
$\mathrm{Q}_{5}$ & Flow from thickening, through & 627,113 & 0.865 & 0.1 & 0.035 \\
& homogenization, \& lipid extraction & & & & \\
$\mathrm{Q}_{6}$ & Influent to dewatering & 550,355 & 0.945 & 0.02 & 0.035 \\
$\mathrm{Q}_{7}$ & Water in the sludge stream & 54,788 & 0.765 & 0.2 & 0.035 \\
$\mathrm{Q}_{8}$ & Recycle from the dewatering operation & 495,568 & 0.9649 & 0.0001 & 0.035 \\
$\mathrm{Q}_{9}$ & Purge & $1,261,186$ & 0.9649 & 0.0001 & 0.035 \\
$\mathrm{Q}_{10}$ & Recycle from thickening & $6,322,395$ & 0.9649 & 0.0001 & 0.035 \\
$\mathrm{Q}_{11}$ & Recycle from auto-flocculation & $87,512,326$ & 0.9649 & 0.0001 & 0.035 \\
$\mathrm{Q}_{12}$ & Recycle before purge & $93,834,721$ & 0.9649 & 0.0001 & 0.035 \\
$\mathrm{Q}_{13}$ & Recycle after purge & $92,573,535$ & 0.9649 & 0.0001 & 0.035 \\
$\mathrm{Q}_{14}$ & Evaporation from cultivation & $10,090,105$ & 1 & 0 & 0 \\
\hline
\end{tabular}

a. For Scenario 4 (compressed flue gas $\mathrm{CO}_{2}$ and wastewater $\mathrm{N}$ and $\mathrm{P}$ supplementation), it was assumed that effluent from a wastewater plant utilizing conventional activated sludge treatment would be used in place of brackish to saline groundwater for make-up flow (Q1). 


\subsubsection{Case A and B - Anaerobic Digestion}

Figure 3.1 (A and B) presents a schematic depiction of both Case A and Case B. An advantage of anaerobic digestion over other conversion methods is its ability to simultaneously convert algae biomass into bioelectricity and also recycle some of the dissolved nutrients in the digestate back into the cultivation pond. For Case A, it was assumed that the entire algae biomass was digested to produce methane, which was then combusted to generate bioelectricity. For Case B, only the algae non-lipid fraction ("residual") was digested and the algae lipid fraction was converted into biodiesel. For both cases, all unit operations are described in the succeeding sections.

\subsubsection{Homogenization}

Homogenization is the disruption of algae cells which improves the overall digestibility of the algae biomass (Stephenson et al., 2010; Samson and Leduy, 1983; Sialve, Bernet and Bernard, 2009). Algae slurry entering the homogenizer $\left(Q_{5}\right)$ was assumed to contain roughly $14 \%$ algae by mass. Electricity and cooling water requirements using a mechanical homogenizer were taken from Stephenson et al. (2010): $67 \mathrm{MJ} / \mathrm{m}^{3}$ algae slurry and $0.045 \mathrm{~m}^{3} / \mathrm{m}^{3}$ algae slurry, respectively. Both values were multiplied by a factor of 2 since it was assumed that two passes would be required through homogenization to achieve roughly $96 \%$ cell disruption. Homogenization electricity demand was on the order of 84,000 MJ/ha for Cases A and B of Scenarios 1-4.

\subsubsection{Digestion}

Table 3.4 presents digestion parameters used in modeling Cases A and B. It is important to note that these values were obtained using bench-scale algae experiments (Samson and Leduy, 1983; Sialve, Bernet and Bernard, 2009; Golueke, 1957; Samson and Leduy, 1982; Samson and Leduy, 1986; Sanchez-Hernandez et al., 1993; Yen and Brune, 2007) since theoretical digestion calculations reflect artificial digestion attractiveness. Relevant empirical distributions are also 
presented in the table. Variations in algae digestibility are closely related to changes in algae lipid contents.

Table 3.4. Parameters for anaerobic digestion models for both Cases A and B.

\begin{tabular}{|c|c|c|c|c|c|}
\hline Parameter & $\begin{array}{l}\text { Modeled } \\
\text { Distribution }\end{array}$ & $\begin{array}{l}\text { Minimum } \\
\text { Value }\end{array}$ & $\begin{array}{l}\text { Maximum } \\
\text { Value }\end{array}$ & $\begin{array}{l}\text { Likeliest } \\
\text { Value }\end{array}$ & Sources \\
\hline $\begin{array}{l}\text { A - VSS Removal Efficiency } \\
\text { (fraction) }\end{array}$ & Triangular & 0.21 & 0.60 & 0.41 & $A-F$ \\
\hline $\begin{array}{l}\text { B - VSS Removal Efficiency } \\
\text { (fraction) }\end{array}$ & Triangular & 0.21 & 0.60 & 0.41 & $A-F$ \\
\hline $\begin{array}{l}\text { A - Methane Production Efficiency } \\
\text { (L CH4/g VSS) }\end{array}$ & Triangular & 0.18 & 0.99 & 0.49 & $A-F$ \\
\hline $\begin{array}{l}\text { B - Methane Production Efficiency } \\
\text { (L CH4/g VSS) }\end{array}$ & Triangular & 0.15 & 0.83 & 0.41 & $A-F$ \\
\hline $\begin{array}{l}\text { A - Biogas Methane Fraction } \\
\text { (vol/vol) }\end{array}$ & Triangular & 0.46 & 0.76 & 0.72 & $A$ \\
\hline $\begin{array}{l}\text { B - Biogas Methane Fraction } \\
\text { (vol/vol) }\end{array}$ & Triangular & 0.46 & 0.76 & 0.72 & A \\
\hline $\mathrm{A}$ - Biogas $\mathrm{CO}_{2}$ Fraction (vol/vol) & Triangular & 0.08 & 0.31 & 0.22 & C \\
\hline $\mathrm{B}$ - Biogas $\mathrm{CO}_{2}$ Fraction (vol/vol) & Triangular & 0.08 & 0.31 & 0.22 & C \\
\hline $\begin{array}{l}\text { A - Digestion Ammonia Release } \\
\text { (mg N/g VSS) }\end{array}$ & Triangular & 27 & 35 & 30 & C \\
\hline $\begin{array}{l}\text { B - Digestion Ammonia Release } \\
\text { (mg N/g VSS) }\end{array}$ & Triangular & 33 & 42 & 40 & $C$ \\
\hline $\begin{array}{l}\text { A - Total } \mathrm{N} \text { Comprising } \mathrm{NH}_{3} \text { in } \\
\text { Recycle (fraction) }\end{array}$ & Uniform & 0.70 & 0.80 & NA & G \\
\hline $\begin{array}{l}\text { B - Total N Comprising } \mathrm{NH}_{3} \text { in } \\
\text { Recycle (fraction) }\end{array}$ & Uniform & 0.70 & 0.80 & NA & G \\
\hline $\begin{array}{l}\text { A - VSS Stoichiometric P Available } \\
\text { in Recycle (fraction) }\end{array}$ & Uniform & 0.20 & 0.25 & NA & $\mathrm{H}$ \\
\hline $\begin{array}{l}\text { B - VSS Stoichiometric P Available } \\
\text { in Recycle (fraction) }\end{array}$ & Uniform & 0.20 & 0.25 & NA & $\mathrm{H}$ \\
\hline
\end{tabular}

A. Sialve, Bernet and Bernard (2009); B. Golueke (1957); C. Samson and Leduy (1982); D. Samson and Leduy (1986); E. Sanchez-Hernandez et al. (1983); F. Yen and Brune (2007); G. Anasruron, Bade and Korner (2010); H. Wild, Kisliakova and Siegrist (1997).

Electricity and heat consumption during algae digestion were calculated using empirical regression equations developed by Soda et al. (2010) at mesophilic conditions in a WWTP (Soda et al., 2010). The equations are presented in Equation 3.3 and Equation 3.4 for electricity and heat consumption, respectively. Here, $y$ is electricity consumption in $\mathrm{kWh} / \mathrm{t}-\mathrm{DS}, z$ is heat consumption in MJ/t-DS, and $x$ is sludge loading rate in $\mathrm{t}-\mathrm{DS} / \mathrm{d}$. 


$$
\begin{aligned}
& y=2587 x^{0.944} \quad \text { Equation } 3.3 \\
& z=5640 \ln (x)+27100 \quad \text { Equation } 3.4
\end{aligned}
$$

Electricity demand for anaerobic digestion in the modeled system was roughly 40,500 MJ/ha. Heat demand for anaerobic digestion was approximately 1,500 MJ/ha. Infrastructure impacts for anaerobic digestion and co-digestion of algae with other carbon sources were excluded from this analysis.

\subsubsection{Digestate Dewatering and Nutrient Recycle}

The algae slurry coming out of the digester was dewatered using belt filter press (BFP) where the nutrient-rich digestate was recycled back into the cultivation pond. Solids were handled as soil amendment for terrestrial agricultural operations. Soda et al. (2010) developed an empirical regression equation, Equation 3.5 that determines electricity consumption during dewatering via BFP (Soda et al., 2010). Here, $y$ is BFP electricity consumption in kWh/t-DS and $x$ is sludge loading rate in t-DS/d. Electricity demand associated with BFP operation was on the order of $42,000-46,000 \mathrm{MJ} / \mathrm{ha}$ for Cases A and B.

$$
y=110 \ln (x)+540 \quad \text { Equation } 3.5
$$

Digestate recycling is a means of offsetting a portion of the cultivation pond's fertilizer demands. In this analysis, nitrogen offset was on the order of $1.5 \mathrm{Mg} \mathrm{N} / \mathrm{ha}-\mathrm{yr}$, comprising roughly $18 \%$ of the stoichiometric $\mathrm{N}$ demand. Phosphorus offset was on the order of $0.1 \mathrm{Mg} \mathrm{P} / \mathrm{ha}-\mathrm{yr}$, comprising roughly $8 \%$ of the stoichiometric $\mathrm{P}$ demand. 
Since BFP-separated solids (i.e., stabilized sludge) could be used as land amendment (i.e., fertilizer) for terrestrial crops, the amount of commercial fertilizer production that could be offset via stabilized sludge generation during bioenergy production must be calculated. These offsets were calculated based on empirical evaluation of a sludge's N-P-K composition and nutrient utilization efficiency (Warman and Termeer, 2005). Table 3.5 presents empirical distributions of these parameters. It was assumed that sludge digestate arising from Case A digestion (with lipids) is identical to sludge digestate arising from Case B (without lipids).

Table 3.5. Parameters used to model digestate nutrient bioavailability during accounting for commercial fertilizer production offsets.

\begin{tabular}{lccccc}
\hline Parameter & $\begin{array}{c}\text { Modeled } \\
\text { Distribution }\end{array}$ & $\begin{array}{c}\text { Minimum } \\
\text { Value }\end{array}$ & $\begin{array}{c}\text { Maximum } \\
\text { Value }\end{array}$ & $\begin{array}{c}\text { Likeliest } \\
\text { Value }\end{array}$ & Source \\
\hline $\begin{array}{l}\text { Digestate Nitrogen Content } \\
\text { (mg N/g digestate) }\end{array}$ & Uniform & 32 & 53 & NA & A \\
$\begin{array}{l}\text { Digestate Phosphorus Content } \\
\text { (mg P/g digestate) }\end{array}$ & Uniform & 8 & 16 & NA & B \\
$\begin{array}{l}\text { Nitrogen Use Efficiency (“Bioavailability") } \\
\text { (fraction) }\end{array}$ & Uniform & 0.20 & 0.25 & NA & C \\
$\begin{array}{l}\text { Phosphorus Use Efficiency ("Bioavailability") } \\
\text { (fraction) }\end{array}$ & Uniform & 0.05 & 0.10 & NA & C \\
\hline
\end{tabular}

A. Anasruron, Bade and Korner (2010); B. Wild, Kisliakova and Siegrist (1997); C. Warman and Termeer (2005).

Offsets presented in Table 3.5 were converted into fertilizer equivalents as ammonium phosphate $\left(\mathrm{H}_{12} \mathrm{~N}_{3} \mathrm{O}_{4} \mathrm{P}\right)$. The amount of ammonium phosphate fertilizer that can be offset by the stabilized sludge is P-limited, such that the remaining nitrogen offsets were computed on the basis of urea avoidance. For Case A, annual digestate production was approximately $39 \mathrm{Mg} / \mathrm{ha}$, corresponding to roughly $0.17 \mathrm{Mg} / \mathrm{ha}$ ammonium phosphate avoidance and $0.37 \mathrm{Mg} / \mathrm{ha}$ urea avoidance. For Case $\mathrm{B}$, annual digestate production was approximately $33 \mathrm{Mg} / \mathrm{ha}$, corresponding to roughly 0.14 $\mathrm{Mg} / \mathrm{ha}$ ammonium phosphate avoidance and $0.31 \mathrm{Mg} / \mathrm{ha}$ urea avoidance. 


\subsubsection{Methane Combustion and $\mathrm{CO}_{2}$ Recycle}

Methane, a predominant component of biogas emitted during anaerobic digestion is a desirable source of energy because it is "clean-burning" and has low $\mathrm{CO}_{2}$ emissions per unit energy content. All methane for Cases A and B was assumed to be combusted in a natural gas turbine to generate bioelectricity. Turbine efficiency triangular distribution is: minimum $=0.50$; maximum $=0.60 ;$ likeliest $=0.53($ Masters, 2008). Methane energy content was $50 \mathrm{MJ} / \mathrm{kg}$ (Masters, 2008).

Annual methane yield and electricity production were approximately $14 \mathrm{Mg} / \mathrm{ha}$ and 391,000 $\mathrm{MJ} / \mathrm{ha}$, respectively for Case A and $10 \mathrm{Mg} / \mathrm{ha}$ and 278,000 MJ/ha, respectively for Case B. Case A had higher methane yield because all of the biomass including algae lipid fraction was anaerobically digested.

There are two sources of $\mathrm{CO}_{2}$ in this system analysis: (1) $\mathrm{CO}_{2}$ product of methane combustion and (2) $\mathrm{CO}_{2}$ by-product of anaerobic digestion, both of which were recycled back to the cultivation pond to offset some of algae's $\mathrm{CO}_{2}$ requirements. Digestion (i.e., biogas) $\mathrm{CO}_{2}$ was on the order of $9 \mathrm{Mg} / \mathrm{ha}$ for Case $\mathrm{A}$ and $6.5 \mathrm{Mg} / \mathrm{ha}$ for Case B. Methane combustion $\mathrm{CO}_{2}$ yield was calculated from the stoichiometric relationship of the complete combustion of methane (i.e., $44 \mathrm{~g}$ $\mathrm{CO}_{2}$ per $18 \mathrm{~g} \mathrm{CH}_{4}$ combusted). Values were $40 \mathrm{Mg} / \mathrm{ha}$ for Case A and $28 \mathrm{Mg} /$ ha for Case B. Both digestion and methane combustion $\mathrm{CO}_{2}$ accounted for some $23-47 \%$ of stoichiometric $\mathrm{CO}_{2}$ demand.

\subsubsection{Residuals Management}

Stabilized sludge was assumed to require transportation to some location to be used as soil amendment. Energy demand for transportation was calculated based on an impact factor 2.31 MJ/Mg-km (Weidema, 2008). Transportation distances were assigned a uniform distribution of $50-100 \mathrm{~km}$. Annual sludge production was on the order of $39 \mathrm{Mg} / \mathrm{ha}$ and $33 \mathrm{Mg} / \mathrm{ha}$ for Case A 
and Case B, respectively such that annual transportation energy demand was between 5,700 7,000 MJ/ha for both cases. Algae dry yield for both cases were reported on a dry basis such that the ash component (likeliest: $11.2 \%$ by weight) would also require transportation. This transportation energy was computed to be on the order of 9,900 and 11,100 MJ/ha*yr for Cases A and $\mathrm{B}$, respectively.

\subsubsection{Case B and C - Biodiesel Production}

Cases B and C are depicted schematically on Figure 3.1 (B and C). Biodiesel production is a common process shared by both Cases B and C since algae lipid fraction-derived biodiesel has several transportation applications. For Case B, the lipid fraction was extracted from the algae and consequently converted in biodiesel while the algae residuals (proteins, carbohydrates, etc.) was digested to produce methane which was then combusted to generate bioelectricity. In Case C, however, the algae lipid fraction was converted into biodiesel but the algae residuals was directly combusted to generate electricity. Relevant unit operations for both cases are described in the following sections.

\subsubsection{Homogenization}

Please refer to Section 3.3.3.1 for a full discussion of homogenization assumptions and calculations.

\subsubsection{Lipid Extraction and Refining}

For both modeled cases requiring biodiesel production, lipid extraction was assumed to follow homogenization. Lipid extraction was modeled as per Stephenson et al. (2010). It was assumed that hexane was used as solvent introduced into the system in a countercurrent fashion via system of settler-mixers. Solvent input ratio was $0.75 \mathrm{~L}$ hexane per $1 \mathrm{~L}$ algae slurry (Stephenson et al., 2010) and lipid extraction efficiency was $99 \%$ by mass (Stephenson et al., 2010). Electricity 
demand during lipid extraction was computed to be $20 \mathrm{MJ} / \mathrm{m}^{3}$ algae slurry (Stephenson et al., 2010).

The heat of consumption required in recovering hexane from the hexane-lipid mixture via separation in a stripper column was calculated to be $2.1 \mathrm{MJ} / \mathrm{Mg}$ algae lipids (Stephenson et al., 2010). It was assumed that solvent recovery is $99.5 \%$ efficient on a mass basis and that annual hexane consumption was on the order of $1,500 \mathrm{~kg} / \mathrm{ha}$.

Prior to conversion to biodiesel, algae lipids must undergo alkali refining to remove free fatty acids that can interfere with the transesterification reaction. Alkali refining is the process of reacting a strong base with fatty acids to form soaps that can be removed from the lipid mixture using hot water (i.e., saponification) (Sheehan et al., 1998). Sodium hydroxide (base), heat and wash water demands were all taken from Sheehan et al. (1998). Values were $22.9 \mathrm{~kg} / \mathrm{Mg}$ algae oil (assuming a $9.5 \% \mathrm{~m} / \mathrm{m}$ solution of $\mathrm{NaOH}$ ), $150 \mathrm{MJ} / \mathrm{Mg}$ algae oil and $0.15 \mathrm{~m}^{3} / \mathrm{Mg}$ algae oil, respectively. Annually, it was estimated that some $61 \mathrm{~kg}$ of $9.5 \% \mathrm{NaOH}, 2,100 \mathrm{MJ}$ heat, and $2 \mathrm{~m}^{3}$ wash water would be required for alkali refining per hectare of algae cultivation.

\subsubsection{Transesterification and Biodiesel Post-Processing}

The process of converting algae lipid into biodiesel is known as base-catalyzed transesterification (Snare et al., 2006). Material and energy requirements for transesterification were extraction from literature sources and are presented in Table 3.6. These parameters were fit to empirical distributions to encapsulate uncertainty in reported values. Resulting distributions are also summarized in Table 3.6. 
Table 3.6. Parameters used to model transesterification of algae oil into raw biodiesel.

\begin{tabular}{|c|c|c|c|c|c|}
\hline Parameter & $\begin{array}{l}\text { Modeled } \\
\text { Distribution }\end{array}$ & $\begin{array}{l}\text { Minimum } \\
\text { Value }\end{array}$ & $\begin{array}{l}\text { Maximum } \\
\text { Value }\end{array}$ & $\begin{array}{l}\text { Likeliest } \\
\text { Value }\end{array}$ & Source \\
\hline $\begin{array}{l}\text { Cooling Water Demand, } \\
\mathrm{m}^{3} / \mathrm{Mg} \text { Biodiesel }\end{array}$ & Uniform & & & 25 & A \\
\hline $\begin{array}{l}\text { Electricity Demand, } \\
\mathrm{MJ} / \mathrm{Mg} \text { Biodiesel }\end{array}$ & Triangular & 32 & 840 & 118 & $A-D$ \\
\hline $\begin{array}{l}\mathrm{HCl} \text { Demand ( } 37 \% \text { solution in } \\
\left.\mathrm{H}_{2} \mathrm{O}\right), \mathrm{kg} / \mathrm{Mg} \text { Biodiesel }\end{array}$ & Uniform & & & 10 & A \\
\hline Heat Demand, MJ/Mg Biodiesel & Triangular & 107 & 2587 & 1134 & $E, C, D$ \\
\hline $\mathrm{KOH}$ Demand, \% algae oil $(\mathrm{m} / \mathrm{m})$ & Triangular & 1 & 1.5 & 1.3 & $F, G$ \\
\hline $\begin{array}{l}\text { Methanol Demand, kg/Mg } \\
\text { Biodiesel }\end{array}$ & Triangular & 96 & 114 & 103 & $A, H$ \\
\hline Transesterification Yield, \% & Triangular & 93 & 99 & 97 & $E, I, G$ \\
\hline
\end{tabular}

A. Lurgi (2010); B. Hill et al. (2006); C. Pradhan, Shrestha and Gerpen (2008); D. Yee et al. (2009); E. NREL (2010); F. Chisti (2007); G. Sharma, Singh and Upadhyay (2008); H. Lardon et al. (2009); I. Ma and Hanna (1999).

Methanol requirement in Table 3.6 reflects net consumption per unit mass biodiesel produced, after recovery of stoichiometric excess. It is added to move the reaction towards the product side. Heat demand associated with methanol recovery was assumed to be $225 \mathrm{MJ}$ per $\mathrm{Mg}$ of biodiesel produced (NREL, 2005).

The biodiesel produced must be further processed prior to transportation use. These unit operations include: washing with water (to remove trace impurities), heating (for residual methanol recovery) and recovery of the glycerin co-product. Values of these parameters are: triangular distribution of post-processing wash water demand $($ minimum $=200 ;$ maximum $=356$; likeliest $=278)(\mathrm{NREL}, 2002)$, heat demand during glycerin recovery $(653 \mathrm{MJ} / \mathrm{Mg}$ raw biodiesel $)$ (NREL, 2002) and acid demand, assuming a 10\% $\mathrm{HCl}$ solution in water, during glycerin recovery (75 kg/Mg raw biodiesel) (NREL, 2002). Although it was assumed that the glycerin would be recovered from the biodiesel, such that the biodiesel would be suitable for use in a passenger vehicle, glycerin co-product offsets were not computed for the overall algae biodiesel life cycle. 


\subsubsection{Biodiesel Combustion}

Biodiesel yield for both Case B and Case C was calculated to be $13.4 \mathrm{Mg} / \mathrm{ha}^{*} \mathrm{yr}$ using algae properties presented in Tables 3.1 and 3.2. Low heating value (LHV) of algae biodiesel was assumed to be uniformly-distributed within the range of 36.9-38.5 MJ/kg (Sheehan et al., 1998). Biodiesel was assumed to be combusted in an unmodified internal combustion vehicle (ICV).

\subsubsection{Case C and D - Direct Combustion}

Figure $3.1(\mathrm{C}$ and $\mathrm{D})$ presents a schematic depiction of both Case $\mathrm{C}$ and Case D. Direct combustion is the common process for both cases. For Case $\mathrm{C}$, algae lipid fraction was assumed to be converted to biodiesel while the algae non-lipid residuals was converted into bioelectricity via direct combustion. For Case D, all of the thickened algae were assumed to be combusted for bioelectricity generation. Detailed unit operations for both cases are presented in the following sections.

\subsubsection{Biomass Drying}

It was assumed that algae biomass to be combusted for production of bioelectricity would first require significant drying. For Case $\mathrm{C}$, it was assumed that roughly $69 \mathrm{Mg} \mathrm{AFDW} / \mathrm{ha}{ }^{*} \mathrm{yr}$, corresponding to the non-lipid fraction of the algae biomass, would need to be dried. For Case D, it was assumed that all of the biomass (some $85 \mathrm{Mg}$ AFDW/ha*y) would need to be dried.

Drying was assumed to be performed using a conveyor dryer plus some waste heat from a power plant flue gas to offset a portion of total drying energy. The use of waste heat from exhaust gases of a power plant for preheating combustion air significantly increases the overall thermal efficiency of the process. Electricity demand for conventional conveyor dryers was $9.4 \mathrm{MJ} / \mathrm{Mg}$ dry biomass (Poirier, 2006). Dried biomass typically contains $90-98 \%$ dry solids, biomass concentration suitable for co-combustion with coal at most conventional coal-fired power plants 
(Mann and Spath, 2001). Energy demand for biomass drying was calculated to be on the order of $650 \mathrm{MJ} / \mathrm{ha}$ an $800 \mathrm{MJ} / \mathrm{ha}$ for Case $\mathrm{C}$ and Case $\mathrm{D}$, respectively. Note that drying energy demand for Case $\mathrm{D}$ is higher than for Case $\mathrm{C}$ since all of the algae slurry coming out of the thickener would have to be burned.

The amount of heat required for biomass drying per hectare basis was determined using Equation 3.6. It is important to note that the heat for biomass drying are both sensible (i.e., heat to cause temperature change) and latent heat (i.e., heat to cause phase change). Here, $Q_{D R Y I N G}$ is the amount of heat required to evaporate a known mass of water $\left(m_{\text {WATER }}\right)$ from algae slurry; $C_{P \text {-WATER }}$ is the specific heat of water $(4 \mathrm{~kJ} / \mathrm{kg}-\mathrm{C})$ (sensible); $C_{V \text {-WATER }}$ is the heat of vaporization of water $(2,257 \mathrm{~kJ} / \mathrm{kg})$ (latent) and $\Delta T_{\text {WATER }}$ is temperature change assuming ambient starting conditions $\left(100-25=75^{\circ} \mathrm{C}\right)$.

$$
Q_{\text {drying }}=m\left(C_{p} \Delta T+C_{v}\right) \quad \text { Equation } 3.6
$$

Biomass drying heat was calculated to be roughly $1.4 * 10^{6} \mathrm{MJ} / \mathrm{ha} * \mathrm{yr}$ for both cases. This heat was then compared with the amount of flue gas heat generated from a standard size coal-fired power plant, $\mathrm{Q}_{\mathrm{FLUE}}$, calculated via Equation 3.7. Inputs are: $m_{F L U E}$, the amount of flue gas available for drying (some $5,000 \mathrm{Mg} / \mathrm{hr}$ from a $500-\mathrm{MW}$ power plant); $C_{P-F L U E}$, the specific heat of flue gas assuming it is primarily $\mathrm{N}_{2}$ gas $(1 \mathrm{~kJ} / \mathrm{kg}-\mathrm{C})$; and $\Delta T_{F L U E}$, which is the flue gas temperature drop from inlet to exit in a conveyor dryer $\left(300-200=100{ }^{\circ} \mathrm{C}\right)$.

$$
Q_{\text {flue }}=m C_{p} \Delta T \quad \text { Equation } 3.7
$$


$\mathrm{Q}_{\mathrm{FLUE}}$ was calculated to be $4.4 * 10^{9} \mathrm{MJ} / \mathrm{yr}$ of waste heat, 3,000-times larger than $\mathrm{Q}_{\mathrm{DRYING}}$. Thus, sufficient heat would have been available for biomass drying. It should be realized that the flue gas in Scenario 3 must be cooled before it could be used as $\mathrm{CO}_{2}$ source for algae cultivation. Thus, the use of a conveyor dryer accomplishes two purposes: (1) supplying heat for biomass drying prior to combustion and (2) absorbing heat for flue gas preparation prior to use in algae cultivation.

\subsubsection{Biomass Combustion}

Both algae and algae non-lipid residuals were assumed to be co-combusted with coal to generate electricity, assuming that algae cultivation is co-located with power plant. Boiler efficiency with triangular distribution is as follows: minimum $=0.30 ;$ maximum $=0.40$; likeliest $=0.34$ (Masters, 2008).

Biomass energy content for algae combusted in Case D (i.e., entire algae) on a per-mass AFDW basis was presented in Table 3.1 (20,000 MJ/Mg AFDW). The energy content of algae non-lipid residuals combusted in Case $\mathrm{C}$ to generate bioelectricity was calculated from this value using an average neutral lipid content of $15.6 \%$ (on an AFDW basis) and an energy content of $9.3 \mathrm{kcal} / \mathrm{g}$ lipid (38,900 MJ/Mg lipid) (Ansell et al., 1963). Resulting values were fit to the following triangular distribution: minimum $=11,400 \mathrm{MJ} / \mathrm{Mg} ;$ maximum $=21,500 \mathrm{MJ} / \mathrm{Mg}$; likeliest $=$ 15,700 MJ/Mg. Estimated electricity production for Cases C and D were roughly 390,000 MJ/hayr and 593,000 MJ/ha-yr, respectively.

\subsubsection{Residuals Management}

Algae-derived ash was assumed to require transportation after combustion. Energy demand for transportation was calculated based on an impact factor $2.31 \mathrm{MJ} / \mathrm{Mg}-\mathrm{km}$ (Weidema, 2008). Transportation distances were assigned a uniform distribution of 50-100 km. Annual sludge 
production was on the order of $10 \mathrm{Mg} / \mathrm{ha}$ * yr. Thus, transportation energy was computed to be on the order of $1,800 \mathrm{MJ} / \mathrm{ha}^{*} \mathrm{yr}$ for direct combustion cases.

\subsubsection{Benchmark Crop Systems}

\subsubsection{Bioelectricity from Switchgrass}

Details of switchgrass cultivation were outlined in the previous chapter, Section 2.3.1.3.2. Life cycle impact factors for switchgrass cultivation were presented in Section 2.3.4.1, Table 2.13 of Chapter 2. Estimated switchgrass wet yield was $25.2 \mathrm{Mg} / \mathrm{ha}$ * $^{\mathrm{yr}}$ for climatic conditions in southwestern USA (San Diego, CA) (See Table 2.5 of Chapter 2). Direct water use was calculated based on evapotranspiration and it was assumed that all $\mathrm{CO}_{2}$ sequestered during photosynthesis is released back to the atmosphere during combustion thus excluding it from the GHG balance. It was assumed that there was no additional biomass drying.

Switchgrass was also assumed to be co-combusted with coal to produce electricity and boiler efficiency was assigned a triangular distribution as per Section 3.3.5.2. Switchgrass energy content was taken from Table 2.10 of Chapter 2 : minimum $=16,700 \mathrm{MJ} / \mathrm{Mg}$; maximum $=18,650$ $\mathrm{MJ} / \mathrm{Mg}$; and likeliest = 18,300 MJ/Mg. Estimated bioelectricity production from switchgrass was $156,800 \mathrm{MJ} / \mathrm{ha} * \mathrm{yr}$.

\subsubsection{Biodiesel and Bioelectricity Production from Canola}

Details of canola cultivation were outlined in the previous chapter, Section 2.3.1.3.3. Life cycle impact factors for canola cultivation were presented in Section 2.3.4.1, Table 2.13 of Chapter 2. Estimated canola biomass dry yield (seeds, pods and stalks) was $7.1 \mathrm{Mg} / \mathrm{ha}$ *yr for climatic conditions in southwestern USA (San Diego, CA) (See Table 2.7 of Chapter 2). Direct water use was calculated based on evapotranspiration and it was assumed that all $\mathrm{CO}_{2}$ sequestered during photosynthesis is released back to the atmosphere during combustion thus excluding it from the 
GHG balance. It was assumed that there was no additional biomass drying. Energy demand for transport, intermediate storage and drying was $266 \mathrm{MJ} / \mathrm{Mg}$ seed (Smith et al., 2009). It was assumed that seed accounts for roughly one-third of total canola biomass.

Biodiesel Production. Lipid content for canola was $41 \%$ (Dunford and Temelli, 2007) and this was assumed to be separated from the residual biomass via hexane extraction (98\% efficient) (Smith et al., 2009). All the steps in canola biodiesel production were modeled similar to that of algae biodiesel production namely: lipid extraction, alkali refining, transesterification, postprocessing and glycerin recovery. Canola biodiesel yield was roughly $0.9 \mathrm{Mg} / \mathrm{ha}-\mathrm{yr}$. Energy content was modeled using the same triangular distribution as for algae biodiesel (See Table 2.10 of Chapter 2). It was assumed that canola biodiesel, like algae biodiesel, is combusted in an unmodified ICV.

Bioelectricity Production. Of the approximately 59\% biomass residual after lipid extraction, 86\% including seedcake and non-seed portions of the harvested biomass, is co-combusted with coal to produce bioelectricity. Boiler efficiency was set similar to what was described in Section 3.3.5.2. Energy content was taken from Table 2.10 of Chapter 2 : minimum $=15,800 \mathrm{MJ} / \mathrm{Mg}$; maximum $=$ $19,700 \mathrm{MJ} / \mathrm{Mg}$ and likeliest $=18,500 \mathrm{MJ} / \mathrm{Mg}$. Estimated bioelectricity production from canola residuals was roughly $29,600 \mathrm{MJ} / \mathrm{ha}-\mathrm{yr}$.

\subsubsection{Calculation of Reported Metrics}

\subsubsection{Energy Return on Investment (EROI)}

Energy ratio is a metric used by various studies in determining the net energy production of bioelectricity and/or biodiesel generated from algae and other terrestrial benchmark crops (Hall and Klitgaard, 2006; Hall, Balogh and Murphy, 2009; Luo et al., 2010). An energy ratio known as energy return on investment (EROI) describes a system to be net energy-producing if its value is 
greater than one and net energy-requiring if less than one. From an LCA standpoint, the minimum tenable EROI is roughly 3 (i.e., $3 \mathrm{MJ}$ energy delivered per $1 \mathrm{MJ}$ consumed) but a system with EROI of 5-10 is imperative if it were to fully displace fossil fuels in the near future (Hall and Klitgaard, 2006; Hall, Balogh and Murphy, 2009; Luo et al., 2010).

Energy generated (numerator) are as follows: biodiesel energy (biodiesel mass $\times$ biodiesel energy content), bioelectricity energy $\left(\mathrm{CH}_{4}\right.$ mass $\times \mathrm{CH}_{4}$ energy content $\times$ turbine efficiency, or biomass mass $\times$ biomass energy content $\times$ boiler efficiency), co-product offsets for soil amendments produced from digestate solids/stabilized sludge (but not glycerine) and an offset to account for upstream burdens that would have accrued on electricity from the US grid if had not been otherwise produced directly within each system. This offset was computed using the ecoinvent impact factor for electricity from the US grid: 3.5 MJ/MJ (Weidema, 2008). For consistency with GREET (Wang, 2010), the electricity upstream avoidance offset was only applied to surplus electricity produced by each modeled system. Thus, the electricity upstream avoidance was not used in instances in which a system consumed more electricity than it produced.

Energy invested (denominator) are as follows: direct electricity use, direct heat use, and upstream energy use for materials and energy inputs. Upstream burdens were computed using life cycle impact factors from the industry-standard ecoinvent database (Weidema, 2008). Upstream burdens associated with heat inputs were computed using impact factors for heating oil. Upstream burdens for electricity inputs were computed using impact factors corresponding to the US grid as noted in the previous paragraph. Since it was assumed that bioelectricity produced from algae, canola or switchgrass would be used to offset direct electricity use in each modeled system, upstream burdens were only assessed for the portion of direct electricity use in excess of the amount generated via methane or biomass combustion. The significant upstream burden 
association with US grid electricity makes it highly desirable to produce as much electricity as possible from biomass. Electricity factor accounts for both fossil (71\%) and non-fossil (29\%) inputs for electricity production. As such, our EROI values account for investments of both fossil and non-fossil energy. Other authors have computed EROI by only accounting for fossil energy inputs (Hall and Klitgaard, 2006; Hall, Balogh and Murphy, 2009).

\subsubsection{Vehicle Kilometers Traveled (VKT)}

Energy generated either as bioelectricity and/or biodiesel were converted into quantitative endpoint for transportation via vehicle kilometers traveled (VKT). Each energy-carrier has its own method of deriving VKT. However, both methods considered gross (rather than net) VKT since the distance generated by the fossil fuel inputs was not deducted from the total VKT.

Biodiesel. Biodiesel VKT was calculated using biodiesel energy output and the internal combustion vehicle (ICV) efficiency $\left(\eta_{\mathrm{ICV}}\right)$. This quantity accounts for the overall average of city and highway mileage (Campbell, Lobell and Field, 2009). Values were assigned the following triangular distribution: minimum $=0.2 \mathrm{~km} / \mathrm{MJ} ;$ maximum $=0.6 \mathrm{~km} / \mathrm{MJ}$; likeliest $=0.38 \mathrm{~km} / \mathrm{MJ}$.

Bioelectricity. There are considerable transmission losses and other inefficiencies in delivering electricity from the power plant to the battery electric vehicle (BEV). It is thus imperative to multiply the bioelectricity produced by several factors prior to calculating VKT. The product of the bioelectricity and all these factors is the energy that made its way into the battery of a BEV. These bioelectricity values were detailed in Sections 3.3.2.2, 3.3.6.1 and 3.3.6.2. Equation 3.8 shows how to calculate VKT from bioelectricity.

$$
V K T_{B E V}=E_{B i o E} * \eta_{\text {trans }} * \eta_{\text {charge }} * \eta_{B E V} \quad \text { Equation } 3.8
$$


Values for $\eta_{\text {trans }}$ (transmission efficiency) and $\eta_{\text {CHARGE }}$ (battery charging efficiency) were taken from Campbell, Lobell and Field (2009) (Campbell, Lobell and Field, 2009). These were 92\% and $90 \%$, respectively. Values for battery efficiency in a BEV $\left(\eta_{\mathrm{BEV}}\right)$ were taken from US EPA data and fit to the following triangular distribution: minimum $=0.6 \mathrm{~km} / \mathrm{MJ}$; maximum $=1.7$; likeliest $=1.3 . \eta_{\mathrm{BEV}}$ values accounted for both city and highway mileage (Campbell, Lobell and Field, 2009).

\subsubsection{LCA Impact Factors}

Table 3.7. Life cycle impact factors for materials and energy inputs used in the LCA models for these analyses. These impact factors were taken from ecoinvent v. 2.0 (Weidema, 2008).

\begin{tabular}{|c|c|c|c|c|}
\hline \multirow[b]{2}{*}{ Item } & \multirow[b]{2}{*}{ Functional Unit } & \multicolumn{3}{|c|}{ Impact category } \\
\hline & & Energy Use (MJ) & Water Use $\left(\mathrm{m}^{3}\right)$ & $\mathrm{GHG}\left(\mathrm{CO}_{2}\right.$-eq) \\
\hline Ammonium phosphate & $1 \mathrm{~kg}$ as $\mathrm{P} 2 \mathrm{O} 5$ & $37.5 / 5.4$ & $0.7 / 0.1$ & $0.8 / 0.1$ \\
\hline Canola & 1 kg DS (seeds) & $11.9 / 11.6$ & $1.8 / 1.8$ & $1.9 / 1.9$ \\
\hline Carbon dioxide & $1 \mathrm{~kg}$ & $8.3 / 2.0$ & $2.2 / 0.6$ & $0.8 / 0.1$ \\
\hline Corn & 1 kg DS (kernels) & $0.4 / 0.1$ & $0.1 / 0.007$ & $0.1 / 0.004$ \\
\hline Electricity (US grid) & $1 \mathrm{kWh}$ & $12.5 / 10.0$ & $0.8 / 0.1$ & $0.2 / 0.01$ \\
\hline Glycerine & $1 \mathrm{~kg}$ & $8.7 / 1.2$ & $0.8 / 0.1$ & $1.7 / 0.2$ \\
\hline Heating oil (light) & $1 \mathrm{MJ}$ & $1.3 / 0.2$ & $0.03 / 0.004$ & $0.1 / 0.01$ \\
\hline Hexane & $1 \mathrm{~kg}$ & $59.7 / 3.3$ & $1.8 / 0.5$ & $0.9 / 0.1$ \\
\hline Hydrochloric acid & $\begin{array}{r}1 \mathrm{~kg} \\
\text { (30\% in water) }\end{array}$ & $10.4 / 3.1$ & $5.5 / 1.2$ & $0.9 / 0.2$ \\
\hline Methanol & $1 \mathrm{~kg}$ & $37.7 / 5.5$ & $0.7 / 0.1$ & $0.8 / 0.1$ \\
\hline Potassium hydroxide & $1 \mathrm{~kg}$ & $23.7 / 4.5$ & $9.0 / 1.2$ & $2.0 / 0.2$ \\
\hline Sodium hydroxide & $\begin{array}{r}1 \mathrm{~kg} \\
\text { (50\% in water) }\end{array}$ & $11.2 / 4.6$ & $7.9 / 1.3$ & $1.2 / 0.2$ \\
\hline Superphosphate & $1 \mathrm{~kg}$ as P2O5 & $33.8 / 14.5$ & $12.4 / 2.4$ & $2.8 / 0.5$ \\
\hline Switchgrass & $1 \mathrm{~kg}$ dry weight & $1.4 / 0.2$ & $0.2 / 0.02$ & $0.2 / 0.04$ \\
\hline Urea & $1 \mathrm{~kg}$ as $\mathrm{N}$ & $62.1 / 11.8$ & $4.0 / 1.3$ & $3.4 / 0.3$ \\
\hline
\end{tabular}




\subsection{Results and Discussion}

\subsubsection{Comparison of EROI Among Algae Systems}

The sixteen algae systems (i.e., four conversion pathways $(A-D) \times$ four nutrient procurement scenarios (1-4)) were initially evaluated in terms of EROI. As pointed out in Section 3.3.6.2, EROI is an effective metric in assessing the environmental performance of a proposed bioenergy pathway by comparing the energy generated by the system with the energy expended. Table 3.8 presents EROI values among all sixteen algae systems, values ranging from $0.65-4.10$. As explained above, an EROI of 3 makes a sustainable system but the complete displacement of fossil fuel energy sources would require a system to have an EROI of 5 - 10 (Hall, Balogh and Murphy, 2009).

Table 3.8. Energy return on investment (EROI) for four algae conversion pathways producing combinations of bioelectricity (BioE) and biodiesel (BioD) via anaerobic digestion (AD) or direct combustion (DC). Each pathway is modeled for four nutrient procurement scenarios: (1) virgin commercial $\mathrm{CO}_{2}$, (2) $\mathrm{CO}_{2}$ from carbon capture at a coal-fired power plant, (3) direct compression of flue gas and (4) flue gas with fertilizer offsets from use of wastewater effluent. Values are medians from 10,000 trials. Canola and switchgrass systems exhibit median EROI values of 2.73 and 15.90 , respectively.

\begin{tabular}{|l|c|c|c|c|}
\hline \multicolumn{1}{|c|}{ Scenario } & 1. Virgin $\mathrm{CO}_{2}$ & 2. Carbon Capture & 3. Flue Gas & $\begin{array}{c}\text { 4. Wastewater } \\
\text { Supplementation }\end{array}$ \\
\hline A. AD to BioE & 1.06 & 1.14 & 1.69 & 1.72 \\
\hline B. BioD + AD to BioE & 0.65 & 0.72 & 1.11 & 1.13 \\
\hline C. BioD + DC to BioE & 0.99 & 1.36 & 1.99 & 1.99 \\
\hline D. DC to BioE & 1.53 & 2.90 & 4.10 & 4.09 \\
\hline
\end{tabular}

The results presented in Table 3.8 indicate that various combinations of cultivation and conversion schemes could lead to energy consumption being higher than energy production (i.e., EROI $<1$ ). It is important to note that the trend of values among nutrient scenarios (columns) is almost identical to each other. This observation also holds validity among conversion pathways (rows) in which EROI values generally increase for left to right. This suggests that both factors affect overall energy balance. 
EROI values among rows (conversion pathways) exhibit a very clear trend true to each nutrient procurement scenario: $\mathrm{D}>\mathrm{C}>\mathrm{A}>\mathrm{B}$. This reflects the relative favorability of each conversion pathway. Although the EROI values for each conversion scheme are near at or over 1 (i.e., energy output is equal to energy input), only case D has EROI values that approach the threshold value for a sustainable bioenergy system (Hall, Balogh and Murphy, 2009). The difference in system performance between anaerobic digestion and direct combustion was revealed by making a paired comparison between Case A vs. Case D and Case B vs. Case C. Both Cases A and B produce bioelectricity by anaerobically digesting either all of the algae or the algae non-lipid fraction. Similarly, Cases C and D produce bioelectricity by directly combusting either all of the algae or the algae non-lipid fraction. It is obvious from these paired comparisons that whether or not biodiesel is extracted from algae cells, direct combustion performs more favorably than anaerobic digestion. This result is counterintuitive considering the fact that anaerobic digestion has been touted as an efficient means of generating energy via methane combustion (Stephenson et al., 2010; Lundquist et al., 2010; Sialve et al., 2009).

This seemingly less ideal energetic performance of anaerobic digestion compared to direct combustion can be explained by three factors. First, the volatile suspended solids (VSS) removal efficiency of algae is only between $40-60 \%$ such that a considerable "undigested" portion must be recycled through the digestion system and ultimately end up in the digestate solids (i.e., stabilized sludge) for land amendment. However, the bioavailability of $\mathrm{N}$ and $\mathrm{P}$ in the stabilized sludge (i.e., $\mathrm{N}$ and $\mathrm{P}$ use efficiency) is only between $8-25 \%$ rendering $\mathrm{N}$ and $\mathrm{P}$ avoidance to be approximately $1 \mathrm{Mg} / \mathrm{ha} \mathrm{N}$ and $0.1 \mathrm{Mg} / \mathrm{ha} \mathrm{P}$ per $100 \mathrm{Mg} / \mathrm{ha}$ digestate. Second, methane and ammonia yields are below their theoretical yields. For methane, the production efficiency is only 0.31L $\mathrm{CH}_{4} / \mathrm{g}$ VSS against $0.67 \mathrm{~L} \mathrm{CH}_{4} / \mathrm{g}$ VSS (46\% of theoretical). Ammonia's production efficiency, on the other hand, is only $30 \mathrm{mg} \mathrm{N}-\mathrm{NH}_{3} / \mathrm{g}$ VSS against $87 \mathrm{mg} \mathrm{N}-\mathrm{NH}_{3} / \mathrm{g}$ VSS $(54 \%$ of theoretical) (Sialve, Bernet and Bernard, 2009). These parameters, algae digestibility and 
methane/ammonia recovery, have been suggested to be the focus of further improvements in anaerobic digestion research (Sialve, Bernet and Bernard, 2009).

Finally, the reason the performance of anaerobic digestion has been shown to be less satisfactory compared to direct combustion can be explained by the overall energy balance. A substantial fraction of methane-derived bioelectricity has been used to offset direct energy use by various digestion unit operations (i.e., homogenization, digestion mixing/heating, belt-filter pressing). For Cases A and B in Scenario 1, $42-57 \%$ of methane-derived bioelectricity has been used to offset digestion energy demand. The total offsets, accounted for by $\mathrm{CO}_{2}$ and nutrients recycle via anaerobic digestion, represent roughly $87 \%$ of methane-derived bioelectricity, or within the same order of magnitude as the total energy output of the system. This is critical insofar as the ability of anaerobic digestion to deliver usable transportation energy. Although its EROI value can be equal to or greater than 1 due to offsets accounting, this only indicates an artificial attractiveness since roughly the same magnitude of energy is "trapped" in the digestate solids.

In terms of EROI values among columns (nutrients procurement scenario), the trends are similar regardless of the conversion pathway: Scenario $1<$ Scenario $2<$ Scenario $3 \approx$ Scenario 4 . The relative favorability among nutrient conditions is independent of the conversion scheme employed. The choice of $\mathrm{CO}_{2}$ source also affects EROI values. Table 3.8 has shown that supplying the pond with virgin $\mathrm{CO}_{2}$ (Scenario 1 ) is more burdensome than providing $\mathrm{CO}_{2}$ from captured flue gas (Scenario 2) which is more burdensome than simply compressing the flue gas (Scenario 3). Similarly, the trend in EROI values on the basis of carbon source reflects in parallel the trend in "energy intensiveness" of $\mathrm{CO}_{2}$ procurement. Virgin $\mathrm{CO}_{2}$ (Scenario 1) consumes 4140 $\mathrm{MJ} / \mathrm{Mg}$, an energy demand more than that of carbon capture (Scenario 2), which consumes 570 $\mathrm{MJ} / \mathrm{Mg}$. Carbon capture, however, consumes more energy than compressed flue gas (Scenario 3), which consumes $135 \mathrm{MJ} / \mathrm{Mg}$. It is important to note that these results are consistent with what has 
been suggested in literature regarding the use of "free" $\mathrm{CO}_{2}$ (Batan et al., 2010). Despite a promising EROI, one disadvantage of carbon capture (Scenario 2) is that it has not been shown to be viable in an industrial scale nor the effects of other constituents in the flue gas might affect algae yield (Doucha, Straka and Livansky, 2005). Additionally, the use of reclaimed flue gas (Scenario 3) carries with it transportation burdens such that it is not considered totally "free" from an LCA standpoint. Lastly, the use of wastewater to counteract the effects of evaporation on the overall water balance has little to no effect on the EROI values in Table 3.8 (Scenario $3 \approx$ Scenario 4). This is because only about $10 \%$ of total flow is supplanted by the wastewater effluent. The use of wastewater also further reduces nutrients offsets since a large percentage of the flow is delivered as effluent. However, this study indicates that the use of marine algae with an increased yield more than compensates the offset reduction.

The denominator portion of the EROI $\left(\mathrm{E}_{\mathrm{IN}}\right)$ presents variations in relative efficiencies of producing bioelectricity. The components of $\mathrm{E}_{\mathrm{IN}}$ include direct electricity use, heat use and upstream energy use for materials and energy inputs. It was assumed that the total direct electricity use would be deducted from the total methane-derived electricity such that the excess would be assessed with an upstream electricity burden (12.5 MJ/kWh). For a system with surplus electricity, this impact factor was used in the numerator ( $\left.\mathrm{E}_{\mathrm{OUT}}\right)$ to account for the "virtual" upstream burdens that would have otherwise accrued on electricity from the US grid. This calculation method, although consistent with the GREET model (Wang, 2010), has bias on bioelectricity by double-charging the electricity surplus (numerator) and the algae that did not become bioelectricity (denominator). For anaerobic digestion (Case A), although all EROI values are greater than 1 , the fraction of methane-derived bioelectricity that was used in the digestion system and the algae fraction that became digestate solids were penalized by virtue of the definition of EROI. Both of these energy components could have been efficiently converted into more output electricity if direct combustion was used. This partly explains why Case D is always 
preferable to all others, and it is one of several reasons why algae bioelectricity is a seemingly appealing transportation energy source.

\subsubsection{Comparison of Vehicle Kilometers Traveled from Algae vs. Other Crops}

After EROI evaluation, the amount of transportation energy generated from each system and their relative environmental impacts were evaluated. The two functional units, as explained in Section 3.3.1.1, provide a meaningful comparison between algae and terrestrial alternatives and also articulate tradeoffs between maximizing usable outputs (VKT) and minimizing system burdens (energy, water, GHG). Figure 3.3 presents annual VKT generated per 1 hectare of biomass cultivation among four bioenergy systems: algae biodiesel production with conversion of residuals into bioelectricity (Case 4C), canola biodiesel production with conversion of residuals into bioelectricity, algae bioelectricity production (Case 4D) and switchgrass bioelectricity production. Cases $\mathrm{C}$ and $\mathrm{D}$ were chosen as algae bioenergy representatives since these systems employed direct combustion, a preferable conversion scheme generating EROIs for which the entire $90 \%$ confidence intervals are greater than 1 and the only median values which are greater than 3. In a similar manner, Scenario 4 was chosen to represent nutrient conditions for algae (i.e., highest EROI among nutrient procurement scenarios). Recall that this scenario assumes that compressed flue gas is used for $\mathrm{CO}_{2}$ and that wastewater nutrients offset some fertilizer and water demands. 


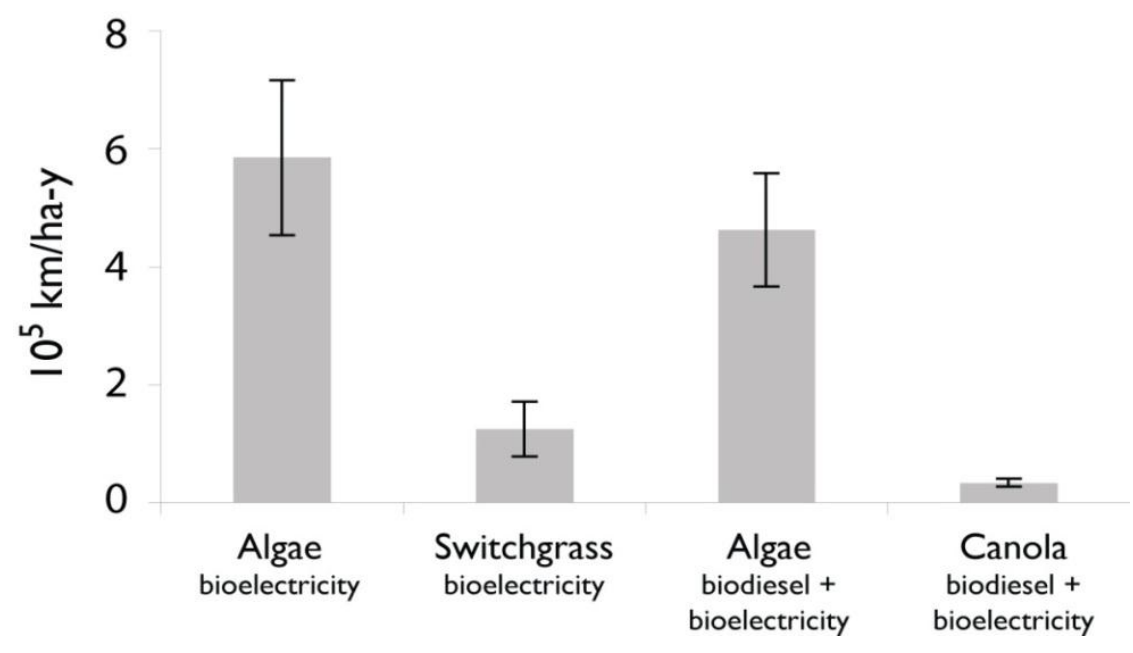

Figure 3.3. Annual gross vehicle kilometers traveled (VKT) per hectare-year for four bioenergy systems (error bars are medians \pm 1 standard deviation). Median values are (from left to right): $500,200 \mathrm{~km} / \mathrm{ha}{ }^{*} \mathrm{yr} ; 124,700 \mathrm{~km} / \mathrm{ha}{ }^{*} \mathrm{yr} ; 409,900 \mathrm{~km} / \mathrm{ha}{ }^{*} \mathrm{yr}$ and 33,400 km/ha*yr. "Algae biodiesel + bioelectricity" is Case 4C in Table 3.8. "Algae bioelectricity" is Case 4D in Table 3.8.

As seen in Figure 3.3, algae systems produce approximately 4 times and 12 times more VKT than the switchgrass and canola systems, respectively. Although not included in this graph due to misalignment of system boundaries, these algae systems are projected to be at least 15 - 19 times more VKT than could be derived from corn ethanol $\left(27,000 \mathrm{~km} / \mathrm{ha}{ }^{*} \mathrm{yr}\right)$ even when accounting for ethanol co-products (Farrell et al., 2006).

The superior performance of algae relative to terrestrial crops in VKT production per hectare, is not unexpected. Recall that algae's primary advantage over corn, canola, and switchgrass is its efficient land use on a raw biomass energy basis (See Chapter 2). Figure 3.3 reaffirms the conclusion in Chapter 2 that accounting for conversion of each crop into usable energy does not significantly affect algae's superior cultivation-phase land efficiency. Since land is a finite resource and algae cultivation leverages land area more efficiently, algae-derived transportation energy is a feasible concept. Moreover, results in Figure 3.3 is assumed to offer conservative estimates of the differences in land use among crops since land quality is not considered in the 
analysis. In the case of algae, they could be grown on marginal lands that are unsuitable for terrestrial agriculture.

\subsubsection{Comparison of VKT from Two Algae Conversion Systems}

Annual VKT per hectare for algae bioelectricity (Case 4D) is considerably greater than that for algae biodiesel + bioelecticity (Case 4C) consistent with Table 3.8 (Figure 3.3). This result might be surprising considering that algae have been regarded as a promising source of liquid fuels (Chisti, 2008; Lardon et al., 2009; Sander and Murthy, 2010). There are two reasons that can explain this phenomenon. First, the energy content of non-lipid residuals is much higher than algae lipids' energy content. This energy content difference (2.6 times) is shown here, neglecting minor losses: $1,211,500 \mathrm{MJ} / \mathrm{ha}^{*} \mathrm{yr}=0.82 \mathrm{~g}$ residuals/g algae $\times 91.2 \mathrm{Mg}$ algae/ha* $\mathrm{yr} \times 16,200$ $\mathrm{MJ} / \mathrm{Mg}$ residuals (non-lipid algae residual); 463,544 $\mathrm{MJ} / \mathrm{ha}^{*} \mathrm{yr}=0.14 \mathrm{~g}$ neutral lipids/g algae $\times$ 91.2 Mg algae/ha*yr $\times 0.96 \mathrm{~g}$ biodiesel/g neutral lipids $\times 37,700 \mathrm{MJ} / \mathrm{Mg}$ biodiesel (algae lipids) The VKT from each energy-carrier is then calculated by multiplying the energy pool with a some efficiency factors. These factors are: boiler efficiency $(0.347) \times$ transmission efficiency $(0.92) \times$ charging efficiency $(0.90) \times \mathrm{BEV}$ mileage efficiency $(1.2 \mathrm{~km} / \mathrm{MJ})=0.34 \mathrm{~km} / \mathrm{MJ}$ (non-lipid algae residual); $0.39 \mathrm{~km} / \mathrm{MJ}$ (algae lipids). Although both factors are almost equal, multiplying each with their corresponding energy yields significantly produces more VKT from the non-lipid algae residuals. Second, the amount of energy required to convert lipids into $1 \mathrm{MJ}$ biodiesel energy is much larger than the amount of energy required to convert non-lipids into $1 \mathrm{MJ}$ bioelectricity: $180-190 \mathrm{~kJ} / \mathrm{MJ}$ (for homogenization, lipid extraction, transesterification, and biodiesel processing) versus $5 \mathrm{~kJ} / \mathrm{MJ}$ (for drying and ash transport). The combined effects of more available energy and lower conversion-phase energy inputs leads to larger VKT for Case D (direct combustion) versus Case $\mathrm{C}$ (direct combustion following biodiesel production). 
For Case 4C, the VKT generated from bioelectricity (47\%) is approximately equal to the VKT generated from biodiesel (53\%). Since almost half of algae's total energy pool comes from bioelectricity, it is no surprise that many algae LCA studies to date have emphasized the importance of algae "co-products" in driving overall environmental or economic sustainability. In this study, only energy co-products were considered. However, there are numerous applications for the non-lipid algae residual (e.g., animal feed). Lastly, it should be emphasized that this analysis excludes the manufacture of BEVs because the focus is on understanding fuel cycle burdens. This affects comparison between Cases C and D, such that better LCA data for manufacture of BEVs will be needed as the market grows in the coming years.

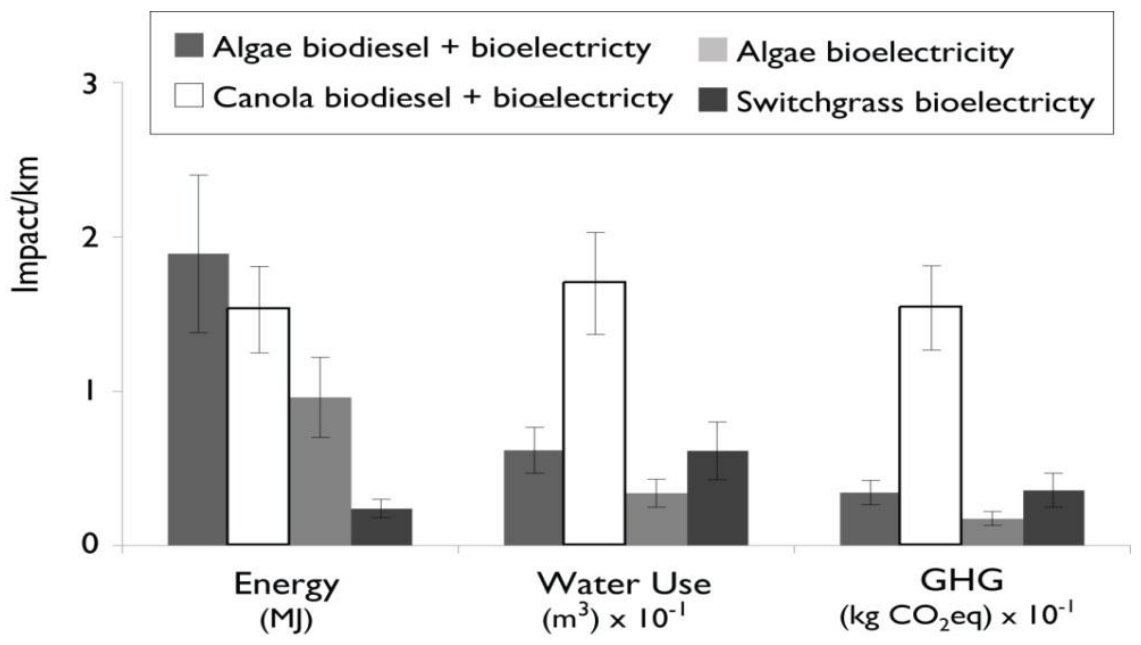

Figure 3.4. Environmental impacts per vehicle kilometer traveled (VKT) for four bioenergy systems (error bars are medians \pm 1 standard deviation). "Algae biodiesel + bioelectricity" is Case $4 \mathrm{C}$ in Table 3.8. "Algae bioelectricity" is Case 4D in Table 3.8.

\subsubsection{Life Cycle Burdens for Transportation Energy from Algae vs. Other Crops.}

The results presented in Figure 3.3 demonstrates algae's superior land use efficiency relative to the benchmarks. However, there are other environmental impact categories that are worth evaluating. The VKT-normalized burdens are depicted in Figure 3.4 for the systems presented in Figure 3.3: net energy use, water use, and GHG emissions. 
The environmental impacts of algae biodiesel and bioelectricity presented in Figure 3.4 convey mixed performance relative to the benchmark crops. Both algae systems consume more energy than canola and switchgrass but utilize less water and emit less GHG. These results demonstrate better environmental performance for algae-derived transporattion energy than those presented in Table 2.17 of Chapter 2, which accounted for only cultivation-phase burdens. This improvement can be attributed to the use of VKT-normalized burden comparison because this metric encapsulates algae's higher energy yield per unit land area compared to switchgrass and canola. The ability of the algae systems to leverage land area efficiently is highlighted int his analysis because the marine algae used in modeling these systems have higher productivity than the freshwater species used in the previous chapter. The very high GHG emission of canola reflects its energy-intensive cultivation. As a point of reference, GHG emissions for canola, corn, and switchgrass taken from ecoinvent are: $1.9 \mathrm{~kg} \mathrm{CO}$ eq $/ \mathrm{kg}$ canola seed, $0.4 \mathrm{~kg} \mathrm{CO} 2 \mathrm{eq} / \mathrm{kg}$ corn kernels and $0.2 \mathrm{~kg} \mathrm{CO}_{2}$ eq/kg switchgrass (Weidema, 2008). Finally, the seeming efficiency of algae-derived bioelectricity, as revealed in Figure 3.4, suggests that it may be worthwhile to compare this system to photovoltaic power production in subsequent analyses.

\subsection{Conclusions}

The potential of algae as a sustainable transportation energy source has been fully evaluated in this study in three ways. First, it allows for a more comprehensive evaluation of algae's performance relative to other bioenergy feedstocks because an expanded well-to-wheel system boundary has been adapted. Detailed assessment of both cultivation and conversion processes for multiple crops within the same system boundaries makes it possible to evaluate algae's potential within the context of the current bioenergy landscape. Second, various conversion pathways have been simultaneously assessed. This rectifies the shortcomings of Chapter 2. Third, the results highlight important tradeoff: algae can deliver more VKT per hectare than the selected benchmark crops but at the same time create larger environmental burdens on a per-km basis. 
This study, however, cannot make normative judgment on whether or not the US and other countries should pursue algae-derived transportation fuels. Factors such as economic feasibility, social acceptance and political climate will undoubtedly have a large impact on the commercialization of algae-derived biodiesel or bioelectricity. On one hand, direct biomass energy technologies have a favorable levelized energy cost (LEC) against other alternative energy technologies and are cost-competitive with fossil power plants (Roth and Ambs, 2004). On the other hand, establishing and maintaining the infrastructure for algae cultivation and conversion will be quite expensive. Regardless, the tremendous demand for transportation energy, increasing fossil-fuel prices and a lack of mechanisms for monetizing environmental performance in the US make it reasonable to expect that algae's excellent land use efficiency could render it financially attractive over the next several decades. Therefore, LCA and life cycle costing (LCC) studies will play a vital role for improving overall sustainability of algae-derived bioenergy systems.

\subsection{References}

Anasruron, D. F. D., Bade, O., Korner, I. "Nitrogen Recovery from Biogas Plant Digestates via Solid-Liquid Separation and Stripping. In Ramiran 2010 - Treatment and Use of Organic Residues in Agriculture, FAO European Cooperative: Lisbon, 2010.

Ansell, A. D., Raymont, J. E. G., Lander, K. F., Crowley, E., Shackley, P. "Studies on the Mass Culture of Phaeodactylum II. The Growth of Phaeodactylum and other Species in Outdoor Tanks." Limnology and Oceanography 8 (1963): 184-206.

Barclay, W. R., Nagle, N. J., Terry, K. L., Ellingson, S. B., Sommerfeld, M. R. “Characterization of Saline Groundwater Resource Quality for Aquatic Biomass Production: A Statistically-Based Approach." Water Research 22, no. 3 (1988): 373-379.

Batan, L., Quinn, J., Willson, B., Bradley, T. "Net Energy and Greenhouse Gas Emission Evaluation of Biodiesel Derived from Microalgae." Environmental Science \& Technology 44, no. 20 (2010): 7975-7980.

Becker, E. W. "Microalgae: Biotechnology and Microbiology." Cambridge University Press: Cambridge, 1994, vii, 293 p.

Benemann, J., Oswald, W. "Systems and Economic Analysis of Microalgae Ponds for Conversion of $\mathrm{CO}_{2}$ to Biomass - Final Report." U.S. Department of Energy: Pittsburgh, 1996, 201. 
Brennan, L., Owende, P. "Biofuels from Microalgae - A Review of Technologies for Production, Processing and Extractions of Biofuels and Co-products." Renewable and Sustainable Energy Reviews 14 (2010): 557-577.

Brown, L. M. "Uptake of Carbon Dioxide from Flue Gas by Microalgae." Energy Conversion and Management 37, no. 6-7 (1996): 1363-1367.

Brune, D. E., Lundquist, T. J., Benemann, J. R. "Microalgal Biomass for Greenhouse Gas Reductions: Potential for Replacement of Fossil Fuels and Animal Feeds." Journal of Environmental Engineering 135, no 11 (2009): 1136-1144.

Campbell, J. E., Lobell, D. B., Field, C. B. "Greater Transportation Energy and GHG Offsets from Bioelectricity than Ethanol." Science 2009.

Chisti, Y. "Biodiesel from Microalgae Beats Bioethanol." Trends in Biotechnology 26 (2008): 126-131.

Dale, B. E., Bals, B. D., Kim, S., Eranki, P. "Biofuels Done Right: Land Efficient Animal Feeds Enable Large Environmental and Energy Benefits." Environmental Science \& Technology 44, no. 22 (2010): 8385-8389.

Doucha, J., Straka, F., Lívanský, K. "Utilization of Flue Gas for Cultivation Microalgae (Chlorella sp.) in an Outdoor Open Thin-Layer Photobioreactor." Journal of Applied Phycology 17 (2005): 403-412.

Dunford, N., Temelli, F. "Extraction of Phospholipids from Canola with Supercritical Carbon Dioxide and Ethanol." Journal of the Amercian Oil Chemists' Society 72, no. 9 (1995): 10091015 .

Farrell, A. E., Plevin, R. J., Turner, B. T., Jones, A. D., O'Hare, M., Kammen, D. M. "Ethanol Can Contribute to Energy and Environmental Goals." Science 311, no. 5760 (2006): 506-508.

Goldman, J. C., Ryther, J. H., Williams, L. D. "Mass Production of Marine Algae in Outdoor Cultures." Nature 254, no. 5501 (1975): 594-595.

Golueke, C. G. “Anaerobic Digestion of Algae.” American Society for Microbiology, 1957.

Hall, C. A. S., Klitgaard, K. A. "The Need for a New, Biophysical-Based Paradigm in Economics for the Second Half of the Age of Oil." International Journal of Transdisciplinary Research 1, no. 1 (2006): 4-22.

Hall, C., Balogh, S., Murphy, D. "What is the Minimum EROI that a Sustainable Society Must Have?" Energies 2, no. 1 (2009): 25-47.

Hauck, J. T., Scierka, S. J., Perry, M. B. "Effects of Simulated Flue Gas on Growth of Microalgae." Preprints of Papers, American Chemical Society, Division of Fuel Chemistry 41, no. 4 (1996).

Hue, N. V., Sobieszczyk, B. A. "Nutritional Values of Some Biowastes as Soil Amendments." Compost Science and Utilization 7, no. 1 (1990): 34-41. 
ISO/TC207/SC5 ISO 14040: 2006. "Environmental Management/Life Cycle Assessment: Principles and Framework." International Organization for Standardization: Geneva, Switzerland, 2006.

Kadam, K. L. "Environmental Implications of Power Generation via Coal-Microalgae Cofiring. Energy 27, no. 10 (2002): 905-22.

Khoo, H. H., Tan, R. B. H. Life Cycle Investigation of $\mathrm{CO}_{2}$ Recovery and Sequestration.” Environmental Science and Technology 40, no. 12 (2006): 4016-4024.

Lardon, L., Helias, A., Sialve, B., Steyer, J. P., Bernard, O. "Life-Cycle Assessment of Biodiesel Production from Microalgae.” Environmental Science and Technology 43, no. 17 (2009): 64756481.

Laws, E. A., Taguchi, S., Hirata, J., Pang, L. "High Algal Production Rates Achieved in a Shallow Outdoor Flume.” Biotechnology and Bioengineering 28, no. 2 (1986): 191-197.

Lundquist, T. J., Woertz, I. C., Quinn, N. W. T., Benemann, J. R. “A Realistic Technology and Engineering Assessment of Algae Biofuel Production." California Polytechnic State University: San Luis Obispo, 2010, p 178.

Luo, D., Hu, Z., Choi, D. G., Thomas, V. M., Realff, M. J., Chance, R. R. "Life Cycle Energy and Greenhouse Gas Emissions for an Ethanol Production Process Based on Blue-Green Algae." Environmental Science \& Technology 44, no. 22 (2010): 8670-8677.

Mann, M., Spath, P. "A Life Cycle Assessment of Biomass Cofiring in a Coal-Fired Power Plant." Clean Technologies and Environmental Policy 3, no. 2 (2001): 81-91.

Masters, G. M. "Introduction to Environmental Engineering and Science, 3rd ed." Prentice Hall: Upper Saddle River, N.J., 2008.

Materassi, R., Tredici, M., Balloni, W. "Spirulina Culture in Sea-Water." Applied Microbiology and Biotechnology 19, no. 6 (1984): 384-386.

NREL, “US LCI Database Project: Final Phase I Report.” Franklin Associates, Sylvatica, 2002.

NREL, National Solar Radiation Database Update (1991-2005). In National Renewable Energy Laboratory, 2005.

Poirier, D. "Conveyor Dryers." In Handbook of Industrial Drying, Third Edition. CRC Press: 2006.

Raymond, L. "Initial Investigations of Shallow-Layer Algal Production System: Report to Hawaii Natural Energy Institute." University of Hawaii and the Department of Planning and Economic Development: Honolulu, Hawaii, 1977, p 27.

Redfield, A. C. "The Biological Control of Chemical Factors in the Environment." American Scientist 64 (1958), 205-221.

Roth, I. F., Ambs, L. L. "Incorporating Externalities into a Full Cost Approach to Electric Power Generation Life-Cycle Costing.” Energy 29, no. 12-15 (2004): 2125-2144. 
Samson, R., Leduy, A. "Biogas Production from Anaerobic Digestion of Spirulina maxima Algal Biomass.” Biotechnology and Bioengineering 24, no. 8 (1982): 1919-1924.

Samson, R., Leduy, A. "Influence of Mechanical and Thermochemical Pretreatments on Anaerobic Digestion of Spirulina maxima Algal Biomass." Biotechnology Letters 5, no. 10 (1983): 671-676.

Samson, R., Leduy, A. "Detailed Study of Anaerobic Digestion of Spirulina maxima Algal Biomass.” Biotechnology and Bioengineering 28, no. 7 (1986): 1014-1023.

Sanchez-Hernandez, E. P., Travieso-Curdoba, L. "Anaerobic Digestion of Chlorella vulgaris for Energy Production.” Resources, Conservation and Recycling 9, no. 1-2 (1993): 127-132.

Sander, K., Murthy, G. "Life Cycle Analysis of Algae Biodiesel." The International Journal of Life Cycle Assessment 15, no. 7 (2010): 704-714.

Sheehan, J., Camobreco, V., Duffield, J., Graboski, M., Shapouri, H. "Life Cycle Inventory of Biodiesel and Petroleum Diesel for Use in an Urban Bus." NREL, 1998, p 315.

Sialve, B., Bernet, N., Bernard, O. "Anaerobic Digestion of Microalgae as a Necessary Step to Make Microalgal Biodiesel Sustainable.” Biotechnology Advances 27, no. 4 (2009): 409-416.

Smith, V. H., Sturm, B. S. M., deNoyelles, F. J., Billings, S. A. "The Ecology of Algal Biodiesel Production." Trends in Ecology and Evolution 25, no. 5 (2009): 301-309.

Snare, M., Kubickova, I., Maki-Arvela, P., Eranen, K., Murzin, D. Y. "Heterogeneous Catalytic Deoxygenation of Stearic Acid for Production of Biodiesel." Industrial and Engineering Chemistry Research 45, no. 16 (2006): 5708-5715.

Spilling, K., Seppälä, J., Tamminen, T. "Inducing Autoflocculation in the Diatom Phaeodactylum tricornutum through $\mathrm{CO}_{2}$ Regulation." Journal of Applied Phycology (2010): 1-8.

Stephenson, A. L., Kazamia, E., Dennis, J. S., Howe, C. J., Scott, S. A., Smith, A. G. "Life-Cycle Assessment of Potential Algal Biodiesel Production in the United Kingdom: A Comparison of Raceways and Air-Lift Tubular Bioreactors.” Energy and Fuels 24, no. 7 (2010): 4062-4077.

Sukenik, A., Shelef, G. "Algal Autoflocculation - Verification and Proposed Mechanism." Biotechnology and Bioengineering 26, no. 2 (1984): 142-147.

Thomas, W. H., Seibert, D. L. R., Alden, M., Neori, A., Eldridge, P. "Yields, Photosynthetic Efficiencies and Proximate Composition of Dense Marine Microalgal Cultures II - Dunaliella primolecta and Tetraselmis suecica Experiments.” Biomass 5, no. 3 (1984): 211-225.

Thomas, J. D., Sterry, P. R., Patience, R. L. "Uptake and Assimilation of Short Chain Carboxylic Acids by Biomphalaria glabrata (Say), the Freshwater Pulmonate Snail Host of Schistosoma mansoni (Sambon)." Proceedings of the Royal Society of London, Series B, Biological Sciences 222, no. 1229 (1984): 447-476.

Wang, M. "The Greenhouse Gases, Regulated Emissions and Energy Use in Transportation (GREET) Model.” University of Chicago Argonne, LLC: Chicago, IL, 2010. 
Warman, P. R., Termeer, W. C. "Evaluation of Sewage Sludge, Septic Waste and Sludge Compost Applications to Corn and Forage: Yields and N, P and K Content of Crops and Soils." Bioresource Technology 96, no. 8 (2005): 955-961.

Weidema, B. "Ecoinvent Data v2.0.” http://www.ecoinvent.org/ (accessed September 2008).

Wild, D., Kisliakova, A., Siegrist, H. "Prediction of Recycle Phosphorus Loads from Anaerobic Digestion." Water Research 31, no. 9 (1997): 2300-2308.

Williams, P. R. D., Inman, D., Aden, A., Heath, G. A. "Environmental and Sustainability Factors Associated with Next-Generation Biofuels in the U.S.: What Do We Really Know?" Environmental Science and Technology 43, no 13 (2009): 4763-4775.

Yen, H.-W., Brune, D. E. "Anaerobic Co-digestion of Algal Sludge and Waste Paper to Produce Methane.” Bioresource Technology 98, no. 1 (2007): 130-134. 


\section{Chapter 4 \\ Comparison of Algae Cultivation Methods for Bioenergy Production Using a Combined Life Cycle Assessment and Life Cycle Costing Approach}

\subsection{Motivation}

In Chapter 2, the life cycle impacts of algae were evaluated in the context of cultivation for the generation of biomass. A functional unit of energy (317 GJ) was chosen as the basis for the analysis which reflected all energy and materials consumed directly onsite at the algae farm plus indirect energy and materials consumption associated with power production and other upstream processes. Burden results for algae were then compared with other terrestrial benchmark crops: corn, canola and switchgrass. It was found that algae cultivation impacts were dependent on nutrients availability and carbon dioxide, not algae yield and sunlight. This has shown that algae consumed more energy and water, emitted more GHG and leveraged land area more efficiently than the benchmarks. The analysis also assumed that all downstream processes for the conversion of algae to bioenergy carrier would not significantly change the result of the LCA given the difference between cultivation and conversion impacts. In Chapter 3, algae's system boundary was expanded (i.e., "well-to-wheel") to include all conversion unit operations in addition to modifying the functional unit. Functional unit modification was employed because results of Chapter 2 disregarded the contributions of converting algae to usable transportation fuels. The new functional units utilized were: (1) overall transportation energy per unit land area (i.e., VKT/ha) and (2) fuel-cycle impacts incurred per kilometer traveled (i.e., $\mathrm{MJ} / \mathrm{km}, \mathrm{m}^{3} / \mathrm{km}$, and $\mathrm{kg}$ $\mathrm{CO}_{2} \mathrm{eq} / \mathrm{km}$ ). Additionally, combinations of nutrient procurement scenarios and conversion pathways were assessed as a means of evaluating EROI. The analysis in Chapter 3 achieved three critical goals: (1) performed a more comprehensive LCA of algae relative to terrestrial crops, (2) analyzed various conversion schemes and (3) refined the results of Chapter 2 by highlighting the 
tradeoff in algae performance - higher VKT per hectare but at the same time larger impacts per kilometer.

Results of Chapters 2 and 3 have revolutionized current understanding on the environmental impacts of algae-to-bioenergy systems. However, it is important to note that in both of these analyses, whether sole algae cultivation process or a combination of cultivation-conversion modules, open pond (OP) system was assumed in growing the algae. Despite the numerous bench-scale explorations on algae cultivation, only a few pilot-scale investigations have dealt with the technical and economic feasibility of this process, let alone the various configuration possibilities of cultivation design (Benemann and Oswald, 1996; Weissman and Tillett, 1990; Kadam, 2002; Chisti, 2007; Masojidek et al., 2003; Lee and Low, 1992). Regardless, literature has generally focused on two primary culture configurations: OP systems or closed tubular photobioreactors (PBRs) (Chisti, 2007). OP systems are open shallow ponds exposed to the environment while PBRs consist typically of closed reactor or vessel isolated from the environment and thus growth conditions can easily be controlled.

Although a majority of studies on algae cultivation to date focused on OP systems, it is unclear which between the two configurations perform better in terms of life cycle burdens (Stephens et al., 2010). Additionally, if algae-to-bioenergy systems were to be implemented on an industrialscale in the near future to supplant fossil-based fuel sources, they must be economically viable. Currently, both the scientific community and the algae industry have no consensus as to which type of configuration provides the least environmental burdens and the least total cost per unit of algae-derived bioenergy. Environmental impacts associated with both of these configurations can easily be assessed using LCA, as performed in both Chapters 2 and 3. However, the evaluation of the full life cycle cost for each system can be accomplished using another tool, the life cycle costing (LCC) analysis. 


\subsection{Literature Review}

The challenge inherent to the appropriate choice of algae growth configuration lies in the fact that both OP systems and PBRS have their respective advantages and disadvantages. OP systems have lower costs and are easier to maintain (Benemann and Oswald, 2006; Fischer et al., 2011; Janssen et al., 2002). They are also easily deployed and scaled-up (Davis et al., 2011). On the other hand, they have distinct limitations including: limited light penetration, which produces unequal distribution of photosynthetically-active radiation (PAR) and lower yields, temperature fluctuations, contamination by wild type algae or bacteria and uncontrolled evaporation, which requires the addition of growth medium or water. These disadvantages can easily be avoided by using PBRs because they can be better controlled (Travieso et al., 2001) and can mitigate the problems of light penetration, temperature fluctuations, contamination and evaporation. PBRs also use "high-quality" algae (i.e., high thermal content and/or increased manageability). Still, the operations- and infrastructure-phase requirements of PBRs are far greater than those for OP systems (Molina-Grima et al., 2003).

Having established the critical advantages and disadvantages associated with algae cultivation in OP systems or PBRs, it is necessary to recapitulate all the LCAs and LCCs related to both systems as a first step in evaluating their relative sustainability for large-scale energy production. These are presented in the following sections.

\subsubsection{LCA on OP Systems / LCC on OP Systems}

There were at least nine LCA studies and eight LCC studies on OP systems published in literature to date. All of these OP analyses were either exclusively LCA or exclusively LCC. These studies have divergent results due to lack of normalization (Liu et al., 2011). Nevertheless, there were apparent trends. First, upstream impacts associated with $\mathrm{CO}_{2}$ and nutrients ( $\mathrm{N}$ and $\mathrm{P}$ ) delivery drove the overall cultivation phase burdens. This has led researches to suggest the use of 
reclaimed $\mathrm{CO}_{2}$ (from flue gas) and $\mathrm{N}, \mathrm{P}$ (from treated effluents) to improve overall LCA performance (Kadam, 2002; Sander and Murthy, 2010; Sturm and Lamer, 2011). Second, the choice of energy-carrier greatly affected LCA outcomes. Fourteen of the existing separate LCA and LCC on OP systems focused on biodiesel while other authors have suggested other energycarriers such as biocrude or bioethanol (Collet et al., 2011; Zamalloa et al., 2011). Even "coproducts" were considered to contribute significantly to total energy generation and financial benefits (Collet et al., 2011; Sander and Murthy, 2010; Shirvani et al., 2011; Sturm and Lamer, 2011; Fischer et al., 2011; Stephens et al., 2010; Zamalloa et al., 2011).

Energy analyses on OP system were inconclusive in terms of whether it is net energy-producing or net energy-consuming. For example, one study concluded that biodiesel production generated $0.13 \mathrm{MJ}$ per MJ consumed (Brentner et al., 2011) while another study obtained 4.3 MJ per MJ consumed (Lardon et al., 2009; Campbell et al., 2009). Financial analyses on OP systems were also substantially varied. The cost of OP-produced biodiesel ranged between \$20-200/GJ produced (Jorquera et al., 2010; Amer et al., 2011). This makes it challenging to conclude whether OP systems are economically tenable.

\subsubsection{LCA on PBRs}

Compared to OP systems, LCA and LCC studies on PBRs were scarce (Shirvani et al., 2011; Fischer et al., 2011; Stephens et al., 2010; Davis et al., 2011) and there has been no comprehensive LCC study published on the topic of PBR algae cultivation to date. This is because PBRs are more complex in design and some studies considered only one specific type of configuration (Chisti, 2007; Molina-Grima et al., 2003). There were only three LCA studies on horizontal tubular PBRs in literature to date: Luo et al. (2010); Batan et al. (2010); and Soretana and Landis (2011) - results of which reiterated trends observed in OP systems. Specifically, all analyses demonstrated that the use of recycled $\mathrm{CO}_{2}$ and nutrients significantly reduced energy use 
and GHG emissions. Luo et al. (2010) investigated on ethanol (Luo et al, 2010), Batan et al. (2010) emphasized the importance of PBR co-products (glycerin, fish feed) on overall energy and GHG balances (Batan et al., 2010) and Soretana and Landis (2011) noted that life cycle impacts associated with construction of the PBR infrastructure are a significant contributor to PBR energy use and GHG emissions (Soretana and Landis, 2011). PBR analyses had also indicated the system's significant EROI uncertainty. EROI values for PBR systems ranged from 1.1 MJ/MJ to $5 \mathrm{MJ} / \mathrm{MJ}$ (Batan et al., 2010; Luo et al., 2010).

\subsubsection{LCA on OP Systems versus PBRs / LCC on OP Systems versus PBRs / Combined LCA and LCC on OP Systems versus PBRs}

There were a number of separate LCAs and LCCs comparing OP systems and PBRs. LCA results from Jorquera et al. (2010) and Stephenson et al. (2010) indicated that OP systems delivered better EROI and GHG performances than analogous PBR systems (Jorquera et al., 2010; Stephenson et al., 2010). Similarly, LCC results from Amer et al. (2011), Davis et al. (2011) and Jorquera et al. (2010) suggested that the cost of PBR-derived algae energy may be roughly two times as high as in OP-derived sources (Amer et al., 2011; Davis et al., 2011; Jorquera et al., 2010) while Norsker et al. (2011) noted that some PBR systems may be economically advantageous compared to OP systems (Norsker et al., 2011). The only study that combined LCA and LCC in comparing OP systems and PBRs was conducted by Jorquera et al. (2010) (Jorquera et al., 2010); however, their analyses did not account for conversion of algae oil into a usable energy product (e.g., biodiesel) and they did not consider possible differences in lipid content between OP and PBR algae cultivation systems, even though this was presumed to be the chief advantage of PBR systems. 


\subsection{Methods}

This modeling effort provided a comprehensive LCA-based and LCC-based comparison between OP and PBR model algae cultivation systems using uniform "cradle-to-wheel" system boundaries. Similar assumptions applied in Chapter 3 were also applied here: (1) use of recycled $\mathrm{CO}_{2}, \mathrm{~N}$ and $\mathrm{P}(2)$ evaluation of non-diesel algal energy sources and (3) full accounting for algae co-products. This analysis also assessed a wide array of possible algae species that could be seeded in each cultivator system, all of which can be broadly classified into two types: (1) freshwater (FW) species (Chlorella sp.; Scenedesmus sp.) and (2) brackish-to-saline water (BSW) species (Phaeodactylum sp.; Tetraselmis sp.).

\subsubsection{Model Overview}

Detailed description of the model overview utilized in this analysis can be found in Section 3.3.1 of Chapter 3.

\subsubsection{Functional Unit}

The FU used in this study was 20,000 VKT per year since this constitutes the average distance traveled by one American via automobile per year (US DOT, 2007; Handy 2002). From Chapter 3, VKT was used as an appropriate metric of normalizing algae's fuel-cycle impacts (as $\mathrm{MJ} / \mathrm{km}$ or $\mathrm{kgCO}_{2} \mathrm{eq} / \mathrm{km}$ ) because it allows for a meaningful comparison between dissimilar biomass feedstocks and reflects the capability of each system to deliver usable transportation energy.

\subsubsection{System Description}

This analysis employed similar system description fully described in Figure 3.1 of Chapter 3. However, there were modifications, namely: (1) the evaluation of two different algae growth configurations (i.e., OP or PBR); (2) the assessment of two types of algae species inoculated to their respective culture mediums (i.e., FW or BSW); and (3) the use of two types of nutrient 
procurement scenarios, Scenario 1 (use of virgin $\mathrm{CO}_{2}$ ) and Scenario 4 (compressed $\mathrm{CO}_{2}$ from power plant flue gas with wastewater supplementation to counteract evaporation losses), in conjunction with Case B (biodiesel production with anaerobic digestion of the algae non-lipid residuals).

\subsubsection{Cultivation}

\subsubsection{Overview}

Both OP systems and PBRs analyzed in this study have been put forth as possibilities for use in large-scale algae-to-energy systems (Benemann and Oswald, 1996; Chisti, 2007; Molina et al., 2001; Acién-Fernandez et al., 2001; Torzillo et al., 2004; Travieso et al., 2001). The purported advantages of OP systems include reduced capital costs and annual operating costs relative to the PBR (Benemann and Oswald, 1996). PBRs, in contrast have the potential of achieving higher productivity and better lipid yields due to controlled environment free of contamination (Chisti, 2007; Molina et al., 2001; Acién-Fernandez et al., 2001; Torzillo et al., 2004; Travieso et al., 2001). Two types of growth media were also assessed in this study: FW and BSW. Both were included because there is literature documentation for each type of growth conditions. Many of the landmark pilot-scale demonstrations of sustained, outdoor algae cultivation have utilized wellcharacterized, easy-to-grow freshwater species (e.g., Chlorella and Spirulina) (Benemann and Oswald, 1996; Kadam, 2002; Weissman and Tillett, 1990). On the other hand, several more recent bench-scale and pilot-scale cultivation experiments have used BSW species (e.g., Phaeodactylum and Tetraselmis). This is especially true for PBR experiments, but unclear for OP systems since BSW species tend to have higher lipid concentrations (i.e., algae suitable for PBRs). BSW systems also minimize freshwater consumption, but they limit the amount of wastewater treatment plant (WWTP) effluent that can be used to supply nutrients (N and P) during algae cultivation. 
Thus, to encompass both growth configuration (OP or PBR) and growth medium (FW or BSW) to give rise to optimally sustainable algae-derived energy production, four possible combinations of cultivation scenarios were generated: OP-FW, OP-BSW, PBR-FW, and PBR-BSW.

\subsubsection{Algae Yields and RUE Values}

Algae dry yields (in "g DW/m²-day") were calculated as the product between RUE (in "g dry weight (DW)/MJ PAR") and PAR (in "MJ/m²-day"). All RUE values in this study were taken from outdoor algae cultivation trials using either OP or PBR. They were calculated using two methods: (1) ratio method - taking the direct ratio of reported dry algae yield (in "Mg dry weight $(\mathrm{DW}) / \mathrm{m}^{2}$-d") to PAR irradiance (in "MJ PAR $/ \mathrm{m}^{2}$-d") at a particular location; or 2) PE method conversion from reported photosynthetic efficiencies (PEs), using each author's documented proximate analysis, and assumed heat contents of $9.3 \mathrm{kcal} / \mathrm{g}$ lipid, $4.2 \mathrm{kcal} / \mathrm{g}$ carbohydrate, and $5.7 \mathrm{kcal} / \mathrm{g}$ protein. RUE values obtained via direct ratio method were reported by Goldman et al. (1975), Laws et al. (1986) and Materassi et al. (1983) (Goldman et al., 1975; Laws et al., 1986; Materassi et al., 1983) while those obtained via PE method were reported by Ansell et al. (1963), Laws et al. (1986a, 1986b), Raymond et al. (1977) and Thomas et al. (1984a, 1984b) (Ansell et al., 1963; Laws et al., 1986a, 1986b; Raymond et al., 1977; Thomas et al., 1984a, 1984b).

RUE values and other pertinent biomass characteristics of algae strains grown in each of the four analyzed systems were presented in Tables 4.1, 4.2, 4.3 and 4.4. Average annual algae and lipid yields for each modeled system were also presented in Table 4.5. 
Table 4.1. RUE and other pertinent biomass characteristics of algae strains suitable for growth in freshwater open pond systems (OP-FW). Model inputs were assigned to triangular distributions, as noted in the bottom three rows.

\begin{tabular}{|c|c|c|c|c|}
\hline Algae & $R U E, g$ DW/MJ PAR ${ }^{a}$ & $\begin{array}{r}\text { Ash } \\
\text { Content, } \\
\%\end{array}$ & $\begin{array}{r}\text { Lipid } \\
\text { Content, } \\
\% \\
\end{array}$ & Sources \\
\hline Chlorella sp. & $\begin{array}{l}0.60,0.60,1.08,0.78 \\
1.19,1.78,1.88,1.97\end{array}$ & 5.6 & 14.0 & $\begin{array}{c}\text { B\&O (1996); W\&T (1990) } \\
\text { Kadam (2002); Yu et al. (2011) }\end{array}$ \\
\hline Chlorella sp. & $2.27,2.63,1.75,0.53$ & & 30.0 & Goldman and Ryther (1975) \\
\hline Chlorella pyrenoidosa & & & 2.0 & Goldman and Ryther (1975) \\
\hline Chlorella vulgaris & & & 18.0 & Goldman and Ryther (1975) \\
\hline Scenedesmus dimorphus & & & 28.0 & Goldman and Ryther (1975) \\
\hline Spirulina maxima & & & 6.5 & Goldman and Ryther (1975) \\
\hline Scenedesmus obliquus & & & 13.0 & Goldman and Ryther (1975) \\
\hline Spirulina platensis & & & 12.0 & Matsui et al. (1977) \\
\hline Spirulina platensis & & & 6.5 & Goldman and Ryther (1975) \\
\hline Scenedesmus quadricauda & & & 1.9 & Goldman and Ryther (1975) \\
\hline Minimum & 0.53 & & 1.9 & \\
\hline Likeliest & 1.40 & 5.6 & 13.4 & \\
\hline Maximum & 2.63 & & 30.0 & \\
\hline
\end{tabular}

a Radiation use efficiency, in units of "g algae dry-weight (DW) per MJ photosynthetically active radiation."

Table 4.2. RUE and other pertinent biomass characteristics of algae strains suitable for growth in brackish-to-saline open pond systems (OP-BSW). Assumed salinity is roughly 2-3\%, representative of abundant groundwater resources in the Southwestern USA (Barclay et al., 1988). Model inputs were assigned to triangular distributions, as noted in the bottom three rows.

\begin{tabular}{|c|c|c|c|c|}
\hline Algae & RUE, g DW/MJ PAR ${ }^{a}$ & $\begin{array}{r}\text { Ash } \\
\text { Content, } \\
\%\end{array}$ & $\begin{array}{r}\text { Lipid } \\
\text { Content, } \\
\%\end{array}$ & Sources \\
\hline $\begin{array}{l}\text { Amphiphora, Amphora, } \\
\text { Phaeodactylum }\end{array}$ & 1.79 & 12 & & Goldman and Ryther (1975) \\
\hline Cyclotella & 3.98 & & 11.4 & B\&O (1996); Laws et al. (1986a) \\
\hline Dunaliella & 1.52 & & 20.3 & Thomas et al. (1984b) \\
\hline Nitzchia & 2.41 & & 23.8 & B\&O (1996); G\&R (1975) \\
\hline Phaeodactylum & 3.24 & & 18.8 & Thomas et al. (1984a) \\
\hline Phaeodactylum & 3.76 & & 7.6 & Ansell et al. (1963) \\
\hline Phaeodactylum & 6.08 & & & Raymond et al. (1977) \\
\hline Tetraselmis & 1.17 & & 15.8 & $\begin{array}{l}\text { B\&O (1996); G\&R (1975) } \\
\text { Ansell et al. (1963) }\end{array}$ \\
\hline Tetraselmis & 2.10 & & & Materassi et al. (1983); G\&R (1975) \\
\hline Tetraselmis & 2.68 & & 20.6 & Thomas et al. (1984b); G\&R (1975) \\
\hline Tetraselmis & 3.67 & & & Laws et al. (1986a); G\&R (1975) \\
\hline Tetraselmis & 5.14 & & 14.1 & Laws et al. (1986b); G\&R (1975) \\
\hline Minimum & 1.17 & & 7.6 & \\
\hline Likeliest & 3.13 & 12 & 16.6 & \\
\hline Maximum & 6.08 & & 23.8 & \\
\hline
\end{tabular}


Table 4.3. RUE and other pertinent biomass characteristics of algae strains suitable for growth in freshwater photobioreactor systems (PRB-FW). Model inputs were assigned to triangular distributions, as noted in the bottom three rows.

\begin{tabular}{|c|c|c|c|c|}
\hline Algae & $R U E, g$ DW/MJ PAR ${ }^{a}$ & $\begin{array}{r}\text { Ash } \\
\text { Content, } \\
\%\end{array}$ & $\begin{array}{r}\text { Lipid } \\
\text { Content, } \\
\%\end{array}$ & Sources \\
\hline Chlorella emersonii & & & $25.0,34.0$ & Scragg et al. (2002) \\
\hline Chlorella pyrenoidosa & $2.20,2.64$ & 5.6 & 30.0 & Lee and Low (1991); Yu et al. (2011) \\
\hline Chlorella sp. & & & 33.0 & Chiu et al. (2008) \\
\hline Chlorella vulgaris & & & 14.0 & Elvi et al. (2010) \\
\hline Chlorella vulgaris & & & 26.0 & Widjaja, Chien and Ju (2009) \\
\hline Chlorella vulgaris & & & $28.0,58.0$ & Scragg et al. (2002) \\
\hline Scenedesmus almeriensis & & & 12.0 & Sánchez et al. (2008) \\
\hline Scenedesmus sp. & & & 9.0 & Yoo et al. (2010) \\
\hline Spirulina platensis & $\begin{array}{r}0.68,0.72,0.93,0.95 \\
1.14\end{array}$ & 8.5 & $16.6,30.0$ & Torzillo et al. (2004); Feinberg (1984) \\
\hline Spirulina platensis & $2.67,5.96$ & & $16.6,30.0$ & Travieso et al. (2001) \\
\hline Minimum & 0.68 & 5.6 & 9.0 & \\
\hline Likeliest & 1.99 & 7.1 & 26.3 & \\
\hline Maximum & 5.96 & 8.5 & 58.0 & \\
\hline
\end{tabular}

a Radiation use efficiency, in units of "g algae dry-weight (DW) per MJ photosynthetically active radiation."

Table 4.4. RUE and other pertinent biomass characteristics of algae strains suitable for growth in brackish- to- saline photobioreactor systems (PRB-BSW). Model inputs were assigned to triangular distributions, as noted in the bottom three rows.

\begin{tabular}{|c|c|c|c|c|}
\hline Algae & $R U E, g$ DW/MJ PAR ${ }^{a}$ & $\begin{array}{r}\text { Ash } \\
\text { Content, } \\
\%\end{array}$ & $\begin{array}{r}\text { Lipid } \\
\text { Content, } \\
\% \\
\end{array}$ & Sources \\
\hline Botryococcus braunii & & 14.3 & 26.0 & Sánchez et al. (2008) \\
\hline Botryococcus barunii & & & 33.0 & Ge, Liu and Tian (2011) \\
\hline Chlorococcum littorale & & & 15.0 & Hu et al. (1998) \\
\hline Haematococcus pluvialis & 8.22 & & 27.8 & $\begin{array}{c}\text { Garcia-Malea Lopez et al. (2006) } \\
\text { Damiani et al. (2010) }\end{array}$ \\
\hline Nannochloropsis sp. & & & 60.0 & Gudin and Chaumont (1991) \\
\hline Nannochloropsis sp. & & & 32.0 & Rodolfi et al. (2008) \\
\hline Nannochloropsis sp. & & & 33.0 & Zittelli et al. (2000) \\
\hline Phaeodactylum tricornutum & $2.22,2.51,3.17,3.51$ & & 25.0 & Chisti, 2007; Molina et al. (2001) \\
\hline Phaeodactylum tricornutum & $\begin{array}{l}2.41,2.41,2.45,2.61 \\
2.80,2.94,3.06,3.17 \\
3.17,3.19,3.33,3.51\end{array}$ & & 25.0 & $\begin{array}{c}\text { Chisti, 2007; Acién-Fernandez } \\
\text { et al. (2001) }\end{array}$ \\
\hline Spirulina platensis & & & 42.0 & Morist et al. (2001) \\
\hline Minimum & 2.22 & & 15.0 & \\
\hline Likeliest & 3.22 & 14.3 & 32.4 & \\
\hline Maximum & 8.22 & & 60.0 & \\
\hline
\end{tabular}

${ }^{a}$ Radiation use efficiency, in units of "g algae dry-weight (DW) per MJ photosynthetically active radiation." 
Table 4.5. Summary of RUE values, lipid contents, biomass yields, lipid yields and nutrient demands for the four systems analyzed in this study. RUE and lipid content are "likeliest values" from respective triangular distributions. Biomass yield and lipid yield are annual averages, as taken from respective models. $\mathrm{N}$ (nitrogen), $\mathrm{P}$ (phosphorus) and $\mathrm{CO}_{2}$ demands are based on algae yields and assumed stoichiometry.

\begin{tabular}{rrrrrrrr}
\hline System & $\begin{array}{r}\text { Likeliest } \\
\text { RUE, } \\
\text { g DW/MJ } \\
\text { PAR }\end{array}$ & $\begin{array}{r}\text { Likeliest } \\
\text { Lipid } \\
\text { Content, \% }\end{array}$ & $\begin{array}{r}\text { Biomass } \\
\text { Yield, }\end{array}$ & $\begin{array}{r}\text { Lipid Yield, } \\
\text { Mg/ha-yr }\end{array}$ & $\begin{array}{r}\text { N Demand, } \\
\text { Mg/ha-yr }\end{array}$ & $\begin{array}{r}\text { P Demand, } \\
\text { Mg/ha-yr }\end{array}$ & $\begin{array}{r}\mathrm{CO}_{2} \\
\text { Demand, } \\
\mathrm{Mg} / \mathrm{ha}-\mathrm{yr}\end{array}$ \\
\hline OP-FW & 1.40 & 13 & 41.6 & 4.7 & 1.5 & 0.5 & 92.3 \\
OP-BSW & 3.10 & 17 & 92.1 & 12.9 & 3.8 & 1.2 & 205.8 \\
PBR-FW & 1.99 & 26 & 59.1 & 13.1 & 2.4 & 0.8 & 134.8 \\
PBR-BSW & 3.22 & 32 & 95.7 & 26.1 & 4.2 & 1.2 & 220.9 \\
\hline
\end{tabular}

\subsubsection{Nutrients Procurement}

Fertilizer requirements were supplied as per Section 2.3.1.5 of Chapter 2. Resulting values were summarized in Table 4.5. To reiterate, Scenario 4 of Chapter 3 applies (i.e., virgin fertilizers with supplementation from municipal wastewater effluent). Ammonium phosphate, $\left(\mathrm{NH}_{4}\right)_{3} \mathrm{PO}_{4}$, was used as principal $\mathrm{N}$ and $\mathrm{P}$ source since this formulation was found to minimize upstream environmental burdens per mole of algae compared to other commercially available options (Weissman and Tillett, 1990). Additional $\mathrm{N}$ was supplied as urea to avoid incurring a P excess.

A fraction of the growth medium flowing through each cultivation system (OP or PBR) comprises municipal wastewater effluent. This offsets some portion of the nutrient demand. Effluent nutrient concentrations were assigned to the following triangular distributions: $15-25-35$ $\mathrm{mg} / \mathrm{L}$ total $\mathrm{N}$ (minimum, likeliest, maximum), and 4-7-10 $\mathrm{mg} / \mathrm{L}$ total $\mathrm{P}$ (minimum, likeliest, maximum) (Carey and Migliaccio, 2009). N and P concentrations were multiplied by the volume of effluent used within each algae system to compute total masses of each nutrient delivered from wastewater (offsets). These were then deducted from the total nutrient demands to compute net nutrients demand. 
As for $\mathrm{CO}_{2}$ demand, Scenario 4 of Chapter 3 also applies (i.e., $\mathrm{CO}_{2}$ is delivered as unaltered, compressed flue gas obtained from an external source). Resulting values were summarized in Table 4.5. The energy of compression per unit mass of flue gas is defined in Equation 3.1 and the value was computed to be $39 \mathrm{~kJ} / \mathrm{kg}$ flue gas. Since it was assumed that flue gas comprises approximately $12.5 \% \mathrm{CO}_{2}$ (Kadam, 2002), total energy demand for carbon dioxide procurement is $314 \mathrm{~kJ} / \mathrm{kg} \mathrm{CO}$. Roughly two-thirds of this value was allocated to algae production, while the remainder was allocated to the emitting coal-fired power plant. This allocation was performed using system boundaries expansion, on an energy basis since it was assumed that both entities (the algae farm and the coal-fired power plant) have an interest in capturing $\mathrm{CO}_{2}$ emissions. Finally, $\mathrm{CO}_{2}$ utilization efficiency was assigned to the following lognormal distribution for the OPS systems: mean $=0.7$ and standard deviation $=0.1$. Use of this parameter reflects the likelihood that some $\mathrm{CO}_{2}$ delivered to open pond will escape to the atmosphere. An assumed $\mathrm{CO}_{2}$ use efficiency of 1.0 was used for both PBR systems, since these are closed to the atmosphere.

A portion of the total $\mathrm{CO}_{2}$ demand for each system was offset by $\mathrm{CO}_{2}$ produced from the combustion of methane derived from anaerobic digestion and residual $\mathrm{CO}_{2}$ generated from the digestion process. This decreased the amount of $\mathrm{CO}_{2}$ which had to be purchased as direct flue gas.

\subsubsection{Generic Water Balance}

Table 4.6 summarizes a water balance for all four modeled systems. 
Table 4.6. Water balance for algae cultivation, conversion and post-processing. $Q$ 's are volumetric flow rates of algae slurry (algae + water) in units of L/ha* yr, as numbered according to Figure 3.2.

\begin{tabular}{|c|c|c|c|c|}
\hline Flows/Modeled Systems & OP-FW & OP-BSW & PBR-FW & PBR-BSW \\
\hline Raw water intake (WWTP effluent), Q1 & $11,405,078$ & $11,407,298$ & $11,405,848$ & $11,407,455$ \\
\hline $\begin{array}{l}\text { Influent to cultivation (WWTP effluent or } \\
\text { brackish groundwater), Q2 }\end{array}$ & $53,181,097$ & $105,505,872$ & $71,340,872$ & $109,199,386$ \\
\hline Effluent from cultivation, $Q 3$ & $43,123,881$ & $95,488,593$ & $61,297,516$ & $99,184,926$ \\
\hline Effluent from autoflocculation, Q4 & $3,920,353$ & $8,680,781$ & $5,572,501$ & $9,016,811$ \\
\hline $\begin{array}{l}\text { Effluent from thickening into } \\
\text { homogenization, Q5 }\end{array}$ & 388,503 & 860,258 & 552,230 & 893,558 \\
\hline $\begin{array}{l}\text { Effluent from homogenization into lipid } \\
\text { extraction, } Q 5 A\end{array}$ & 388,503 & 860,258 & 552,230 & 893,558 \\
\hline $\begin{array}{l}\text { Effluent from lipid extraction into } \\
\text { anaerobic digestion, } Q 5 B\end{array}$ & 383,350 & 846,120 & 537,851 & 864,896 \\
\hline Influent to dewatering, $Q 6$ & 355,614 & 787,432 & 505,480 & 817,913 \\
\hline Water content of sludge, Q7 & 35,401 & 78,389 & 50,320 & 81,423 \\
\hline Recycle from dewatering, Q8 & 320,213 & 709,043 & 455,160 & 736,490 \\
\hline Purge, Q9 & $1,279,572$ & $1,238,805$ & $1,265,423$ & $1,235,927$ \\
\hline Recycle from thickening, $Q 10$ & $3,531,849$ & $7,820,524$ & $5,020,272$ & $8,123,254$ \\
\hline Recycle from autoflocculation, Q11 & $39,203,528$ & $86,807,812$ & $55,725,015$ & $90,168,115$ \\
\hline Recycle before purge, Q12 & $42,735,377$ & $94,628,336$ & $60,745,286$ & $98,291,368$ \\
\hline Recycle after purge, Q13 & $41,455,806$ & $93,389,531$ & $59,479,863$ & $97,055,441$ \\
\hline Evaporation from cultivation/cooling pond, Q14 & $10,090,105$ & $10,090,105$ & $10,090,105$ & $10,090,105$ \\
\hline Evaporation from $P B R, Q 15$ & NA & NA & 0 & 0 \\
\hline
\end{tabular}

\subsubsection{OP Operations}

The following subsections document cultivation-phase inputs and selected outputs for the OP-FW and OP-BSW models. Note that operations energy and materials requirements were first computed on a "per-ha" basis and then multiplied by the direct land use that would be required to produce one functional unit $(20,000$ VKT per year) from each system. Direct land use requirements were 0.09 ha for OPS-FW and 0.04 ha for OPS-BSW.

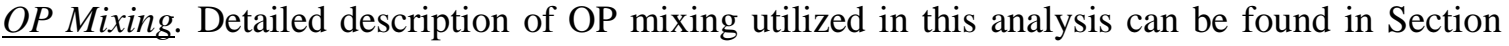
2.3.2.3.1 of Chapter 2. Energy consumption for mixing was calculated to be $1,167 \mathrm{MJ} / \mathrm{ha}{ }^{*} \mathrm{yr}$. 
OP Liquids Pumping. Detailed description of OP liquids pumping utilized in this analysis can be found in Section 2.3.2.3.3 of Chapter 2. Pumping energy demands are 19,762 MJ/ha*yr for OPFW and 41,244 MJ/ha*yr for OP-BSW. The difference between these two values was attributed to the difference in volumetric flow rates per hectare; whereby, increased algae yields per hectare mediated increased volumetric flows. Pumps were assumed to be of the centrifugal, singlesuction type with a 40-kW nominal power rating (for consistency with available pump data from the ecoinvent life cycle database).

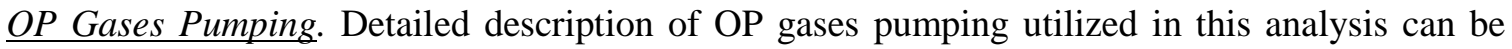
found in Section 3.3.2.1 of Chapter 3, represented by Scenario 3, Equation 3.1. The resulting value for $W_{C}\left(39 \mathrm{~kJ} / \mathrm{kg}\right.$ flue gas) was divided by $12.5 \%$ to adjust for the mass fraction of $\mathrm{CO}_{2}$ in flue gas and then multiplied by the masses of flue gas required for each OP system. Final electricity demands for $\mathrm{CO}_{2}$ delivery were $28,976 \mathrm{MJ} / \mathrm{ha} * \mathrm{yr}$ for OP-FW and 64,596 MJ/ha*yr for OP-BSW. These energy demand values are exclusively for delivering the $\mathrm{CO}_{2}$. The additional upstream burdens associated with offsite compression of the flue gas for use in the OP cultivation system was excluded in this study since it was assumed that the coal-fired power plant emitting $\mathrm{CO}_{2}$ is collocated with the algae cultivation pond.

\subsubsection{PBR Operations}

The modeled PBR was of the type "enclosed tubular horizontal photobioreactors." Mixing in this type of PBR is generally achieved using some combination of flue gas and liquid pumping. Significant pumping energy is required to move the algae suspension through the irradiated enclosed vessels comprising a PBR and also to move the algae suspension into and out of the vertical degassing system. This induces significant turbulence, which in turn, ensures that nutrients, algae and gases are well mixed. It has been demonstrated that the bulk velocity must be carefully controlled to ensure optimal algae growth. Overly fast flows can engender too much 
turbulence and shear the algae cell walls, killing the organisms. In contrast, overly slow flows increase travel time through the system such that each particle of fluid takes longer to reach the degasser. This can lead to premature depletion of dissolved $\mathrm{CO}_{2}$ and unacceptably high dissolved $\mathrm{O}_{2}$ concentrations, which inhibit photosynthesis and ultimately reduce algae yields. The PBR systems used for this model were thus designed based on control of bulk velocity.

Operational energy and material requirements for PBR systems were first computed on a "per-ha" basis and then multiplied by the direct land use that would be required to produce one functional unit (20,000 VKT per year) from each system. Direct land use requirements were 0.05 for PBRFW and 0.03 for PBR-BSW.

$\underline{\text { PBR Liquids Pumping. Literature values were used to construct triangular distributions of both }}$ bulk velocity $(u)$ and pipe inner diameter $\left(d_{i}\right)$. Previously documented bulk velocities were on the range 626 - 1980 m/h (Chisti, 2007; Molina et al., 2001; Acién-Fernandez et al., 2001; Torzillo et al., 2004; Travieso et al., 2001), and likeliest value was set to the overall average (1303 m/h). Pipe inner diameters $d_{i}$ were found to be on the range $0.02-0.05 \mathrm{~m}$ (Chisti, 2007; Molina et al., 2001; Acién-Fernandez et al., 2001; Torzillo et al., 2004; Travieso et al., 2001), and likeliest value was set to overall average $(0.03 \mathrm{~m})$.

Here, $u$ and $d_{i}$ were used to compute volumetric flow rate $Q$ in the PBR system according to Equation 4.1, the Continuity Equation.

$$
Q=u \times A_{P I P E}=u \times \pi \times\left(\frac{d_{i}}{2}\right)^{2} \quad \text { Equation } 4.1
$$


$Q$ was then cross-referenced against a pump curve (Geankoplis, 2003) to determine acceptable head loss per pump, $H_{L-P U M P}$. It was found that the average $Q$ value resulting from Equation 4.1 $\left(0.92 \mathrm{~m}^{3} / \mathrm{h}\right)$ was within the recommended range for a centrifugal single-stage, single-suction pump with nominal power rating equal to $0.5 \mathrm{hp}(0.37 \mathrm{~kW})$ (Perry, 1997). This head loss for this pump was approximately $13 \mathrm{~m}(43 \mathrm{ft})$.

The number of pumps required per 1-ha PBR was computed by dividing head loss per pump $\left(H_{L-}\right.$ $\left.{ }_{P U M P}=13 \mathrm{~m}\right)$ into total system head loss $\left(H_{L}\right)$, where $H_{L}$ is computed using Equation 4.2.

$$
H_{L}=H_{L-M A J O R}+H_{L M I N O R}+\Delta z \quad \text { Equation } 4.2
$$

Here, $H_{L}$ is the total head loss in the PBR system, $H_{L-M A J O R}$ is major head losses due to friction at the pipe walls (both solar collector pipes + degassing risers + degassing downcomers), $H_{L-M I N O R}$ is minor head losses due to valves and elbow fittings and $\Delta z$ is elevation difference between the horizontal solar collector tubes and each degassing reservoir $(0.75 \mathrm{~m})$.

Major losses $H_{L-M A J O R}$ for the entire PBR system were computed using Equation 4.3, as taken from Geankoplis (2003) (Geankoplis, 2003).

$$
H_{L-M A J O R}=f \times \frac{L}{d_{i}} \times \frac{U^{2}}{2 g} \quad \text { Equation } 4.3
$$

Here, $f$ is friction factor, which was selected on the basis of estimated roughness-to-diameter ratio $(\varepsilon / d i)$ for a polymethyl methacrylate $(\mathrm{PMMA})$ pipe $\approx 10^{-5}$. This value, characteristic of a "smooth pipe", was used in conjunction with estimated Reynolds number $(\sim 8,000)$ to select an appropriate $f$ value (0.008 from a Moody diagram presented by Geankoplis, 2003) (Geankoplis, 
2003). Bulk velocity $u$ and pipe inner diameter $d_{i}$ were assigned values from the distributions described in a previous section. $g$ is the acceleration of gravity. $L$ is total PBR pipe run length per 1-ha irradiated surface area $\left(S A_{I}\right)$. To compute $L$, it was first necessary to compute $S A_{I}$. This was done using Equation 4.4, wherein $P A R$ is photosynthetically active radiation (in $\mathrm{MJ} / \mathrm{m}^{2}$ ) and $R U E$ is radiation use efficiency (in $\mathrm{Mg} / \mathrm{MJ}$ )

$$
S A_{I}=\frac{\text { Functional Unit }}{\Sigma(P A R \times R U E)} \quad \text { Equation } 4.4
$$

Having computed $S A_{I}$ (that land area which would need to be covered with PBRs to produce one functional unit), this value was then used to compute total run length $L$. This was done using Equation 4.5, wherein $S A_{I}$ is irradiated surface area (in $\mathrm{m}^{2}$ ), $D$ is tube inner diameter (in $\mathrm{m}$ ) and $L$ is total tube length (in m). Dividing by two in the denominator accounts for the fact that only half of the tube length is irradiated at any given time.

$$
S A_{I}=\frac{\pi D L}{2} \quad \text { Equation } 4.5
$$

All calculations were done on a "per ha" basis and then scaled by direct land use; i.e., number of ha required to produce one functional unit per year. Inputs to Equation 4.5 are thus: $S A_{I}=10,000$ $\mathrm{m}^{2}$ (such that all burdens can be scaled to 1 ha of irradiated surface) and $D_{i}=0.03 \mathrm{~m}$ (likeliest value from range noted above).

This formulation conceptualizes the irradiated surface area as a single, very long, very thin pipe of thickness $d_{i}$. In reality, the total run length is folded back and forth into shorter segments, which must be separated some distance from each other to accommodate turns at each end. Resulting $L$ was $212,207 \mathrm{~m} / \mathrm{ha}$ for both PBR systems. 
For accurate estimation of $H_{L-M A J O R}$, it was also necessary to compute the distance traversed by solar collector medium through as many degassing units are required per ha in each type of PBR system; i.e., 13.2 units per 1-ha PBR-FW and 8.1 units per 1-ha PBR-BSW. Based on an assumed riser height of $1 \mathrm{~m}$ and an assumed downcomer height of $0.5 \mathrm{~m}$, the total distance traversed per degassing unit is $1.5 \mathrm{~m}$. It was thus necessary to add $9 \mathrm{~m} / \mathrm{ha}$ to run length $L$ for PBR-FW and $15 \mathrm{~m} / \mathrm{ha}$ to run length L for PBR-BSW. These additional distances were negligible compared to the magnitude of $L$, so it was assumed that both PBR-FW and PBR-BSW share a single value for $H_{L-M A J O R}, 392 \mathrm{~m} / \mathrm{ha}$.

Minor losses $H_{L-M I N O R}$ in the modeled PBR system were computed according to Equation 4.6.

$$
H_{L-M I N O R}=n \times K \times \frac{U^{2}}{2 g} \quad \text { Equation } 4.6
$$

Here, $n$ is the number of channels comprising total pipe run length $L$. This quantity was computed based on $50 \mathrm{~m}$ as an acceptable channel length from literature reports; i.e., $n=L \div 50$ (Chisti, 2007; Molina et al., 2001; Acién-Fernandez et al., 2001; Torzillo et al., 2004; Travieso et al., 2001). Each channel is connected to its neighboring channels using elbow connectors, which necessitates the use of an elbow constant, $K=1.5$ in Equation 4.6 (Geankoplis, 2003). $u$ is average velocity as taken from the distribution described in a previous paragraph and $g$ is the acceleration of gravity. $H_{L-M I N O R}$ was $43 \mathrm{~m}$ in both PBR systems.

Following determination of $H_{L-M A J O R}, H_{L-M I N O R}$, and $\Delta z$, total head loss was $436 \mathrm{~m} / \mathrm{ha}$ for both types of PBR systems. This value was used to compute how many pumps of the nominal $0.5 \mathrm{hp}$ rating are required per 1-ha of irradiated surface area, and it was equal to total head loss divided by head loss per pump. The resulting for $n_{P U M P}$ was 33.30 .5 -hp pumps. Power consumption was 
thus $16.7 \mathrm{hp} / \mathrm{ha}(12.4 \mathrm{~kW} / \mathrm{ha})$. This is roughly equivalent to the amount of power that could be delivered by $0.3140-\mathrm{kW}$ pumps. This is noteworthy only insofar as LCA impact factors are only available for one specific $40-\mathrm{kW}$ pump; and it is more reasonable to expect that actual systems would use a larger number of smaller pumps to achieve the same amount of power output. Assuming pump operating time is 7,920 h/year $(24 \mathrm{~h} / \mathrm{d} \times 330 \mathrm{~d} /$ year $)$, electricity demand for liquids pumping is roughly $353,669 \mathrm{MJ} / \mathrm{ha} * \mathrm{yr}$ in both PBR systems.

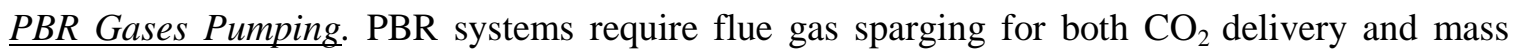
transfer (mixing) within the tubes. Energy demand calculations for both functions are summarized in the paragraphs below.

Annual energy consumption for PBR flue gas delivery was calculated using the same approach outlined for OP flue gas delivery in Section 4.3.2.5 (OP gases pumping). Resulting values were 42,313 MJ/ha*yr for the PBR-FW system and 69,327 MJ/ha*yr for the PBR-BSW system.

Gas pumping energy for PBR flue gas mass transfer was required to move the algae suspension within the solar collector tubes. This quantity $(G k W)$ was calculated using Equation 4.7 (Molina et al., 2001; Molina-Grima et al., 2003).

$$
G k W=\frac{M * Q_{G} * h_{R} * g}{\eta * V} \quad \text { Equation } 4.7
$$

Here, $G k W$ is the required power rating for pumping flue gas (in $\mathrm{kW}$ ), $M$ is the mass of the liquid inside the reactor (in $\mathrm{kg}$ ), $Q_{G}$ is the volumetric flow rate of the pumped gas at STP, $h_{R}$ is the height of the riser, $g$ is acceleration due to gravity $\left(9.8 \mathrm{~m} / \mathrm{s}^{2}\right), \eta$ is the gas pump efficiency $(75 \%)$ and $V$ is the volume of the liquid $\left(\mathrm{m}^{3}\right)$. Resulting values were $467 \mathrm{MJ} / \mathrm{ha} * \mathrm{yr}$ for the PBR-FW and 
$762 \mathrm{MJ} / \mathrm{ha}$ *yr for the PBR-BSW. The difference between these values reflects increased $\mathrm{CO}_{2}$ demand in the PBR-BSW on a per-ha basis. Also, since these values were so small compared to the energy demands for flue gas delivery, it is possible flue gas delivery alone would ensure adequate PBR mixing. To be conservative, these two quantities were added together.

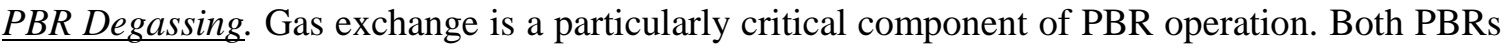
used in this study were based on one popular type of degassing system, whereby the algae suspension exits the clear solar collection tubes, is pumped up a riser into an degassing reservoir that is open to the atmosphere (expelling accumulated dissolved $\mathrm{O}_{2}$ as it traverses the reservoir), and then flows by gravity back down into the solar collector tubes to begin another pass through the solar collector. Nutrients were added to the system via the degassing reservoir, and a mixture of air and $\mathrm{CO}_{2}$ (as flue gas) is sparged into the algae suspension as it exits the degassing reservoir. In this work, the portion of a 1-ha PBR system serviced by a single degasser is referred to as a PBR “module."

Overly long travel times between successive degassings may result in decreased productivity; therefore, it was necessary to determine what number of degassing units (degasser + riser pipe length + downcomer pipe length) are required for a 1-ha PBR system. This was based on the maximum allowable time between successive degassings (effectively the retention time of each degassing module), $t^{*}$. Acceptable $t^{*}$ values were obtained from the literature and fit to two separate triangular distributions: minimum $=11.1$ hours, likeliest $=12.4$ hours, and maximum $=$ 13.6 hours for PBR-FW (Scragg et al., 2002) and minimum $=16.4$ hours, likeliest $=20.0$ hours, and maximum $=27.0$ hours for PBR-BSW (Molina et al., 2001). For known values of both $t^{*}$ and culture velocity $u$, total run length per PBR module $\left(l^{*}\right)$ can be calculated. Resulting values were on the order of 16,100 m per module of PBR-FW and 26,060 m per model of PBR-BSW. These 
were then divided into total run length $L$ to compute the number of degassing modules required per 1-ha PBR: 13.2 degassers per ha PBR-FW and 8.1 degassers per ha PBR-BSW.

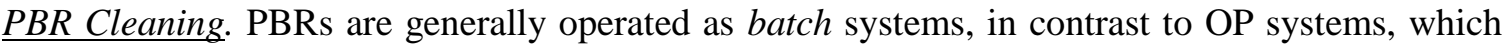
are operated as continuous systems. To prevent bacterial, fungal, or other contamination in a PBR system, it is advisable to clean the system after every harvest (Borowitzka, 1997). In order to compute the number of cleanings required per year, it was first necessary to compute time per batch. Overly long batch times may result in self-shading, which decreases productivity; however, overly short batch times may increase system down time and necessitate excessively frequent washing. For this model, batch times were taken from several literature sources and found to be on the order of $0.6-6$ days (Borowitzka, 1997). These values were fit to a triangular distribution, using 2.4 days per harvest as likeliest value. It was also assumed that some 35 days per year are required as mandatory downtime for cleaning and other PBR maintenance functions. The total number of harvests per calendar year was thus computed as follows: $365 \mathrm{~d} / \mathrm{yr}-35 \mathrm{~d} / \mathrm{yr}$ for cleaning $=330$ operational $\mathrm{d} / \mathrm{yr} \div 2.4 \mathrm{~d} /$ harvest $\approx 138$ harvests/yr. It was also assumed that the cleaning solution comprises dilute bleach in water $(0.01 \% \mathrm{NaOCl} \mathrm{m} / \mathrm{m})$ and that the entire PBR system is filled with this solution one time per cleaning and then emptied.

\subsubsection{Conversion and Post-Processing}

\subsubsection{Preliminary Dewatering}

Detailed description of preliminary dewatering utilized in this analysis can be found in Section 3.3.2.5 of Chapter 3. Electricity demands for algae dewatering as a result of Equation 3.2 of Chapter 3 were: 7,600 MJ/ha*yr for OP-FW; 7,362 MJ/ha*yr for OP-BSW; 7,494 MJ/ha*yr for PBR-FW and 7,351 MJ/ha*yr for PBR-BSW. All models have similar output suspension concentration $(100 \mathrm{~g} / \mathrm{L})$, such that differences in energy consumption reflect variations in culture volumes to be processed (i.e., $\mathrm{Q}_{5}$ in Table 4.6). 


\subsubsection{Homogenization}

Detailed description of homogenization utilized in this analysis can be found in Section 3.3.3.1 of Chapter 3. Resulting homogenization energy demands were as follows: 52,060 MJ/ha*yr for OPFW; 115,274 MJ/ha*yr for OP-BSW; 73,999 MJ/ha*yr for PBR-FW and 119,737 MJ/ha*yr for PBR-BSW. The variations can be attributed to dramatic differences in culture volumes per ha (reflecting underlying differences in algae yield per ha) among the four evaluated systems.

\subsubsection{Lipid Extraction and Refining}

Detailed description of lipid extraction and refining utilized in this analysis can be found in Section 3.3.4.2 of Chapter 3. Heat, $\mathrm{NaOH}$ and wash water demands were as follows: $155 \mathrm{MJ}$ heat/Mg algae oil, $24 \mathrm{~kg} \mathrm{NaOH} / \mathrm{Mg}$ algae oil (assuming $9.5 \% \mathrm{NaOH}$ by mass) and $0.15 \mathrm{~m}^{3}$ wash water/Mg alga oil. These values were based on published transesterification reports (NREL, 2002).

\subsubsection{Transesterification and Biodiesel Post-Processing}

Detailed description of transesterification and biodiesel post-processing utilized in this analysis can be found in Section 3.3.4.3 of Chapter 3.

\subsubsection{Biodiesel Combustion}

As noted in Table 4.5, biodiesel yields were $4.4 \mathrm{Mg} / \mathrm{ha}{ }^{*} \mathrm{yr}$ for OP-FW, $12.1 \mathrm{Mg} / \mathrm{ha} * \mathrm{yr}$ for OPBSW, $12.3 \mathrm{Mg} / \mathrm{ha}^{*} \mathrm{yr}$ for PBR-FW and $24.6 \mathrm{Mg} / \mathrm{ha}{ }^{*} \mathrm{yr}$ for PBR-BSW. Further detailed description of biodiesel combustion utilized in this analysis can be found in Section 3.3.4.4 of Chapter 3. 


\subsubsection{Anaerobic Digestion}

The algae anaerobic digestion model used in this study was identical to that used for Case B of Chapter 3 (Section 3.3.3). Further detailed description of anaerobic digestion utilized in this analysis can be found in Section 3.3.3.2 of Chapter 3. Electricity demands were on the order of 38,000-41,000 MJ/ha*yr for all modeled systems. In general, systems producing large volumes of non-lipid algae residuals exhibited higher electricity demands for anaerobic digestion. Heat demand for digestion was approximately $1,500 \mathrm{MJ} / \mathrm{ha} * \mathrm{yr}$ in all four systems.

\subsubsection{Digestate Dewatering and Nutrients Recycle}

Detailed description of digestate dewatering and nutrients recycle utilized in this analysis can be found in Section 3.3.3.3 of Chapter 3. BFP electricity demands were 25,569 MJ/ha*yr for OPFW; 41,734 MJ/ha*yr for OP-BSW; 29,509 MJ/ha*yr for PBR-FW and 38,306 MJ/ha*yr for PBR-BSW. BSW systems exhibited higher BRP electricity demands per hectare than FW systems, presumably because BSW algae possess higher non-digestible (ash) contents.

Recycling of liquid digestion effluent offsets some $17-21 \%$ of stoichiometric $\mathrm{N}$ and $8-17 \%$ of stoichiometric P demands for all four evaluated systems. Similarly, recycle of solid digestate to supplant commercial fertilizer use in terrestrial agriculture yields various "fertilizer offsets." These offsets were computed based on the bioavailability of $\mathrm{N}$ and $\mathrm{P}$ in digestate solids relative to commercial fertilizers and impact factors from ecoinvent. In all four cases, offsets were expressed as amounts of ammonium triphosphate $\left(\mathrm{H}_{12} \mathrm{~N}_{3} \mathrm{O}_{4} \mathrm{P}\right.$ for $\mathrm{N}$ and $\left.\mathrm{P}\right)$ and urea $\left(\mathrm{N}_{2} \mathrm{H}_{4} \mathrm{CO}\right.$ for additional N) that could be replaced by algae digestate: $0.02 \mathrm{Mg} / \mathrm{ha} * \mathrm{yr} \mathrm{H}_{12} \mathrm{~N}_{3} \mathrm{O}_{4} \mathrm{P}$ and $0.19 \mathrm{Mg} / \mathrm{ha} * \mathrm{yr}$ $\mathrm{N}_{2} \mathrm{H}_{4} \mathrm{CO}$ for OPS-FW; $0.05 \mathrm{Mg} / \mathrm{ha}{ }^{*} \mathrm{yr} \mathrm{H}_{12} \mathrm{~N}_{3} \mathrm{O}_{4} \mathrm{P}$ and $0.41 \mathrm{Mg} / \mathrm{ha} * \mathrm{yr} \mathrm{N}_{2} \mathrm{H}_{4} \mathrm{CO}$ for OPS-BSW; 0.03 $\mathrm{Mg} / \mathrm{ha} * \mathrm{yr} \mathrm{H}_{12} \mathrm{~N}_{3} \mathrm{O}_{4} \mathrm{P}$ and $0.23 \mathrm{Mg} / \mathrm{ha}^{*} \mathrm{yr} \mathrm{N}_{2} \mathrm{H}_{4} \mathrm{CO}$ for PBR-FW; and $0.05 \mathrm{Mg} / \mathrm{ha}{ }^{*} \mathrm{yr} \mathrm{H}_{12} \mathrm{~N}_{3} \mathrm{O}_{4} \mathrm{P}$ and $0.35 \mathrm{Mg} / \mathrm{ha}{ }^{*} \mathrm{yr} \mathrm{N}_{2} \mathrm{H}_{4} \mathrm{CO}$ for PBR-BSW. 


\subsubsection{Methane Combustion and $\mathrm{CO}_{2}$ Recycle}

Detailed description of methane combustion and $\mathrm{CO}_{2}$ recycle utilized in this analysis can be found in Section 3.3.3.5 of Chapter 3. Methane yields were 5.8, 12.3, 7.1, and 10.7 Mg/ha* $\mathrm{yr}$ for the OP-FW, OP-BSW, PBR-FW and PBR-BSW systems, respectively. Corresponding electricity yields were 287,$551 ; 616,104 ; 355,384$ and 534,224 MJ/ha*yr.

It was assumed that $\mathrm{CO}_{2}$ arising from methane combustion and the $\mathrm{CO}_{2}$ fraction of digestionderived biogas would be recycled for use during algae cultivation, thus offsetting some $\mathrm{CO}_{2}$ demand. $\mathrm{CO}_{2}$ mass flows from biogas directly were computed using the $\mathrm{CO}_{2}$ volumetric fraction noted in Table 3.4 of Chapter 3. $\mathrm{CO}_{2}$ mass flows from methane combustion were computed assuming complete combustion and stoichiometric conversion (i.e., $44 \mathrm{~g} \mathrm{CO}_{2}$ per $18 \mathrm{~g} \mathrm{CH}_{4}$ combusted). Total recycled $\mathrm{CO}_{2}$ was $19.3 \mathrm{Mg} / \mathrm{ha}$ *yr for OP-FW, $41.4 \mathrm{Mg} / \mathrm{ha}$ *yr for OP-BSW, 23.9 Mg/ha*yr for PBR-FW and 35.9 Mg/ha*yr for PBR-BSW. These quantities accounted for $16-21 \%$ of each system's stoichiometric $\mathrm{CO}_{2}$ demands (see Table 4.5).

\subsubsection{Infrastructure}

The following paragraphs summarize calculations of infrastructure requirements for large-scale algae cultivation. All materials required to construct and operate an OP or PBR system could be annualized over a 30-year time horizon. This was done to facilitate direct yearly comparison between the two types of growth configurations, whereby $1 / 30$ th of each system's infrastructure burdens were added to its annual operational burdens. Operational requirements were first computed on a "per-ha" basis and then multiplied the direct land use that would be required to produce one functional unit $(20,000 \mathrm{VKT}$ per year) from each system. This was also done for capital requirements. To recap, direct land uses for each system are as follows: 0.09 ha for OPFW, 0.04 ha for OP-BSW, 0.05 for PBR-FW, and 0.03 for PBR-BSW. 


\subsubsection{OP Cultivation Infrastructure}

Materials required for the construction of an OP algae cultivation system are: polypropylene (PP), aggregates and polyvinyl chloride (PVC). Equipment needed for its operations are: water pumps, flue gas pumps (for $\mathrm{CO}_{2}$ delivery) and paddle wheels. All OP cultivation infrastructure materials were computed on a "per-ha" basis and then scaled to the functional unit by multiplying through by direct land use for each system.

Liner. It was assumed that a PP geotextile would be used to line certain portions of each OP, since it has been demonstrated that liners prevent erosion and percolation of culture medium through the earthen base. It was decided that only $5 \%$ of the basic OP geometry described by Benemann and Oswald (1996) should be lined, because suitable geotextiles are quite expensive (Benemann and Oswald, 1996). Figure 4.1 depicts a slightly modified version of the basic 1-ha OP module (Benemann and Oswald, 1996), wherein walkways have been configured in regular geometric shapes for easy calculations of areal surfaces, and peripheral/walkway areas have been subtracted from the gross OP area. The resulting mass of polypropylene required as liner was found to be 5,520 kg/ha. Assuming the environmental burdens for this and other materials can be amortized over a 30 -year useful life, the annualized liner requirement is $184 \mathrm{~kg} / \mathrm{ha} * \mathrm{yr}$. This value was multiplied by OP direct land uses and then the life cycle impact factors from the ecoinvent database to compute energy use and other environmental burdens associated with manufacture of the required liners.

Aggregates. Gravel aggregates are used to stabilize the pond base of an OP and to prevent erosion of the compacted soil near the paddle wheels. The aggregate layer also serves as an interface layer (secondary barrier) between the culture medium and the pond bed. For this study, it was assumed that a $0.05-\mathrm{m}$ thick layer of medium-sized, concrete construction-quality gravel was placed underneath $5 \%$ of the OPS base area, principally underneath the paddle wheels. This 
coverage required 22,380 $\mathrm{kg}$ aggregates per 1-ha OP. Assuming the environmental burdens for this and other materials can be amortized over a 30-year useful life, the annualized aggregate requirement is $746 \mathrm{~kg} / \mathrm{ha}^{*} \mathrm{yr}$. This value was multiplied by OP direct land uses and life cycle impact factors from the ecoinvent database to compute energy use and other environmental burdens associated with manufacture of the required aggregates.

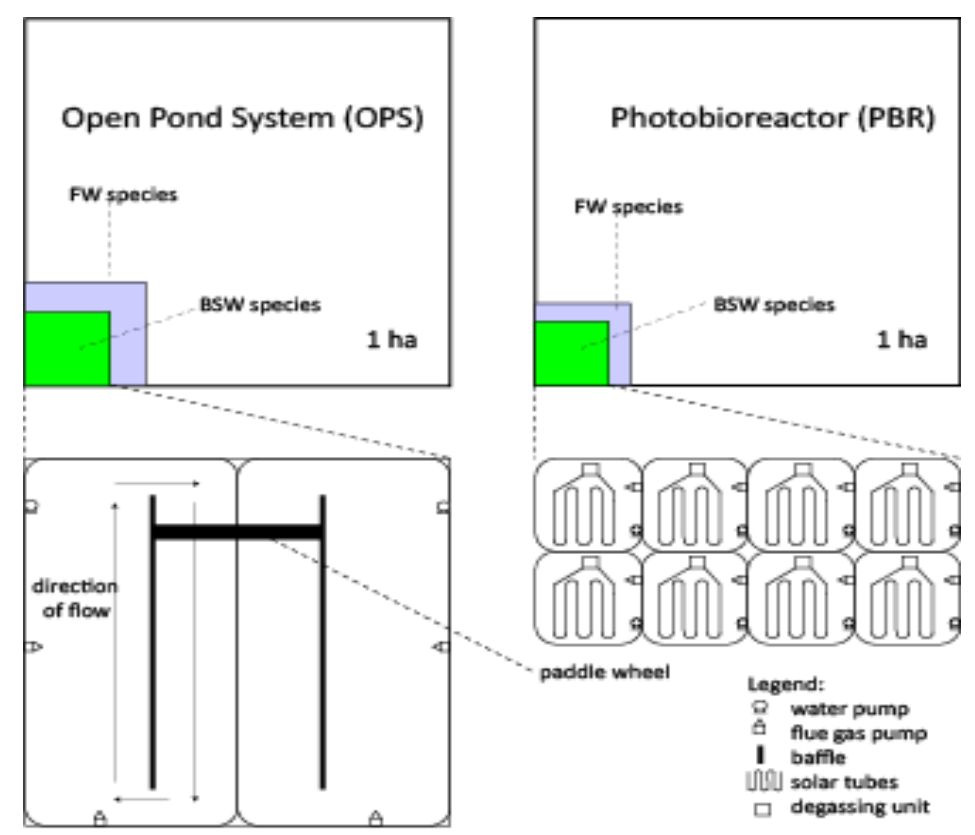

Figure 4.1. Top view of a 1-ha OP module used in this study, as adapted from a layout described by Benemann and Oswald (1996) (Benemann and Oswald, 1996). 5\% of the total OP growth area was lined with polypropylene geotextile. Top view of a 1-ha PBR system as described by Molina et al. (2001) and Acién-Fernandez et al. (2001) (Molina et al., 2001; Acién-Fernandez et al., 2001). Each 1-ha system comprises of 8 PBR modules, each of which contains a long solar collector tube and a degasser unit.

Piping. It was assumed that PVC piping would be used for all conveyances of culture medium, nutrients, flue gas and air in the OP system. The total mass of PVC required for each 1-ha module was calculated based on the total length and thickness of each pipe and PVC density of 1.35 $\mathrm{g} / \mathrm{cm}^{3}$ (Perry, 1997). 
(1) Liquid Pipes. The pipe thickness required for conveyance of culture medium into and out of the OP system was computed using Barlow's Formula (Equation 4.8) (Perry, 1997), wherein: $t_{M I N}$ is minimum acceptable pipe thickness (in inches), $P$ is the internal pressure (in $\mathrm{lb}_{\mathrm{f}} / \mathrm{in}^{2}, \mathrm{psi}$ ), $D$ is the outside diameter (in inches), and $S$ is PVC material design stress ( $\mathrm{lb}_{\mathrm{f}} / \mathrm{in}^{2}, \mathrm{psi}$ ) (Perry, 1997).

$$
t_{M I N}=\frac{P D}{2 S} \quad \text { Equation } 4.8
$$

Values for Equation 4.8 were as follows: $P=275,790 \mathrm{~N} / \mathrm{m}^{2}$ (40 psi), based on inlet and outlet pressures of 1 and 2.72 atm, respectively (to be compatible with pump head loss calculations above), $D=3.5$ in and $S=2,000$ psi for PVC 2120 (Perry, 1997). Resulting $t$ value was 0.035 in. Comparing this value with pipe specifications for "off-the-shelf" commercial products, the closest available thickness for PVC 2120 is 0.135 in $(0.0034 \mathrm{~m})$ (Perry, 1997). Final specifications for the OP water pipes were thus as follows: nominal size $=3$ in, schedule 40 , outer diameter $=3.5$ in, $t=0.135$ in. A conservative estimate for total tube length was $100 \mathrm{ft} / \mathrm{ha}(30.48 \mathrm{~m} / \mathrm{ha})$. Taken together, these dimensions correspond to PVC masses of $1.1 \mathrm{~kg} / \mathrm{ha} * \mathrm{yr}$ for both OP models, after amortizing over 30 years.

(2) Gas Pipes. The pipe thickness required for flue gas conveyance was also computed using Equation 4.8. It was assumed that the internal pressure required for flue gas transport is $20 \%$ that of required for water $(40 \times 0.20=8$ psi). Values for Equation 4.8 were thus as follows: $P=$ $55,158 \mathrm{~N} / \mathrm{m}^{2}$ (8 psi), $D=2.875$ and $S=2,000$ psi for PVC 2120 (Perry, 1997). Resulting $t$ value was 0.0058 in. Comparing this value with pipe specifications for "off-the-shelf" commercial products, the closest available thickness for PVC 2120 is 0.11 in $(2.8 \mathrm{~mm})$. Final specifications for the OP gas pipes were thus as follows: nominal size $=2.5$ in, schedule 40 , outer diameter $=$ 
$2.875 \mathrm{in}, \mathrm{t}=0.11 \mathrm{in}$. Total tube length was $2624 \mathrm{ft} / \mathrm{ha}(800 \mathrm{~m} / \mathrm{ha})$. These dimensions correspond to PVC masses of $22.2 \mathrm{~kg} / \mathrm{ha} * \mathrm{yr}$ for both OP systems, after amortization over 30 years.

Total PVC demand is on the order of $23.3 \mathrm{~kg} / \mathrm{ha}^{*} \mathrm{yr}$ for both OP systems, assuming materials burdens can be annualized over 30 year. This mass was multiplied by direct land uses and then by life cycle impact factors from the ecoinvent database to compute energy use and other environmental burdens associated with manufacture of the required PVC.

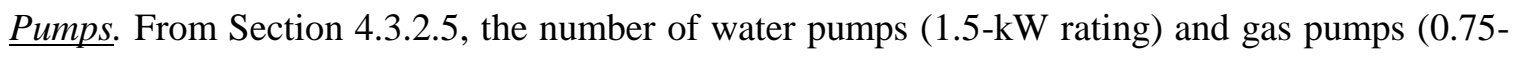
$\mathrm{kW}$ rating) required per 1-ha OP pond area were as follows: 0.5 water pump and 1.4 gas pump for OP-FW and 1.0 water pump and 3.0 gas pump for OP-BSW. These values were scaled by the direct land use (ha) required to produce one functional unit and then multiplied by life cycle impact factors from the ecoinvent database to compute energy use and other environmental burdens associated with manufacture of the required pump. It must be noted that the burdens calculated for both water and flue gas pumps were reported on an annual basis since it was assumed that the same pumps were used each year for 30 years.

Paddle Wheels. The paddle wheel design used for this study was based on Benemann and Oswald (1996) (Benemann and Oswald, 1996). This comprises a cylindrical six-bladed PVC paddle wheel with blade diameter equal to 0.5 and total length of $24.5 \mathrm{~m}$. It was assumed that the six "spiked" blades comprise $25 \%$ of the volume of a cylinder with the same diameter. The total mass of PVC required to produce 10 paddle wheels/ha was $64,950 \mathrm{~kg}$ for both OP-FW and OPBSW. Assuming that the environmental burden for this material can be amortized over 30 years, the annualized burden is computed using 2,165 $\mathrm{kg}$ PVC/ha*yr times PVC life cycle impact factors from the ecoinvent database. 


\subsubsection{PBR Cultivation Infrastructure}

Materials required for the construction of a PBR algae cultivation system are: polymethyl methacrylate (PMMA), steel, concrete and PVC. Equipment needed for its operations are: water pumps and flue gas pumps (for $\mathrm{CO}_{2}$ delivery). All PBR cultivation infrastructure materials were computed on a "per-ha" basis and then scaled to the functional unit by multiplying through by direct land use for each system.

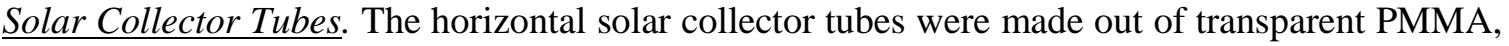
specifically cast acrylic tubing. This material provides suitable transparency and also withstands temperature fluctuations within the expected operational range, $35-70{ }^{\circ} \mathrm{C}$. As noted in Section 4.3.2.6, tube inner diameters on the range $0.02-0.05 \mathrm{~m}$. Average tube thickness was $0.32 \mathrm{~cm}$. Total run length $L$ was calculated based on irradiated surface area $S A_{I}$ as in Equation 4.5. Corresponding PMMA demand was computed based on solar collector dimensions (thickness and length) and an assumed PMMA density of $\left(1.18 \mathrm{~g} / \mathrm{cm}^{3}\right)$ (Perry, 1997). The resulting required mass was $2,786 \mathrm{~kg} / \mathrm{ha}{ }^{*} \mathrm{yr}$ (after amortization over 30 years) for both PBR systems. This mass was multiplied by direct land use in each PBR system and then life cycle impact factors from the ecoinvent database to compute energy use and other environmental burdens associated with manufacture of the PMMA required produce one functional unit in both PBR systems.

Degassing Units. PBR degassing units were constructed from PMMA. These units comprise one elevated PMMA tank (degassing reservoir) plus two PMMA pipes for use as riser (inlet) and downcomer (exit).

(1) Reservoir. The principal design parameter for the degassing units is flow length through the reservoir, since this dictates the amount of time available for gas exchange with the atmosphere. Based on previously published reports, this parameter was assigned to the following triangular 
distribution: minimum $=0.20 \mathrm{~m}$, maximum $=0.22 \mathrm{~m}$, and likeliest value $=0.21 \mathrm{~m}$. The heights of the degasser side walls $\left(H_{1}\right.$ and $\left.H_{2}\right)$ were $0.98 \mathrm{~m}$ and $0.6 \mathrm{~m}$, respectively and all five faces of the degassing reservoir were assumed to be $1 \mathrm{~cm}$ thick. With these dimensions, a single degassing reservoir holds up to $0.0017 \mathrm{~m}^{3}$ of culture medium. This volume corresponds to a weight of $141 \mathrm{~N}$ and internal pressures as follows: 3,998 N/m² (0.004 MPa) (base basis); 1,795 N/m² (0.002 MPa) $\left(H_{l}\right.$ basis $)$ and $2,932 \mathrm{~N} / \mathrm{m}^{2}(0.003 \mathrm{MPa})\left(H_{2}\right.$ basis $)$. All internal pressures were several orders of magnitude less than the strength limits for PMMA (tensile strength $=69 \mathrm{MPa}$ according to ASTM D638, flexural strength rupture $=114 \mathrm{MPa}$ according to ASTM D790 and shear strength $=62$ MPa according to ASTM D732) (ASTM, 2011a).

The volume of PMMA cast acrylic sheet required per degasser was computed based on the above dimensions and converted to mass using an assumed density of $1.18 \mathrm{~g} / \mathrm{cm}^{3}$ (Perry, 1997). This mass was then multiplied by the number of degassing units $\left(n_{D E G A S S E R S}\right)$ required per PBR system to compute total PMMA demand for degassing reservoirs. These values were $2.56 \mathrm{~kg} / \mathrm{ha} * \mathrm{yr}$ for PBR-FW and $1.58 \mathrm{~kg} / \mathrm{ha}^{*} \mathrm{yr}$ for PBR-BSW, after amortizing over the assumed 30-year asset lifetime. Required PMMA masses per ha were multiplied by direct land use requirements for each PBR system and then multiplied by life cycle impact factors from the ecoinvent database to compute energy use and other environmental burdens associated with manufacture of materials for the required degassing reservoirs.

(2) Risers and Downcomers. Degassing risers and downcomers are constructed out of PMMA cast acrylic tube with inner and outer diameters of 0.07 and $0.08 \mathrm{~m}$, respectively. It was assumed that these have different heights, 1 and $0.5 \mathrm{~m}$ respectively, such that the degassing reservoir has a slight downward slope. This allows the algae suspension to flow partly by gravity through the degassing reservoir. Multiplying the total riser + downcomer run length by annular crosssectional area yielded the volume of PMMA required per degassing unit, some $0.01 \mathrm{~m}^{3}$. This was 
then multiplied by the total number of degassing units required per PBR unit and PMMA density. Total masses of PMMA for risers and downcomers were $0.55 \mathrm{~kg} / \mathrm{ha} * \mathrm{yr}$ for PBR-FW and 0.34 $\mathrm{kg} / \mathrm{ha}$ * yr for PBR-BSW, after amortization over 30 years. These masses were then multiplied by direct land uses for each PBR and life cycle impact factors from the ecoinvent database to compute energy use and other environmental burdens associated with manufacture of the required degassing piping.

Braces and Connections. The PBR design used in this study requires several types of braces and connections, all of which are made from steel. The following paragraphs summarize design calculations for these items.

(1) Braces. It was assumed that the PMMA solar collector tubes would require reinforcement across their run length in order to bear the combined load of their own weight and that of the algae suspension. The Euler-Bernoulli Formulation (Equation 4.9) was used to compute maximum acceptable distance between two successive braces based on PMMA material properties and solar collector tube specifications (Perry, 1997)

$$
\sigma=\frac{M y}{I_{x}} \quad \text { Equation } 4.9
$$

Here, $\sigma$ is bending stress (in $\mathrm{N} / \mathrm{m}^{2}$ ), $M$ is moment about the neutral axis (in N-m), $y$ is the vertical distance from the neutral axis to the point of maximum flexure (in $\mathrm{m}$ ), and $I_{x}$ is the second moment of area with respect to the neutral axis $x\left(\right.$ in $\left.\mathrm{m}^{4}\right)$. Equation 4.9 requires the following assumptions and simplifications:

- There are no shear stresses, torsional stresses, buckling, or axial loads in this system.

- PMMA's maximum stress occurs below its yield stress, such that it obeys Hooke's Law. 
- The solar collectors comprise slender, straight tubes with constant cross section and isotropic and homogeneous material properties.

Specific inputs for Equation 4.9 were as follows: $M=5.425 \times 10^{2}$ (based on the estimated weight of pipe and algae slurry), $y=0.005 \mathrm{~m}, I_{x}=(\pi / 64) \times(0.036-0.034)=4.64 \times 10^{-8} \mathrm{~m}^{4}$. The resulting value is $\sigma=581,897 \mathrm{~N} / \mathrm{m}^{2}$. Equating this value with PMMA's flexural strength rupture (114 MPa) (Perry, 1997) and assuming that maximum acceptable vertical deflection at the centroid of each tube segment is $5 \mathrm{~mm}$, the maximum allowable distance between successive supports $\left(L_{\text {SUPPORT }}\right)$ is $14 \mathrm{~m}$. Applying a $30 \%$ factor of safety, $L_{S U P P O R T} \approx 10.8 \mathrm{~m}$. Thus, steel supports are located at roughly 11-m intervals across the entire pipe run length $L$, and the number of steel supports $\left(n_{\text {SUPPORTS }}\right)$ per ha is roughly $(L / 11)+1$. The value of $n_{\text {SUPPORTS }}$ is $1,498 /$ ha for PBR-FW and 2,421/ha for PBR-BSW.

Each support consists of the following assemblage: one steel support ring wrapped around the outside of the pipe, plus two steel legs. Rings are $1-\mathrm{cm}$ wide by $1-\mathrm{cm}$ deep, with the same circumference as the solar collector tubes. Legs are $0.15 \mathrm{~m}$ tall with a square cross-sectional area equal to $2.25 \mathrm{~cm}^{2}$ (i.e., $1.5 \mathrm{~cm} \mathrm{x} 1.5 \mathrm{~cm}$ ). From these dimensions and an assumed density of 7.8 $\mathrm{g} / \mathrm{cm}^{3}$ (Perry, 1997), the mass of steel required for support assemblages (rings and legs) is 12,150 $\mathrm{kg} / \mathrm{ha}{ }^{*} \mathrm{yr}$ for both PBR systems.

(2) Elbows. Steel elbows are used to link each 50-m pipe segment to its neighbors. The number of elbows required is thus equal to $n_{\text {CHANNELS }}-1$ (Section 4.3.2.6). Elbows were assumed to be 0.25 $\mathrm{cm}$ thick by $0.11 \mathrm{~m}$ long, with inner diameter equal to the outer diameter of the solar collector tubes. From these dimensions and an assumed density of $7.8 \mathrm{~g} / \mathrm{cm}^{3}$ (Perry, 1997), the mass of steel required for elbows is $1,110 \mathrm{~kg} / \mathrm{ha}^{*} \mathrm{yr}$. 
(3) Flanges. Flange fittings were also constructed from steel. One flange fitting comprises 0.10 $\mathrm{kg}$ steel (one support ring plus two bolts). The total mass of steel required for PBR flange assemblages is $65 \mathrm{~kg} / \mathrm{ha} * \mathrm{yr}$, after amortization over 30 years.

(4) Total Steel Demand. The total amount of steel required for rings, legs, elbows and flanges was $507 \mathrm{~kg} / \mathrm{ha}$ *yr for both PBR systems, assuming that the environmental burden of the steel could be amortized over 30 years. The annual steel mass was then multiplied by both direct land use and life cycle impact factors from the ecoinvent database to compute annualized environmental burdens.

Foundations and Cooling Ponds. Braces (supports) for the solar collector tubes require foundations and the tubes themselves are generally immersed within shallow cooling ponds to maintain operating temperatures within the range $20-30{ }^{\circ} \mathrm{C}$ (Posten, 2009). It was assumed that both the foundations and the cooling ponds were fashioned from concrete. Design calculations for these items are summarized in the following paragraphs.

(1) Foundations. Foundations were rectangular in cross section, extending $20 \%$ farther in each direction than the cross section of each steel leg (see section on Braces and Connections) to ensure stability. The foundations hold both legs together. Dimensions were thus $7.2 \mathrm{~cm}$ long by $1.8 \mathrm{~cm}$ wide. The depth of each foundation was $0.06 \mathrm{~m}$. Based on these dimensions and the magnitude of $n_{\text {SUPPORTS }}$ noted above, concrete demand for support foundations was $3,171 \mathrm{~kg} / \mathrm{ha}$ for both PBR-FW and PBR-BSW.

(2) Cooling Ponds. Cooling ponds were assigned length and width that are $10 \%$ greater than the corresponding dimensions of required irradiated surface area $\left(S A_{I}\right)$ per 1-ha PBR. The crosssectional area was thus $178 \mathrm{~m} \times 53 \mathrm{~m}=9,049 \mathrm{~m}^{2}$ per 1-ha $S A_{I}$. Cooling ponds were also assumed 
to be $0.20 \mathrm{~m}$ deep, to accommodate the maximum combined height of support legs plus pipe outer diameter. Walls and the underlying concrete slab were assumed to be $0.01 \mathrm{~m}$ thick. Cooling pond concrete demand based on these dimensions was $211,200 \mathrm{~kg} / \mathrm{ha}$. The resulting volume was $96 \mathrm{~m}^{3} /$ ha or $3.2 \mathrm{~m}^{3} / \mathrm{ha}^{*} \mathrm{yr}$ after amortization over 30 years.

(3) Total Concrete Demand. The total volume of concrete required for foundations and cooling ponds is $97.5 \mathrm{~m}^{3} / \mathrm{ha}(214,500 \mathrm{~kg} / \mathrm{ha})$ for both PBR-FW and PBR-BSW. Assuming that these burdens can be amortized over 30 years, annualized concrete demand is $3.25 \mathrm{~m}^{3} / \mathrm{ha}$ *yr. This volume was multiplied by life cycle impact factors from the ecoinvent database to compute energy use and other environmental burdens associated with manufacture of required concrete elements.

Pumps. From Section 4.3.2.6, the number of water pumps required per 1-ha PBR was calculated based on the total head loss in the system and the acceptable head loss per pump. Both PBR systems require 33.30 .5 -hp water pumps/ha. This is roughly the same power output achieved by $0.3140-\mathrm{kW}$ pumps/ha. Multiplying this value by direct land use yields the number of water pumps required to deliver one functional unit in each PBR.

The number of flue gas pumps required per 1-ha PBR was set equal to the number of degassing stations required per 1-ha PBR. This was computed based on acceptable time between degassings, as noted in section on PBR Degassing: 7.8 gas pumps/ha PBR-FW and 12.8 gas pumps/ha PBR-BSW. Multiplying this value by direct land use yields the number of gas pumps required to deliver one functional unit in each PBR.

The total number of pumps required per functional unit of each PBR system (FW and BSW) was taken as the sum of water pump requirements and gas pump requirements. All pump requirements 
were scaled, on an equivalent power basis, to a $40-\mathrm{kW}$ nominal rating so that life cycle impact factors from the ecoinvent database could be used to compute energy use and other environmental burdens associated with manufacture of the required pumps. In particular, pump requirements were multiplied by pump impact factors, and then divided by an assumed 30-year useful life to compute annualized pump burdens.

\subsubsection{Conversion Infrastructure}

It was assumed that the only significant infrastructure required for conversion of algae into usable energy carriers is a series of tanks for biodiesel production unit processes and anaerobic digestion unit processes. The same sequence of conversion processes was used for all four algae cultivation systems (OP-FW, OP-BSW, PBR-FW and PBR-BSW), but different lipid fractions in each type of algae necessitated different flows through each unit operation. Since residence times $(\tau)$ for each process were fixed based on literature values, different sized flows required different tank sizes for the same process in different algae cultivation systems.

Tanks for all required unit operations were constructed out of Grade 55 carbon steel plates, since this material offers excellent strength, weldability and toughness (ASTM, 2011a). A five-sided cubic geometry was used, and top covers were excluded from this analysis since it was assumed these would be produced from a material that is significantly lighter, cheaper, and less environmentally burdensome than steel. As noted above, different flows necessitated different size tanks for the various algae cultivation system. Still, all internal pressures resulting from liquid weights were orders of magnitude less than the minimum yield point for carbon steel plate at moderate temperatures $(207 \mathrm{MPa})$. For operating pressures in this range, minimum plate thickness in all tanks is $1 / 4 "(0.0065 \mathrm{~m})$, according to the ASME Pressure Vessel Code (ASTM, 2011a) and ASTM A516: Specifications for Carbon Steel Plates for Pressure Vessels for Moderate and Lower Temperature Service (ASTM, 2011b). Table 4.7 summarizes tank 
specifications required to compute how much steel is needed for algae conversion unit operations $\left(M_{T A N K}\right)$. Resulting values are in units of $\mathrm{kg} / \mathrm{ha}^{*} \mathrm{yr}$ assuming steel burdens can be annualized over 30 years. These values were ultimately scaled by direct land use (in ha) for each algae cultivation system to compute total masses of steel required to produce one functional unit from each modeled system.

Table 4.7. Flow rates $(Q)$, residence times $(\tau)$, capacity volumes $\left(V_{T A N K}\right)$, capacity liquid weights $\left(M_{\text {LIQUID }}\right)$ and internal tank pressures $\left(P_{\text {TANK }}\right)$ required to compute tank steel demand $\left(M_{\text {TANK }}\right)$ for conversion unit operations following all four algae cultivation systems (OP-FW, OP-BSW, PBRFW and PBR-BSW). $M_{\text {TANK }}$ values were represented using units of "per hectare per year" because it was assumed that burdens associated with steel manufacture can be amortized over a 30-year useful life to compute the fraction of overall burden which should be charged to each year.

\begin{tabular}{|c|c|c|c|c|c|c|c|}
\hline Unit Operations & $\begin{array}{c}\text { Q, } \\
\mathrm{m}^{3} / \mathrm{ha} \text { *d }\end{array}$ & $\tau, d$ & $\begin{array}{l}V_{\text {LIQUID, }} \\
\mathrm{m}^{3} / \mathrm{ha}\end{array}$ & $\begin{array}{c}\text { M LIQUID } \\
\mathrm{kg} / \mathrm{ha}\end{array}$ & $\mathrm{P}_{\text {TANK, }} \mathrm{Pa}$ & $\begin{array}{c}\mathrm{M}_{\text {TANK, }} \\
\mathrm{kg} / \mathrm{ha}{ }^{2} \mathrm{yr}\end{array}$ & Source \\
\hline \multicolumn{8}{|l|}{ OP-FW } \\
\hline Autoflocculation & 118.1 & 0.1 & 11.5 & 11,500 & 22,112 & 43.0 & $A$ \\
\hline Thickening & 10.7 & 0.1 & 1.0 & 1,000 & 9,942 & 8.7 & \\
\hline Homogenization & 1.1 & 0.2 & 0.2 & 200 & 5,507 & 2.7 & A \\
\hline Lipid Extraction & 1.1 & 0.03 & 0.04 & 40 & 3,264 & 0.9 & A \\
\hline Solvent Recovery & 1.1 & 0.03 & 0.04 & 40 & 3,250 & 0.9 & A \\
\hline Transesterification & 1.1 & 0.03 & 0.04 & 40 & 3,264 & 0.9 & A \\
\hline Biodiesel Post-Processing & 1.1 & 0.03 & 0.04 & 40 & 3,264 & 0.9 & A \\
\hline Anaerobic Digestion & 1.1 & 14 & 14.7 & 14,700 & 24,009 & 50.7 & B \\
\hline \multicolumn{8}{|l|}{ OP-BSW } \\
\hline Autoflocculation & 261.6 & 0.1 & 25.4 & 25,400 & 28,820 & 73.1 & A \\
\hline Thickening & 23.8 & 0.1 & 2.3 & 2,300 & 12,959 & 14.8 & \\
\hline Homogenization & 2.4 & 0.2 & 0.4 & 400 & 7,177 & 4.5 & $A$ \\
\hline Lipid Extraction & 2.4 & 0.03 & 0.08 & 80 & 4,255 & 1.6 & A \\
\hline Solvent Recovery & 2.3 & 0.03 & 0.08 & 80 & 4,231 & 1.6 & A \\
\hline Transesterification & 2.4 & 0.03 & 0.08 & 80 & 4,255 & 1.6 & $A$ \\
\hline Biodiesel Post-Processing & 2.4 & 0.03 & 0.08 & 80 & 4,255 & 1.6 & A \\
\hline Anaerobic Digestion & 2.3 & 14 & 32.5 & 32,500 & 31,259 & 86.0 & B \\
\hline \multicolumn{8}{|l|}{ PBR-FW } \\
\hline Autoflocculation & 167.9 & 0.1 & 16.3 & 16,300 & 24,862 & 54.4 & $A$ \\
\hline Thickening & 15.3 & 0.1 & 1.5 & 1,500 & 11,179 & 11.0 & \\
\hline Homogenization & 1.5 & 0.2 & 0.3 & 300 & 6,191 & 3.4 & $A$ \\
\hline Lipid Extraction & 1.5 & 0.03 & 0.05 & 50 & 3,670 & 1.2 & A \\
\hline Solvent Recovery & 1.5 & 0.03 & 0.05 & 50 & 3,638 & 1.2 & $A$ \\
\hline Transesterification & 1.5 & 0.03 & 0.05 & 50 & 3,670 & 1.2 & $A$ \\
\hline Biodiesel Post-Processing & 1.5 & 0.03 & 0.05 & 50 & 3,670 & 1.2 & $A$ \\
\hline Anaerobic Digestion & 1.5 & 14 & 20.6 & 20,600 & 26,878 & 63.6 & B \\
\hline \multicolumn{8}{|l|}{ PBR-BSW } \\
\hline Autoflocculation & 271.7 & 0.1 & 26.4 & 26,400 & 29,188 & 75.0 & $A$ \\
\hline Thickening & 24.7 & 0.1 & 2.4 & 2,400 & 13,124 & 15.2 & \\
\hline
\end{tabular}




\begin{tabular}{|c|c|c|c|c|c|c|c|}
\hline Homogenization & 2.4 & 0.2 & 0.4 & 400 & 7,269 & 4.6 & $A$ \\
\hline Lipid Extraction & 2.4 & 0.03 & 0.09 & 90 & 4,309 & 1.6 & A \\
\hline Solvent Recovery & 2.4 & 0.03 & 0.08 & 80 & 4,262 & 1.6 & A \\
\hline Transesterification & 2.4 & 0.03 & 0.09 & 90 & 4,309 & 1.6 & A \\
\hline Biodiesel Post-Processing & 2.4 & 0.03 & 0.09 & 90 & 4,309 & 1.6 & A \\
\hline Anaerobic Digestion & 2.4 & 14 & 33.2 & 33,200 & 31,489 & 87.2 & B \\
\hline
\end{tabular}

A. Stephenson et al. (2010).

B. Sialve, Bernet and Bernard (2009).

\subsubsection{Calculation of Reported LCA Metrics}

\subsubsection{Vehicle Kilometers Traveled}

Detailed description of VKT calculations from either the combustion of biodiesel in an ICV $\left(V K T_{I C V}\right)$ or the use of bioelectricity in a BEV $\left(V K T_{B E V}\right)$ can be found in Section 3.3.7.2 of Chapter 3. The direct land use per functional unit for each of the four modeled systems was then computed as the sum of $V K T_{I C V}+V K T_{B E V}$ in $\mathrm{km} / \mathrm{ha} \mathrm{*}^{*} \mathrm{yr}$. This value, which quantifies production of usable transportation energy from algae per hectare per year, was then divided into the functional unit $(20,000 \mathrm{VKT} / \mathrm{yr} * \mathrm{FU})$ to determine what direct land use (in ha/FU) is required to produce one functional unit via each type of algae cultivation system. As noted in several locations throughout this document, direct land uses were 0.09 ha for OP-FW, 0.04 ha for OPBSW, 0.05 for PBR-FW, and 0.03 for PBR-BSW.

Energy Return on (Energy) Investment Ratio (EROI). Detailed description of EROI utilized in this analysis can be found in Section 3.3.7.1 of Chapter 3.

Net Global Warming Potential Ratio - NGR. The GWP ratio was conceived of for use in this study to evaluate GHG emissions performance on a normalized basis. The NGR ratio is functionally similar to EROI; whereby, GHG outputs (emitting processes) are used as numerator and GHG uptakes (sequestering processes) are used as denominator. Unlike EROI, NGR values less than one are increasingly favorable (i.e., net-GWP consuming) and values greater than one are decreasingly favorable (i.e., net-GWP emitting).Components of the NGR numerator (GWP 
emissions) are associated with manufacture of energy inputs (electricity and heat) and materials inputs (fertilizers, etc.). The NGR denominator (GHG-sequestering processes) accounts for two processes: use of algae digestate to offset commercial fertilizer use and permanent sequestration of the photosynthesis $\mathrm{CO}_{2}$ that is buried into the ground when algae sludge is used as land amendment.

\subsubsection{LCA Impact Factors}

Inputs are required to produce the energy and materials for one functional unit in each OP or PBR system. Impact factors used in this study were taken from the industry-standard ecoinvent database (Weidema, 2008). These are summarized in Table 4.8.

Table 4.8. Life cycle impact factors for materials and energy inputs used in all four models, as expressed using $\mu / \sigma$ notation, where $\mu$ is mean value and $\sigma$ is standard deviation. All data were from ecoinvent v. 2.0 (Weidema, 2008).

\begin{tabular}{|c|c|c|c|c|}
\hline Item & Unit Basis & Energy Use (MJ) & Water Use $\left(\mathrm{m}^{3}\right)$ & $\begin{array}{r}\mathrm{GHG}(\mathrm{kg} \mathrm{CO} \\
\text { eq) }\end{array}$ \\
\hline Aggregates & 1 kg gravel & $0.04 / 0.007$ & $0.04 / 0.007$ & $0.003 / 0.0004$ \\
\hline Bleach & $1 \mathrm{~kg} 15 \% \mathrm{NaOCl}$ in $\mathrm{H}_{2} \mathrm{O}(\mathrm{m} / \mathrm{m})$ & $10.2 / 4.0$ & $5.4 / 0.9$ & $0.9 / 0.1$ \\
\hline Carbon Dioxide & $1 \mathrm{~kg} \mathrm{CO} 2$ & $8.3 / 2.0$ & $2.2 / 0.6$ & $0.8 / 0.1$ \\
\hline Concrete & $1 \mathrm{~m}^{3}$ & $1,180.0 / 836.0$ & $561.0 / 87.1$ & $265.0 / 47.7$ \\
\hline Electricity & $1 \mathrm{kWh}$ from US grid & $12.5 / 10.0$ & $0.8 / 0.1$ & $0.2 / 0.01$ \\
\hline Fertilizer $-\mathrm{N}_{2} \mathrm{H}_{4} \mathrm{CO}$ & $1 \mathrm{~kg}$ as $\mathrm{N}$ & $62.1 / 11.8$ & $4.0 / 1.3$ & $3.4 / 0.3$ \\
\hline Fertilizer $-\mathrm{H}_{12} \mathrm{~N}_{3} \mathrm{O}_{4} \mathrm{P}$ & $1 \mathrm{~kg} \mathrm{P}_{2} \mathrm{O}_{5}$ & $37.5 / 5.4$ & $0.7 / 0.1$ & $0.8 / 0.1$ \\
\hline Fertilizer - $\mathrm{CaH}_{2} \mathrm{P}_{2} \mathrm{O}_{8}$ & $1 \mathrm{~kg} \mathrm{P}_{2} \mathrm{O}_{5}$ & $33.8 / 14.5$ & $12.4 / 2.4$ & $2.8 / 0.5$ \\
\hline Glycerine & $1 \mathrm{~kg} \mathrm{C}_{3} \mathrm{H}_{5}(\mathrm{OH})_{3}$ & $8.7 / 1.2$ & $0.8 / 0.1$ & $1.7 / 0.2$ \\
\hline Heating Oil (Light) & $1 \mathrm{MJ}$ from light heating oil & $1.3 / 0.2$ & $0.03 / 0.004$ & $0.1 / 0.01$ \\
\hline Hexane & $1 \mathrm{~kg} \mathrm{C}_{6} \mathrm{H}_{14}$ & $59.7 / 3.3$ & $1.8 / 0.5$ & $0.9 / 0.1$ \\
\hline Hydrochloric acid & $1 \mathrm{~kg} 30 \% \mathrm{HCl}$ in in $\mathrm{H}_{2} \mathrm{O}(\mathrm{m} / \mathrm{m})$ & $10.4 / 3.1$ & $5.5 / 1.2$ & $0.9 / 0.2$ \\
\hline Methanol & $1 \mathrm{~kg} \mathrm{CH}_{3} \mathrm{OH}$ & $37.7 / 5.5$ & $0.7 / 0.1$ & $0.8 / 0.1$ \\
\hline Polymethyl methacrylate & $1 \mathrm{~kg}\left(\mathrm{C}_{3} \mathrm{H}_{8} \mathrm{O}_{2}\right)_{\mathrm{n}}$ & $132.0 / 0.08$ & $0.1 / 0.005$ & $8.3 / 0.009$ \\
\hline Polypropylene & $1 \mathrm{~kg}\left(\mathrm{C}_{3} \mathrm{H}_{6}\right)_{\mathrm{n}}$ & $70.7 / 0.01$ & $0.05 / 0.0008$ & $2.0 / 0.0007$ \\
\hline Polyvinyl chloride & $1 \mathrm{~kg}\left(\mathrm{C}_{2} \mathrm{H}_{3} \mathrm{Cl}\right)_{\mathrm{n}}$ & $47.2 / 3.6$ & $0.5 / 0.04$ & $2.0 / 0.1$ \\
\hline Potassium hydroxide & $1 \mathrm{~kg} \mathrm{KOH}$ & $23.7 / 4.5$ & $9.0 / 1.2$ & $2.0 / 0.2$ \\
\hline Pump (Water/Flue Gas)* & 1 piece & $0.3 / 0.06$ & $0.9 / 0.2$ & $0.01 / 0.002$ \\
\hline Sodium hydroxide & $1 \mathrm{~kg} 50 \% \mathrm{NaOH}$ in $\mathrm{H}_{2} \mathrm{O}(\mathrm{m} / \mathrm{m})$ & $11.2 / 4.6$ & $7.9 / 1.3$ & $1.2 / 0.2$ \\
\hline Steel & $1 \mathrm{~kg}$ steel $(>10.5 \% \mathrm{Cr})$ & $62.3 / 19.9$ & $59.3 / 3.1$ & $5.2 / 0.3$ \\
\hline
\end{tabular}




\subsubsection{Economics}

The second component of this study was assessment of economic feasibility for each of the four modeled algae cultivation systems. Economic analysis was performed by calculating likely initial outlays (for construction of cultivation and conversion infrastructure, etc.) and annual operations cash flows over the project's lifetime. For an algae project to be deemed economically attractive, the capital outlay must be recouped within a short amount of time at a certain prevailing discount rate.

\subsubsection{Initial and Annual Cash Flows}

Initial Outlay and Capital Costs. Components of initial outlay/capital costs include infrastructure costs, major equipment costs (MEC) and miscellaneous expenses (Molina-Grima et al., 2003). Infrastructure costs are associated with the establishment of physical assets including land, buildings, roads, and electrical distribution. MECs are associated with procurement of heavy machinery (pumps, paddle wheels, etc.) and other unit operations paraphernalia (tanks, etc.). Miscellaneous expenses refer to extraneous costs such as start-up costs and engineering and contingencies.

Annual Cash Flows. Annual cash flows (annuities) are calculated as the difference between revenues and operating costs. Revenues are positive cash flows from sale of biodiesel or methane-derived electricity and may also include credits and offsets. Operating costs are negative cash flows. There are four major categories of operating costs: process costs, energy costs, indirect costs, and depreciation. Process costs include procurement of raw materials (e.g., $\mathrm{CO}_{2}$ and nutrients) and labor. Energy costs include payments for electricity and heat required to operate cultivation and conversion equipment. Indirect costs include fees for waste disposal, infrastructure maintenance and insurance. Annual depreciation is the percentage of initial outlay apportioned to the use of major equipment during one year of operation (Ross et al., 2007). 
Although depreciation may be viewed as a "non-cash" cost, it is categorized as a negative cash flow and counted against annual revenue.

Incremental cash flows can be calculated once annual revenues and operating costs are determined. This requires a series of calculations. First, before-tax earnings (gross income) are calculated as the difference between revenues and operating costs. Then, after-tax earnings (net income) are determined based on the prevailing tax rate (20\% for this study) (Ross et al., 2007). Depreciation is then added to generate annual gross cash flow.

\subsubsection{Costs Data Collection}

Every effort was made to ensure that economic models were based on current economic data. The average value of commercial farmland in California was obtained from Livanis et al. (2006) (Livanis et al., 2006) and updated using the most recent Consumer Price Index (CPI) (2010) conversion factors (CPI, 2010). The 2006 figure was \$7,410/ha. Many construction and major equipment costs (e.g., clearing, excavation, grading) were extracted from the most recent edition of RS Means Costworks (2010) (RS Means, Costworks, 2010). Costs for some items specific to the algae industry were taken from Benemann and Oswald (1996) (Benemann and Oswald, 1996) (particularly for OP systems) and Molina et al. (2003) (Molina et al., 2003) (particularly for PBR systems) and also updated using the 2010 CPI conversion factors (CPI, 2010). Costs for electricity, heat, and pertinent materials values were determined from US Energy Information Administration (2011) (US EIA, 2011).

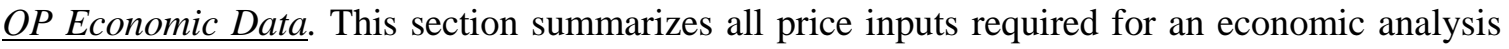
of an OP algae cultivation system. Data pertaining to initial outlay/capital costs are in Table 4.9. Data pertaining to annual cash flows are in Table 4.10. All prices in both tables are expressed in US dollars (\$). 
Table 4.9. Cost data showing initial outlays for OP-FW and OP-BSW delivering 20,000 VKT per year. Direct land use is 0.09 ha for OP-FW and 0.04 ha for OP-BSW.

\begin{tabular}{|c|c|c|c|c|c|}
\hline Item & Unit Price & $\begin{array}{r}\text { Total } \\
\text { Outlay - FW }\end{array}$ & $\begin{array}{r}\text { Total } \\
\text { Outlay-BSW }\end{array}$ & Sources & Notes \\
\hline \multicolumn{6}{|l|}{ INFRASTRUCTURE } \\
\hline Buildings, roads, drainage & $\$ 2,879 / \mathrm{ha}$ & $\$ 253$ & $\$ 146$ & 1,5 & \\
\hline Distribution system - electricity & $\$ 2,879 / \mathrm{ha}$ & $\$ 253$ & $\$ 146$ & 1,5 & \\
\hline Distribution system - water & $\$ 8.20 /$ linear $m$ & $\$ 22$ & $\$ 10$ & 2 & A \\
\hline Distribution system - gases & $\$ 14.30 /$ linear $\mathrm{m}$ & $\$ 1,006$ & $\$ 436$ & 2 & B \\
\hline Distribution system - nutrients & $\$ 8.20 /$ linear $m$ & $\$ 13$ & $\$ 6$ & 2 & C \\
\hline Extraction system & $\$ 2,208$ or $\$ 6,059 / \mathrm{ha}$ & $\$ 194$ & $\$ 231$ & 3 & $\mathrm{D}$ \\
\hline Harvesting system & $\$ 12,517$ or $\$ 27,712 / \mathrm{ha}$ & $\$ 1,101$ & $\$ 1,055$ & 3 & $\mathrm{E}$ \\
\hline Digestion system & $\$ 7,697$ or $\$ 16,497 / \mathrm{ha}$ & $\$ 677$ & $\$ 628$ & 3 & $\mathrm{~F}$ \\
\hline Generator (methane-powered) & $\$ 7,175$ or $\$ 15,167 / p c$ & $\$ 631$ & $\$ 577$ & 3 & G \\
\hline Miscellaneous infrastructure costs & $\$ 288 /$ ha & $\$ 25$ & $\$ 15$ & & $\mathrm{H}$ \\
\hline Land (total $=$ pond area + peripherals) & $\$ 8,011 / \mathrm{ha}$ & $\$ 881$ & $\$ 381$ & 4 & \\
\hline Waste treatment (blow down) & $\$ 1,052 / \mathrm{ha}$ & $\$ 92$ & $\$ 40$ & 1,5 & \\
\hline TOTAL INFRASTRUCTURE COST & & $\$ 5,148$ & $\$ 3,671$ & & \\
\hline \multicolumn{6}{|c|}{ CONSTRUCTION AND MAJOR EQUIPMENT COSTS } \\
\hline Clearing and grubbing & $\$ 7,992 /$ ha & $\$ 703$ & $\$ 304$ & 1,6 & \\
\hline Excavation & $\$ 8.70 /$ bank $^{3}$ & $\$ 414$ & $\$ 179$ & 1,6 & I \\
\hline Fine grading - lagoon bottoms (@ 90\%) & $\$ 3.5 / \mathrm{m}^{2}$ & $\$ 187$ & $\$ 81$ & 1,6 & J \\
\hline Fine grading - lagoon tops (@ 10\%) & $\$ 0.5 / \mathrm{m}^{2}$ & $\$ 3$ & $\$ 1$ & 1,6 & \\
\hline Fine grading - slopes (gentle finish) & $\$ 0.2 / \mathrm{m}^{2}$ & $\$ 8$ & $\$ 4$ & 1,6 & \\
\hline Gas sumps, aerators (for $\mathrm{CO}_{2}$ delivery) & $\$ 2,099 /$ piece & $\$ 250$ & $\$ 241$ & 1,6 & K \\
\hline Geotextile & $\$ 3 / \mathrm{m}^{2}$ & $\$ 123$ & $\$ 53$ & & L \\
\hline Gravel & $\$ 0.02 / \mathrm{kg}$ & $\$ 105$ & $\$ 45$ & & $M$ \\
\hline Paddle wheels & $\$ 526 /$ piece & $\$ 463$ & $\$ 200$ & 1,4 & \\
\hline Steel - tanks & $\$ 0.26 / \mathrm{kg}$ & $\$ 2$ & $\$ 2$ & 5,7 & \\
\hline Settling ponds (for algae harvest) & $\$ 2,103 / \mathrm{ha}$ & $\$ 99$ & $\$ 43$ & 5,7 & \\
\hline Water pumps & $\$ 657 /$ piece & $\$ 27$ & $\$ 24$ & 6 & $\mathrm{~N}$ \\
\hline TOTAL COST FOR CONSTRUCTION AND M & OR EQUIPMENT & $\$ 2,384$ & $\$ 1,177$ & & \\
\hline \multicolumn{6}{|l|}{ MISCELLANEOUS COSTS } \\
\hline Start-up & & $\$ 377$ & $\$ 242$ & 1,5 & \\
\hline Engineering and contingencies & & $\$ 1,130$ & $\$ 727$ & 1,5 & \\
\hline Working capital & & $\$ 2,260$ & $\$ 1,455$ & 1,5 & \\
\hline TOTAL MISCELLANEOUS COSTS & & $\$ 3,767$ & $\$ 2,424$ & & \\
\hline TOTAL INITIAL OUTLAY & & $\$ 11,299$ & $\$ 7,273$ & & $\mathrm{O}$ \\
\hline
\end{tabular}

A. Assume $100 \mathrm{ft} / \mathrm{ha}(30.5 \mathrm{~m} / \mathrm{ha})$ for algae media, water supply; PVC Class 150, 3"-diameter; excludes excavation or backfill.

B. Assume 800 m/ha; polyethelyene, 60 PSI, 1.25"-diameter, @100' ft, coupling, SDR 11, excludes excavation or backfill.

C. Assume $60 \mathrm{ft} / \mathrm{ha}(18.3 \mathrm{~m} / \mathrm{ha})$ for inflows of nutrient solution.

D. $\$ 16,000,000$ extraction cost per $34,065 \mathrm{Mg}$ oil produced/year. Our oil yield is 4.7 and $12.9 \mathrm{Mg}$ oil/year for OP-FW and OP-BSW, respectively. Assume linearity.

E. $\$ 41,000,000$ harvesting cost per $136,260 \mathrm{Mg}$ DS produced/year. Our DS yield is 41.6 and $92.1 \mathrm{Mg}$ DS/year for OP-FW and OP-BSW, respectively. Assume linearity.

F. $\$ 23,000,000$ digestion cost per $102,195 \mathrm{Mg}$ TSS produced/year. Our TSS yield is 34.2 and $74.3 \mathrm{Mg}$ TSS/year for OP-FW and OP-BSW, respectively. Assume linearity.

G. $\$ 15,167$ generator cost per $12.26 \mathrm{Mg} \mathrm{CH} 4$ produced/yr. Our $\mathrm{CH} 4$ yield is 5.8 and $12.3 \mathrm{Mg} \mathrm{CH} 4 /$ year for OP-FW and OP-BSW, respectively. Assume linearity. 
H. Assumed price per hectare includes service facilities, instrumentation, and machinery.

I. Excavated areas are as follows: long ends, cones, divider levees, interior levees, top circles, bottom circles. Total excavated volume is $47.7 \mathrm{~m}^{3}$ per 1-ha OP-FW module and $20.7 \mathrm{~m}^{3}$ per 1-ha OP-BSW module. Total area to be excavated is $481 \mathrm{~m}^{2}$ per ha for OP-FW and $214 \mathrm{~m}^{2}$ per ha for OP-BSW. Price assumes trench or continuous footing, common earth, 3/8 CY excavator, 1-4' deep; excludes sheeting or dewatering.

J. Lagoon bottoms to be graded for paving with grader; lagoon tops to be graded for compaction.

K. Lake aeration system, 110/220 volt motor, 9.2 amp @ (110v), 4.8amp @ (220v), 10psi-10.0 cfm open air flow (pumps air to 20' depth).

L. Geotextile dimensions are calculated as twice the walkway area to account for the slopes: $(2 * 4658 * \mathrm{x}$ ha/FU*0.05) $=41 \mathrm{~m}^{2} / \mathrm{ha}(\mathrm{OP}-\mathrm{FW})$ or $17.7 \mathrm{~m}^{2} / \mathrm{ha}(\mathrm{OP}-\mathrm{BSW}) @ 5 \%$.

M. Compacted gravel layer is 4'-deep, covering $10 \%$ of pond area, mostly near paddlewheels and other erosion-prone areas.

N. Price based on Pentair Whisperflo pool pump: controllable, single phase, $2 \mathrm{HP}$.

O. Depreciable base = Infrastructure cost - Land cost + Construction and major equipment cost; $\$ 6,652$ for OP-FW and $\$ 4,467$ for OP-BSW.

1. Benemann and Oswald (1996).

2. Chapter 3 assumptions.

3. Davis, Aden and Pienkos (2011).

4. Livanis et al. (2006).

5. Consumer Price Index (2010).

6. RS Means Costwork (2010).

7. Spilling, Seppala and Tamminen (2010). 
Table 4.10. Annual cash flows of operations for OP-FW or OP-BSW algae cultivation systems delivering 20,000 VKT per year. Direct land use is 0.09 ha for OP-FW and 0.04 ha for OP-BSW.

\begin{tabular}{|c|c|c|c|c|}
\hline Item & Annual Cash Flow - FW & Annual Cash Flow - BSW & Sources & Notes \\
\hline \multicolumn{5}{|l|}{ REVENUES } \\
\hline Total biodiesel produced @ \$4.54/gallon & $\$ 530$ & $\$ 629$ & & A \\
\hline Net electricity sold to grid @ $\$ 0.13 / \mathrm{kWh}$ & $\$ 369$ & $\$ 425$ & 1 & B \\
\hline Fertilizer substitute credits @ \$425/Mg & $\$ 1$ & $\$ 1$ & 2 & C \\
\hline TOTAL REVENUES & $\$ 900$ & $\$ 1,054$ & & \\
\hline \multicolumn{5}{|l|}{ EXPENSES AND OPERATING COSTS } \\
\hline \multicolumn{5}{|l|}{ PROCESS COSTS } \\
\hline $\mathrm{CO}_{2}$ (from recycled flue gas) @ $\$ 40 / \mathrm{Mg} \mathrm{CO}_{2}$ & $\$ 174$ & $\$ 167$ & 2 & \\
\hline Nutrients @ \$425/Mg H $22 \mathrm{~N}_{3} \mathrm{O}_{4} \mathrm{P}$ & $\$ 31$ & $\$ 33$ & 2 & \\
\hline Labor and overhead & $\$ 74$ & $\$ 32$ & 2 & D \\
\hline Other miscellaneous materials & $\$ 7$ & $\$ 3$ & & $\mathrm{E}$ \\
\hline \multicolumn{5}{|l|}{ ENERGY COSTS } \\
\hline Direct energy @ \$0.13/kWh & $\$ 39$ & $\$ 42$ & 1 & \\
\hline Other power & $\$ 32$ & $\$ 28$ & & $\mathrm{~F}$ \\
\hline \multicolumn{5}{|l|}{ INDIRECT COSTS } \\
\hline Waste disposal & $\$ 36$ & $\$ 35$ & 3 & G \\
\hline Maintenance and insurance & $\$ 200$ & $\$ 134$ & 3 & $\mathrm{H}$ \\
\hline TOTAL EXPENSES AND OPERATING COSTS & $\$ 592$ & $\$ 474$ & & \\
\hline \multicolumn{5}{|l|}{ INCREMENTAL CASH FLOWS } \\
\hline (-) Depreciation & $\$ 218-\$ 1,197$ & $\$ 147-\$ 804$ & 4 & I \\
\hline Operating Income & $(\$ 890)-\$ 308$ & $(\$ 224)-\$ 580$ & & \\
\hline (-) Tax (at 23.6\%) & $(\$ 210)-\$ 73$ & $(\$ 53)-\$ 137$ & 5 & \\
\hline Net Operating Profit After Tax (NOPAT) & $(\$ 680)-\$ 235$ & $(\$ 77)-\$ 443$ & & \\
\hline (+) Depreciation & $\$ 218-\$ 1,197$ & $\$ 147-\$ 804$ & 4 & \\
\hline GROSS ANNUAL CASH FLOW & $\$ 235-\$ 518$ & $\$ 537-\$ 633$ & & \\
\hline
\end{tabular}

A. $\quad$ Biodiesel yield (in $\mathrm{Mg} / \mathrm{ha}) \times$ direct land use $($ in ha) $\times 7.14$ barrels $/ \mathrm{Mg}$ biodiesel $) \times 42$ gallon/barrel $\times \$ 4.54 /$ gallon.

B. Total energy (in MJ/ha) - Methane yield (in $\mathrm{kg} / \mathrm{ha}$ ) x Methane energy $(50 \mathrm{MJ} / \mathrm{kg}) \times$ direct land use (in ha) $\times$ $\$ 0.04 / \mathrm{kWh}$.

C. Fertilizer substitute revenues are computed based on quantities of diammonium phosphate and urea that could be supplanted via use of digestate as alternative fertilizer, based on bioavailabilty equivalence between commercial fertilizers and the algae digestate on an $\mathrm{N}$ basis.

D. $\$ 10 / \mathrm{hr} \times 8 \mathrm{hrs} /$ day $\times 330$ days/yr x 1 person/50 ponds x 1 pond/ha x direct land use. Overhead assumed to be $60 \%$ of labor.

E. Assumed to be $10 \%$ of labor and overhead.

F. Assumed to be $10 \%$ of process cost and direct energy.

G. Assumed to be $50 \%$ of total energy cost.

$\mathrm{H}$. Annual maintenance and insurance is assumed to be $3.0 \%$ of the respective depreciable bases (Benemann and Oswald, 1996).

I. Calculated assuming an 11-year MACRS depreciation schedule (US IRS, 2011) and a 23.6\% average marginal tax rate for the US (Hassett and Mathur, 2011).

1. US Energy Information Agency (2011).

2. Handy (2002).

3. Benemann and Oswald (1996).

4. US Internal Revenue Service (2011).

5. Hassett and Mathur (2011). 
$\underline{P B R}$ Economic Data. This section summarizes all price inputs required for an economic analysis of a PBR algae cultivation system. Data pertaining to initial outlay/capital costs are in Table 4.11. Data pertaining to annual cash flows are in Table 4.12. All prices in both tables are expressed in US dollars (\$).

Table 4.11. Cost data showing initial outlays for PBR-FW and PBR-BSW delivering 20,000 VKT per year. Direct land use is 0.05 ha for PBR-FW and 0.03 ha for PBR-BSW.

\begin{tabular}{|c|c|c|c|c|c|}
\hline Item & Unit Price & $\begin{array}{r}\text { Total } \\
\text { Outlay - FW }\end{array}$ & $\begin{array}{r}\text { Total } \\
\text { Outlay - BSW }\end{array}$ & Sources & Notes \\
\hline \multicolumn{6}{|l|}{ INFRASTRUCTURE } \\
\hline Buildings, roads, drainage & $\$ 2,879 /$ ha & $\$ 152$ & $\$ 117$ & 1 & \\
\hline Distribution system - electricity & $\$ 2,879 /$ ha & $\$ 152$ & $\$ 117$ & 1 & \\
\hline Distribution system - nutrients & $\$ 8.20 /$ linear m & $\$ 8$ & $\$ 5$ & 1 & \\
\hline Distribution system - piping & $\$ 8.20 /$ linear m & $\$ 13$ & $\$ 8$ & 1 & \\
\hline Extraction system & $\$ 8,306$ or $\$ 16,550 / \mathrm{ha}$ & $\$ 438$ & $\$ 504$ & 2 & $A$ \\
\hline Harvesting system & $\$ 4,684$ or $\$ 7,585 /$ ha & $\$ 247$ & $\$ 231$ & 2 & B \\
\hline Digestion system & $\$ 8,941$ or $\$ 13,443 /$ ha & $\$ 471$ & $\$ 409$ & 2 & $\mathrm{C}$ \\
\hline Generator (methane-powered) & $\$ 8,783$ or $\$ 13,237 / p c$ & $\$ 463$ & $\$ 403$ & 2 & $\mathrm{D}$ \\
\hline Miscellaneous infrastructure costs & $\$ 250 /$ ha & $\$ 15$ & $\$ 12$ & & E \\
\hline Land (total = PBR + peripherals) & $\$ 8,011 / \mathrm{ha}$ & $\$ 528$ & $\$ 305$ & 3 & \\
\hline Waste treatment (blow down) & $\$ 1,052$ & $\$ 55$ & $\$ 32$ & 1 & \\
\hline TOTAL INFRASTRUCTURE COST & & $\$ 2,542$ & $\$ 2,143$ & & \\
\hline \multicolumn{6}{|c|}{ CONSTRUCTION AND MAJOR EQUIPMENT COSTS } \\
\hline Clearing and grubbing & $\$ 7,992 / \mathrm{ha}$ & $\$ 421$ & $\$ 243$ & 4 & \\
\hline Concrete - foundations, cooling ponds & $\$ 118 / \mathrm{m}^{3}$ & $\$ 20$ & $\$ 12$ & 4 & \\
\hline Gas spargers (for $\mathrm{CO}_{2}$ delivery) & $\$ 105 /$ piece & $\$ 43$ & $\$ 41$ & & $\mathrm{~F}$ \\
\hline PMMA - degassing reservoirs & $\$ 64 / m^{2}$ & $\$ 25$ & $\$ 14$ & 4 & \\
\hline PMMA - degassing pipes & $\$ 64 / \mathrm{m}^{2}$ & $\$ 16$ & $\$ 9$ & 4 & \\
\hline PMMA - solar collector pipes & $\$ 64 / m^{2}$ & $\$ 81,838$ & $\$ 47,263$ & 4 & \\
\hline Steel - supports, connections & $\$ 0.26 / \mathrm{kg}$ & $\$ 7$ & $\$ 4$ & 4 & \\
\hline Steel - tanks & $\$ 0.26 / \mathrm{kg}$ & $\$ 2$ & $\$ 1$ & 5,1 & \\
\hline Settling ponds (for algae harvest) & $\$ 2,103 /$ ha & $\$ 111$ & $\$ 64$ & 6,1 & \\
\hline Water pumps & $\$ 86 /$ piece & $\$ 151$ & $\$ 87$ & 4 & G \\
\hline \multicolumn{2}{|c|}{ TOTAL COST FOR CONSTRUCTION AND MAJOR EQUIPMENT } & $\$ 82,634$ & $\$ 47,738$ & & \\
\hline \multicolumn{6}{|l|}{ MISCELLANEOUS COSTS } \\
\hline Start-up & & $\$ 4,259$ & $\$ 2,494$ & 6,1 & \\
\hline Engineering and contingencies & & $\$ 12,776$ & $\$ 7,482$ & 6,1 & \\
\hline Working capital & & $\$ 25,552$ & $\$ 14,964$ & 6,1 & \\
\hline TOTAL MISCELLANEOUS COSTS & & $\$ 42,587$ & $\$ 24,940$ & & \\
\hline TOTAL INITIAL OUTLAY & & $\$ 127,762$ & $\$ 74,818$ & & $\mathrm{H}$ \\
\hline
\end{tabular}

A. $\$ 21,600,000$ extraction cost per 34,065 Mg oil produced/year. Our oil yield is 13.1 and $26.1 \mathrm{Mg}$ oil/year for PBRFW and PBR-BSW, respectively. Assume linearity.

B. $\$ 10,800,000$ harvesting cost per $136,260 \mathrm{Mg}$ DS produced/year. Our DS yield is 59.1 and $95.7 \mathrm{Mg}$ DS/year for PBR-FW and PBR-BSW, respectively. Assume linearity.

C. $\$ 21,600,000$ digestion cost per $102,195 \mathrm{Mg}$ TSS produced/year. Our TSS yield is 42.3 and $63.6 \mathrm{Mg} \mathrm{TSS} /$ year for PBR-FW and PBR-BSW, respectively. Assume linearity. 
D. $\$ 15,167$ generator cost per $12.26 \mathrm{Mg} \mathrm{CH} 4$ produced/yr. Our CH4 yield is 7.1 and $10.7 \mathrm{Mg}$ CH4/year for PBR-FW and PBR-BSW, respectively. Assume linearity.

E. Assumed price per hectare includes service facilities, instrumentation, and machinery.

F. Lake aeration system, 110/220 volt motor, 9.2 amp @ (110v), 4.8amp @ (220v), 10psi-10.0 cfm open air flow (pumps air to 20' depth).

G. Price based on Pentair Whisperflo pool pump: controllable, single phase, $2 \mathrm{HP}$.

H. Depreciable base $=$ Infrastructure cost - Land cost + Construction and major equipment cost; $\$ 84,647$ for PBRFW and \$49,574 for PBR-BSW.

1. Consumer Price Index (2010).

2. Davis, Aden and Pienkos (2011).

3. Livanis et al. (2006).

4. RS Means Costwork (2010).

5. Spilling, Seppala and Tamminen (2010).

6. Benemann and Oswald (1996). 
Table 4.12. Annual cash flows of operations for PBR-FW or PBR-BSW algae cultivation systems delivering 20,000 VKT per year. Direct land use is 0.05 ha for PBR-FW and 0.03 ha for PBR-BSW.

\begin{tabular}{|c|c|c|c|c|}
\hline Item & Annual Cash Flow - FW & Annual Cash Flow - BSW & Sources & Notes \\
\hline \multicolumn{5}{|l|}{ REVENUES } \\
\hline Total biodiesel produced @ \$4.54/gallon & $\$ 885$ & $\$ 1,019$ & & A \\
\hline Net electricity sold to grid @ $\$ 0.13 / \mathrm{kWh}$ & $\$ 0$ & $\$ 0$ & 1 & B \\
\hline Fertilizer substitute credits @ \$425/Mg & $\$ 1$ & $\$ 1$ & 2 & $\mathrm{C}$ \\
\hline TOTAL REVENUES & $\$ 886$ & $\$ 1,020$ & & \\
\hline \multicolumn{5}{|l|}{ EXPENSES AND OPERATING COSTS } \\
\hline \multicolumn{5}{|l|}{ PROCESS COSTS } \\
\hline $\mathrm{CO}_{2}$ (from recycled flue gas) @ $\$ 40 / \mathrm{Mg} \mathrm{CO}_{2}$ & $\$ 284$ & $\$ 269$ & 2 & \\
\hline Nutrients @ $\$ 425 / \mathrm{Mg} \mathrm{H}_{22} \mathrm{~N}_{3} \mathrm{O}_{4} \mathrm{P}$ & $\$ 55$ & $\$ 54$ & 2 & \\
\hline Labor and overhead & $\$ 89$ & $\$ 51$ & 2 & $\mathrm{D}$ \\
\hline Other miscellaneous materials & $\$ 9$ & $\$ 5$ & & $\mathrm{E}$ \\
\hline \multicolumn{5}{|l|}{ ENERGY COSTS } \\
\hline Direct energy @ \$0.13/kWh & $\$ 419$ & $\$ 169$ & 1 & \\
\hline Other power & $\$ 86$ & $\$ 55$ & & $\mathrm{~F}$ \\
\hline \multicolumn{5}{|l|}{ INDIRECT COSTS } \\
\hline Waste disposal & $\$ 252$ & $\$ 112$ & 2,3 & G \\
\hline Maintenance and insurance & $\$ 2,539$ & $\$ 1,487$ & 2,3 & $\mathrm{H}$ \\
\hline TOTAL EXPENSES AND OPERATING COSTS & $\$ 3,734$ & $\$ 2,203$ & & \\
\hline \multicolumn{5}{|l|}{ INCREMENTAL CASH FLOWS } \\
\hline (-) Depreciation & $\$ 2,776-\$ 15,236$ & $\$ 1,626-\$ 8,923$ & 4 & I \\
\hline Operating Income & $(\$ 18,084)-(\$ 2,848)$ & $(\$ 10,106)-\$ 1,183$ & & \\
\hline (-) Tax (at 23.6\%) & $(\$ 4,268)-(\$ 672)$ & $(\$ 2,385)-(\$ 279)$ & 5 & \\
\hline Net Operating Profit After Tax (NOPAT) & $(\$ 13,816)-(\$ 2,176)$ & $(\$ 7,721)-(\$ 904)$ & & \\
\hline (+) Depreciation & $\$ 2,776-\$ 15,236$ & $\$ 1,626-\$ 8,923$ & 4 & \\
\hline GROSS ANNUAL CASH FLOW & $(\$ 2,176)-\$ 1,420$ & $(\$ 904)-\$ 1,202$ & & \\
\hline
\end{tabular}

A. $\quad$ Biodiesel yield (in $\mathrm{Mg} / \mathrm{ha}) \times$ direct land use $($ in $\mathrm{ha}) \times 7.14$ barrels $/ \mathrm{Mg}$ biodiesel $) \times 42$ gallon/barrel $\times \$ 4.54 /$ gallon.

B. Total energy (in MJ/ha) - Methane yield (in $\mathrm{kg} / \mathrm{ha}$ ) x Methane energy $(50 \mathrm{MJ} / \mathrm{kg}) \times$ direct land use (in ha) $\times$ $\$ 0.04 / \mathrm{kWh}$.

C. Fertilizer substitute revenues are computed based on quantities of diammonium phosphate and urea that could be supplanted via use of digestate as alternative fertilizer, based on bioavailabilty equivalence between commercial fertilizers and the algae digestate on an $\mathrm{N}$ basis.

D. $\$ 10 / \mathrm{hr} \times 8 \mathrm{hrs} /$ day x 330 days/yr x 1 person/25 ha x direct land use. Overhead assumed to be $60 \%$ of labor.

E. Assumed to be $10 \%$ of labor and overhead.

F. Assumed to be $10 \%$ of process cost and direct energy.

G. Assumed to be $50 \%$ of total energy cost.

H. Annual maintenance and insurance is assumed to be $3.0 \%$ of the respective depreciable bases (Benemann and Oswald, 1996).

I. Calculated assuming an 11-year MACRS depreciation schedule (US IRS, 2011) and a 23.6\% average marginal tax rate for the US (Hassett and Mathur, 2011).

1. US Energy Information Agency (2011).

2. Handy (2002).

3. Consumer Price Index (2010).

4. US Internal Revenue Service (2011).

5. Hassett and Mathur (2011). 


\subsubsection{Project Analysis}

Data from Tables 4.9 - 4.12 were used to analyze the expected financial performance of each proposed algae cultivation system. The subsequent section describes a commonly-employed financial metric that is used to evaluate economic feasibility: profitability index (PI).

Profitability Index. The profitability index (PI) is a financial decision metric which compares initial outlay with annuities (Ross et al., 2007). PI is defined using Equation 4.10.

$$
P I=\frac{P V(A)}{C C} \quad \text { Equation } 4.10
$$

Here, $P I$ is the profitability index (fraction), $P V(A)$ is the present value of all cash flows/annuities (positive or negative) incurred until time $t_{n}$ subsequent to initial investment (dollars) and $C C$ is the initial outlay/capital costs (dollars). Projects with PI $>1$ are said to be accepted and PI $<1$ are rejected. PI values also provide ranking of projects based on economic preferability, with the highest PI being the most preferable and the lowest PI being the least preferable. The results are as follows: 0.41 for OP-FW, 0.77 for OP-BSW, 0.00 for PBR-FW and 0.04 for PBR-BSW (OPBSW > OP-FW > PBR-BSW > PBR-FW). Only the OP systems are found to be financially attractive based on PI (i.e., PI >1). In addition, relative comparison suggests that OP-BSW is the most economically feasible since it has the highest PI among all the four modeled systems.

\subsection{Results and Discussion}

\subsubsection{Overview of Key Inputs and Outputs}

Relevant LCA input parameters and model outputs are summarized in Table 4.13. One particular point of comparison among the four algae systems is their direct land use because it was assumed that it was linearly scalable with impacts. Less productive and environmentally burdensome 
systems are said to have a larger footprint, and thus require more energy, material and economic inputs (Amer et al., 2011). In order of increasing land use, the four cultivation regimes are: PBRBSW < OP-BSW < PBR-FW < OP-FW. The exact opposite trend is evident among their respective dry biomass yields. In contrast, there is no clear relationship between land use trend and lipid yield trend. This observation seems to suggest that biomass yield, not lipid yield, is the main driver of land use efficiency.

The lack of direct correlation between land use and lipid yield undermines the role of PBRs in bioenergy generation since they have been widely accepted to deliver increased lipid content and thus, increased biodiesel yields. Additionally, the significant contribution of bioelectricity VKT from algae non-lipids reduces the importance of biodiesel energy in the total VKT pool. In all systems, bioelectricity VKT accounts to $46-72 \%$ of total VKT, a fact that has been overlooked by previous analyses because of their focus on biodiesel (Lardon et al., 2009; Shirvani et al., 2011; Sturm and Lamer, 2011). This observation undoubtedly directs a growing emphasis on algae co-products as a means of improving overall system performance (Liu et al., 2011; Sander and Murthy, 2010; Stephens et al., 2010). 
Table 4.13. Summary of key model inputs and outputs for production of one functional unit (FU) (FU $=20,000 \mathrm{VKT} /$ year) in four evaluated algae systems. Inputs are "likeliest" values from their respective input distributions. Outputs represent median values from their respective empirical distributions.

\begin{tabular}{|c|c|c|c|c|}
\hline Model Parameter & OP-FW & OP-BSW & PBR-FW & PBR-BSW \\
\hline Algae RUE (g/MJ PAR) ${ }^{a}$ & 1.4 & 3.1 & 2.0 & 3.2 \\
\hline Algae biomass yield $(\mathrm{Mg} / \mathrm{ha})^{\mathrm{b}}$ & 41.6 & 92.1 & 59.1 & 95.7 \\
\hline Algae lipid content (\%) & 13.4 & 16.6 & 26.3 & 32.4 \\
\hline Algae lipid yield (Mg/ha) & 4.7 & 12.9 & 13.1 & 26.1 \\
\hline Algae biomass required per FU (ha) & 3.7 & 3.5 & 3.1 & 2.9 \\
\hline Direct land use required per FU (ha) & 0.09 & 0.04 & 0.05 & 0.03 \\
\hline Biodiesel produced per FU (Mg) & 0.39 & 0.46 & 0.65 & 0.75 \\
\hline Methane produced per FU (Mg) & 0.51 & 0.47 & 0.37 & 0.33 \\
\hline Nitrogen demand per FU (Mg) & 0.14 & 0.14 & 0.13 & 0.13 \\
\hline Phosphorus demand per FU (kg) & 47 & 45 & 40 & 37 \\
\hline $\mathrm{CO}_{2}$ demand per $\mathrm{FU}(\mathrm{Mg})$ & 8.1 & 7.8 & 7.1 & 6.7 \\
\hline VKT produced as biodiesel (km) & 5,573 & 6,618 & 9,317 & 10,725 \\
\hline VKT produced as bioelectricity $(\mathrm{km})$ & 14,427 & 13,382 & 10,683 & 9,275 \\
\hline Total VKT per FU (km) & 20,000 & 20,000 & 20,000 & 20,000 \\
\hline
\end{tabular}

a RUE is "radiation use efficiency" in units of $\mathrm{g}$ algae DW (dry weight) per MJ of photosynthetically active radiation (PAR).

b Yield accounts for Mg of algae DW (dry weight) per ha of direct land use.

\subsubsection{Energy Analysis}

Figure 4.2 presents the results of energy analysis among all four algae-to-bioenergy systems. The results are clustered into three categories: (1) total energy input ( $\left.\mathrm{E}_{\mathrm{IN}}\right)(\mathrm{left}),(2)$ total energy output $\left(\mathrm{E}_{\mathrm{OUT}}\right)($ middle $)$ and EROI $\left(\mathrm{EROI}=\mathrm{E}_{\mathrm{OUT}} / \mathrm{E}_{\mathrm{IN}}\right)$ (right). Interesting conclusions can be deduced from this data set. First, there is a clear demarcation between the OP systems (leftmost two bars in each cluster) against PBR systems (rightmost two bars in each cluster). Both OP systems consume less energy to deliver one FU of transportation energy (expressed as VKT) compared to PBRs. This is consistent with the notion that OP systems use less energy in growing algae and are easier to maintain and build than PBRs. Second, PBRs produce slightly more energy output than OP systems although the difference is less pronounced than that of energy input. This difference 
is a result of the relative mileage inefficiency of ICV $(0.38 \mathrm{MJ} / \mathrm{km})$ compared to BEV $(0.57$ $\mathrm{MJ} / \mathrm{km}$ ) (Campbell et al., 2010). Alternatively, this means that in order to travel the same FU (20,000 VKT), an ICV has to consume slightly more energy than BEV because a larger percentage of its total energy comes from biodiesel. Therefore, PBRs are somewhat penalized by the relative inefficiency of internal combustion engines. Third, EROI values for OP systems are slightly greater than or equal to one; they produce more energy than they consume to deliver one FU. In contrast, PBRs have slightly less than or equal to one EROI values. OP systems are thus more preferable on a normalized net energy basis. Lastly, the energy input for FW algae systems is significantly higher than that for BSW algae systems in both OP and PBR case. The difference is attributed to lower biomass yields of FW algae, which require more energy to produce the same VKT.

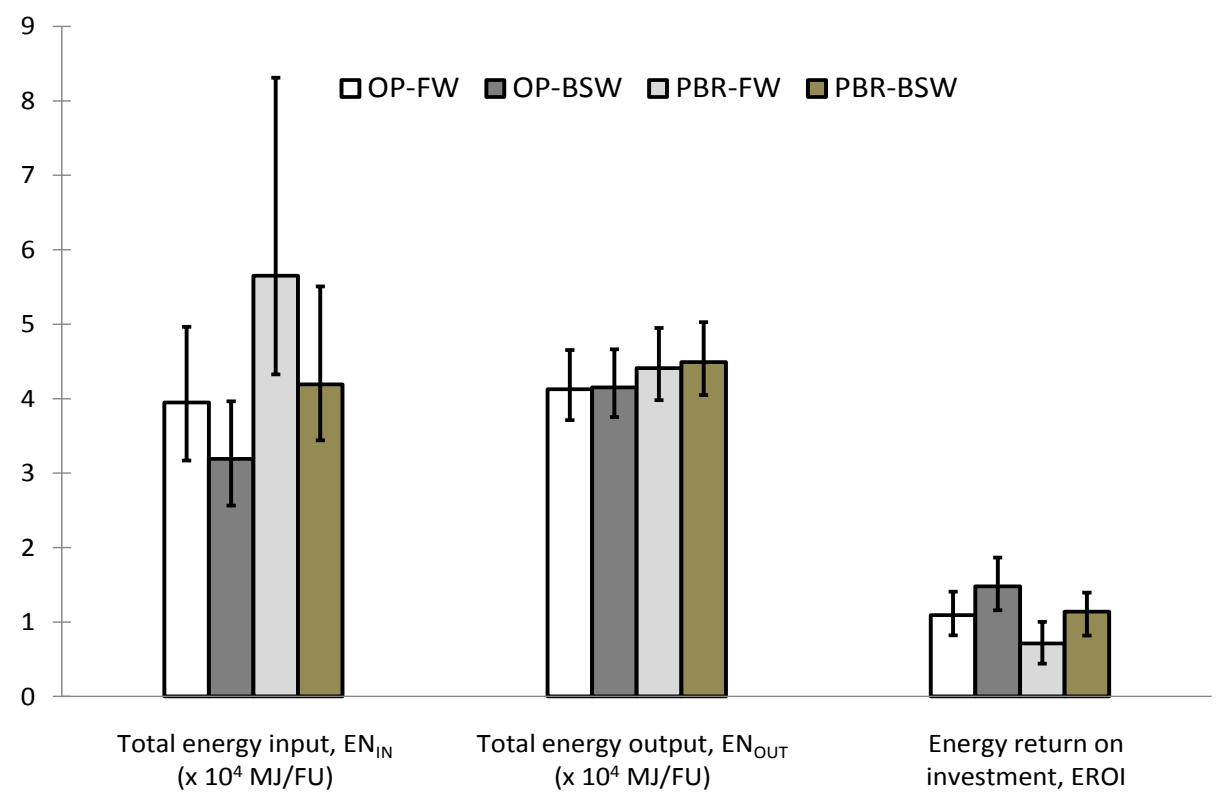

Figure 4.2. Total energy input $\left(\mathrm{EN}_{\mathrm{IN}}\right)$, total energy output $\left(\mathrm{EN}_{\mathrm{OUT}}\right)$ and energy return on investment $\left(\mathrm{EROI}=\mathrm{EN}_{\mathrm{OUT}} / \mathrm{EN}_{\mathrm{IN}}\right)$ for production of one functional unit $(20,000 \mathrm{VKT} / \mathrm{year})$ in four selected algae cultivation systems. EROI median values are 1.09 for OP-FW, 1.49 for OPBSW, 0.63 for PBR-FW, and 1.08 for PBR-BSW. Error bars represent $25^{\text {th }}-75^{\text {th }}$ percentiles from empirical output distributions. 
Figure 4.3 demonstrates the contribution of infrastructure energy consumption against operationsphase energy consumption (panel a, left) and the relative percentage of bioenergy carriers (i.e., bioelectricity or biodiesel) to the total energy output (panel b, right). In panel a, PBR infrastructure energy is roughly $90 \%$ greater than OP infrastructure energy. Moreover, the combined OP operations-phase and infrastructure energy use is significantly less than the sole PBR operations-phase energy use. This result is very critical as it relates to the argument that further improvements in PBR's materials upstream energy consumption could potentially put PBR on par with OP systems (Starbuck, 2010; Subhadra, 2010). It is apparent that even with zero material upstream burdens (highly unlikely), PBR's operations-phase impacts will still be significantly greater than OP's primarily due to the pump head loss incurred as the algae growth medium circulates within the narrow-diameter PBR tubes.

The trend in energy use shown in Figure 4.3a is: OP-BSW < OP-FW < PBR-BSW < PBR-FW. Generally, OP systems consume less energy per FU than PBRs, as previously shown in Figure 4.2. In terms of algae species, BSW systems consume less energy than their counterpart FW systems because higher productivity (i.e., denser algae) impacts the size of the system required to deliver one FU. This means that all things being equal, a BSW system needs less land, less infrastructure materials and less energy than FW system in order to deliver the same VKT.

The middle cluster in Figure 4.2 is dissected further and is shown in panel b of Figure 4.3. To reiterate from the previous paragraph, PBRs require slightly more energy than OP systems per FU because majority of its energy output is biodiesel and the use of bioelectricity in a BEV is more efficient. One key assumption in Figure $4.3 \mathrm{~b}$ is that all algae systems are converted into bioenergy using the same process: extraction of lipid for biodiesel production and anaerobic digestion of algae non-lipid residuals to generate methane for biodiesel production. This is beneficial because it allows for direct comparison between OP and PBR. However, not all 
conversion technologies are suited for all types of algae. Specifically, forcing an OP system to generate biodiesel duly penalizes it since it supports algae with low lipid content and the use of bioelectricity is a more efficient means of delivering the desired VKT. Regardless, PBR still exhibits lower EROI value compared to OP. Thus, even for the case that PBRs have a distinct advantage over OP systems in terms of conversion pathway, they are still energetically inferior.
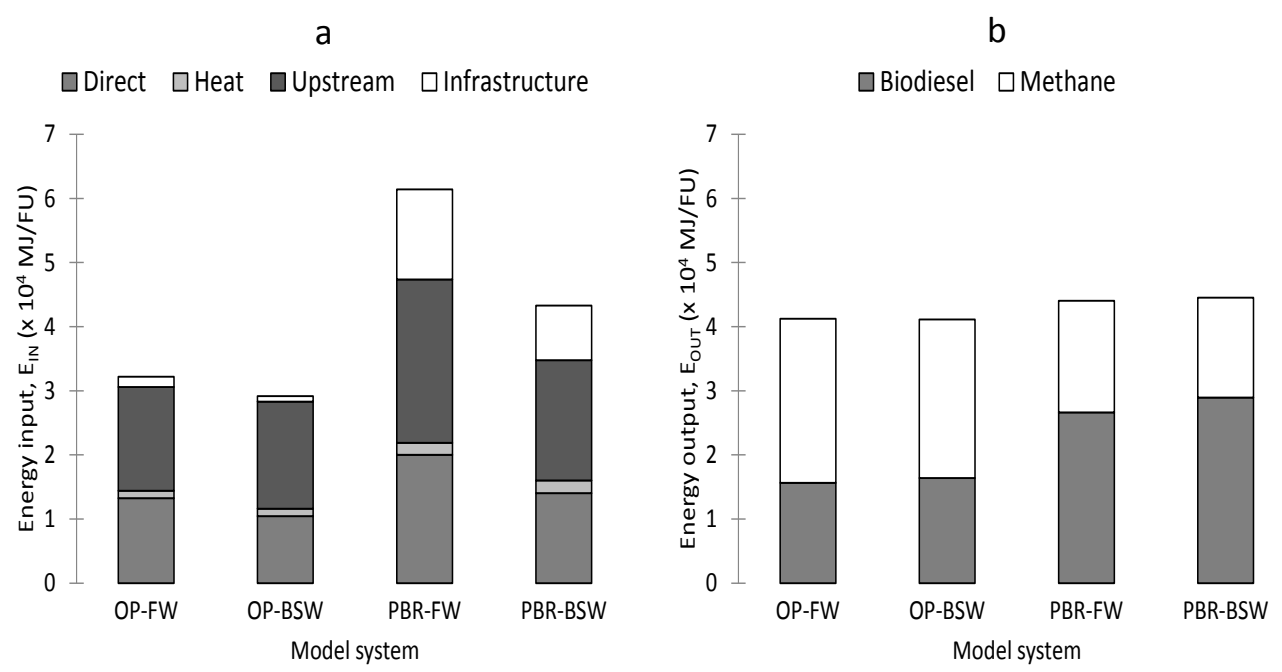

Figure 4.3. Components of total energy inputs (left, panel a) and energy outputs (right, panel b) in four selected algae cultivation systems. In panel a, infrastructure burdens have been divided by a 30-year useful life to compute "annualized" infrastructure burdens. Direct electricity use, heat use and upstream materials energy consumption are expressed per year.

\subsubsection{Greenhouse Gas Analysis}

The results of greenhouse gas balances are presented in Figure 4.4. The components of the graph are: (1) GHG emissions (left), (2) GHG offsets (middle) and (3) "net GHG ratios" (i.e., NGR = $\left.\mathrm{GHG}_{\text {EMISSIONS}} / \mathrm{GHG}_{\text {OFFSETS }}\right)$. Note that the components of Figure 4.4 are plotted using different orders of magnitude as indicated in the axes. Figure 4.4 also shows a pattern very similar to the energy balance in Figure 4.2. OPs have lower GHG emissions than PBRs (left) and they have lower self-normalized "net greenhouse gases ratio" than the PBR systems (right) (i.e., lower GHG emissions). This is not surprising since systems that consume more energy are likely to emit more 
GHG. However, the key difference between Figure 4.2 and Figure 4.4 is the inversion of the middle cluster.

The middle cluster also shows a more favorable environmental performance for OP systems than PBRs: slightly lower energy outputs per FU (Figure 4.2) and larger GHG offsets (Figure 4.4). OP's better performance is attributed to its lower lipid content and larger algae non-lipid residuals left for anaerobic digestion. This, in turn, yields larger quantities of digestate residuals for use as soil amendment/stabilized sludge ("fertilizer"). Variations in sludge production for soil amendment cause changes in the magnitudes of GHG offsets. The effects are manifested in two ways: direct and indirect. The direct impact of sludge production on GHG offset arises from the mass of $\mathrm{CO}_{2}$ taken up during photosynthesis for production of non-lipid algal biomass. This accounted for roughly $98 \%$ of the total GHG offsets in all systems. The indirect impact, on the other hand, consists of the emissions that would otherwise accrue should chemical fertilizers be entirely provided instead of algal digestate as nutrient source. Relevant impact factors for $\mathrm{CO}_{2}$ and nutrients were all taken from ecoinvent database (Weidema, 2008). Judging from relative GHG offset percentage, it is apparent that the magnitude of direct $\mathrm{CO}_{2}$ sequestration is much larger than the fertilizer avoidance GHG savings.

The combined results of EROI and NGR highlights the fact that energy-intensive PBR systems are less desirable for algae production despite producing larger quantities of lipids. The analysis also points to bioelectricity as an efficient method of producing energy and sequestering $\mathrm{CO}_{2}$ compared to biodiesel. However, although PBR has been shown to be environmentally undesirable, it is worthwhile to note that the current transportation energy landscape still favors biodiesel because there is currently no infrastructure for bioelectricity-based personal transportation. Thus, biodiesel's selling price is still much cheaper on a per MJ basis than bioelectricity's selling price per kW-hr. The increased selling price of liquid fuels must be 
weighed against the increased costs for PBR infrastructure and operations. Given all of these factors, a complementary full-scale LCC evaluation is necessary to fully understand the comparison between OP and PBR systems.

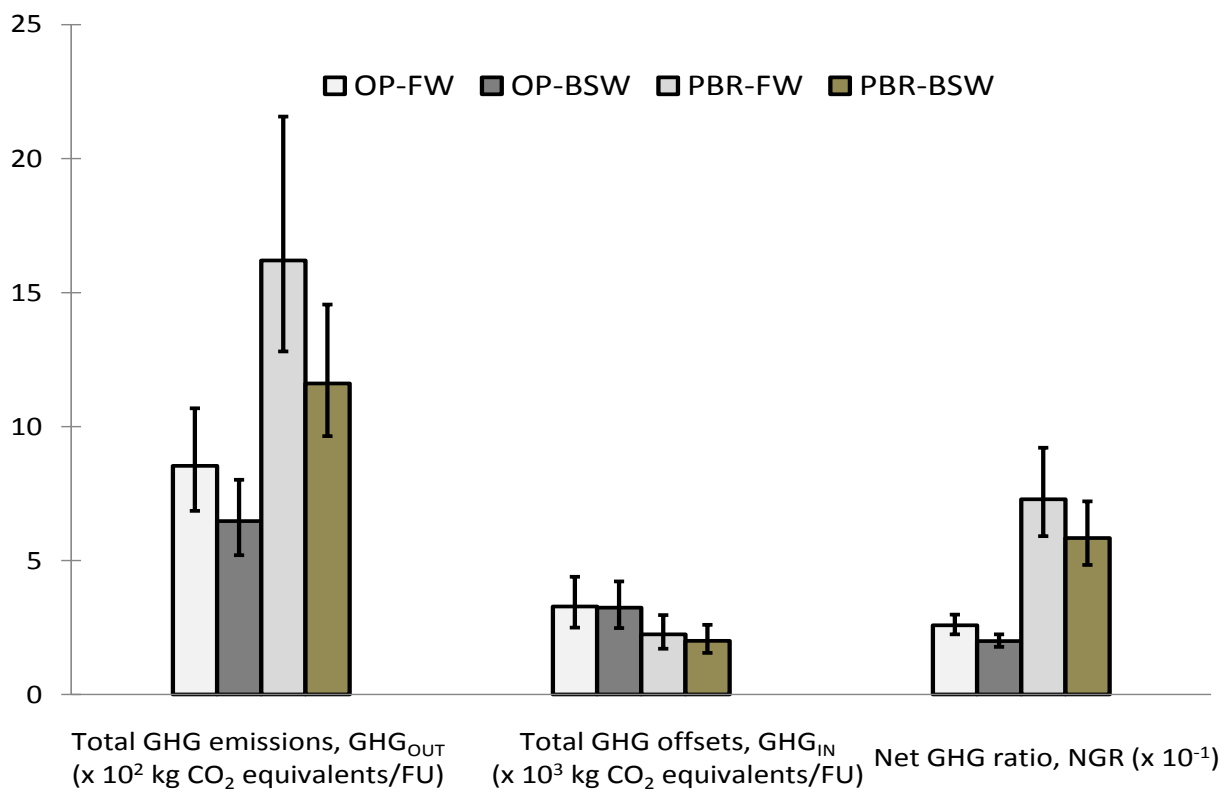

Figure 4.4. Total greenhouse gas emissions $\left(\mathrm{GHG}_{\mathrm{OUT}}\right)$, total greenhouse gas offsets $\left(\mathrm{GHG}_{\mathrm{IN}}\right)$ and net greenhouse gas ratio $\left(\mathrm{NGR}=\mathrm{GHG}_{\mathrm{OUT}} / \mathrm{GHG}_{\mathrm{IN}}\right)$ for production of one functional unit $(20,000$ VKT/year) in four selected algae cultivation systems. NGR values are 0.26 for OP-FW, 0.20 for OP-BSW, 0.73 for PBR-FW and 0.58 for PBR-BSW. Error bars represent $25^{\text {th }}-75^{\text {th }}$ percentiles from empirical output distributions. Note differences in order of magnitude for plotted quantities.

\subsubsection{Financial Analysis}

It is reasonable to assume that economic analysis will track roughly with some LCA results (e.g., energy efficiency usually corresponds to cost savings). However, a full economic analysis via LCC is still required to fully identify startup costs, revenues and expenses associated with the operation of each algae-to-bioenergy system.

Similarto LCA, the LCC process assumed a productive output equivalent to 20,000 VKT. All inputs, revenues and costs were scaled accordingly to obtain a profitability index (PI) for each alternative. PI is expressed as the quotient of (1) the present value of a project's discounted 
expected future cash flows and (2) its initial outlay. Systems with PIs $>1$ are profitable and systems with PIs $<1$ must be rejected. Although PI is an appropriate method of determining relative attractiveness of each alternative, financial viability must be assessed in absolute terms. The results of this LCC analysis (unit costs, revenues, expenses and annual cash flows), expressed in 2010 dollars, are summarized in Table 4.14 .

Table 4.14. Cash flows and profitability indices associated with production of biodiesel and bioelectricity in four evaluated algae-to-bioenergy systems, per FU of output.

\begin{tabular}{|l|r|r|r|r|}
\hline \multicolumn{1}{|c|}{ Financial Variable } & \multicolumn{1}{|c|}{ OP-FW } & OP-BSW & \multicolumn{1}{|c|}{ PBR-FW } & PBR-BSW \\
\hline Initial outlay (\$) & $\$ 11,299$ & $\$ 7,273$ & $\$ 127,762$ & $\$ 74,818$ \\
PV of future cash flows (\$) & 3,242 & 4,868 & $-7,442$ & -867 \\
Median profitability index (PI) & 0.41 & 0.77 & 0.00 & 0.04 \\
\hline
\end{tabular}

Startup costs include infrastructure costs, major equipment costs, construction costs and contingencies. Annual revenues include the sale of biodiesel and surplus electricity generated from methane released during the biodigestion of algal biomass, while annual expenditures consist of process costs $\left(\mathrm{CO}_{2}\right.$, nutrients, labor), energy costs and labor costs. For the base case, a 30-year useful life and a $10 \%$ hurdle rate were assumed. Salvage values at the end of this period were assumed to be minimal and were ignored in the analysis.

According to Table 4.14, the PI of all modeled systems is less than one, meaning none of the systems would be profitable on a present value basis, i.e., offering financial returns in excess of the initial outlay. However, it is apparent that only the OP systems have a PI value closer to 1.0 (the break-even point). With some improvements to the processing pathways modeled here, it thus seems likely that OP systems could be profitable. However, the road to commercialization for PBRs is less clear.

Sensitivity analyses related to the financial viability of OP and PBR systems are summarized in Figure 4.5 as tornado charts representing the variability in profitability index arising from $\pm 10 \%$ 
change in input parameters. For clarity's sake, only the ten inputs having the largest impact on PI are presented for each model. Black bars indicate a positive correlation with the input parameter and PI; gray bars reflect negative correlations. These results reveal that the profitability of algaebased biodiesel is driven most directly by input parameters in three broad classes: market forces (input and output prices, discount rate), conversion parameters (yields and efficiencies) and cultivation inputs.
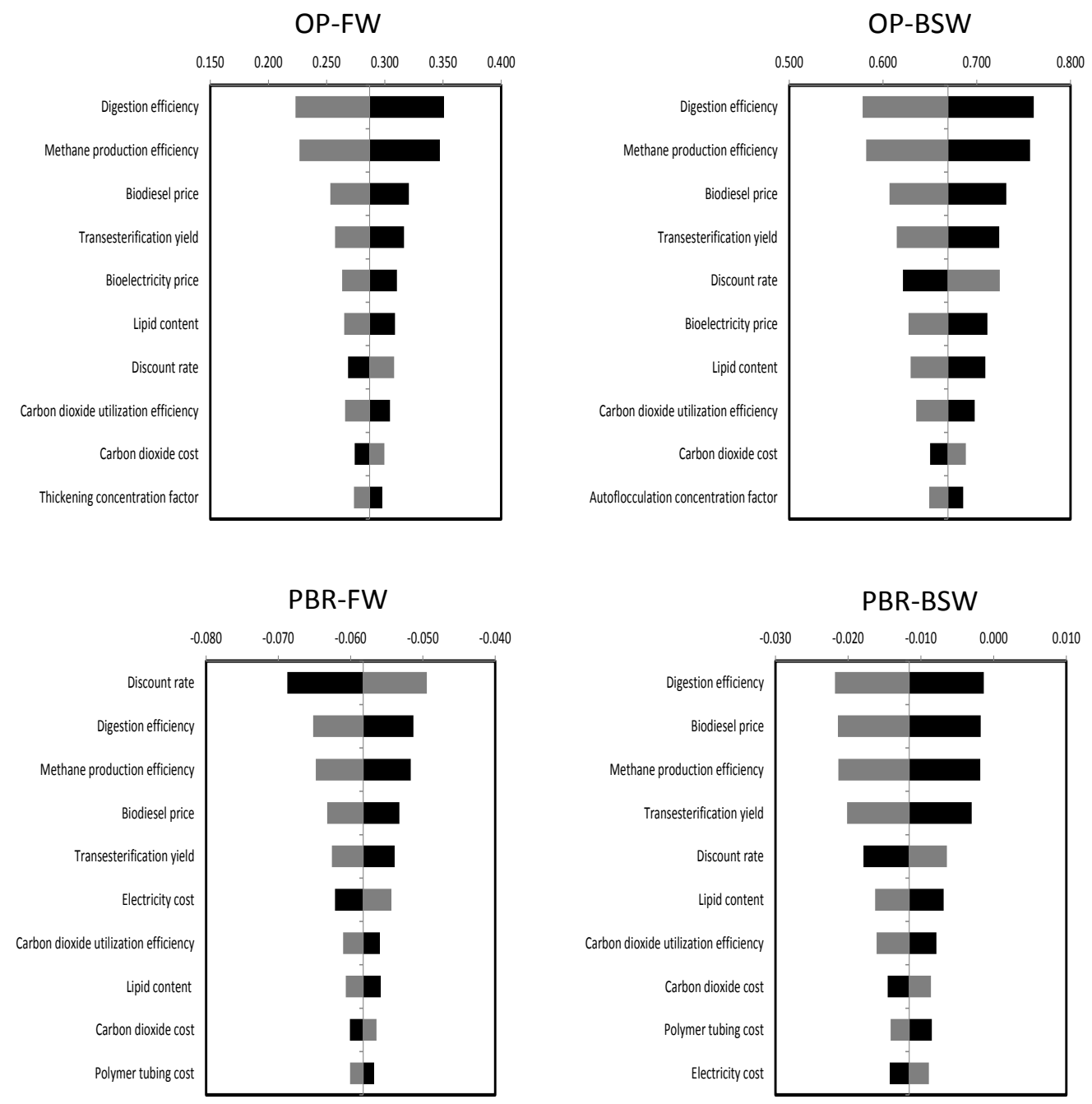

Figure 4.5. Tornado plots for assessing the sensitivity of profitability index (PI) to inputs in four modeled algae cultivations systems. Bar widths represent per cent change in PI arising from $\pm 10 \%$ variation in each input. The top ten most impactful parameters are shown for each model. Black and gray shading indicate direct and indirect correlations between each input and PI, respectively. Note: The base values for the profitability indices reported in this figure are actual forecast values derived from "base case" input values in each scenario. 
Market forces, specifically the selling price of biodiesel and the discount rate, have the most pronounced impact on the profitability of algae-to-bioenergy systems. The selling price of biodiesel appears as one of the top three most important parameters in all four modeled systems. The discount rate also appears among the top ten most influential parameters determining the profitability of the proposed algae projects. It reflects the financial risk of a project. These results are encouraging because it suggests that subsidies or other financial incentives might alter the profitability of algae biodiesel in the near term. In the long run, the commercialization of algae biodiesel for profit will be realized if solutions to cultivation-phase and conversion-phase hurdles are met.

In terms of conversion parameters, the most pronounced input affecting PI are parameters related to anaerobic digestion (volatile suspended solids removal efficiency and methane production efficiency). Although digestion has long been an established process in some industries (e.g., wastewater treatment), it is still inefficient. Increasing the amount of carbon that becomes usable fuel (either biodiesel or methane) and ensuring that most of the nutrients $(\mathrm{N}, \mathrm{P})$ are recycled back into cultivation, can improve PI.

Lastly, inputs embodied in cultivation techniques were found not to be prominent drivers of PI although a few interesting trends emerge. Lipid content is important, as expected, since liquid fuels are so profitable vis-à-vis bioelectricity. $\mathrm{CO}_{2}$ uptake efficiency is also important, since most commercial algae cultivation facilities have a $\mathrm{CO}_{2}$ uptake rate $<1$ and the producer has to pay for the unused $\mathrm{CO}_{2}$. In the case of PBRs, PI is mainly driven by cultivation parameters such as cost of pumping electricity and the cost of PMMA used in constructing the reactor. While these two factors adversely affect PBR PI, no direct effect has been found on OP PI. Figure 4.6 presents the distributions of PIs for all modeled algae-to-bioenergy systems. From this figure (and the values in Table 4.14), it can be noted that PI varies widely among the four evaluated systems. Also, $60 \%$ 
of the OP-BSW system distribution (the best-case OP system) achieves a profitability index greater than 1.0. Put differently, there is a $60 \%$ chance that an open pond system using brackishsaltwater algae species will achieve a financial return in excess of the $10 \%$ required minimum rate of return if improvements can be realized in some or all of the input parameters from Figure 4.5 .

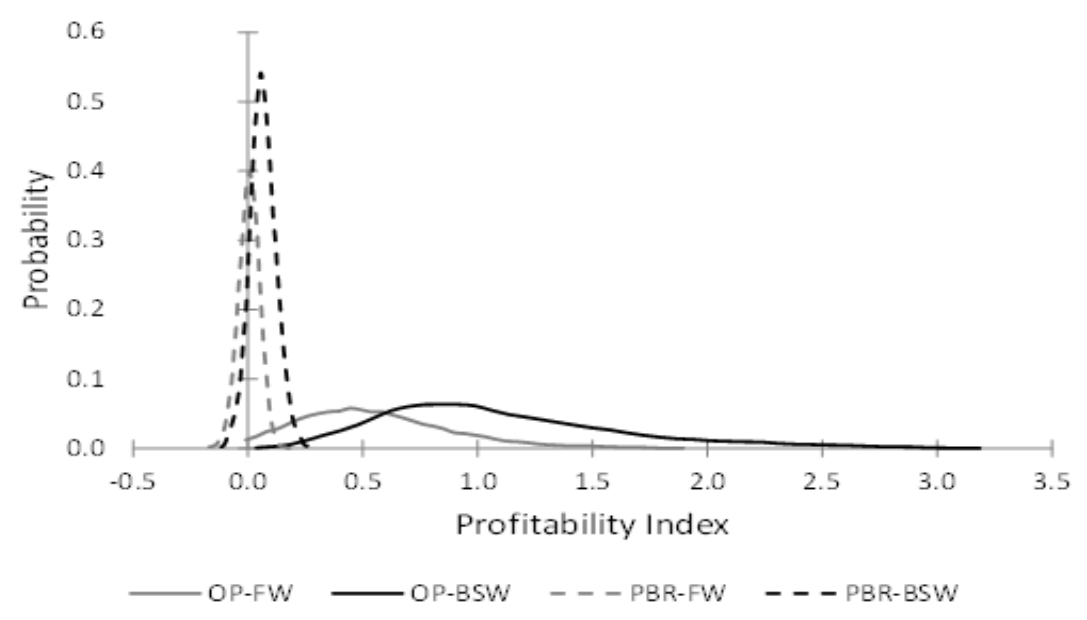

Figure 4.6. Profitability index probability distributions in four selected algae cultivation systems.

To further evaluate the extent to which market conditions, conversion parameters and cultivation inputs can be improved, Figure 4.7 presents probability distributions corresponding to various alternative scenarios of price-and-process improvements. Because brackish-saltwater algae outperform freshwater algae in all cases, only OP-BSW and PBR-BSW results are shown.

In Figure 4.7a, optimizations were made to five important market force parameters ("Scenario 1") that includes: decreasing by half the cost of commercial $\mathrm{CO}_{2}$, electricity from the US grid and the acceptable hurdle rate (i.e., discount rate); and doubling the selling price of biodiesel and bioelectricity, from their respective values in the base case model. Results indicate that OP-BSW is particularly attractive, as there is almost a $100 \%$ chance of PI $\geq 1.0$ under these (admittedly optimistic) conditions. 
In Figure 4.7b, improvements in three important conversion parameters ("Scenario 2") were made. Anaerobic digestion efficiency was set to its theoretical maximum (60\%, based on Sialve, Bernet and Bernard, 2009), methane yield was set to the highest value from the distribution used in the base case models $\left(0.83 \mathrm{~L} \mathrm{CH}_{4} / \mathrm{g}\right.$ algae organic matter, based on Sialve, Bernet and Bernard, 2009) and transesterification efficiency was set to $99 \%$. Improvement in PI of OP-BSW is less pronounced here than in Figure 4.7a, and there is no appreciable improvement for the PBR-BSW system.

In Figure 4.7c, changes in two cultivation inputs ("Scenario 3") were performed. $\mathrm{CO}_{2}$ utilization efficiency is set to $100 \%$ and lipid content is assigned to the highest value on the input range from the median (base case model): $30 \%$ for OP-FW, $24 \%$ for OP-BSW, $58 \%$ for PBR-FW and $60 \%$ for PBR-BSW. As in Scenario 1, the improvement in OP-BSW PI is encouraging but not as dramatic as in Scenario 2 or Scenario 1. Also, there is no marked improvement for PBR-BSW among Scenario 1, Scenario 2 or Scenario 3.

Finally, Figure $4.7 \mathrm{~d}$ presents the distribution of PIs for each system based on the best-case values for all ten parameters manipulated in Scenarios 1, 2 and 3. These results ("Scenario 4") are representative of the best possible performance of algae-to-bioenergy systems producing biodiesel and bioelectricity. Encouragingly, both OP-BSW and PBR-BSW exhibit PI values that are always much greater than 1 . Still, the forecasted profitability of OP systems is dramatically better (approximately six times more) than the forecasted profitability of PBR systems. 

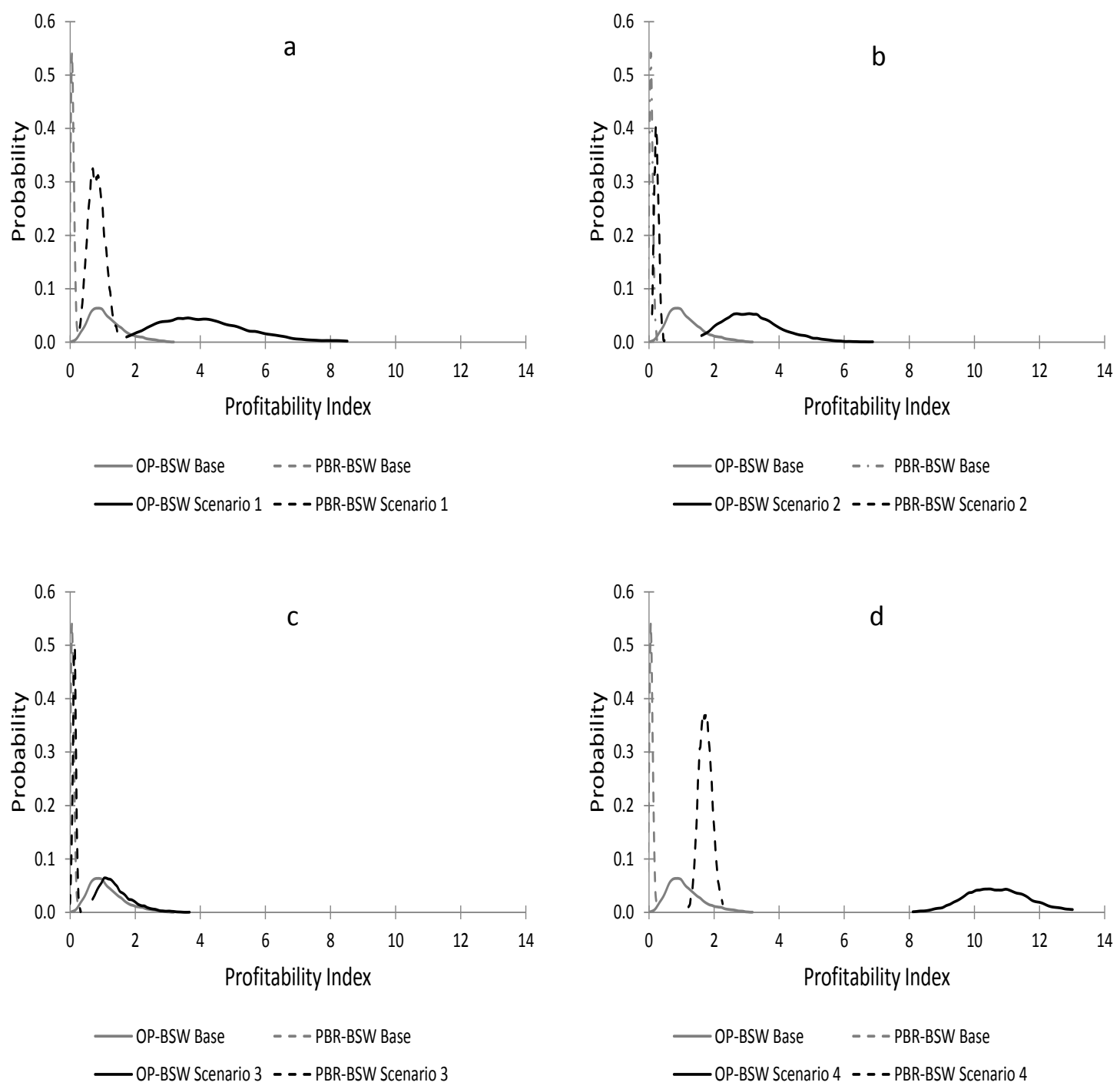

Figure 4.7. Profitability index probability distributions for two selected algae cultivation systems, OP-BSW and PBR-BSW. In panel a, base case results are shown with Scenario 1 ("Improved Market Conditions") results for optimization of five market forces parameters: cost of $\mathrm{CO}_{2}$, cost of electricity from US grid, discount rate, sale price of algae bioelectricity and sale price of algal biodiesel. In panel b, base case results are shown with Scenario 2 ("Improved Conversion") results for optimization of three conversion parameters: anaerobic digestion efficiency, methane production efficiency and transesterification efficiency. In panel c, base case results are shown with Scenario 3 ("Improved Cultivation") results for optimization of two cultivation parameters: $\mathrm{CO}_{2}$ utilization efficiency, and algal lipid content. In panel $\mathrm{d}$, base case results are shown with Scenario 4 ("Best Possible Conditions") results, which reflect simultaneous optimization of all ten inputs from Scenarios 1-3. 


\subsection{Conclusions}

This chapter offered conclusive evidence suggesting that OP algae-to-bioenergy systems are more environmentally and economically preferable than PBRs in delivering transportation energy, either as bioelectricity or biodiesel. In both LCA and LCC analysis, PBRs have been proven not a viable algae cultivation method at an industrial-scale. Algae energy-carriers (bioelectricity and biodiesel) from OP-BSW are shown to be sustainable, having EROI $>1$ and NGR $<1$, but economically marginal. Optimizations in market forces, conversion parameters and cultivation inputs were conducted to further improve profitability between two best performers: OP-BSW and PBR-BSW. Results indicated that market conditions determine the potential of large-scale algae energy production in the near future, rather than strictly technological feasibility. It has also been found that in order to fully supplant fossil-based fuels, BSW algae species must be grown in an OP, with all possible best-case conditions applied.

\subsection{References}

Acién-Fernandez, F. G., Fernández-Sevilla, J. M., Sánchez-Pérez, J. A., Molina-Grima, E., Chisti, Y. "Airlift-Driven External-Loop Tubular Photobioreactors for Outdoor Production of Microalgae: Assessment of Design and Performance." Chemical Engineering Science 56 (2001): 2721-2732.

Ansell, A. D., Raymont, J. E. G., Lander, K. F., Crowley, E., Shackley, P. "Studies on the Mass Culture of Phaeodactylum II. The Growth of Phaeodactylum and other Species in Outdoor Tanks." Limnology and Oceanography 8 (1963): 184-206.

Amer, L., Adhikari, B., Pellegrino, J. "Technoeconomic Analysis of Five Microalgae-to-Biofuels Processes of Varying Complexity.” Bioresource Technology 102 (2011): 9350-9359.

ASTM Standard D638, "Standard Test Method for Tensile Properties of Plastics." ASTM International: West Conshohocken, P.A., U.S.A., 2011.

ASTM Standard A516, "Standard Specification for Pressure Vessel Plates, Carbon Steel, for Moderate- and Lower-Temperature Service." ASTM International: West Conshohocken, P.A., U.S.A., 2011.

Barclay, W. R., Nagle, N. J., Terry, K. L., Ellingson, S. B., Sommerfeld, M. R. "Characterization of Saline Groundwater Resource Quality for Aquatic Biomass Production: A Statistically-Based Approach." Water Research 22, no. 3 (1988): 373-379. 
Batan, L., Quinn, J., Willson, B., Bradley, T. "Net Energy and Greenhouse Gas Emission Evaluation of Biodiesel Derived from Microalgae." Environmental Science \& Technology 44, no. 20 (2010): 7975-7980.

Benemann, J., Oswald, W. "Systems and Economic Analysis of Microalgae Ponds for Conversion of $\mathrm{CO}_{2}$ to Biomass - Final Report." U.S. Department of Energy: Pittsburgh, 1996, 201.

Brentner, L. B., Eckelman, M. J., Zimmerman, J. B. "Combinatorial Life Cycle Assessment to Inform Process Design of Industrial Production of Algal Biodiesel." Environmental Science and Technology 45, 7060-7067.

Borowitzka, M. A. "Microalgae for Aquaculture: Opportunities and Constraints." Journal of Applied Phycology 9 (1997): 393-401.

Campbell, J. E., Lobell, D. B., Field, C. B. "Greater Transportation Energy and GHG Offsets from Bioelectricity than Ethanol." Science 2009.

Carey, R., Migliaccio, K. "Contribution of Wastewater Treatment Plant Effluents to Nutrient Dynamics in Aquatic Systems: A Review." Environmental Management 44, no. 2 (2009): 205217.

Chisti, Y. "Biodiesel from Microalgae.” Biotechnology Advances 25, no. 3 (2007): 294-306.

Chisti, Y. "Biodiesel from Microalgae Beats Bioethanol." Trends in Biotechnology. 26 (2008): 126-131.

Chiu, S., Kao, C., Chen, C., Kuan, T., Ong, S., Lin, C. "Reduction of $\mathrm{CO}_{2}$ by a High-Density Culture of Chlorella sp. in a Semicontinuous Photobioreactor." Bioresource Technology 99 (2008): 3389-3396.

Collet, P., Hélias, A., Lardon, L., Ras, M., Goy, R., Steyer, J. "Life-Cycle Assessment of Microalgae Culture Coupled to Biogas Production.” Bioresource Technology 102 (2011): 207214.

Consumer Price Index, 2010: http://oregonstate.edu/cla/polisci/sites/default/files/facultyresearch/sahr/inflation-conversion/pdf/cv2010.pdf (accessed April 2011).

Damiani, M. C., Popovich, C. A., Constenla, D., Leonardi, P. I. "Lipid Analysis in Haematococcus pluvialis to Assess its Potential Use as a Biodiesel Feedstock." Bioresource Technology 101, no. 11 (2010): 3801-3807.

Davis, R., Aden, A., Pienkos, P. T. "Techno-Economic Analysis of Autotrophic Microalgae for Fuel Production.” Applied Energy 88, no. 10 (2011): 3524-3531.

Elvi, J., Cheng, L., Xu, X., Zhang, L., Chen, H. "Enhanced Lipid Production of Chlorella vulgaris by Adjustment of Cultivation Conditions." Bioresource Technology 101, no. 17 (2010): 6797-6804.

Feinberg, D. A. "Fuel Options from Microalgae with Representative Chemical Compositions Solar Energy Research Institute Final Report.” US Department of Energy: 1984. 
Fischer, B. L., Richardson, J. W., Outlaw, J. L. "Economic Feasibility of Commercial Algae Oil Production in the United States - Final Report." Southern Agricultural Economics Association Annual Meeting: Corpus Christi, 2011.

García-Malea López, M. C., Del Río-Sánchez, E., Casas-López, J. L., Acién-Fernandez, F. G., Fernández-Sevilla, J. M., Rivas, J., Guerrero, M. G., Molina-Grima, E. "Comparative Analysis of the Outdoor Culture of Haematococcus pluvialis in Tubular and Bubble Column Photobioreactors." Journal of Biotechnology 123 (2006): 329-342.

Ge, Y., Liu, J., Tian, G. "Growth Characteristics of Botryococcus braunii 765 Under High $\mathrm{CO}_{2}$ Concentration in Photobioreactor." Bioresource Technology 102, no. 1 (2011): 130-134.

Geankoplis, C. J. "Transport Processes and Separation Process Principles (Includes Unit Operations), 4th Edition.” Prentice Hall Professional Technical Reference: Upper Saddle River, N.J., 2003.

Goldman, J. C., Ryther, J. H., Williams, L. D. "Mass Production of Marine Algae in Outdoor Cultures." Nature 254, no. 5501 (1975): 594-595.

Gudin, C., Chaumont, D. "Cell Fragility: The Key Problem of Microalgae Mass Production in Closed Photobioreactors." Bioresource Technology 38 (1991): 145-151.

Handy, S. "Accessibility- vs. Mobility-Enhancing Strategies for Addressing Automobile Dependence in the U.S. - Final Report." European Conference of Ministers of Transport, 2002.

Hassett, K. A., Mathur, A. "Report Card on Effective Corporate Tax Rates - Report 2011": http://www.aei.org/print/report-card-on-effective-corporate-tax-rates/ (accessed February 2012).

Hu, Q., Kurano, N., Kawachi, M., Iwasaki, I., Miyachi, S. "Ultrahigh-Cell-Density of a Marine Green Alga Chlorococcum littorale in a Flat-Plate Photobioreactor." Applied Microbiology and Biotechnology 49 (1998): 655-662.

Janssen, M., Tramper, J., Mur, L. R., Wijffels, R. H. "Enclosed Outdoor Photobioreactors: Light Regimes, Photosynthetic Efficiency, Scale-up and Future Prospects." Biotechnology and Bioengineering 81, no. 2 (2002): 193-210.

Jorquera, O., Kiperstok, A., Sales, E. A., Embiruçu, M., Ghirardi, M. L. "Comparative Energy Life-Cycle Analyses of Microalgal Biomass Production in Open Ponds and Photobioreactors." Bioresource Technology 101 (2010): 1406-1413.

Kadam, K. L. "Environmental Implications of Power Generation via Coal-Microalgae Cofiring. Energy 27, no. 10 (2002): 905-22.

Lardon, L., Helias, A., Sialve, B., Steyer, J. P., Bernard, O. "Life-Cycle Assessment of Biodiesel Production from Microalgae." Environmental Science and Technology 43, no. 17 (2009): 64756481.

Lee, Y., Low, C. "Effect of Photobioreactor Inclination on the Biomass Productivity of an Outdoor Algal Culture.” Biotechnology and Bioengineering 38 (1991): 995-1000. 
Lee, Y., Low, C. "Productivity of Outdoor Algal Cultures in Enclosed Tubular Photobioreactor." Biotechnology and Bioengineering 40 (1992): 1119-1122.

Laws, E. A., Taguchi, S., Hirata, J., Pang, L. "High Algal Production Rates Achieved in a Shallow Outdoor Flume." Biotechnology and Bioengineering 28, no. 2 (1986): 191-197.

Laws, E. A., Taguchi, S., Hirata, J., Pang, L. "Continued Studies of High Algal Productivities in a Shallow Flume.” Biomass 11, no. 1 (1986): 39-50.

Liu, X., Clarens, A. F., Colosi, L. M. "Algae Biodiesel Has Potential Despite Inconclusive Results to Date." Bioresource Technology 104 (2011): 803-806.

Livanis, G., Moss, C. B., Breneman, V. E., Nehring, R. F. "Urban Sprawl and Farmland Prices." American Journal of Agricultural Economics 88, no. 4 (2006): 915-929.

Luo, D., Hu, Z., Choi, D. G., Thomas, V. M., Realff, M. J., Chance, R. R. "Life Cycle Energy and Greenhouse Gas Emissions for an Ethanol Production Process Based on Blue-Green Algae." Environmental Science \& Technology 44, no. 22 (2010): 8670-8677.

Materassi, M., Tredici, R., Milicia, F., Sili, C., Pelosi, E., Vincenzini, M., Torzillo, G., Balloni, W., Florenzano, G., Wagener, K. "Development of a Production Size System for the Mass Culture of Marine Microalgae." Energy from Biomass 5, no. 150 (1983).

Masojídek, J., Papácek, S., Sergejevová, M., Jirka, V., Cervený, J., Kunc, J., Korecko, J., Verbovikova, O., Kopecký, J., Stys, D., Torzillo, G. "A Closed Solar Photobioreactor for Cultivation of Microalgae Under Supra-High Irradiance: Basic Design and Performance." Applied Phycology 15 (2003): 239-248.

Molina, E., Fernández, J., Acién, F. G., Chisti, Y. "Tubular Photobioreactor Design for Algal Cultures." Journal of Biotechnology (2001): 113-131.

Molina-Grima, E., Belarbi, E. H., Acién-Fernandez, F. G., Robles-Medina, A., Chisti, Y. "Recovery of Microalgal Biomass and Metabolites: Process Options and Economics." Biotechnology Advances 20 (2003): 491-515.

Morist, A., Montesinos, J. L., Cusidó, J. A., Gòdia, F. "Recovery and Treatment of Spirulina platensis Cells Cultured in a Continuous Photobioreactor to be Used as Food." Process Biochemistry 37, no. 5 (2001): 535-547.

Norsker, N., Barbosa, M. J., Vermuë, M. H., Wijiffels, R. H. "Microalgal Production - A Close Look at the Economics.” Biotechnology Advances 29 (2011): 24-27.

NREL, "US LCI Database Project: Final Phase I Report.” Franklin Associates, Sylvatica, 2002.

Perry, R. H., Green, D. W. "Perry's Chemical Engineers' Handbook, $\quad$ 7th Edition.” McGrawHill: 1997.

Posten, C. "Design Principles of Photobioreactors for Cultivation of Microalgae. Engineering Life Science 9, no. 3 (2009): 165-177. 
Raymond, L. "Initial Investigations of Shallow-Layer Algal Production System: Report to Hawaii Natural Energy Institute." University of Hawaii and the Department of Planning and Economic Development: Honolulu, Hawaii, 1977, p 27.

Rodolfi, L., Zittelli, G., Bassi, N., Padovani, G., Biondi, N., Bonini, G., Tredici, M. R. "Microalgae for Oil: Strain Selection, Induction of Lipid Synthesis and Outdoor Mass Cultivation in a Low-Cost Photobioreactor." Biotechnology and Bioengineering 102, no. 1 (2008): 100-112.

Ross, S. A., Westerfield, R. W., Jaffe, J. F., Jordan, B. D. "Corporate Finance: Core Principles and Applications." McGraw Hill: New York, N.Y., 2007.

RS Means CostWorks, 2010: http://www.meanscostworks.com/ (accessed July 2011).

Sánchez, J. F., Fernández, J. M., Acién, F. G., Rueda, A., Pérez-Parra, J., Molina, E. "Influence of Culture Conditions on the Productivity and Lutein Content of the New Strain Scenedesmus almeriensis." Process Biochemistry 43 (2008): 398-405.

Sander, K., Murthy, G. "Life Cycle Analysis of Algae Biodiesel." The International Journal of Life Cycle Assessment 15, no. 7 (2010): 704-714.

Scragg, A. H., Illman, A. M., Carden, A., Shales, S. W. "Growth of Microalgae with Increased Calorific Values in a Tubular Bioreactor." Biomass and Bioenergy 23 (2002): 67-73.

Sheehan, J., Camobreco, V., Duffield, J., Graboski, M., Shapouri, H. "Life Cycle Inventory of Biodiesel and Petroleum Diesel for Use in an Urban Bus." NREL, 1998, p 315.

Sialve, B., Bernet, N., Bernard, O. "Anaerobic Digestion of Microalgae as a Necessary Step to Make Microalgal Biodiesel Sustainable.” Biotechnology Advances 27, no. 4 (2009): 409-416.

Shirvani, T., Yan, X., Inderwildi, O. R., Edwards, P. P., King, D. A. "Life Cycle Energy and Greenhouse Gas Analysis for Algae-Derived Biodiesel." Energy and Environmental Science 4 (2011): 3773-3778.

Spilling, K., Seppälä, J., Tamminen, T. "Inducing Autoflocculation in the Diatom Phaeodactylum tricornutum through $\mathrm{CO}_{2}$ Regulation.” Journal of Applied Phycology (2010): 1-8.

Soda, S., Iwai, Y., Sei, K., Shimod, Y., Ike, M. "Model Analysis of Energy Consumption and Greenhouse Gas Emissions of Sewage Sludge Treatment Systems with Different Processes and Scales." Water Science \& Technology 61, no. 2 (2010): 365-73.

Soratana, K., Landis, A. E. "Evaluating Industrial Symbiosis and Algae Cultivation from a Life Cycle Perspective.” Bioresource Technology 102 (2011): 6892-6901.

Starbuck, C. M. Comment on "Environmental Life Cycle Comparison of Algae to Other Bioenergy Feedstocks." Environmental Science and Technology (2010).

Stephens, E., Ross, I. L., King, Z., Mussgnug, J. H., Kruse, O., Posten, C., Borowitzka, M. A., Hankamer, B. "An Economic and Technical Evaluation of Microalgal Biofuels." Nature Biotechnology 28, no. 2 (2010): 126-128. 
Stephenson, A. L., Kazamia, E., Dennis, J. S., Howe, C. J., Scott, S. A., Smith, A. G. "Life-Cycle Assessment of Potential Algal Biodiesel Production in the United Kingdom: A Comparison of Raceways and Air-Lift Tubular Bioreactors.” Energy and Fuels 24, no. 7 (2010): 4062-4077.

Sturm, B. S. M., Lamer, S. L. "An Energy Evaluation of Coupling Nutrient Removal from Wastewater with Algal Biomass Production.” Applied Energy 88 (2011): 3499-3506.

Subhadra, B. G. Comment on "Environmental Life Cycle Comparison of Algae to Other Bioenergy Feedstocks.” Environmental Science and Technology 44, no. 9 (2010): 3641-3642.

Thomas, J. D., Sterry, P. R., Patience, R. L. "Uptake and Assimilation of Short Chain Carboxylic Acids by Biomphalaria glabrata (Say), the Freshwater Pulmonate Snail Host of Schistosoma mansoni (Sambon)." Proceedings of the Royal Society of London, Series B, Biological Sciences 222, no. 1229 (1984): 447-476.

Thomas, W. H., Seibert, D. L. R., Alden, M., Neori, A., Eldridge, P. "Yields, Photosynthetic Efficiencies and Proximate Composition of Dense Marine Microalgal Cultures II - Dunaliella primolecta and Tetraselmis suecica Experiments." Biomass 5, no. 3 (1984): 211-225.

Torzillo, G., Carlozzi, P., Pushparaj, B., Montaini, E., Materassi, R. "A Two-Plane Tubular Photobioreactor for Outdoor Culture of Spirulina." Biotechnology and Bioengineering 42 (2004): 891-898.

Travieso, L., Hall, D. O., Rao, K. K., Benitez, F., Sánchez, E., Borja, R. A. "Helical Tubular Photobioreactor Producing Spirulina in a Semicontinuous Mode." International Biodeterioration and Biodegradation 47 (2001): 151-155.

U.S. Department of Transportation, Federal Highway Administration, Highway Statistics, 2007: http://www.fhwa.dot.gov/policyinformation/statistics/2007/vm1.cfm (accessed February 2011).

U.S. Energy Information Administration: http://www.eia.gov/ (accessed March 2011).

U.S. Internal Revenue Service, "How to Depreciate Property? - IRS Instructional Form CAT No. 13081F.” Internal Revenue Service: Washington D.C., 2011.

Weidema, B. “Ecoinvent Data v2.0.” http://www.ecoinvent.org/ (accessed September 2008).

Weissman, J. C., Tillett, D. M. "Design and Operation of an Outdoor Microalgae Test Facility: Large-Scale System Results.” NREP: Golden, CO, 1990.

Widjaja, A., Chien, C., Ju, Y. "Study of Increasing Lipid Production from Fresh Water Microalgae Chlorella vulgaris." Journal of the Taiwan Institute of Chemical Engineers 40 (2009): 13-20.

Yoo, C., Jun, S., Lee, J., Ahn, C., Oh, H. "Selection of Microalgae for Lipid Production under High Levels Carbon Dioxide.” Bioresource Technology 101 (2010): S71-S74.

Yu, G., Zhang, Y., Schideman, L., Funk, T. L., Wang, Z. "Hydrothermal Liquefaction of Low Lipid Content Microalgae into Bio-crude Oil." Transactions of the American Society of Agricultural and Biological Engineers 54, no. 1 (2011): 239-246. 
Zamalloa, C., Vulsteke, E., Albrecht, J., Verstraete, W. "The Techno-Economic Potential of Renewable Energy through the Anaerobic Digestion of Microalgae." Bioresource Technology 102 (2011): 1149-1158.

Zittelli, G., Pastorelli, R., Tredici, M. R. "A Modular Flat Panel Photobioreactor (MFPP) for Indoor Mass Cultivation of Nannochloropsis sp. under Artificial Illumination." Journal of Applied Phycology 12 (2000): 521-526. 


\section{Chapter 5 \\ Evaluating Estrogenicity Removal and Bioenergy Production in an Integrated WWTP + Algae Cultivation System}

\subsection{Motivation}

The proposed integrated algae-wastewater system can benefit both wastewater treatment plant (WWTP) and algae farming. WWTPs could forgo advanced nutrient removal processes to maximize algae yields by recapturing these nutrients in the form of biomass, which can be converted fuel. However, it has been demonstrated that the extent of nitrogen removal in a typical WWTP is linked with removal of estrogenic endocrine disrupting compounds (eEDCs) (Ternes, Joss and Siegrist, 2004; Khanal et al., 2006). Although these chemicals are currently unregulated, they have been shown to cause adverse impacts on aquatic ecosystems and human health (Campbell et al., 2006). Thus, it is desirable to assess whether eEDCs are appreciably removed during algae cultivation conditions. If so, coupling algae cultivation and wastewater treatment could simultaneously address three environmental challenges: eutrophication caused by excessive nutrient content of wastewater effluents; harmful effects of anthropogenic estrogens (i.e., eEDCs) on ecosystem and human health; and the energy and greenhouse gas footprint associated with producing energy from biomass feedstock.

The synergism between algae cultivation for bioenergy production and municipal wastewater treatment presents difficulties. First, nutrient and eEDC flows cannot be uncoupled during wastewater treatment, since both are present in the wastewater stream. These materials may impact algae growth very differently (Ternes, Joss and Siegrist, 2004; Khanal et al., 2006). Second, eEDC removal during conventional activated sludge (CAS) treatment is not a straightforward process; rather, it occurs via some combination of sludge sorption and biodegradation by ammonia-oxidizing bacteria or aerobic heterotrophs. This suggests that algaemediated eEDC removal, if it does occur, may proceed in a complicated manner (Khunjar et al., 
2011; Ren et al., 2007). This combination of possible benefits and costs associated with integration of municipal wastewater treatment and algae cultivation makes it desirable to perform an overall assessment of the proposed system.

\subsection{Review of Literature}

Measurements of the so-called "estrogenic emerging" contaminants or eEDCs in municipal and industrial effluents has been reported in literature, and it has been demonstrated that eEDCs simulate the physiological effects of steroid hormones by binding with estrogen receptors causing disruption to the endrocrine system (Campbell et al., 2006; Desbrow and Routledge, 1998). WWTPs are the primary of sources of eEDCs into the environment, though livestock and agricultural runoff also constitute non-point sources (Sumpter and Johnson, 2005; Kolpin et al., 2002). The chemical structures, relative estrogenicity, and typical concentrations of several representative natural and synthetic steroid eEDCs are depicted in Table 5.1.

Table 5.1. Representative estrogens and their properties.

$\begin{array}{ccc}\text { Estrogen } & \text { Chemical Structure } & \text { Relative Estrogenicity }{ }^{\mathrm{A}} \begin{array}{c}\text { Concentrations in } \\ \text { U.S. waters (ng/L) }\end{array} \\ \text { Estrone (E1) } & 0.1-0.2 & 160\end{array}$

A. Khanal et al. (2006); In 17- $\beta$ estradiol (E2) equivalent

B. Kolpin et al. (2002).

Conventional WWTPs generally remove $85 \%$ - $99 \%$ of $17-\beta$ estradiol (E2) and $25-80 \%$ of estrone (E1) (Khanal et al., 2006) under normal conditions. But the sustainability benefits of integrated algae-wastewater systems increase as effluent nitrogen $(\mathrm{N})$ and phosphorus $(\mathrm{P})$ concentrations increase, and, there is evidence to suggest that WWTP's nutrient removal and 
estrogen removal are linked. The mechanism is not completely understood at present, but some authors speculate that there may be overlap between the microbial communities responsible for nitrification and estrogen removal (Khanal et al., 2006; Ternes, Joss and Siegrist, 2004). Thus, if WWTP operators were to scale back on nutrient removal to save on WWTP energy costs and leave higher $\mathrm{N}$ and $\mathrm{P}$ concentrations for algae farmers, estrogen concentrations in the effluent will likely also increase. Certain advanced tertiary treatments (e.g., ozonation, UV radiation, reverse osmosis, and adsoprtion) could be deployed to decrease eEDC concentrations in WWTP effluent (Sumpter and Johnson, 2005) but these are costly and difficult to scale up. In addition, they frequently create unknown by-products that can be more harmful than the parent steroid (Westerhoff et al., 2005). As such, it would be highly desirable if the algae themselves could remove the eEDCs during effluent-irrigated algae cultivation. This would further compound the synergies between algae cultivation and municipal wastewater treatment.

Bench-scale laboratory studies provide preliminary evidence for algae-mediated eEDC removal under highly controlled conditions, and it has been previously observed that certain algae strains can mediate eEDC removal via biosorption and/or biotransformation (Lai, Scrimshaw and Lester, 2002). Figure 5.1 depicts the various removal mechanisms in wastewater-irrigated algae cultivation. The fractions of each removal mechanism can be determined experimentally.

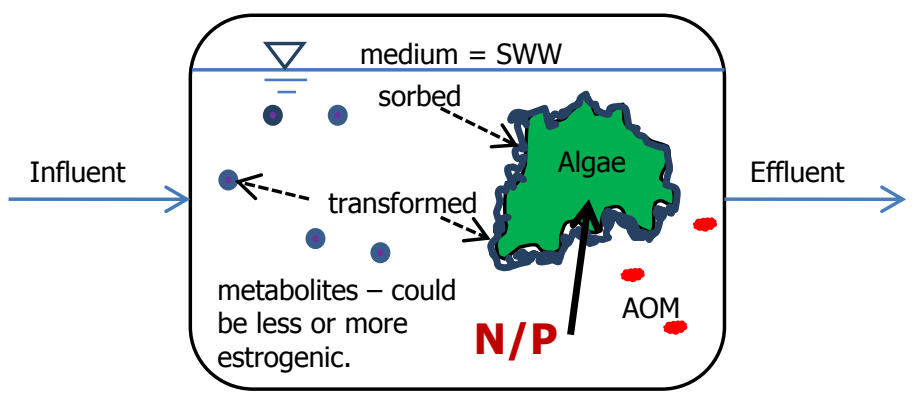

Figure 5.1. Schematic of hypothesized estrogen removal reactions for the proposed algaemediated tertiary treatment. Possible mechanisms for eEDC removal include photolysis, biodegradation, or biosorption. AOM is algal organic matter. 


\subsection{Methods}

The methodology for this chapter was divided into three distinct tasks - one experimental and two modeling namely:

1. Experimental measurement of $17 \beta$-estradiol (E2) removal during algae cultivation;

2. Life cycle assessment modeling of an integrated WWTP + algae cultivation system incorporating estrogenic endocrine-disrupting compound (eEDC) removal; and

3. Life cycle assessment modeling of selected conventional tertiary wastewater treatments (i.e., chemical, filtration and adsorption) as benchmarks for the proposed algae-mediated tertiary treatment system.

For the experimental analyses, an analytical method was developed to quantify algae-mediated eEDC removal during simulated algae cultivation. These results were combined with limited literature values for other eEDC removal studies and then incorporated into the LCA model comprising Task 2 above. For both Tasks 2 and 3, it was assumed that secondary effluent from a WWTP utilizing conventional activated sludge (CAS) with minimal biological nutrient removal (BNR) was fed to each type of tertiary treatment (algae or conventional) and that all WWTP processes upstream of tertiary treatment were identical. The subsequent sections describe these tasks in more detail.

\subsubsection{Laboratory Measurement of Algae-Mediated Estrogen Removal}

\subsubsection{Chemicals and Culture Media}

Analytical standards of E2 (Sigma Aldrich, Inc., 2012) were prepared in LCMS-grade methanol (Fisher Scientific, Inc., 2012). E2 concentrations ranged from $20-800 \mu \mathrm{g} / \mathrm{L}$. These standards were stored at $-20{ }^{\circ} \mathrm{C}$ for up to one month. Two types of algae growth media were prepared based 
on previously published formulations: protease medium and modified Bold 3N (MB3N) medium (University of Texas Culture Collection of Algae, 2012) (See Appendix A).

\subsubsection{In-Vitro Algae Cultivation}

Scenedesmus dimorphus was cultivated in bench-scale batch reactors. A three-step process was used to produce sterile monocultures: (1) pre-incubation using protease medium (10 $\mathrm{mL}$ per tube with cap $\times 8$ tubes) for 5 days; (2) pre-incubation using protease medium $(200 \mathrm{~mL}$ per flask with sealed cover $\times 4$ flasks) for another 5 days; and (3) "simulated cultivation" in MB3N medium spiked with eEDC (600-800 mL per flask with sealed cover $\times 3$ flasks). Cultures were subjected to 12 hours of darkness and 12 hours of light in all three stages, using a 125-W CFL grow light bulb 6,500 K (Feliz World, 2011). The light intensity was approximately $100 \mu \mathrm{E} / \mathrm{m}^{2} * \mathrm{sec}$ in all culture flasks at different angles. For the first and second stages of pre-incubations, the medium containing the algae cells was agitated using a rotisserie shaker and a crab shaker, respectively. The caps and covers for the tubes and flasks for both pre-incubation stages were periodically loosened (but not completely opened) to permit air exchange. Roughly $75 \%$ of the volume in each reactor was head space. Solutions in the third-stage incubation were stirred $(100 \mathrm{rpm})$ and sparged with sterile air at 0.7 SCFM. Several types of flasks prepared for the third-stage incubation were as follows: (1) one irradiated ("lit") flask containing $800 \mathrm{~mL}$ MB3N medium and autoclaved algae, for the evaluation of photolysis and biosorption together in the absence of biodegradation; (2) one dark (foil-wrapped) flask containing $800 \mathrm{~mL}$ of MB3N medium spiked with E2, for use as a dark positive control; (3) one irradiated flask containing $800 \mathrm{~mL}$ of MB3N medium spiked with E2, for use as a light positive control; and, (4) three irradiated flasks containing $600 \mathrm{~mL}$ of MB3N medium spiked with E2 and also live algae biomass (at $100 \mathrm{mg} / \mathrm{L}$ ), to evaluate photolysis, biosorption, and biodegradation together under simulated algae cultivation conditions. At appropriate intervals, samples were extracted from each reactor. Each sample's 
optical density reading at $662 \mathrm{~nm}$ was taken using UV-spectrophotometer and algae cells were counted using hemocytometer (See Appendix B). Figure 5.2 is a schematic of the in-vitro algae cultivation set-up employed in this study.

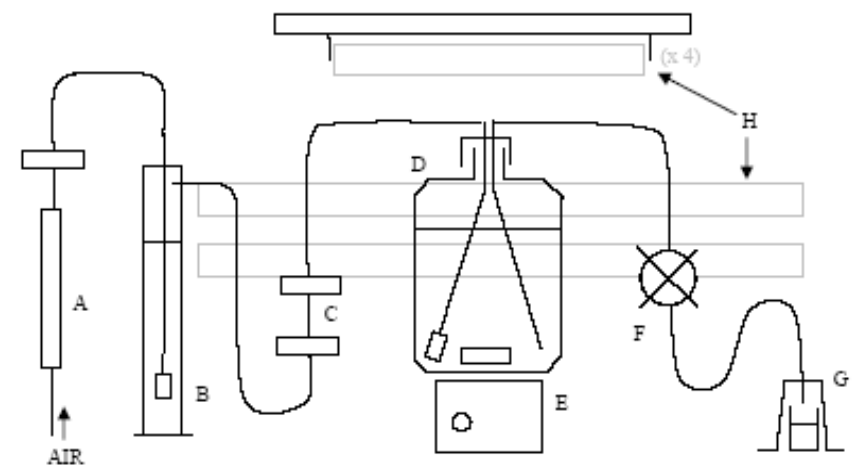

Figure 5.2. Schematic of the algae cultivation set-up employed in this analysis. Components are denoted with upper-case letters as follows: $\mathrm{A}=$ air vessel, $\mathrm{B}=$ humidifier, $\mathrm{C}=$ air filter, $\mathrm{D}=$ sterile flask with algae solution, $\mathrm{E}=$ stirrer/heater combo, $\mathrm{F}=$ sterile pinchcock, $\mathrm{G}=$ ground, and $\mathrm{H}=$ light source.

\subsubsection{Sample Clean-Up and Concentration}

$100-\mathrm{mL}$ samples collected from each of the reactors described above were filtered using $0.8-\mu \mathrm{m}$ Whatman glass fiber filters. The permeates were then subjected to previously validated solidphase extraction (SPE) and high performance liquid chromatography-mass spectrometry (HPLC) protocols, for analysis of aqueous phase E2 concentration (Pagsuyoin, Lung and Colosi, 2012). Prior to analysis of actual samples, an E2 standard calibration curve was generated by preparing various E2 concentrations in methanol $(20-800 \mathrm{ng} / \mathrm{L})$ (See Appendix B). An Oasis® HLB (3 cc/60 mg) SPE cartridge and a pump with a vacuum pressure of 5-15 psig were used. Preconditioning with $3 \mathrm{~mL} \mathrm{MeOH}$ and equilibration with $3 \mathrm{~mL}$ Milli-Q water were done prior to loading ( 10 mL/min) of samples. After loading, cartridges were washed with $3 \mathrm{~mL} 5 \%(\mathrm{v} / \mathrm{v})$ $\mathrm{MeOH} / \mathrm{Milli}-\mathrm{Q}$ water. Cartridges were eluted by passing $2 \mathrm{~mL} \mathrm{MeOH}$ at $5 \mathrm{psig}$. The eluate was vacuum-dried to dryness under a gentle stream of air and then reconstituted into $500 \mu \mathrm{L} \mathrm{MeOH}$ in 
a glass sampling vial. The reconstituted eluate was then filtered using a $0.20-\mu \mathrm{m} \times 13-\mathrm{mm}$ Millipore PTFE syringe filter and then transferred to glass HPLC vials.

The filter cakes arising from passage of the collected samples through 0.8 - $\mu \mathrm{m}$ Whatman glass fiber filters were analyzed for sorbed-phase E2 concentrations using a modified protocols from (Lai, Scrimshaw and Lester, 2002; Ottmar, Colosi and Smith, 2012). The filter paper was dried at $105{ }^{0} \mathrm{C}$ for 2 hours. The wet and dry masses of all filters collected were measured. Extraction was done through re-suspension of the dried algae cells into $50 \mathrm{~mL}$ dichloromethane (DCM) and shaking in an incubator for 12 hours. The samples were then centrifuged at 2,000 $\mathrm{g}$ for 60 minutes. The supernatants were dried to $2-\mathrm{mL}$ final volumes, syringe-filtered to remove particulates, and then transferred to HPLC vials for E2 measurement. Figure 5.3 summarizes preparation of aqueous-phase and sorbed-phase E2 concentrations in samples collected from the algae reactors. 


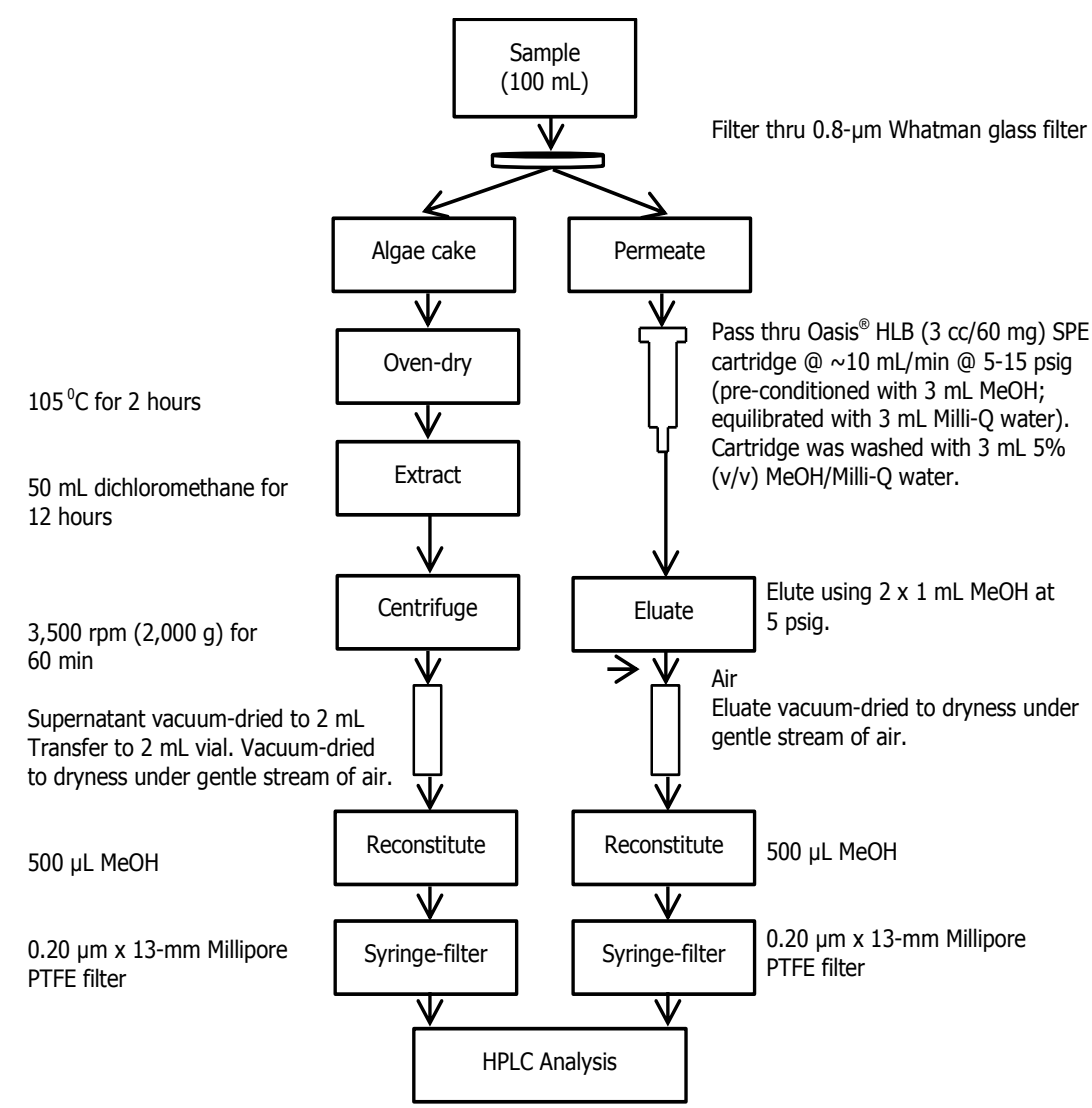

Figure 5.3. Summary of sample preparation protocols used prior to high-performance liquid chromatography (HPLC) analysis.

\subsubsection{Measuring E2 Concentrations via HPLC}

Prior to actual sample HPLC measurements, a solution containing $50 \mathrm{ng} / \mathrm{L}$ E2 in $100 \mathrm{~mL}$ sample was prepared as per Figure 5.3 to evaluate background "noise" and E2 recovery ( $90 \%$ of initial sample concentration was recovered). E2 concentrations in prepared samples were measured using a Shimadzu Prominence 20A-series chromatograph equipped with UV-Vis and fluorescence detectors. Best detection results were achieved using the fluorescence detector, with excitation wavelength set to $280 \mathrm{~nm}$ and emission wavelength set to $310 \mathrm{~nm}$. The column was a $\operatorname{Restek}^{\circledR}$ reverse-phase biphenyl column $(150 \mathrm{~mm} \times 2.1 \mathrm{~mm} \times 5 \mu \mathrm{m})$. The mobile phase comprised a mixture of deionized (DI) water containing $25 \mathrm{mM} \mathrm{H}_{3} \mathrm{PO}_{4}$ (A) and HPLC-grade acetonitrile (ACN) (B) pumped at a rate of $0.75 \mathrm{~mL} / \mathrm{min}$. The following gradient method was 
used: 0-15 minutes (30\% B); 15-23 minutes (30-40\% B); 23-26 minutes (40\% B); 26-27 minutes (40-10\% B); 27-32 minutes (10-30\% B); 32-40 minutes (30\% B). The injection volume was 100 $\mu \mathrm{L}$. Using this method, E2 retention time was determined to be approximately 24.4 minutes.

\subsubsection{Description of WWTP Unit Processes}

It was assumed that the same WWTP operations upstream of tertiary treatment were used in all LCA methods. This includes primary treatment and secondary treatment using conventional activated sludge. These processes are explained in more detail in the following paragraphs.

Primary Treatment. Primary treatment is also referred to as sedimentation or clarification, wherein, wastewater flows into large, quiescent tanks to reduce the concentrations of suspended solids and some organic materials (Menger-Krug, Niederste-Hollenberg and Hillenbrand, 2012). Table 5.2 presents typical water quality characteristics of the raw influent and the partially pretreated wastewater flowing into primary treatment. The differences between these two wastewaters arise from use of a flow equalization basin, for dilution, and also screening and grit removal. These operations were excluded from the modeled WWTP system, but it was assumed that they have occurred. 
Table 5.2. Typical water quality parameters for medium-strength wastewater in the U.S. "Raw" refers to the influent wastewater. "Pretreated" refers to the wastewater flowing into primary treatment, after it has undergone equalization, screening, and grit removal.

\begin{tabular}{|c|c|c|c|}
\hline Wastewater Component & $\begin{array}{c}\text { Raw } \\
(\mathrm{mg} / \mathrm{L})\end{array}$ & $\begin{array}{l}\text { Pretreated } \\
(\mathrm{mg} / \mathrm{L})\end{array}$ & Source \\
\hline $\begin{array}{l}\text { Chemical Oxygen } \\
\text { Demand (COD) }\end{array}$ & 538 & 430 & Metcalf and Eddy (2003) \\
\hline $\begin{array}{l}\text { Biological Oxygen } \\
\text { Demand }\left(\mathrm{BOD}_{5}\right)\end{array}$ & 208 & 166 & Rivanna Water and Sewer Authority (2007) \\
\hline $\begin{array}{l}\text { Total Suspended Solids } \\
\text { (TSS) }\end{array}$ & 263 & 210 & Metcalf and Eddy (2003) \\
\hline $\begin{array}{l}\text { Volatile Suspended } \\
\text { Solids (VSS) }\end{array}$ & 200 & 160 & Metcalf and Eddy (2003) \\
\hline $\begin{array}{l}\text { Total Kjeldahl Nitrogen } \\
\text { (TKN) }\end{array}$ & 63 & 50 & $\begin{array}{l}\text { Carey and Migliaccio (2009); Zorita, Martensson and } \\
\text { Mathiasson (2009) }\end{array}$ \\
\hline $\begin{array}{l}\text { Nitrogen as Ammonia } \\
\left(\mathrm{NH}_{3}-\mathrm{N}\right)\end{array}$ & 36 & 29 & Carey and Migliaccio (2009) \\
\hline $\begin{array}{l}\text { Nitrogen as Nitrate } \\
\left(\mathrm{NO}_{3}^{-}-\mathrm{N}\right)\end{array}$ & 0 & 0 & Carey and Migliaccio (2009) \\
\hline Total Phosphorus (TP) & 12 & 9 & $\begin{array}{l}\text { Carey and Migliaccio (2009); Zorita, Martensson and } \\
\text { Mathiasson (2009) }\end{array}$ \\
\hline Alkalinity $\left(\right.$ as $\left.\mathrm{CaCO}_{3}\right)$ & 250 & 200 & Metcalf and Eddy (2003) \\
\hline
\end{tabular}

Average daily flow to the primary treatment basin was based on the current design capacity of the Moore's Creek WWTP (Rivanna Water and Sewer Authority, 2007) plus an additional 5\% for expected future growth. This flow rate corresponds to roughly $59,400 \mathrm{~m}^{3} / \mathrm{day}$. The peak surface daily flow is 35.3 MGD or $133,625 \mathrm{~m}^{3} /$ day. The corresponding overflow rate based on average flow was $40 \mathrm{~m}^{3} / \mathrm{m}^{2} *$ day (Metcalf and Eddy, 2003). This overflow rate is critical since it is used to determine the total area occupied by primary treatment tanks as in Equation 5.1.

$$
A=\frac{Q_{\text {ave }}}{O R} \quad \text { Equation } 5.1
$$

Here, $A$ is the total base area of $n$ primary basins (ha), $Q_{\text {ave }}$ is the design capacity of the WWTP based on average flow $\left(133,625 \mathrm{~m}^{3} /\right.$ day) and $O R$ is the overflow rate based on average flow (40 $\mathrm{m}^{3} / \mathrm{m}^{2} *$ day). Total base area for primary treatment was computed to be 0.15 ha. 
In actuality, the Virginia Sewage Collection and Treatment (VSCAT) Regulations recommend operation at higher than design overflow rates, to increase carbon loading into downstream biological processes (VSCAT, 2007). Thus, in this study, we used the same primary treatment configuration that is currently in place at the Moore's Creek WWTP; whereby two primary basins are used together to deliver the total basin area from Equation 5.1. The length of each rectangular basin, for an assumed channel width of $6 \mathrm{~m}$ and an assumed depth of $4 \mathrm{~m}$, is roughly $124 \mathrm{~m}$ (Rivanna Water and Sewer Authority, 2007). Thus, the final dimensions of a rectangular PT basin are $6 \mathrm{~m} \times 124 \mathrm{~m} \times 4 \mathrm{~m}(\mathrm{~W} \times \mathrm{L} \times \mathrm{H})$.

The accurate determination of hydraulic retention time (HRT) is an important design consideration because it dictates five-day biological oxygen demand $\left(\mathrm{BOD}_{5}\right)$ removal, total suspended solids (TSS) removal and electricity demand of the primary treatment module. In this analysis, two types of HRT were calculated for primary treatment: HRT based on average flow and HRT based on peak flow. HRT calculation is represented by Equation 5.2.

$$
H R T=\frac{V}{Q} \quad \text { Equation } 5.2
$$

Where $V$ is the total volume of influent wastewater $\left(\mathrm{m}^{3}\right)$ and $Q$ is the daily flow $\left(59,424.5 \mathrm{~m}^{3} /\right.$ day $)$ or peak daily flow $\left(133,625 \mathrm{~m}^{3} /\right.$ day $)$. HRT values were calculated to be 2.4 hours and 1.1 hours, based on average flow and peak flow, respectively. To be conservative, the HRT employed in this analysis was 2.4 hours.

It was also necessary to calculate and compare scouring velocity $v_{H}$ and peak flow velocity $v_{\text {peak }}$ to ensure satisfactory sedimentation during primary treatment. Scouring velocity is defined as the minimum velocity of water flowing into the primary basin that will result in re-suspension of 
primary sludge. To avoid re-suspension, the maximum allowable velocity of water flow into the primary basin (i.e., $v_{\text {peak }}$ ) must always be significantly lower than $v_{H}$. Calculation of $V_{H}$ is given by Equation 5.3 (Metcalf and Eddy, 2003).

$$
v_{H}=\left(\frac{8 k(s-1) g d}{f}\right)^{1 / 2} \quad \text { Equation } 5.3
$$

Here, $k$ is the cohesion constant (0.05), $s$ is the specific gravity of primary sludge (1.25), $g$ is the acceleration due to gravity $\left(9.81 \mathrm{~m} / \mathrm{s}^{2}\right), d$ is the average diameter of solid particles in primary sludge $(0.1 \mathrm{~mm})$, and $f$ is the Darcy-Weisbach friction factor $(0.025)$. With these values, Equation 5.3 gives $V_{H}=0.063 \mathrm{~m} / \mathrm{s}$. A value for $v_{\text {peak }}$ is obtained by dividing $Q_{\text {peak }}$ by the total crosssectional area perpendicular to flow in two rectangular basins $\left(A=6 \mathrm{~m} \mathrm{~W} \times 4 \mathrm{~m} \mathrm{~L} \times 2=24 \mathrm{~m}^{2}\right)$. The resulting value for $v_{\text {peak }}(0.032 \mathrm{~m} / \mathrm{s})$ is substantially smaller than $v_{H}$, thus there will be no appreciable re-suspension during primary treatment.

TSS removal efficiency is an important parameter for calculation of the water balance during primary treatment. It is defined by Equation 5.4, where $R$ is TSS removal efficiency, $H R T$ is hydraulic retention time (days), $a$ and $b$ are TSS empirical constants $(0.0075$ and 0.014 for a and b, respectively) (Metcalf and Eddy, 2003).

$$
R=\frac{H R T}{a+b * H R T} \quad \text { Equation } 5.4
$$

From Equation 5.4, $R$ is $58.4 \%$ for primary treatment within the modeled WWTP system. Other removal efficiencies for primary treatment were taken from literature: 33\% COD removal, 10\% TKN removal, and 11\% TP removal (Menger-Krug, Niederste-Hollenberg and Hillenbrand, 2012). 
Electricity demand for primary treatment was based on the power consumption of three variablespeed waste activated sludge (WAS) pumps in operation at the Moore's Creek WWTP. Each of these has the following specifications: 475-1,195 gallons per minute (gpm), $15 \mathrm{ft}$ total discharge head, $60 \%$ efficiency, $695 \mathrm{rpm}$ maximum speed, and $7.5 \mathrm{hp}$ motor size. Resulting electricity demand for operating two primary treatment basins was $242 \mathrm{MJ} / \mathrm{yr} * \mathrm{FU}$.

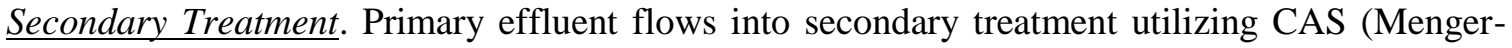
Krug, Niederste-Hollenberg and Hillenbrand, 2012). The key objective of secondary treatment is conversion of dissolved organic carbon (DOC) (i.e., $\mathrm{BOD}_{5}$ ) in the wastewater into $\mathrm{CO}_{2}$ through the action of heterotrophic aerobic microorganisms (Maier, Pepper and Garba, 2009). Literature values were used for DOC conversion during secondary treatment. It was assumed that approximately $93 \%(\mathrm{~m} / \mathrm{m})$ of DOC is removed; $43 \%$ is incorporated into secondary sludge, and $50 \%$ is transferred into the air as $\mathrm{CO}_{2}$.

Nitrogen removal proceeds via simultaneous nitrification-denitrification (Metcalf and Eddy, 2003). Nitrification is the oxidation of ammonium $\left(\mathrm{NH}_{4}{ }^{+}\right)$to nitrate $\left(\mathrm{NO}_{3}{ }^{-}\right)$via the action of nitrifying microorganisms (Maier, Pepper and Garba, 2009). Denitrification is the reduction of $\mathrm{NO}_{3}{ }^{-}$to $\mathrm{N}_{2}$ gas via denitrifying microorganisms (Maier, Pepper and Garba, 2009). In this analysis, it was assumed that $55 \%(\mathrm{~m} / \mathrm{m})$ of total Kjeldahl nitrogen (organic $\mathrm{N}, \mathrm{NH}_{4}^{+}$and $\mathrm{NO}_{3}^{-}$.) is removed during secondary treatment; whereby, $30 \%$ is incorporated into secondary sludge, and $25 \%$ is transferred into the air as $\mathrm{N}_{2}$ (Carey and Migliaccio, 2009; Zorita, Martensson and Mathiasson, 2009). The $45 \%$ of TKN that is not removed during secondary treatment remains in the secondary effluent. Enhanced biological removal of phosphorus is accomplished during secondary treatment by a group of microorganisms known as polyphosphate-accumulating organisms (PAOs) (Menger-Krug, Niederste-Hollenberg and Hillenbrand, 2012). These 
microorganisms preferentially take up large quantities of phosphorus into their cells. Removal of total phosphorus (i.e., organic $\mathrm{P}+\mathrm{PO}_{4}{ }^{3-}$ ) removal (TP) during secondary treatment was assumed to be $90 \%$; all of which is incorporated into secondary sludge, since none can be transferred into the air (Carey and Migliaccio, 2009; Zorita, Martensson and Mathiasson, 2009). Table 5.3 summarizes nutrient concentrations in typical secondary effluent.

Table 5.3. Average nutrient concentrations of a typical medium-strength wastewater in the U.S. after secondary treatment secondary treatment via CAS employing BNR.

\begin{tabular}{|c|c|c|}
\hline Nutrient & $\begin{array}{l}\text { Concentration } \\
\text { Range (mg/L) }\end{array}$ & Source \\
\hline $\begin{array}{l}\text { Total Kjeldahl Nitrogen } \\
\text { (TKN) }\end{array}$ & $9.3-35$ & $\begin{array}{l}\text { Carey and Migliaccio (2009); Zorita, Martensson and } \\
\text { Mathiasson (2009) }\end{array}$ \\
\hline $\begin{array}{l}\text { Nitrogen as Ammonia } \\
\left(\mathrm{NH}_{3}-\mathrm{N}\right)\end{array}$ & $1-10$ & Carey and Migliaccio (2009) \\
\hline $\begin{array}{l}\text { Nitrogen as Nitrate } \\
\left(\mathrm{NO}_{3}^{-}-\mathrm{N}\right)\end{array}$ & $10-30$ & Carey and Migliaccio (2009) \\
\hline Total Phosphorus (TP) & $1.4-10$ & $\begin{array}{l}\text { Carey and Migliaccio (2009); Zorita, Martensson and } \\
\text { Mathiasson (2009) }\end{array}$ \\
\hline
\end{tabular}

Design of the secondary treatment basins was also based on average daily flow rate $(59,424.5$ $\mathrm{m}^{3} /$ day) and an overflow rate of $22 \mathrm{~m}^{3} / \mathrm{m}^{2} *$ day (Metcalf and Eddy, 2003). Using Equation 5.1, the total base area for secondary treatment, which includes aeration and clarification tanks, was computed to be 0.54 ha $(0.27$ ha for aeration tanks +0.27 ha for clarification tanks).

VSCAT recommends that there be as many secondary treatment modules as there are primary treatment tanks. As such, there were two secondary aeration basins and two secondary clarifiers in the modeled system. Each of the clarifiers occupies half of the total secondary clarification area, thus the footprint for each clarifier is 0.135 ha $\left(1,351 \mathrm{~m}^{2}\right)$. Assuming each clarifier has a cylindrical shape, the design diameter of each clarifier is $41.5 \mathrm{~m}$. This is somewhat larger than the actual diameter (39.6 m) of the secondary clarifiers currently in use at the Moore's Creek WWTP (Rivanna Water and Sewer Authority, 2007). Therefore, the average of these two values, $40.5 \mathrm{~m}$, was used as the clarifier diameter in this study. The height of the clarifier was set to the height of 
the water in plus a $30 \%$ safety factor; i.e., $3.66 \mathrm{~m} \times 1.3=4.76 \mathrm{~m}$ (Rivanna Water and Sewer Authority, 2007). Thus, the final dimensions of each cylindrical secondary clarifier are $40.5 \mathrm{~m} \times$ $4.76 \mathrm{~m}(\mathrm{D} \times \mathrm{H})$. The HRT in each clarifier, based on the volume from these dimensions and the average daily flow rate $\left(59,424.5 \mathrm{~m}^{3} /\right.$ day $)$, is 3.82 hours from Equation 5.2.

Electricity consumption for secondary treatment comprises three parts: (1) power for variablespeed RAS pumps, (2) power for constant-speed RAS pumps, and (3) power for blowers in the secondary aeration system (Rivanna Water and Sewer Authority, 2007). This analysis used two variable-speed RAS pumps, three constant-speed RAS pumps, two low-powered electric blowers, and two high-powered electric blowers (Rivanna Water and Sewer Authority, 2007; MengerKrug et al., 2012). Energy consumption for each item was as follows: 20-hp for each variablespeed RAS pump; 20-hp for each constant-speed RAS pump; 300-hp for each low-powered electric blower running at 1,200 rpm; and 500-hp for each high-powered electric blower running at 1,200 rpm (Rivanna Water and Sewer Authority, 2007). Efficiencies for each piece of equipment were $74 \%$ for both kinds of RAS pumps and $80 \%$ for both kinds of electric blowers (Rivanna Water and Sewer Authority, 2007). Resulting electricity demand for operation of two, parallel secondary treatment modules (aeration basin + clarifier) was on the order of 21,886 $\mathrm{MJ} / \mathrm{yr} * \mathrm{FU}$ for the Moore's Creek flow rate.

\subsubsection{Analysis of Algae Cultivation System as a Tertiary Treatment Step}

\subsubsection{Model Overview}

The LCA model framework for the WWTP-algae cultivation was similar to the model architecture utilized in Chapters 2, 3, and 4. It was built in a spreadsheet format using Microsoft Excel in conjunction with the Crystal Ball predictive modeling suite. Detailed description of the model overview utilized in this analysis can be found in Section 3.3.1 of Chapter 3. 
Figure 5.4 shows an overview of the proposed system integrating municipal wastewater treatment and algae cultivation in OP reactors. The wastewater treatment system was presumed to comprise primary treatment (i.e., sedimentation) and secondary via activated sludge with biological nutrient removal. Biomass solids ("sludge") from both primary and secondary treatment are fed to an anaerobic digester to produce biogas via anaerobic digestion $(A D)$. For the proposed algaeintegrated system, algae biomass from the OP reactors is also fed into anaerobic digestion following autoflocculation $(A F)$ and gravity thickening $(T H)$ for dewatering. Thus, the dewatered algae biomass is "co-digested" with the WWTP sludge.

It was assumed that autoflocculation of the algae biomass proceeds spontaneously with no energy input, so long as the growth medium contains at least $0.2 \mathrm{mM} \mathrm{PO}_{4}{ }^{3-}$ in excess of the stoichiometric P demand (Spilling, Seppällä and Tamminen, 2010; Sukenik and Shelef, 1984). Supernatant from both autoflocculation and gravity thickening are combined and exit the system as treated effluent, while the thickened algae slurry enters the digester together with primary and secondary sludge. The post-digestion slurry from the digester is dewatered using a belt-filter press $(B F P)$ to a solids concentration of roughly $67.5 \%$ by weight. The nutrient-rich liquid digestate is recycled back into primary treatment. Recycling of liquid digestate further enhances nutrient removal and increases the generation of primary and secondary sludge. The biogas generated in anaerobic digestion is combusted to generate bioelectricity. Some portion of this bioelectricity is used to offset or supplant on-site electricity demands. Section 5.3.5 describes the water, solids, and estrogen balances for the algae system and its selected benchmarks. 


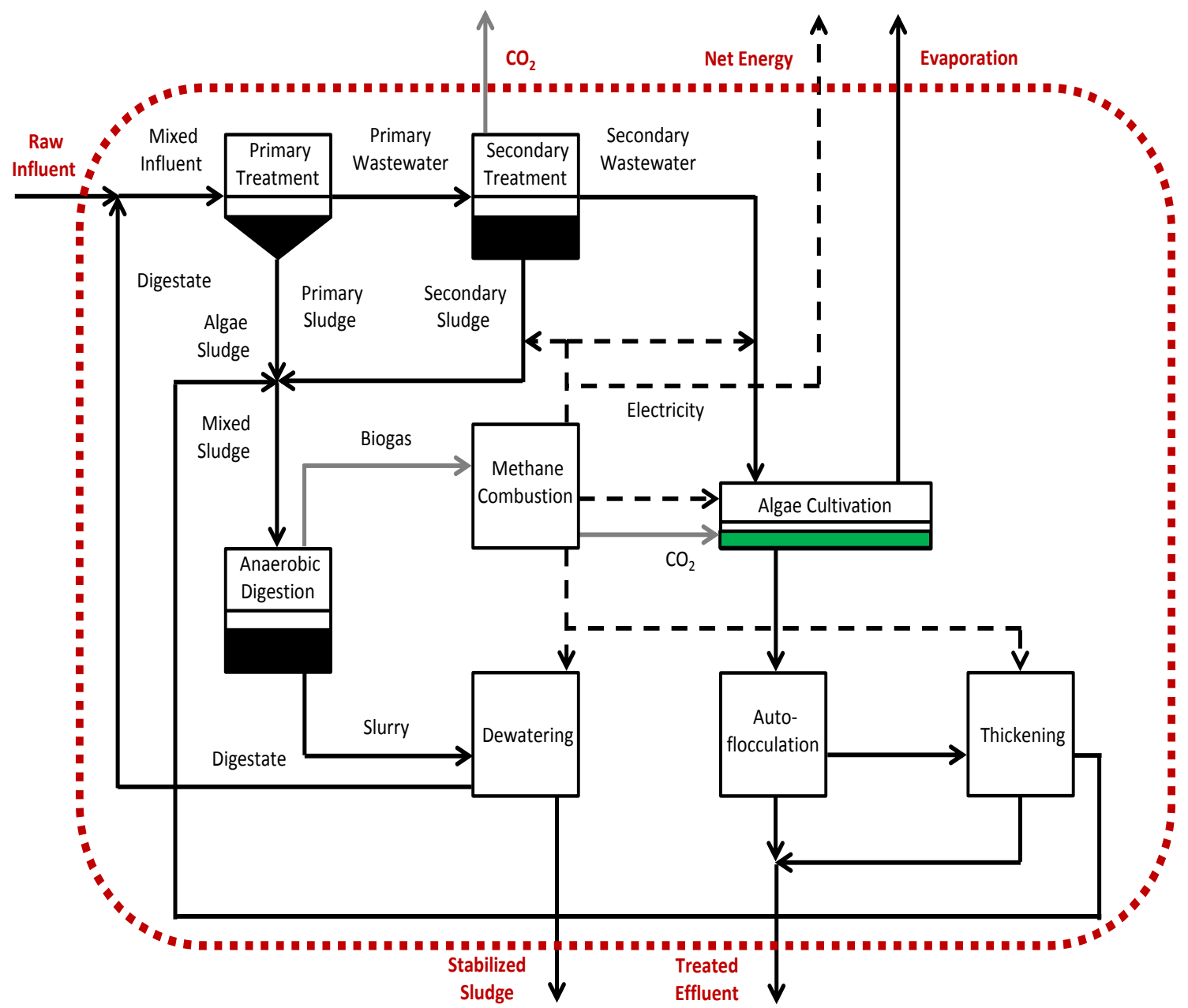

Figure 5.4. Overall process flow for a wastewater treatment plant (WWTP) employing algae cultivation (AC) to improve effluent water quality and generate bio-electricity. The "algae cultivation" unit process represents a total of 40 1-ha algae cultivation ponds. Solid dark arrows indicate solid or liquid mass flows; solid gray arrows indicate gaseous mass flows; and dashed dark arrows indicate energy flows. The heavy dashed red box represents the system boundaries.

The LCA model framework for the WWTP-algae cultivation was similar to the model architecture utilized in Chapters 2, 3, and 4. It was built in a spreadsheet format using Microsoft Excel in conjunction with the Crystal Ball predictive modeling suite. Detailed description of the model overview utilized in this analysis can be found in Section 3.3.1 of Chapter 3. 


\subsubsection{Functional Unit}

For this Chapter, it was assumed that a WWTP wishes to provide tertiary treatment for 15.7 million gallons per day (MGD) $\left(5.94 \times 10^{7} \mathrm{~L} /\right.$ day $)$ of municipal wastewater effluent. This quantity, specifically the average daily flow at a medium-sized WWTP in Charlottesville, Virginia, was used as the FU (Rivanna Water and Sewer Authority, 2007). It was selected for two reasons. First, the goal for this LCA was to compare various tertiary treatments method for delivery of effluent quality that not only satisfies pertinent water quality standards but also contains significantly lower estrogenicity relative to the raw influent. Unlike the LCAs in Chapters 2, 3, and 4, which focused primarily on generation of algae bioenergy, this work focuses on water quality benefits. Second, use of this particular quantity as FU allows for determination of physical footprint required for each system, which is an important consideration when considering actual implementation of the proposed system.

\subsubsection{Direct Land Use: Sizing the Algae-Based Tertiary Treatment System}

This modeling framework utilized OP systems because they are preferable to PBR systems, as explained in Chapter 4. The size of the algae cultivation ponds was computed based on residence time as the principal design parameter. In particular, two different residence times had to be considered: (1) the hydraulic residence time required to achieve "acceptable" eEDC removal via algae-mediated reactions in the cultivation ponds, whereby longer residence times yield better removal; and (2) the algae solids retention time yielding highest biomass concentrations during cultivation, whereby algae concentration increases up to some optimum residence time and then decreases thereafter. Other factors, including reactor type (i.e., plug-flow reactor or constantlystirred tank reactor), achievement of steady-state operations, and minimization of operations and maintenance energy costs, were also considered. 
For this study, $70 \%$ was chosen as the desired level of eEDC removal. This value corresponds to the rapid, exponential-phase removal observed during bench-scale experiments on algae-mediated eEDC removal. From our own experiments and previously published literature, $70 \%$ removal of the prototypical eEDC (17ß-estradiol, "E2") occurs in 1.2-1.8 days (Shi et al., 2010; this study's experimental data). Thereafter, the rate of eEDC removal per time decreases dramatically; whereby the slope of the concentration versus time graph approaches a horizontal asymptote. Concurrently, the concentration of the algae biomass (as measured using optical density at 662 nm) also decreases with increasing residence times longer than five days (this study's experimental data). Thus, algae pond residence time was assigned to a triangular distribution based on these constraints: minimum $=1.2$ days, maximum $=5$ days, and likeliest value $=1.7$ days. Actual removal for this range of residence times varies for individual eEDCs: $64 \%-80 \%$ for E2 from Shi et al. (2010) and this study; 45\% - 58\% for estrone (E1); and 47\% - 60\% for 17 $\alpha$ ethinylestradiol (EE2) (Shi et al., 2010). These ranges were converted to triangular distributions using $72 \%, 52 \%$, and $56 \%$ as likeliest values for E2, E1 and EE2, respectively. Minimum and maximum removals were based on the ranges specified above.

After the residence time had been established, direct land use for the algae cultivation ponds was computed based on the total flow rate $(\mathrm{Q})$ of WW per FU $\left(5.94 \times 10^{7} \mathrm{~L} /\right.$ day $)$, pond design criteria set forth by Benemann and Oswald (1996), and Equation 5.2, which defines hydraulic retention time. For the likeliest value of residence time (1.7 days), likeliest pond volume is $101,000 \mathrm{~m}^{3} / \mathrm{FU}$. Multiplying this value by a 1.5 factor of safety and assuming pond depth is $0.5 \mathrm{~m}$ (Benemann and Oswald, 1996), the direct land use requirement for algae cultivation is roughly $25 \mathrm{ha} / \mathrm{FU}$. It was assumed that this total land area would comprise 25 1-ha, square ponds. Each would have dimensions of $100 \mathrm{~m} \times 100 \mathrm{~m}$. Refer to Section 4.3.5.1 for additional calculation details pertaining to pond design. 


\subsubsection{Description of the Algae Cultivation and Conversion Processes}

Stoichiometric $\mathrm{CO}_{2}$, nitrogen and phosphorus requirements. Detailed description of nutrient requirements utilized in this analysis can be found in Section 3.3.2. However, unlike Chapter 3, the full stoichiometric demands for both $\mathrm{N}$ and $\mathrm{P}$ are supplied by WWTP effluent; thereby minimizing the cost of nutrient removal for the WWTP and also maximizing algae yields. Likeliest $\mathrm{N}$ and $\mathrm{P}$ concentrations in the secondary effluent were $25 \mathrm{mg} / \mathrm{L}$ and $7 \mathrm{mg} / \mathrm{L}$, respectively, more than sufficient for the algae's photosynthetic needs (Menger-Krug, NiedersteHollenberg and Hillenbrand, 2012). Table 5.4 presents the stoichiometric $\mathrm{CO}_{2}, \mathrm{~N}$, and $\mathrm{P}$ requirements per FU of algae cultivation alongside the relative amounts provided by the system during operation at steady-state.

Table 5.4. Stoichiometric carbon dioxide $\left(\mathrm{CO}_{2}\right)$, total nitrogen $(\mathrm{N})$ and total phosphorus $(\mathrm{P})$ requirements during algae cultivation in an integrated wastewater treatment + algae cultivation system. All quantities are based on one functional unit $(\mathrm{FU})$ of wastewater $\left(5.94 \times 10^{7} \mathrm{~L} /\right.$ day $)$.

\begin{tabular}{|c|c|c|}
\hline Quantity & Value & Notes \\
\hline Total $\mathrm{CO}_{2}$ required $\left(\mathrm{Mg} \mathrm{CO}_{2} / \mathrm{ha} * \mathrm{yr}\right)$ & 178 & $\begin{array}{l}\text { Stoichiometric based on molecular weight; } \\
\text { Redfield (1958). }\end{array}$ \\
\hline $\begin{array}{l}\mathrm{CO}_{2} \text { mass flow from digestion and methane } \\
\text { combustion }\left(\mathrm{Mg} \mathrm{CO}_{2} / \mathrm{ha} * \mathrm{yr}\right)\end{array}$ & 16,503 & Digestion $\mathrm{CO}_{2}+$ combustion flue gas. \\
\hline $\mathrm{CO}_{2}$ utilization efficiency (fraction) & 0.7 & Assumed. \\
\hline Total N required (Mg N/ha*yr) & 8 & $\begin{array}{l}\text { Stoichiometric based on molecular weight; } \\
\text { Redfield (1958). }\end{array}$ \\
\hline $\begin{array}{l}\mathrm{N} \text { mass flow from secondary treatment } \\
\left(\mathrm{Mg} \mathrm{N} / \mathrm{ha}^{*} \mathrm{yr}\right)\end{array}$ & 13.5 & Based on CAS WW flow. \\
\hline $\begin{array}{l}\mathrm{N} \text { concentration in secondary effluent } \\
(\mathrm{mg} \mathrm{N} / \mathrm{L})\end{array}$ & 25 & $\begin{array}{l}\text { Carey and Migliaccio (2009); Dodd et al. (2008); } \\
\text { Zorita, Martensson and Mathiasson (2009). }\end{array}$ \\
\hline Total $\mathrm{P}$ required $\left(\mathrm{Mg} \mathrm{P} / \mathrm{ha}{ }^{*} \mathrm{yr}\right)$ & 1.2 & $\begin{array}{l}\text { Stoichiometric based on molecular weight; } \\
\text { Redfield (1958). }\end{array}$ \\
\hline $\begin{array}{l}\text { P mass flow from secondary treatment } \\
\text { (Mg P/ha*yr) }\end{array}$ & 3.8 & Based on CAS WW flow. \\
\hline $\begin{array}{l}\text { P concentration in secondary effluent } \\
(\mathrm{mg} \mathrm{P} / \mathrm{L})\end{array}$ & 7 & $\begin{array}{l}\text { Carey and Migliaccio (2009); Dodd et al. (2008); } \\
\text { Zorita, Martensson and Mathiasson (2009). }\end{array}$ \\
\hline
\end{tabular}

Algae dewatering and drying. Detailed descriptions of algae dewatering and drying processes utilized in this analysis can be found in Sections 3.3.3.3 and 3.3.5.1 of Chapter 3. 
Anaerobic co-digestion and energy production. It was assumed that primary sludge, secondary sludge, and dewatered algae are co-digested to produce biogas. This biogas is combusted to produce bio-electricity, analogous to Case A of Section 3.3.3. Biogas $\mathrm{CO}_{2}$ and post-combustion $\mathrm{CO}_{2}$ are recycled back to the algae cultivation module, satisfying the entire stoichiometric $\mathrm{CO}_{2}$ demand for algae growth.

$\underline{R U E}$ and Yield. The algae modeled in this analysis were assumed to be exclusively phototrophic, whereby they produce all of their energy and organic cell structures from photosynthetic $\mathrm{CO}_{2}$ fixation. This is in contrast to heterotrophic or "mixotrophic" algae, which use dissolved carbon for all or part of their metabolic needs, respectively. Values of radiation use efficiency (RUE), in units of "g algae dry-weight (DW) per MJ photosynthetically-active radiation (PAR)", were based on the freshwater algae species modeled in previous studies (Table 4.1). These values were assigned a triangular distribution: minimum $=0.5$; likeliest $=1.4$; and maximum $=2.6$. The RUE values were then used in conjunction with solar radiation (specifically PAR) data for the Southwestern USA (NREL, 2005) to compute expected algae yields. The likeliest value for algae yield was $41.6 \mathrm{Mg} / \mathrm{ha}{ }^{*} \mathrm{yr}$ (see Table 4.5 ). Other pertinent algae biomass characteristics employed in this model are also summarized in Table 4.5.

Mixing and Pumping. Mixing and pumping energy demands for algae cultivation ponds were described in Sections 2.3.2.3.1 and 2.3.2.3.3. Paddle wheel power consumption follows a triangular distribution: minimum $=0.0001 \mathrm{~kW}$, likeliest $=0.0037 \mathrm{~kW}$, maximum $=0.01 \mathrm{~kW}$. Overall mixing energy demand was about 29,423 MJ/yr*FU. Overall pumping energy demand was on the order of $4.64 \times 10^{6} \mathrm{MJ} / \mathrm{yr} * \mathrm{FU}$.

Anaerobic Co-Digestion and Production of Bio-Electricity. The digestion system modeled in this chapter is quite different from what was discussed in Chapters 3 and 4, because algae biomasss is 
co-digested together with primary and secondary sludge from the WWTP (Menger-Krug, Niederste-Hollenberg and Hillenbrand, 2012). For this modeled case as specified by MengerKrug, Niederste-Hollenberg and Hillenbrand (2012), dry algae biomass accounts for less than $25 \%$ of the total VSS (volatile suspended solids) inflow. Neither of the sludges nor the algae biomass is fully converted into biogas; therefore, distributions of percent "digestibility" were assigned. These values were $55 \%$, for primary sludge, $35 \%$ for secondary sludge, and $41 \%$ for algae biomass (Menger-Krug, Niederste-Hollenberg and Hillenbrand, 2012; Samson and Leduy, 1983; Sialve et al., 2009). Methane yield was 0.27 $\mathrm{L} \mathrm{CH}_{4} / \mathrm{g}$ VSS removed (likeliest) (Sosnowski, Wieczorek and Ledakowicz, 2003). Biogas methane fraction (v/v) was 0.72 (likeliest value) (Sialve et al., 2009), and biogas $\mathrm{CO}_{2}$ fraction was 0.22 (likeliest value) (Sanchéz-Hernandez, 1993). Table 5.5 provides an overview of anaerobic digestion parameters, with relevant empirical distributions.

Table 5.5. Parameters for anaerobic co-digestion of primary and secondary WWTP sludges with algae biomass.

\begin{tabular}{|c|c|c|c|c|}
\hline Parameter & $\begin{array}{c}\text { Modeled } \\
\text { Distribution }\end{array}$ & $\begin{array}{c}\text { Minimum } \\
\text { Value }\end{array}$ & $\begin{array}{c}\text { Maximum } \\
\text { Value }\end{array}$ & $\begin{array}{c}\text { Likeliest } \\
\text { Value }\end{array}$ \\
\hline Primary Sludge VSS Digestibility (fraction) ${ }^{a}$ & Triangular & 0.50 & 0.61 & 0.55 \\
\hline Primary Sludge VSS Digestibility (fraction) ${ }^{a}$ & Triangular & 0.32 & 0.39 & 0.35 \\
\hline Algae VSS Digestibility (fraction) ${ }^{\mathrm{b}-\mathrm{g}}$ & Triangular & 0.21 & 0.60 & 0.41 \\
\hline Methane Production Efficiency (L CH4/g VSS) ${ }^{\mathrm{h}}$ & Triangular & 0.22 & 0.34 & 0.27 \\
\hline Biogas Methane Fraction (vol/vol) ${ }^{b}$ & Triangular & 0.46 & 0.76 & 0.72 \\
\hline Biogas $\mathrm{CO}_{2}$ Fraction (vol/vol) ${ }^{\mathrm{b}, \mathrm{i}}$ & Triangular & 0.08 & 0.31 & 0.22 \\
\hline $\begin{array}{l}\text { Digestion } \mathrm{NH}_{3} \text { Release } \\
(\mathrm{mg} \mathrm{N} / \mathrm{g} \mathrm{VSS})^{\mathrm{b}}\end{array}$ & Triangular & 27 & 35 & 30 \\
\hline Total N Comprising $\mathrm{NH}_{3}$ in Recycle (fraction) ${ }^{\mathrm{j}}$ & Uniform & 0.70 & 0.80 & NA \\
\hline $\begin{array}{l}\text { VSS Stoichiometric P Available in Recycle } \\
\text { (fraction) }^{k}\end{array}$ & Uniform & 0.20 & 0.25 & NA \\
\hline
\end{tabular}

Sources are as follows: ${ }^{a}$ Menger-Krug, Niederste-Hollenberg and Hillenbrand (2012); ${ }^{\mathrm{b}}$ Sialve, Bernet and Bernard (2009); ${ }^{\mathrm{c}}$ Golueke (1957); ${ }^{\mathrm{d}}$ Samson and Leduy (1982); ${ }^{\mathrm{e}}$ Samson and Leduy (1986); ${ }_{\mathrm{f}}^{\mathrm{f}}$ Sanchez-Hernandez et al. (1993); $\mathrm{g}$ Yen and Brune (2007); ${ }^{\mathrm{h}}$ Sosnowski, Wieczorek and Ledakowicz (2003); ${ }^{\mathrm{i}}$ Sanchez-Hernandez et al. (1993); ${ }^{\mathrm{j}}$ Anasruron, Bade and Korner (2010); ${ }^{k}$ Wild, Kisliakova and Siegrist (1997). 
The principal design parameter for sizing of the anaerobic digester was sludge retention time (SRT), which is defined as the total time digestible materials spend inside the digester (Metcalf and Eddy, 2003; Golueke, 1957; Masayuki, Murata and Nakata, 2006). Typically, SRT is much larger than the HRT defined by Equation 5.2, because the solids are detained and recycled within the plant for a longer time than the liquids. SRT was assigned to a triangular distribution based on previously published date: likeliest value $=30$ days, $\min =20$ days, $\max =40$ days (Golueke, 1957),

Once SRT has been defined, Equations 5.5 is useful for calculating the volume of sludge requiring digestion per unit time (Metcalf and Eddy, 2003).

$$
V_{\text {Sludge }}=\frac{Q * S C}{\rho_{w} * S_{S l} * P_{S}} \quad \text { Equation } 5.5
$$

Here, $Q$ is the WWTP's influent flowrate (FU $=5.94 \times 10^{7} \mathrm{~L} /$ day $) ; S C$ is the solids density in the incoming digester slurry, $0.11 \mathrm{~kg} / \mathrm{m}^{3}$ based on (Masayuki, Murata and Nakata, 2006); $\rho_{w}$ is the density of wastewater $\left(1,000 \mathrm{~kg} / \mathrm{m}^{3}\right) ; S_{s l}$ is the specific gravity of the sludge, 1.02 based on (Masayuki, Murata and Nakata, 2006); and $P_{s}$ is the mass fraction of solids in incoming slurry, 0.06 based on based on (Menger-Krug, Niederste-Hollenberg and Hillenbrand, 2012). The resulting sludge volume for the algae co-digestion scenario was $104 \mathrm{~m}^{3}$. For the distribution of SRT values used in this study, the required digester capacity is roughly $3,109 \mathrm{~m}^{3}$. In comparison, the Moore's Creek WWTP has two cylindrical digesters with the following dimensions: $27.43 \mathrm{~m}$ $\mathrm{D} \times 9.07 \mathrm{~m} \mathrm{H}$ (Rivanna Water and Sewer Authority, 2007). The capacity of each digester is 5,361 $\mathrm{m}^{3}$, and the total digester capacity is $10,721 \mathrm{~m}^{3}$. This indicates that the size of the digester(s) required for co-digestion of algae and WWTP sludge will not be unreasonably large compared to those that are currently in use at existing WWTPs. 
Electricity and heat consumption during anaerobic digestion were calculated using the method presented in Section 3.3.3.2. Electricity demand was $1.96 \times 10^{6} \mathrm{MJ} / \mathrm{yr} * \mathrm{FU}$. Heat requirement was $2.82 \times 10^{7} \mathrm{MJ} / \mathrm{yr} * \mathrm{FU}$.

Methane Combustion and $\mathrm{CO}_{2}$ Recycle. Detailed descriptions of the methane combustion and $\mathrm{CO}_{2}$ recycle calculations utilized in this analysis can be found in Section 3.3.3.5. Annual methane yield was 4,900 Mg/ha-yr for the co-digestion system, accounting for annual bio-electricity production on the order of $9.19 \times 10^{9} \mathrm{MJ} / \mathrm{yr} * \mathrm{FU}$. It was assumed that methane-derived bioelectricity was produced using one biogas-powered generator with a power rating of $600 \mathrm{~kW}$ and a generator efficiency of 0.80 .

Digestate Dewatering and Nutrients Recycle. The post-digestion slurry is dewatered using a beltfilter press (BFP), to a solids content of $67.5 \%$ by mass. The nutrient-rich liquid digestate is recycled back to primary treatment. Approximately $80 \%(\mathrm{~m} / \mathrm{m})$ the carbon entering the digester is transformed as methane in the biogas, while the rest is contained within the slurry that is fed into the dewatering stage (BFP) (Menger-Krug, Niederste-Hollenberg and Hillenbrand, 2012). Similarly, $25 \%(\mathrm{~m} / \mathrm{m})$ of the $\mathrm{N}$ entering the digester entering is transformed as ammonia in the biogas, and the remainder is contained within the slurry that is fed into the dewatering stage (BFP) (Menger-Krug, Niederste-Hollenberg and Hillenbrand, 2012). Finally, all of the P entering the digester is transferred to the slurry that is fed into the dewatering stage (BFP). No $\mathrm{P}$ is transferred to the gaseous phase during digestion (Menger-Krug, Niederste-Hollenberg and Hillenbrand, 2012).

In general, the belt-filter pressing and nutrient recycle calculations are similar to what was presented in Section 3.3.3.3, and it was once again assumed that the dewatered digestate solids 


\subsubsection{Analysis of Conventional Tertiary Treatment Methods}

\subsubsection{Model Overview}

Four conventional tertiary treatments were analyzed using LCA, in order to provide benchmark comparisons for the results from the proposed WWTP + algae cultivation system. The selected benchmarks include: ozonation (OZ), ultraviolet irradiation $(U V)$, reverse osmosis $(R O)$, and adsorption in a downflow fixed-bed granulated activated carbon (GAC) reactor (GAC). The same general WWTP configuration from the WWTP + algae cultivation LCA was used in the benchmark analyses. From Section 5.3.2, this configuration comprises primary treatment and secondary treatment followed by anaerobic digestion to produce biogas; however, there is no algae biomass co-digested with the WWTP sludge. The post-digestion slurry is dewatered using a belt-filter press (BFP), and the liquid digestate is recycled back to primary treatment. Biogas from digestion is combusted to generate bioelectricity, which can be used to meet on-site electricity demands. Figure 5.5 depicts the overall process flow for this system, wherein "tertiary treatment" corresponds to one of the four treatments (OZ, UV, RO, or GAC) referenced above. 


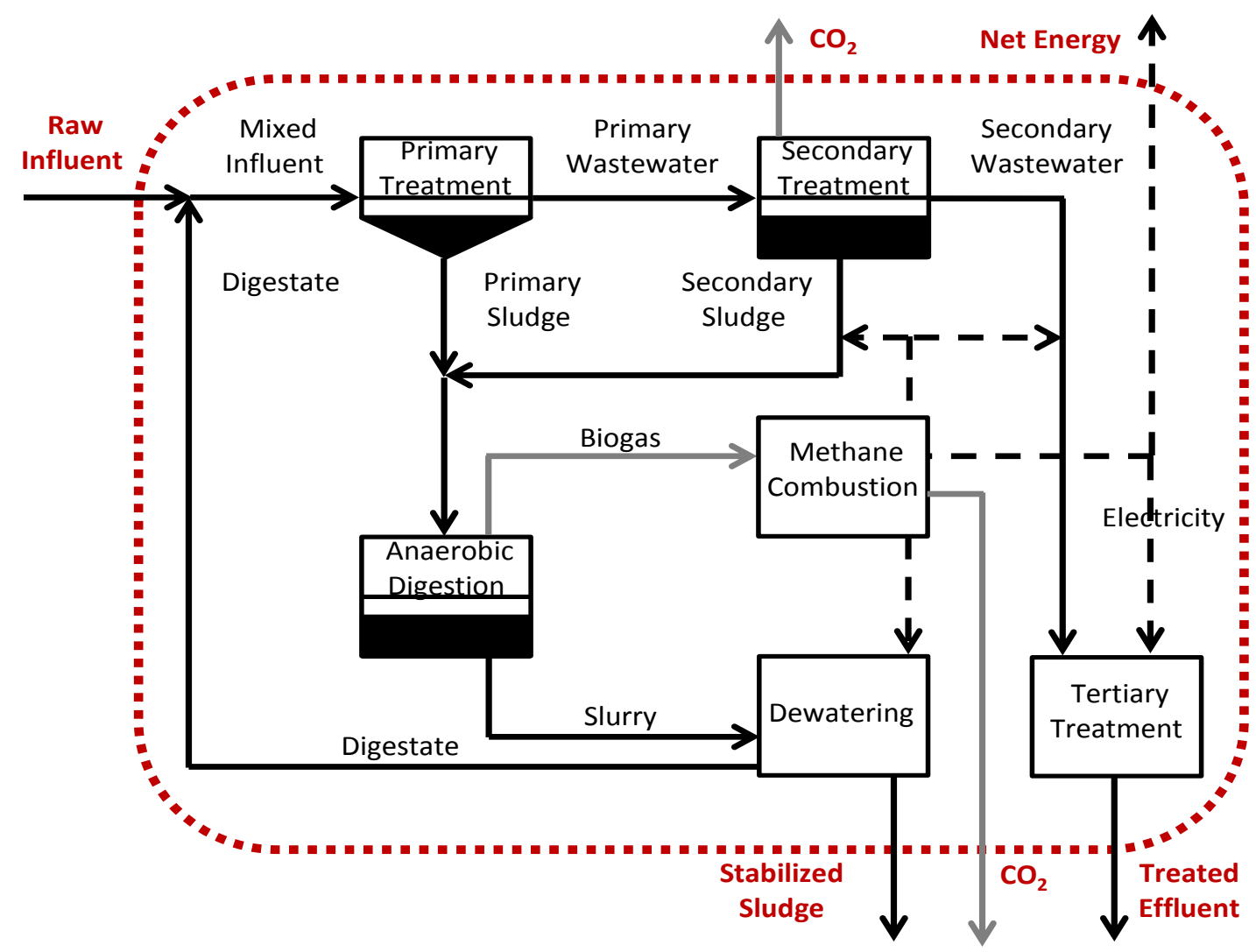

Figure 5.5. Overall process flow for the benchmark systems comprising primary treatment, secondary treatment, and one of four evaluated tertiary treatments; i.e., ozonation, UV irradiation, reverse osmosis, or adsorption onto granular activated carbon. Solid dark arrows indicate solid or liquid mass flows; solid gray arrows indicate gaseous mass flows; and dashed dark arrows indicate energy flows. The heavy dashed red box represents the system boundaries.

The LCA models for this investigation were built in a spreadsheet format using Microsoft Excel in conjunction with the Crystal Ball predictive modeling suite. These analyses had the same FU as was used applied to the integrated WWTP + algae cultivation system, to ensure meaningful comparison between the system of interest and its selected benchmarks. Recapping from Section 5.3.3.2, the FU was tertiary treatment for as much secondary effluent as is produced in a typical medium-sized WWTP; specifically, 15.7 MGD $\left(5.94 \times 10^{7}\right.$ L/day $)$. 


\subsubsection{Ozonation $(\mathrm{OZ})$}

Ozonation provides microbial disinfection and also removes eEDCs from the secondary effluent. OZ systems comprise the following components: (1) air preparation, (2) ozone generation, (3) ozone contact, and (4) residual ozone destruction (Metcalf and Eddy, 2003; Rakness, Stover and Krenek, 1984). Figure 5.6 presents the overall process flow for the WWTP + OZ system.

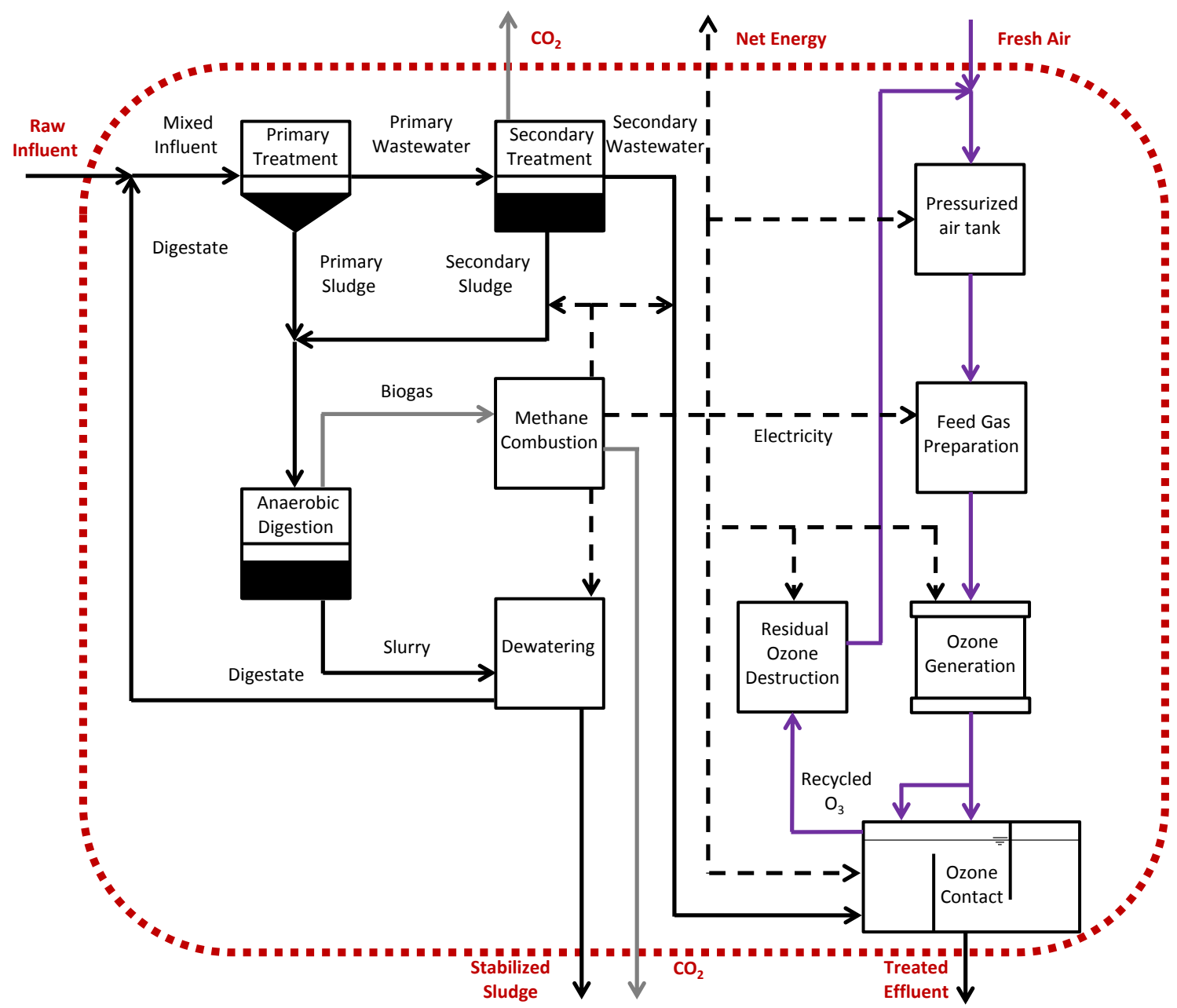

Figure 5.6. Overall process flow for a WWTP employing ozonation (OZ) for tertiary treatment. Solid dark arrows indicate solid or liquid mass flows; solid gray arrows indicate gaseous mass flows; solid purple arrows indicate air and ozone $\left(\mathrm{O}_{3}\right)$ flows; and dashed dark arrows indicate energy flows. The heavy dashed red box represents the system boundaries.

As in Section 5.3.3.3, the principal design parameter for sizing of the OZ system was HRT, based on Equation 5.2. Flow rate was the FU $\left(5.94 \times 10^{7} \mathrm{~L} /\right.$ day $)$. HRT was set to the following 
triangular distribution, based on previously published literature: minimum $=10 \mathrm{~min}$; likeliest $=$ 15 minutes; maximum = 18 minutes (Alum et al., 2004; Nakagawa et al., 2002; Jones et al., 2007; Ternes et al., 2003). From this calculation, it was determined that the OZ module must have a volume capacity of $594 \mathrm{~m}^{3}$ to accommodate the FU. This volume was allocated over two contact basins, based on (Rakness, Stover and Krenek, 1984), such that the required volume per contact basin was $297 \mathrm{~m}^{3}$. The dimensions of each contact basin were then assigned, as follows: $8 \mathrm{~m} \mathrm{~L} \times$ $5.6 \mathrm{~m} \mathrm{~W} \times 6.7 \mathrm{~m} \mathrm{H}$. These basins correspond to a combined physical footpint (i.e., direct land use) of 0.009 ha for the selected FU. Figure 5.7 presents a zoomed-in illustration of one ozone contact basin.

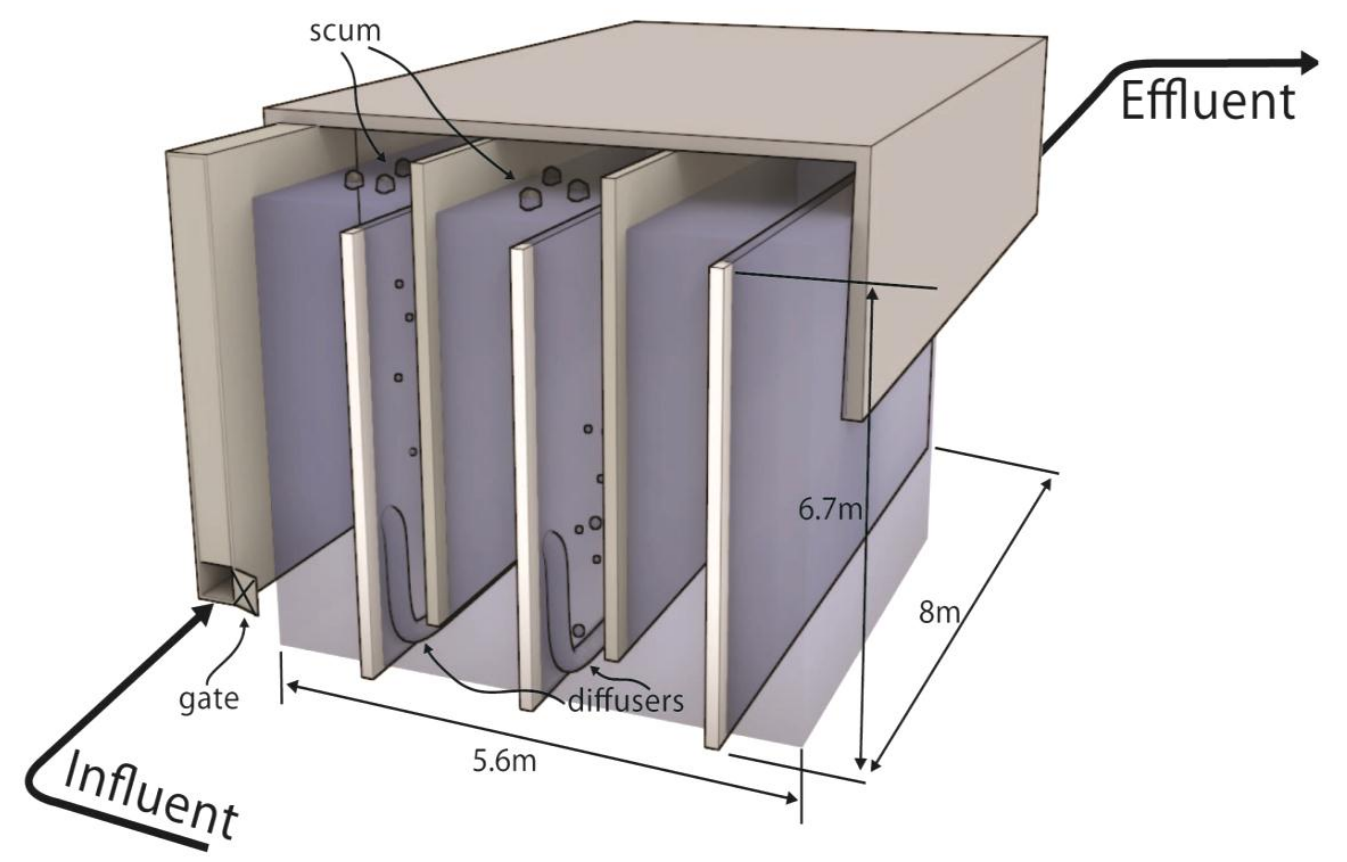

Figure 5.7. Schematic representation of an ozone contact unit modeled in this analysis, as sized to handle one-half of the FU $\left(5.94 \times 10^{7} \mathrm{~L} /\right.$ day $)$. Likeliest hydraulic retention time (HRT) is 15 minutes. Material of construction is stainless steel. Dimensions are drawn to scale. Shaded blue region indicates water level. 
For the HRTs used in this study, OZ typically exhibits removal efficiencies between $85 \%$ - $99 \%$ for TKN and 13.6 - 17.6\% for TP (Stalter et al., 2010). Corresponding eEDCs' removal, based on literature reports, are as follows: 95\% - 99\% for E2 (Ternes et al., 2003; Nakagawa et al., 2002; Deborde et al., 2005; Nakada et al., 2007; Zhang, Yamada and Tsuno, 2008); 74\% - 99\% for estrone E1 (Nakagawa et al., 2002; Deborde et al., 2005; Nakada et al., 2007; Filby et al., 2007); and 64\% - 99\% for 17 $\alpha$-ethinylestradiol EE2 (Deborde et al., 2005; Filby et al., 2007). Finally, removal efficiencies for other water quality parameters are as follows: $23 \%$ for COD, $37 \%$ for BOD and $3.2 \log$ reduction for E. coli (Rakness, Stover and Krenek, 1984).

The amount of ozone required per FU was calculated by evaluating the total required ozone dosage $D(\mathrm{mg} / \mathrm{L})$ and the utilized/transferred ozone dose $U(\mathrm{mg} / \mathrm{L})$. These were calculated using Equations 5.6 and 5.7 (Metcalf and Eddy, 2003).

$$
\begin{array}{ll}
D=U * \frac{100}{T E} & \text { Equation 5.6 } \\
\frac{N}{N_{0}}=\left(\frac{U}{q}\right)^{-n} & \text { Equation 5.7 }
\end{array}
$$

Here, $D$ is the total required ozone dosage $(\mathrm{mg} / \mathrm{L}), U$ is the utilized/transferred ozone dose (mg/L), $T E$ is the ozone dose transfer efficiency (85\%), $N$ is the final E. coli concentration (300 MPN/100 mL), $N_{0}$ is the initial E. coli concentration $\left(3 \times 10^{6} \mathrm{MPN} / 100 \mathrm{~mL}\right), n$ and $q$ are inactivation constants ( 4 and 0.79 , respectively). MPN stands for "most probable number." All inputs and constants were taken from (Metcalf and Eddy, 2003; Rakness, Stover and Krenek, 1984). Resulting values of $D$ and $U$ were calculated to be $9.29 \mathrm{mg} / \mathrm{L}$ and $7.9 \mathrm{mg} / \mathrm{L}$, respectively. 
Therefore, using $D$ and the FU $\left(5.94 \times 10^{7}\right.$ L/day $)$, ozone demand was computed to be 4.9 $\mathrm{kg} / \mathrm{yr} * \mathrm{FU}$.

Air Preparation. There are three possible sources of ozone that can be used as feed gas: air, $\mathrm{O}_{2^{-}}$ enriched air, or pure $\mathrm{O}_{2}$ (Metcalf and Eddy, 2003). This work assumed that pressurized ambient air is used as feed gas, for economic considerations. It was assumed that the cost and energy burdens associated with the procurement of pure $\mathrm{O}_{2}$ would be significantly higher than those for ambient air, despite additional steps required in "conditioning" the air prior to ozone generation (Gehringer and Fiedler, 1998). These conditioning steps include: (1) air compression, (2) air cooling and drying, and (3) air filtration. For this model, it was assumed that a medium-sized WWTP operating at 15.7 MGD would require two air compressors, one refrigerant dryer, two desiccant dryers ,and one pressurized air tank for storage (Rakness, Stover and Krenek, 1984; Gehringer and Fiedler, 1998). The total air preparation time was 60 minutes at an air production rate of $4.4 \mathrm{~m}^{3} / \mathrm{min}^{*} \mathrm{FU}$ (Rakness, Stover and Krenek, 1984; Gehringer and Fiedler, 1998). Using this rate in conjunction with the energy requirement for air preparation $(5.5 \mathrm{kWh} / \mathrm{kg}$ ozone) (Metcalf and Eddy, 2003), resulting energy demand was on the order of 3,990 GJ/yr*FU.

Ozone Generation. Most WWTPs generate ozone onsite because it is relatively unstable radical and easily reacts with other chemical species (Metcalf and Eddy, 2003). In this analysis, a "dielectrics" system was used, wherein air is passed through two parallel high-voltage electrodes, one of which contains a dielectric material (Rakness, Stover and Krenek, 1984; Metcalf and Eddy, 2003). Air passes through the plates via the corona discharge gap, and is released with 1\% $3 \% \mathrm{O}_{3}$ by weight. The heat generated by this exothermic process was not accounted for in the model since it was assumed to be used elsewhere (Metcalf and Eddy, 2003). Design calculations indicated that ten ozone generators would be required to handle the desired FU considered. Total ozone generation time was 15 minutes (Rakness, Stover and Krenek, 1984). Assuming the ozone 
generation requirement consumes $16.5 \mathrm{kWh}$ to produce $1 \mathrm{~kg}$ of ozone (Metcalf and Eddy, 2003), resulting energy demand was on the order of $12,000 \mathrm{GJ} / \mathrm{yr} * \mathrm{FU}$.

Ozone Contact. Reiterating from a previous paragraph, this model assumed that two ozone contact basins, each with HRT $=15$ minutes, would be required to accommodate the desired FU (Rakness, Stover and Krenek, 1984; Jones et al., 2007; Ternes et al., 2003). The energy requirement for ozone contact is $4.4 \mathrm{kWh} / \mathrm{kg}$ ozone (Metcalf and Eddy, 2003), resulting energy demand was on the order of 3,190 GJ/yr*FU.

Thermal Destruction. Consistent with standard practice, residual ozone should be fully destroyed prior to discharge of the treated effluent into the environment. The destruction reaction yields, which is siphoned back into the incoming fresh air stream to increase its $\mathrm{O}_{2}$ concentration before it enters the dielectric ozone generation system. Two ozone destruction units are necessary for the modeled system, each has a reaction time of 60 min (Rakness, Stover and Krenek, 1984). Discharge ozone concentration was $0.002 \mathrm{mg} / \mathrm{L}$ (0.1 ppmv) (Rakness, Stover and Krenek, 1984). Residual ozone rate was calculated as the product of ozone requirement ( $4.9 \mathrm{~kg} / \mathrm{yr} * \mathrm{FU})$ times (100-TE), where TE is the transfer efficiency of the ozone into the wastewater (85\%). This value was roughly $0.08 \mathrm{Mg} / \mathrm{day}$. Using this value and an assumed ozone destruction energy requirement of $1.7 \mathrm{kWh} / \mathrm{kg}$ ozone (Metcalf and Eddy, 2003), energy consumption for the destruction of residual ozone was on the order of $185 \mathrm{GJ} / \mathrm{yr} * \mathrm{FU}$. The total energy requirement for ozonation of the FU was the sum of energy uses each sub-process, including air preparation, ozone generation, ozone contact, and ozone destruction. This value was approximately 19,300 GJ/yr*FU.

\subsubsection{UV Irradiation (UV)}

UV irradiation systems use the ultraviolet portion of the electromagnetic spectrum $(100-400$ nm) to disinfect certain wastewater contaminants. A key consideration in the design of an 
irradiation unit is the appropriate choice of UV lamps specific to the target wastewater characteristic. Lamps emitting the so-called "germicidal fraction" of the UV range, $220-320 \mathrm{~nm}$ ("UV-C"), are especially usefully for disinfection purposes. These wavelengths also engender significant degradation and chemical transformation of aqueous steroid hormones and other eEDCs (Chowdhury, Charpentier and Ray, 2011). Thus, this study assumes that UV-C is used as tertiary treatment for delivery of the FU. Figure 5.8 depicts the process flow for the WWTP + UV system.

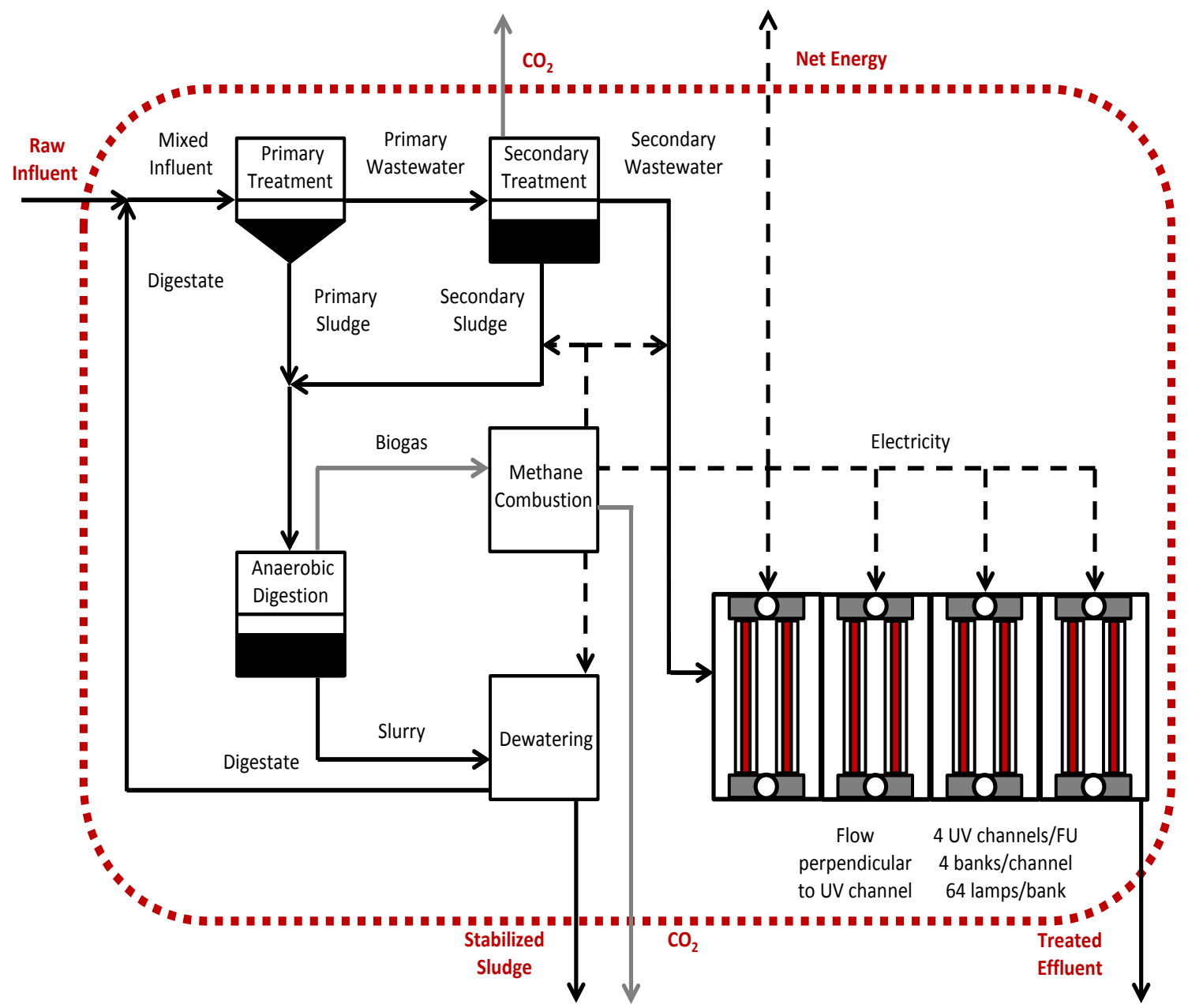

Figure 5.8. Overall process flow for a WWTP employing UV irradiation (UV) for tertiary treatment. There are four channels or irradiation units modeled in this study, each of which consists of four banks housing UV lamps. Solid dark arrows indicate solid or liquid mass flows; solid gray arrows indicate gaseous mass flows; and dashed dark arrows indicate energy flows. The heavy dashed red box represents the system boundaries. 
As in Sections 5.3.3.3 and 5.3.4.3, the principal design parameter for sizing of the UV system was HRT, based on Equation 5.2. HRT was set to the following triangular distribution, based on pertinent literature: minimum $=10$ minutes; likeliest $=23$ minutes; maximum $=36$ minutes (Chowdhury, Charpentier and Ray, 2011; Coleman et al., 2004; Lin and Reinhard, 2005; Atkinson et al., 2001). From this calculation, it was determined what total volume capacity the UV module must have to accommodate the FU. This volume was allocated over four "channels. In this study, each channel constitutes one single irradiation unit, which consists of four "banks" (Metcalf and Eddy, 2003). Each bank holds an array of medium-pressure high-intensity UV lamps, oriented horizontally or vertically. The final dimensions of each channel were: $8 \mathrm{~m} \mathrm{~L} \times$ $2.75 \mathrm{~m} \mathrm{~W} \times 2.75 \mathrm{~m} \mathrm{H}$. Based on these dimensions for each of four channels, the physical footprint (i.e, direct land use) for the UV module was 0.035 ha for the selected FU. Figure 5.9 depicts a zoomed-in view of one UV channel, as modeled in this analysis.

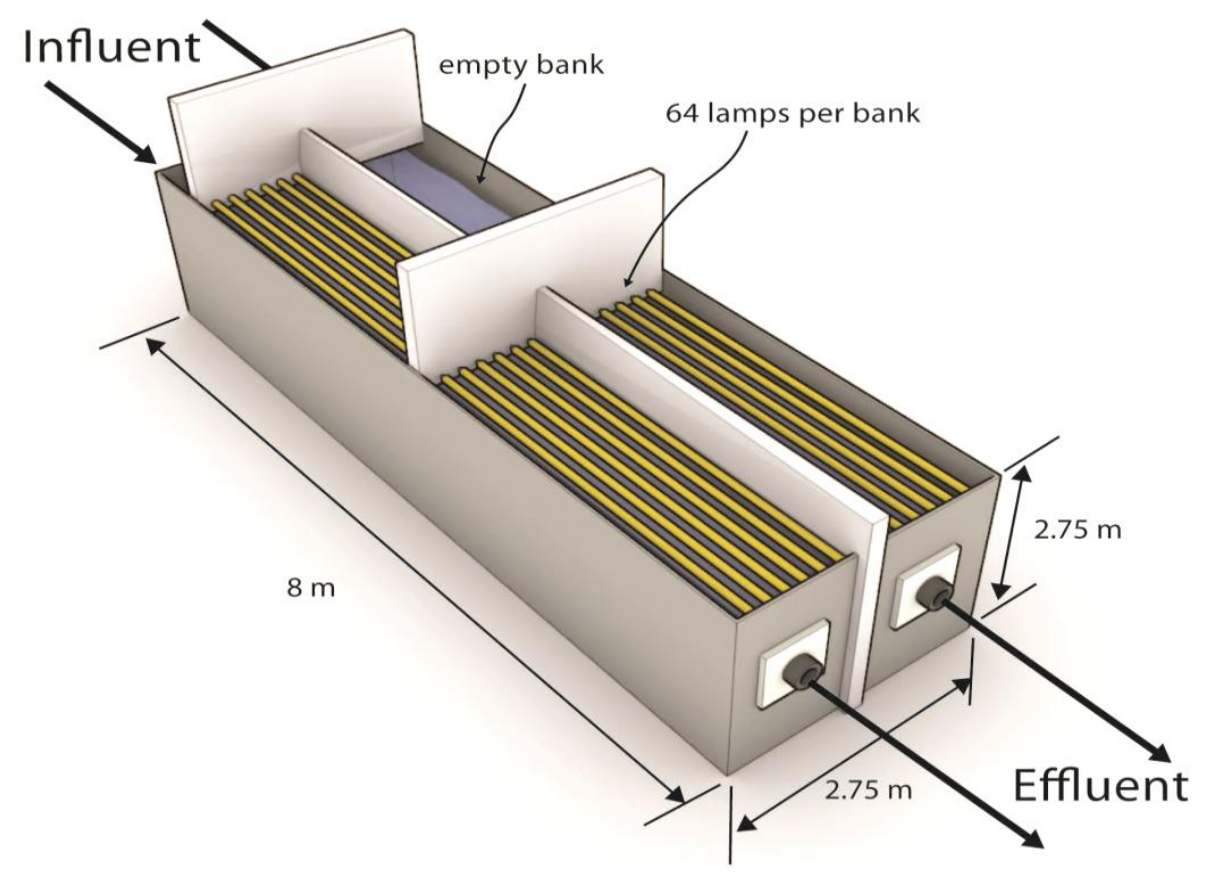

Figure 5.9. Schematic representation of a UV irradiation unit modeled in this analysis, as sized to handle one-fourth of the FU $\left(5.94 \times 10^{7} \mathrm{~L} /\right.$ day $)$. Likeliest hydraulic retention time (HRT) is 23 minutes. Material of construction is stainless steel. Dimensions are drawn to scale. 
For the HRTs used in this study, UV typically exhibits removal efficiencies of $40 \%-80 \%$ for E2 (Coleman et al., 2004; Leech, Snyder and Wertzel, 2009; Lin and Reinhard, 2005); 50\% - 80\% for E1 (Coleman et al., 2004; Lin and Reinhard, 2005); and 50\% - 100\% for EE2 (Coleman et al., 2004; Lin and Reinhard, 2005; Linden et al., 2007; Rosenfeldt et el., 2007). These ranges were converted to triangular distributions for input into the model.

Metcalf and Eddy (2003) recommend a UV lamp loading rate corresponding to $80 \mathrm{~L} / \mathrm{min}$-lamp. Using the FU as the total flow rate $\left(5.94 \times 10^{7} \mathrm{~L} /\right.$ day $), 520$ lamps are required to fully irradiate the FU. These lamps are allocated over the four channels, based on common practice (Linden et al., 2007), such that roughly 130 lamps are required per channel. Assuming that each channel comprises four banks, three of which contain lamps and the fourth remains empty for use during maintenance interruptions (Metcalf and Eddy, 2003), the number of lamps required per bank should be 43 . However, most commercially available UV modules are sold in 4-lamp or 8-lamp modules, such that the number of lamps per bank is generally a multiple of four (Chowdhury, Charpentier and Ray, 2011; Coleman et al., 2004; Lin and Reinhard, 2005; Atkinson et al., 2001). In this study, it was therefore assumed that each bank contains one 8 lamp $\times 8$ lamp module. Multiplying this by three banks per channel and four channels per FU, the total number of lamps required 768 .

One advantage of UV compared to other tertiary treatments is the great degree of flexibility afforded by the large number of lamp choices currently on the market (Metcalf and Eddy, 2003; Coleman et al., 2004; Lin and Reinhard, 2005; Liu and Liu, 2004; Caupos, Mazellier and Croue, 2011; Canonica, Meunier and von Gunten, 2008). Table 5.7 summarizes the key characteristics of the UV lamps selected for evaluation in this study. 
Table 5.7. Lamp characteristics corresponding to the UV module analyzed in this study.

\begin{tabular}{|c|c|c|}
\hline Lamp Characteristics & Value & Notes \\
\hline Power rating per lamp (kW) & 3.5 & $\begin{array}{l}\text { Medium-pressure high intensity UV lamp; High flow; } \\
\text { Xenon gas; Metcalf and Eddy (2003); Mukherjee and } \\
\text { Ray (1999). }\end{array}$ \\
\hline Lamp life (hrs) & 11,000 & $\begin{array}{l}\text { Replace lamp every } 1.25 \text { years ( } 15 \text { months) based on a } \\
\text { 30-year life project; Metcalf and Eddy (2003). }\end{array}$ \\
\hline Quartz sleeve life (hrs) & 6 & $\begin{array}{l}\text { Replace quartz sleeve } 4 \text { times based on a } 30 \text {-year life } \\
\text { project; Metcalf and Eddy (2003). }\end{array}$ \\
\hline Efficiency (fraction) & 0.11 & $\begin{array}{l}\text { Output in the germicidal range (250-260 nm); Use } 254 \\
\mathrm{~nm} \text {; UV-C; Metcalf and Eddy (2003). }\end{array}$ \\
\hline Temperature $\left({ }^{0} \mathrm{C}\right)$ & 700 & $600-800^{\circ} \mathrm{C} ;$ Metcalf and Eddy (2003). \\
\hline Pressure (mmHg) & 1,000 & $\begin{array}{l}\text { Polychromatic radiation. 100-10,000 mmHg; Metcalf } \\
\text { and Eddy (2003). }\end{array}$ \\
\hline Wavelength $(\mathrm{nm})$ & 254 & $\begin{array}{l}\text { Germicidal range; Harris et al. (1987); Benotti et al. } \\
\text { (2009); Harris et al. (1987). }\end{array}$ \\
\hline Diameter of lamp + sleeve $(\mathrm{m})$ & 0.10 & Harris et al. (1987). \\
\hline Thickness of sleeve (m) & 0.01 & Harris et al. (1987). \\
\hline Diameter of lamp (m) & 0.08 & 15-20 mm range; Harris et al. (1987). \\
\hline Center-to-center distance (m) & 0.32 & Harris et al. (1987). \\
\hline
\end{tabular}

The average UV intensity $I$ required in this model framework was calculated using the formula by Harris et al. (1987). This is presented in Equation 5.8 (Harris et al., 1987).

$$
D=I * t \quad \text { Equation } 5.8
$$

Here, $D$ is the average UV dose $\left(\mathrm{mJ} / \mathrm{cm}^{2}\right)$ with an assigned triangular distribution (minimum = 100; likeliest $=122 ;$ maximum $=200)($ Metcalf and Eddy, 2003; Coleman et al., 2004; Lin and Reinhard, 2005; Liu and Liu, 2004; Caupos, Mazellier and Croue, 2011; Canonica, Meunier and von Gunten, 2008); $I$ is the average UV intensity $\left(\mathrm{mW} / \mathrm{cm}^{2}\right)$ and $t$ is the exposure time (seconds) with an assigned distribution $($ minimum $=10$ minutes; likeliest $=23$ minutes; maximum $=36$ minutes) (Chowdhury, Charpentier and Ray, 2011; Coleman et al., 2004; Lin and Reinhard, 2005; Atkinson et al., 2001). Using Equation 5.8 and plugging-in $D$ and $t, I$ was computed to be 0.088 $\mathrm{mW} / \mathrm{cm}^{2}$. 
The surface UV intensity $I_{0}$ was calculated using Equation 5.9 (Harris et al., 1987). Here, $I$ is the average UV intensity $\left(\mathrm{mW} / \mathrm{cm}^{2}\right)$ calculated above via Equation $5.8, I_{0}$ is the surface UV intensity $\left(\mathrm{mW} / \mathrm{cm}^{2}\right), a$ is the absorption coefficient $\left(0.25 \mathrm{~cm}^{-1}\right)$ (Harris et al., 1987; Metcalf and Eddy, 2003), and $x$ is the surface depth $(10.86 \mathrm{~cm})$ calculated from the diameter of lamp + sleeve $(\mathrm{m})$ and center-to-center distance $(\mathrm{m})$, based on parameters in Table 5.7 . $I_{0}$ was $1.33 \mathrm{~mW} / \mathrm{cm}^{2}$. Finally, the total energy requirement for UV treatment of the entire FU can be computed from the number of lamps required and the power rating per lamp (3.5 $\mathrm{kW}$ from Table 5.7). This value is $84,800 \mathrm{GJ} / \mathrm{FU}^{*} \mathrm{yr}$.

$$
I=I_{0} e^{-a x} \quad \text { Equation } 5.9
$$

\subsubsection{Reverse Osmosis (RO)}

Reverse osmosis has been shown to achieve good removal of eEDCs, especially compared to other types of filtration processes (e.g., nanofiltration) (Nghiem et al., 2004; Schäfer, Nghiem and Waite, 2003; Huang and Sedlak, 2001; Alturki, 2010). Reverse osmosis has been shown to achieve good removal of eEDCs, especially compared to other types of filtration processes (e.g., nanofiltration) (Schäfer, Nghiem and Waite, 2003). In this study, it was assumed that the secondary effluent is suitable for RO without additional pre-treatment steps upstream of the RO module. Figure 5.10 depicts the process flow for the WWTP + RO system. 


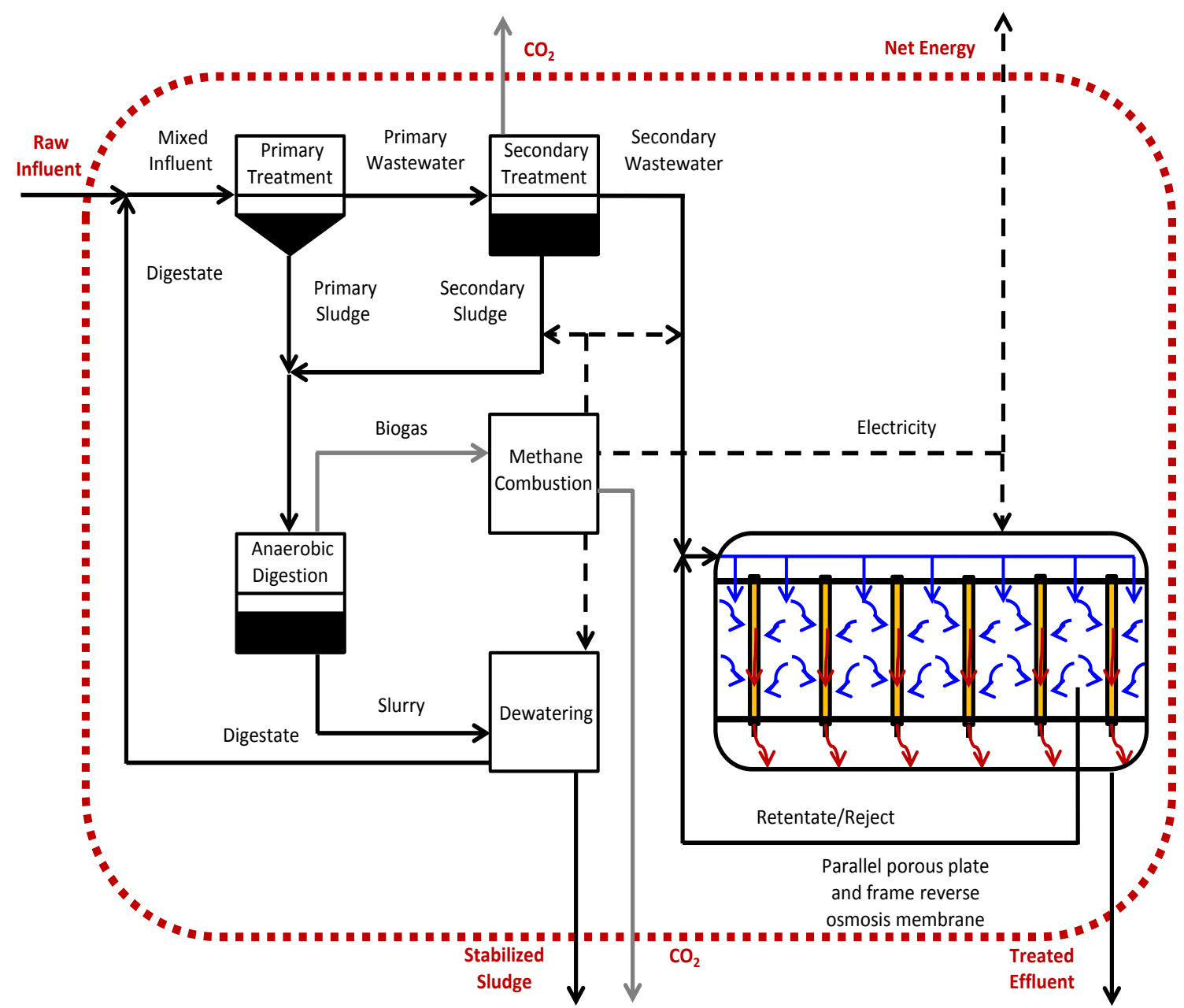

Figure 5.10. Overall process flow for a WWTP employing reverse osmosis (RO) for tertiary treatment. There are ten modules or filtration units, each consisting of 207 parallel plate- and frame-membranes. Solid dark arrows indicate solid or liquid mass flows; solid gray arrows indicate gaseous mass flows; and dashed dark arrows indicate energy flows. The heavy dashed red box represents the system boundaries.

The principal design parameter for sizing of the RO system was once again HRT, based on Equation 5.2. HRT was set to the following triangular distribution, based on industrial and benchscale investigations: minimum $=100$ minutes; likeliest $=180$ minutes; maximum $=300$ minutes (Bodzek and Dudziak, 2006; Schäfer, Nghiem and Waite, 2003). From this calculation, it was determined that the $\mathrm{RO}$ module must have a volume capacity of $7,428 \mathrm{~m}^{3}$ to accommodate the FU. This volume was allocated over ten RO "modules", such that the volume per module was roughly $743 \mathrm{~m}^{3}$. For this model, each RO module houses 207 parallel plate-and-frame 
membranes, each with dimensions of $8 \mathrm{~m} \mathrm{~L} \times 8 \mathrm{~m} \mathrm{~W} \times 0.01 \mathrm{~m}$ thickness. The cross sectional area of each membrane is $64 \mathrm{~m}^{2}$. The dimensions of each module are $17.87 \mathrm{~m} \times 8 \mathrm{~m} \times 2.75 \mathrm{~m}(\mathrm{~L} \times \mathrm{W}$ $\times \mathrm{H}$ ). The physical footprint (i.e., direct land use) for each of the ten RO modules is $143 \mathrm{~m}^{2}$, such that $1420 \mathrm{~m}^{2}$ is required to fully accommodate the FU. The calculation to determine the required quantity of members per module will be explained in a subsequent section. Figure 5.11 depicts a three-dimensional illustration of one RO filtration module, as analyzed in this study.

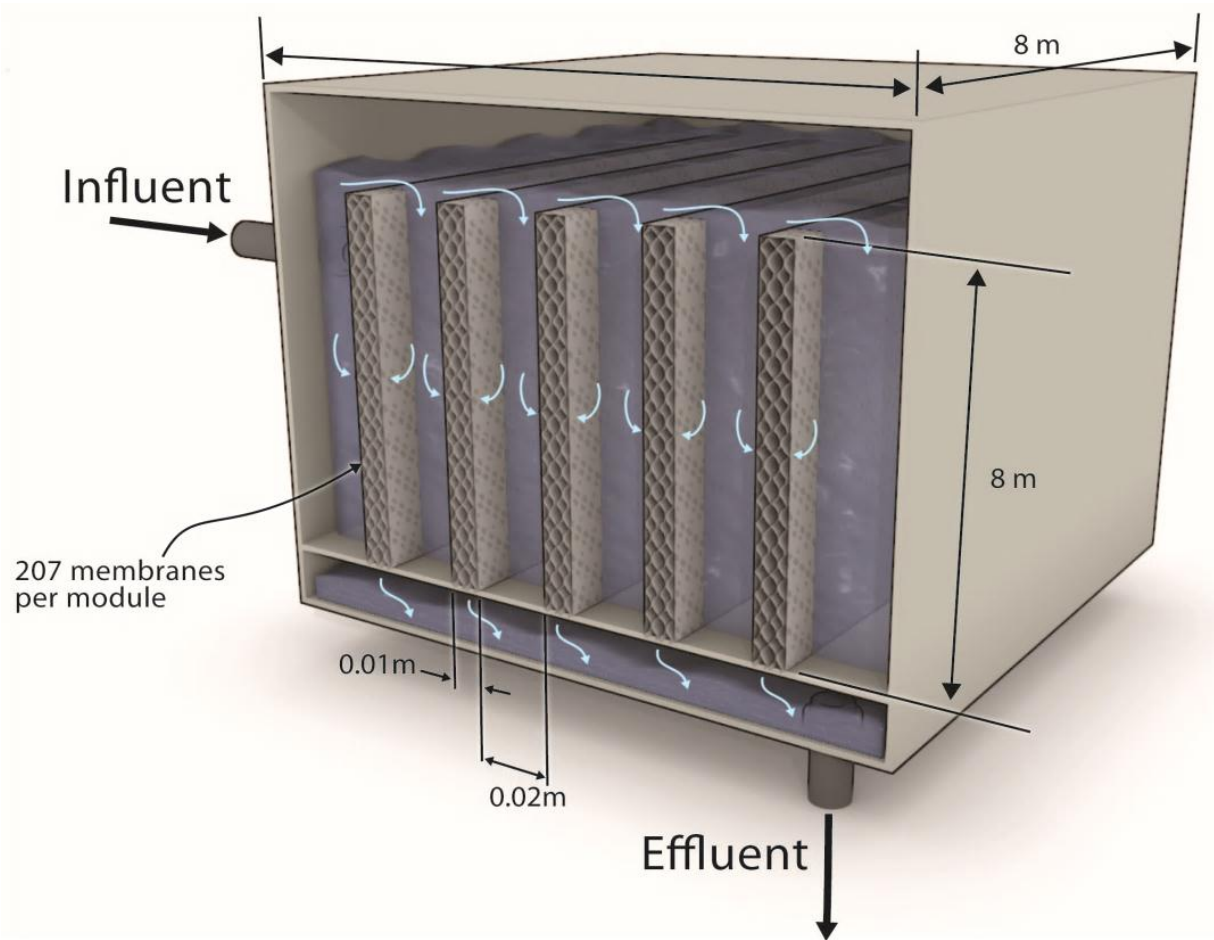

Figure 5.11. Schematic representation of an RO filtration module, as sized to handle one-tenth of the FU $\left(5.94 \times 10^{7} \mathrm{~L} /\right.$ day. Likeliest hydraulic retention time (HRT) is 180 minutes. Material of construction is stainless steel. Dimensions are drawn to scale.

For the HRTs used in this study, typical nutrient removal efficiencies for RO are $65 \%-98 \%$ for TKN and 95 - 99\% for TP (Metcalf and Eddy, 2003). Corresponding eEDCs' removal efficiencies are 90\% - 95\% for E2 (Nghiem and Waite, 2003; Huang and Sedlak, 2001), 90\% 99\% for E1 (Nghiem and Waite, 2003; Schäfer, Nghiem and Waite, 2003), and 95\% - 99\% for 
EE2 (Alturki et al., 2010; Huang and Sedlak, 2001). These ranges were converted to triangular distributions for input into the model.

There were four pertinent membrane specifications evaluated in this study: (1) total membrane area per FU, (2) membrane area per module, (3) cross-sectional area per membrane, and (4) membrane lifetime. These parameters are discussed in detail in the following paragraphs. In all paragraphs, "feed" refers to the secondary effluent entering the RO modules. "Retentate" refers to the film or slurry existing at the surface of the membrane, where large concentrations of solutes become "trapped" as RO proceeds. Finally, "permeate" refers to the effluent coming out of RO. after being stripped of contaminants.

Total membrane area per FU. This parameter was calculated as the product of recovery $R$ (fraction) and product flowrate $Q\left(\mathrm{~m}^{3} / \mathrm{sec}\right)$ divided by the feed wastewater mass flux $F_{w}$ $\left(\mathrm{kg} / \mathrm{m}^{2} * \mathrm{sec}\right) . R$ was 0.95 (i.e., likeliest fraction removal of E2 using FL as detailed above) and $Q$ was $0.69 \mathrm{~m}^{3} / \mathrm{sec}\left(5.94 \times 10^{7} \mathrm{~L} /\right.$ day $) . F_{w}$ was evaluated using Equation 5.10 (Zidouri, 2000).

$$
F_{w}=k_{w} * P \quad \text { Equation } 5.10
$$

Here, $F_{w}$ is the feed wastewater mass flux $\left(\mathrm{kg} / \mathrm{m}^{2} * \mathrm{sec}\right), k_{w}$ is the mass transfer coefficient $(1.67 \times$ $10^{-9} \mathrm{~s} / \mathrm{m}$ ) (Metcalf and Eddy, 2003), and $P$ is net operating pressure specific for an industrial-scale filtration of CAS WW $\left(2.8 \times 10^{6} \mathrm{~kg} / \mathrm{m}^{*} \mathrm{~s}^{2}\right)$ (Zidouri, 2000). Resulting $F_{w}$ was $4.68 \times 10^{-3}$ $\mathrm{kg} / \mathrm{m}^{2} * \mathrm{~s}$, the total membrane area required to accommodate the $\mathrm{FU}$ was $136,056 \mathrm{~m}^{2}$.

Membrane area per FU. Dividing through by the desired number of modules, 10, the total membrane area per module was $13,606 \mathrm{~m}^{2}$. 
Cross-sectional area per membrane. As noted above, typical commercially available membranes have a cross-sectional area of $64 \mathrm{~m}^{2}(8 \mathrm{~m} \times 8 \mathrm{~m})(\mathrm{L} \times \mathrm{W})$.

Membrane life. Over time, membranes can "foul" and can have substantial concentration polarization (Al-Bastaki and Abbas, 1999). This is especially true for polyamide and cellulosic membranes. Thus, this model assumed that all membranes are replaced every 3 years, for a total of 9 changes within a 30-year period (Bodzek and Dudziak, 2006). At this replacement rate, it was assumed that the effects of fouling and concentration polarization were counteracted. Additionally, it was assumed that monthly backwashing is performed on all membrane plates. However, neither the impacts associated with disposal of the membranes at the end of their useful life nor the backwashing were included in this analysis. The total energy requirement for RO management of the desired FU was calculated based on published information for typical WWWTP configurations. This value was $14.2 \mathrm{kWh} / \mathrm{m}^{3}$ of wastewater effluent treated (Metcalf and Eddy, 2003). For the desired FU, this constitutes total energy demand of 1,110,000 $\mathrm{GJ} / \mathrm{yr} * \mathrm{FU}$.

\subsubsection{Adsorption on Granular Activated Carbon (GAC)}

Activated carbon is used extensively as an adsorption material for various wastewater contaminants, including steroid hormones and pharmaceuticals (Fuerhacker, Dürauer and Jungbauer, 2001; Kumar and Mohan, 2011; Yoon et al., 2003; Zhang and Zhou, 2005). Commonly used configurations for use of granular or powdered activated carbon include fixedbed or expanded-bed adsorption, moving-bed adsorption, or fluidized-bed adsorption (Perry, 1997). A downflow fixed-bed granular activated carbon (GAC) reactor was chosen for this study, for several reasons. First, downflow fixed-bed adsorbers are one of the most common types of adsorption columns for wastewater treatment (Sundstrom and Klei, 1979). Second, these columns 
have provisions for the removal of spent carbon and the addition of fresh or regenerated carbon. Third, these columns can be "backwashed" or "air-scoured", a means of periodically cleaning the activated carbon which minimizes frequent replacement (Sundstrom and Klei, 1979). Finally, GAC was used instead of powdered activated carbon because it exhibits better removal efficiency for wastewater contaminants and has higher contact surface area (Eckenfelder, 1989; Perry, 1997; Metcalf and Eddy, 2003). Figure 5.12 depicts the process flow for the WWTP + GAC system.

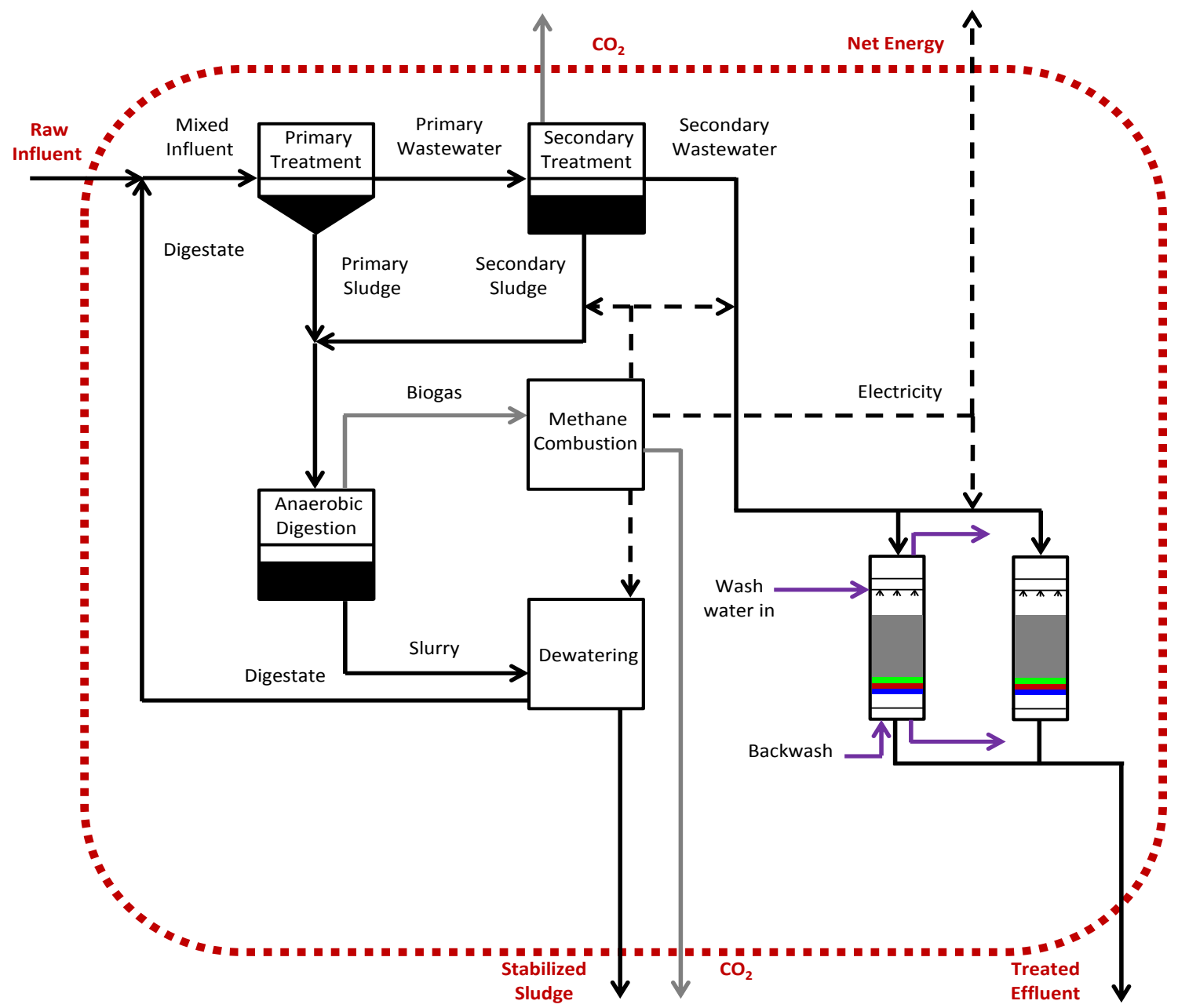

Figure 5.12. Overall process flow for a WWTP employing GAC for tertiary treatment. Solid dark arrows indicate solid or liquid mass flows; solid gray arrows indicate gaseous mass flows; and dashed dark arrows indicate energy flows. The heavy dashed red box represents the system boundaries. 
The principal design parameter for sizing of the GAC system was, as for all other tertiary treatments, based on HRT and Equation 5.2. Though, the HRT parameter for adsorption systems is generally characterized using empty-bed contact time (EBCT) (Sundstrom and Klei, 1979). Typical EBCTs were collected from previously published bench-scale and industrial-scale studies, and assigned to a triangular distribution: minimum $=10 \mathrm{~min}$; likeliest $=30 \mathrm{~min}$; maximum $=60 \mathrm{~min}$ (Sundstrom and Klei, 1979). These residence times were taken from literature, representing both industrial and bench-scale investigations. From this calculation, it was determined that the GAC module must have a total volume capacity of $1,236 \mathrm{~m}^{3}$ to accommodate the FU. This volume was allocated over two GAC "columns", such that the volume per column was roughly $619 \mathrm{~m}^{3}$. The height of the mass transfer zone (MLZ) within each column is given by EBCT $\times \mathrm{L}$, where $\mathrm{L}$ is "hydraulic loading rate" with dimensions approximating the acceptable flow velocity of the liquid through the GAC column. From literature, $4.4 \mathrm{~L} / \mathrm{m}^{2}$-s (i.e., $0.004 \mathrm{~m} / \mathrm{s}$ ) is an acceptable value for L (Rajagopal and Kapoor, 2001; Sundstrom and Klei, 1979). As such, the height of the MLZ must be at least $7.91 \mathrm{~m}$ in each GAC column. This packing height falls within the acceptable range specified by Sundstrom and Klei (1979). The total height of the column is $10 \mathrm{~m}$, to allow $\sim 2 \mathrm{~m}$ above the height of the MLZ, to ensure adequate airspace for efficient solid-liquid mass transfer (Perry, 1997). The physical footprint of each GAC column together is equal to GAC column volume $\left(619 \mathrm{~m}^{3}\right)$ divided by GAC height $(7.91 \mathrm{~m})$. This area is $78 \mathrm{~m}^{2}$ per column, or $156 \mathrm{~m}^{2}$ for both columns together. Assuming that both columns are cylindrical, their final dimensions are $10 \mathrm{~m} \mathrm{H} \times 9.98 \mathrm{~m} \mathrm{D}$. Table 5.8 presents GAC specifications as modeled in this study. Figure 5.13 shows a zoomed-in illustration of the GAC column configuration modeled in this analysis. 
Table 5.8. Granulated activated carbon (GAC) specifications utilized in this modeling approach. The height of the mass transfer zone (MLZ) or GAC packing height was $7.91 \mathrm{~m}$, for each of the two columns required to service one functional unit (FU) $\left(5.94 \times 10^{7} \mathrm{~L} /\right.$ day $)$.

\begin{tabular}{|c|c|c|}
\hline GAC Specifications & Value & Notes \\
\hline Surface area $\left(\mathrm{m}^{2} / \mathrm{g}\right.$ GAC) & 1,075 & Rajagopal and Kapoor (2001). \\
\hline Particles size (mesh) & 40 & $\begin{array}{l}\text { Rajagopal and Kapoor (2001); Sundstrom and Klei } \\
\text { (1979); Metcalf and Eddy (2003). }\end{array}$ \\
\hline Average particles size $(\mathrm{mm})$ & 1.18 & $\begin{array}{l}\text { Rajagopal and Kapoor (2001); Sundstrom and Klei } \\
\text { (1979); Metcalf and Eddy (2003). }\end{array}$ \\
\hline Particle density (mg/L) & 0.85 & $\begin{array}{l}\text { Rajagopal and Kapoor (2001); Sundstrom and Klei } \\
\text { (1979); Metcalf and Eddy (2003). }\end{array}$ \\
\hline Packing life (yrs) & 1.5 & $\begin{array}{l}\text { Assumed time is well before the breaking point; } \\
\text { Rajagopal and Kapoor (2001); Sundstrom and Klei } \\
\text { (1979); Metcalf and Eddy (2003). }\end{array}$ \\
\hline Pressure ( $\mathrm{kPa} / \mathrm{m}$ bed height) & 18 & $\begin{array}{l}\text { Rajagopal and Kapoor (2001); Sundstrom and Klei } \\
\text { (1979); Metcalf and Eddy (2003). }\end{array}$ \\
\hline $\begin{array}{l}\text { GAC requirement (g GAC/m } \mathrm{m}^{3} \\
\text { water) }\end{array}$ & 100 & Sundstrom and Klei (1979). \\
\hline
\end{tabular}

For the GAC HRTs used in this study, typical eEDCs removal efficiencies using 50\% - 95\% for E2 (Westerhoff et al., 2005; Stalter et al., 2011; Filby et al., 2010), 50\% - 99\% for E1 (Westerhoff et al., 2005; Stalter et al., 2010; Filby et al., 2010), and 50\% - 99\% for EE2 (Westerhoff et al., 2005; Stalter et al., 2010; Filby et al., 2010). These ranges were converted to triangular distributions for input into the model.

It was assumed that spent GAC is replaced every 18 months, for a total of 19 changes over thirty years (Rajagopal and Kapoor, 2001). It was also assumed that backwashing and air scouring was performed every month on both columns. However, similar to RO, neither disposal of GAC at end-of-life nor backwashing was included in the LCA analysis. The total energy requirement for operation of the GAC module was calculated based on pressure differential (kPa), flowrate, and the number of GAC columns required. Pressure differential was calculated as the product of pressure (18 kPa/m of bed height from Table 5.8) time MLZ height (7.91 m). The value was 142 $\mathrm{kPa}$. Plugging this and other known values into Equation 2.15 of Chapter 2, the total energy requirement for GAC was roughly 7,230 GJ/yr*FU. 


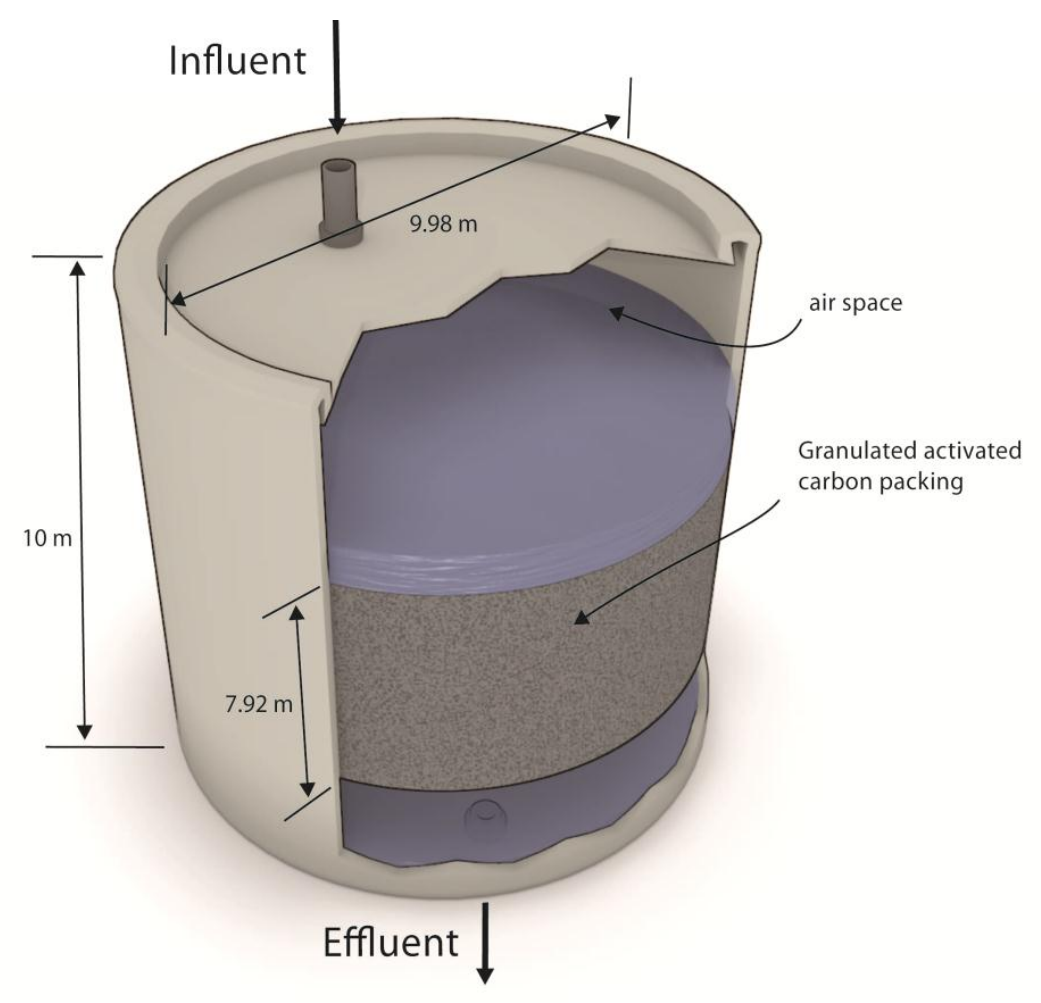

Figure 5.13. Schematic representation of a GAC adsorption module, as sized to handle one-half of the FU (5.94 $\times 10^{7} \mathrm{~L} /$ day). Likeliest hydraulic retention time (HRT) is 30 minutes. Dimensions are drawn to scale. Shaded blue region indicates water level.

\subsubsection{Modifications to the Base WWTP Model for Conventional Tertiary Treatments}

Figure 5.5 in Section 5.3.4.1 shows a generic process flow for WWTP systems utilizing conventional tertiary treatments. In these modeled systems, it is assumed that primary and secondary sludges are anaerobically digested to produce methane, which is then combusted to produce bio-electricity. Because algae is not co-digested with the sludges in the systems using conventional tertiary treatments, different digestion parameters were used for the LCA models of WWTP + OZ (ozonation is tertiary treatment), WWTP + UV (UV irradiation is tertiary treatment), WWTP + RO (reverse osmosis is tertiary treatment), and WWTP + GAC (adsorption onto granular activated carbon is tertiary treatment. Table 5.9 summarizes the digestion parameters for systems in which there is no algae to be co-digested with the WWTP sludges. 
Table 5.9. Parameters for anaerobic co-digestion of primary and secondary sludge without algae.

\begin{tabular}{|c|c|c|c|c|c|}
\hline Parameter & $\begin{array}{c}\text { Modeled } \\
\text { Distribution }\end{array}$ & $\begin{array}{l}\text { Minimum } \\
\text { Value }\end{array}$ & $\begin{array}{l}\text { Maximum } \\
\text { Value }\end{array}$ & $\begin{array}{l}\text { Likeliest } \\
\text { Value }\end{array}$ & Sources \\
\hline $\begin{array}{l}\text { Primary VSS Removal Efficiency } \\
\text { (fraction) }\end{array}$ & Triangular & 0.50 & 0.61 & 0.55 & $A$ \\
\hline $\begin{array}{l}\text { Secondary VSS Removal Efficiency } \\
\text { (fraction) }\end{array}$ & Triangular & 0.32 & 0.39 & 0.35 & A \\
\hline $\begin{array}{l}\text { Methane Production Efficiency } \\
\text { (L CH4/g VSS) }\end{array}$ & Triangular & 0.22 & 0.34 & 0.27 & B \\
\hline Biogas Methane Fraction (vol/vol) & Triangular & 0.46 & 0.76 & 0.72 & C \\
\hline Biogas $\mathrm{CO}_{2}$ Fraction (vol/vol) & Triangular & 0.08 & 0.31 & 0.22 & C-D \\
\hline $\begin{array}{l}\text { Digestion Ammonia Release } \\
\text { (mg N/g VSS) }\end{array}$ & Triangular & 27 & 35 & 30 & C \\
\hline $\begin{array}{l}\text { Total } \mathrm{N} \text { Comprising } \mathrm{NH}_{3} \text { in Recycle } \\
\text { (fraction) }\end{array}$ & Uniform & 0.70 & 0.80 & NA & $E$ \\
\hline $\begin{array}{l}\text { VSS Stoichiometric P Available in } \\
\text { Recycle (fraction) }\end{array}$ & Uniform & 0.20 & 0.25 & NA & $\mathrm{F}$ \\
\hline
\end{tabular}

Sources are as follows: ${ }^{a}$ Menger-Krug, Niederste-Hollenberg and Hillenbrand (2012); ${ }^{b}$ Sosnowski, Wieczorek and Ledakowicz (2003); ${ }^{\mathrm{c}}$ Sialve, Bernet and Bernard (2009); ${ }^{\mathrm{d}}$ Sanchez-Hernandez et al. (1993); ${ }^{\mathrm{e}}$ Anasruron, Bade and Korner (2010); ${ }^{\mathrm{f}}$ Wild, Kisliakova and Siegrist (1997).

Calculation of electricity and heat consumption for digestion in the benchmark tertiary treatment systems was performed using Equations 3.3 and 3.4 from Chapter 3. Since each of the four conventional tertiary treatment systems has different retention time to service $5.94 \times 10^{7} \mathrm{~L}$ of wastewater, their overall water balance and rate at which the combined slurry is fed to the digester vary from each other. Thus, each digester consumed different amounts of energy and heat. Electricity demands for anaerobic digestion were: $4.94 \times 10^{6} \mathrm{GJ} / \mathrm{yr} * \mathrm{FU}$ for OZ; $2.38 \times 10^{6}$ $\mathrm{GJ} / \mathrm{yr} * \mathrm{FU}$ for $\mathrm{UV} ; 7.05 \times 10^{5} \mathrm{GJ} / \mathrm{yr} * \mathrm{FU}$ for $\mathrm{RO}$; and $4.79 \times 10^{6} \mathrm{GJ} / \mathrm{yr} * \mathrm{FU}$ for GAC. Corresponding heat requirements were: $1.76 \times 10^{11} \mathrm{GJ} / \mathrm{yr} * \mathrm{FU}$ for $\mathrm{OZ} ; 4.44 \times 10^{10} \mathrm{GJ} / \mathrm{yr} * \mathrm{FU}$ for $\mathrm{UV} ; 4 \times 10^{9} \mathrm{GJ} / \mathrm{yr} * \mathrm{FU}$ for RO; and $1.77 \times 10^{11} \mathrm{GJ} / \mathrm{yr} * \mathrm{FU}$ for GAC.

As in the WWTP + algae scenario, the slurry coming out of the digester is belt-filter pressed to separate liquids and solids. The nutrient-rich liquid is recycled back to primary treatment, and the solids are used as soil amendment to offset commercial fertilizer use. The amounts of digestate produced in each benchmark system was $5.86 \times 10^{5} \mathrm{Mg} / \mathrm{yr} * \mathrm{FU}$. It was assumed that two belt- 
filter pressers with a power rating of $400 \mathrm{~kW}$ and a presser efficiency of 0.80 were used for all four tertiary treatment cases. Table 5.10 presents information about the composition and bioavailability of nutrients in dewatered digestate solids for digestion of just primary and secondary sludge.

Table 5.10. Parameters used to model digestate nutrient in dewatered digestate solids.

\begin{tabular}{|c|c|c|c|c|c|}
\hline Parameter & $\begin{array}{c}\text { Modeled } \\
\text { Distribution }\end{array}$ & $\begin{array}{l}\text { Minimum } \\
\text { Value }\end{array}$ & $\begin{array}{l}\text { Maximum } \\
\text { Value }\end{array}$ & $\begin{array}{l}\text { Likeliest } \\
\text { Value }\end{array}$ & Source \\
\hline $\begin{array}{l}\text { Digestate Nitrogen Content for (PS+SS) mixture } \\
\text { (mg N/g digestate) }\end{array}$ & Uniform & 150 & 202 & NA & $A$ \\
\hline $\begin{array}{l}\text { Digestate Phosphorus Content for (PS+SS) mixture } \\
\text { (mg P/g digestate) }\end{array}$ & Uniform & 15 & 20 & NA & A \\
\hline $\begin{array}{l}\text { Nitrogen Use Efficiency (“Bioavailability") } \\
\text { (fraction) }\end{array}$ & Uniform & 0.20 & 0.25 & NA & B \\
\hline $\begin{array}{l}\text { Phosphorus Use Efficiency ("Bioavailability") } \\
\text { (fraction) }\end{array}$ & Uniform & 0.05 & 0.10 & NA & B \\
\hline
\end{tabular}

A. Borowski and Szopa (2007); Harrison et al. (1994).

B. Warman and Termeer (2005).

Finally, methane combustion calculations similar to those in Section 3.3.3.5 were performed for the benchmark tertiary treatment systems. For all benchmark tertiary systems, it was assumed that bioelectricity was produced using one biogas-powered generator with a power rating of $600 \mathrm{~kW}$ and a generator efficiency of 0.80 . Because there were no algae cultivation ponds in any of these systems, the biogas $\mathrm{CO}_{2}$ and post-combustion $\mathrm{CO}_{2}$ could not be "recycled". Annual methane yield was $1.96 \times 10^{5} \mathrm{Mg} / \mathrm{yr} * \mathrm{FU}$ for all modeled conventional tertiary treatment systems. Corresponding electricity production was $9.81 \times 10^{6} \mathrm{GJ} / \mathrm{yr} * \mathrm{FU}$.

\subsubsection{Mass Balances for All Modeled Systems}

Mass flows within each of the five modeled cases $(W W T P+$ algae, WWTP + OZ, WWTP + UV, $\mathrm{WWTP}+\mathrm{RO}$, and WWTP + GAC) were obtained by performing comprehensive mass balances. A system of equations was developed based on flows of mass within each unit operation, and then solved in parallel. Results were validated using the ASPEN modeling suite. Table 5.11 
summarizes all flows in all five modeled systems. Table 5.12 outlines the mass fractions comprising waste, algae, and sludge for systems with and without algae cultivation as a tertiary treatment process.

Table 5.11. Water balance for all modeled cases: ozonation (OZ), UV irradiation (UV), reverse osmosis (RO), adsorption onto granular activated carbon (GAC), and algae cultivation (Algae). $Q$ 's are volumetric flow rates in units of $\mathrm{L} / \mathrm{ha}^{*} \mathrm{yr}$, such that multiplication by direct land use for each system (last row) gives flow per FU. NA indicates non-applicable.

\begin{tabular}{|c|c|c|c|c|c|}
\hline Flows/Modeled System & $\mathrm{OZ}$ & UV & RO & GAC & Algae \\
\hline Raw influent, Q1 (ALL) & $2.43 \times 10^{12}$ & $6.15 \times 10^{11}$ & $1.51 \times 10^{11}$ & $1.39 \times 10^{12}$ & $8.60 \times 10^{08}$ \\
\hline Mixed Influent, Q2 (ALL) & $4.87 \times 10^{12}$ & $1.23 \times 10^{12}$ & $3.01 \times 10^{11}$ & $2.78 \times 10^{12}$ & $1.72 \times 10^{09}$ \\
\hline Primary wastewater, Q3 (ALL) & $2.44 \times 10^{12}$ & $6.15 \times 10^{11}$ & $1.51 \times 10^{11}$ & $1.39 \times 10^{12}$ & $8.60 \times 10^{08}$ \\
\hline Primary sludge, Q4 (ALL) & $2.44 \times 10^{12}$ & $6.15 \times 10^{11}$ & $1.51 \times 10^{11}$ & $1.39 \times 10^{12}$ & $8.60 \times 10^{08}$ \\
\hline Secondary wastewater, Q5 (ALL) & $2.42 \times 10^{12}$ & $6.12 \times 10^{11}$ & $1.50 \times 10^{11}$ & $1.38 \times 10^{12}$ & $8.55 \times 10^{08}$ \\
\hline Secondary sludge, Q6 (ALL) & $1.22 \times 10^{10}$ & $3.08 \times 10^{09}$ & $7.52 \times 10^{08}$ & $6.94 \times 10^{09}$ & $4.30 \times 10^{06}$ \\
\hline Mixed sludge, Q7 (ALL) & $2.44 \times 10^{12}$ & $6.18 \times 10^{11}$ & $1.51 \times 10^{11}$ & $1.40 \times 10^{12}$ & $8.65 \times 10^{08}$ \\
\hline Slurry from anaerobic digestion, Q8 (ALL) & $1.10 \times 10^{12}$ & $2.78 \times 10^{11}$ & $6.81 \times 10^{10}$ & $6.28 \times 10^{11}$ & $4.20 \times 10^{08}$ \\
\hline Stabilized sludge, Q9 (ALL) & $1.21 \times 10^{10}$ & $3.08 \times 10^{09}$ & $7.52 \times 10^{08}$ & $6.94 \times 10^{09}$ & $4.31 \times 10^{06}$ \\
\hline Recycle digestate, Q10 (ALL) & $1.09 \times 10^{12}$ & $2.75 \times 10^{11}$ & $6.73 \times 10^{10}$ & $6.21 \times 10^{11}$ & $4.15 \times 10^{08}$ \\
\hline Treated effluent, Q11 (OZ, UV, GAC) & $2.42 \times 10^{12}$ & $6.12 \times 10^{11}$ & NA & $1.38 \times 10^{12}$ & NA \\
\hline $\begin{array}{l}\text { From algae cultivation to } \\
\text { Autoflocculation, Q11 (Algae) }\end{array}$ & NA & NA & NA & NA & $4.16 \times 10^{07}$ \\
\hline Feed to reverse osmosis module, Q11 (RO) & NA & NA & $1.66 \times 10^{11}$ & NA & NA \\
\hline Autoflocculation solids, Q12 (Algae) & NA & NA & NA & NA & $4.16 \times 10^{06}$ \\
\hline Retentate/Reject, Q12 (RO) & NA & NA & $1.66 \times 10^{10}$ & NA & NA \\
\hline Treated effluent, Q13 (RO) & NA & NA & $1.50 \times 10^{11}$ & NA & NA \\
\hline Autoflocculation water, Q13(Algae) & NA & NA & NA & NA & $3.74 \times 10^{07}$ \\
\hline $\begin{array}{l}\text { Recycle algae sludge/Thickening } \\
\text { Solids, Q14 (Algae) }\end{array}$ & NA & NA & NA & NA & $4.16 \times 10^{05}$ \\
\hline Thickening water, Q15 (Algae) & NA & NA & NA & NA & $8.10 \times 10^{08}$ \\
\hline Treated effluent, Q16 (Algae) & NA & NA & NA & NA & $8.48 \times 10^{08}$ \\
\hline Evaporation, Q17 (Algae) & NA & NA & NA & NA & $8.17 \times 10^{06}$ \\
\hline Land use, LU (ha) & 0.009 & 0.035 & 0.144 & 0.016 & 25 \\
\hline
\end{tabular}


Table 5.12. Mass fractions comprising water, algae, and sludge for systems with conventional tertiary treatment or algae-mediated tertiary treatment. Codes in parentheses indicate corresponding system flows from Table 5.11. Items in parenthesis indicate which of the five modeled tertiary treatment systems each flow corresponds to, including many flows which correspond to all five cases (as indicated by "all").

\begin{tabular}{|c|c|c|c|c|c|c|}
\hline \multirow[t]{2}{*}{ Flows/Modeled System } & \multicolumn{3}{|c|}{$\begin{array}{c}\text { Conventional Tertiary Treatment } \\
\text { (OZ, UV, RO, GAC) }\end{array}$} & \multicolumn{3}{|c|}{$\begin{array}{l}\text { Algae Cultivation } \\
\text { (Algae) }\end{array}$} \\
\hline & Water & Algae & Sludge & Water & Algae & Sludge \\
\hline Raw influent, Q1 (ALL) & 0.995 & 0.000 & 0.005 & 0.995 & 0.000 & 0.005 \\
\hline Mixed Influent, Q2 (ALL) & 0.998 & 0.000 & 0.003 & 0.739 & 0.000 & 0.003 \\
\hline Primary wastewater, Q3 (ALL) & 0.995 & 0.000 & 0.005 & 0.995 & 0.000 & 0.005 \\
\hline Primary sludge, Q4 (ALL) & 0.940 & 0.000 & 0.060 & 0.940 & 0.000 & 0.060 \\
\hline Secondary wastewater, Q5 (ALL) & 0.995 & 0.000 & 0.005 & 0.995 & 0.000 & 0.005 \\
\hline Secondary sludge, Q6 (ALL) & 0.990 & 0.000 & 0.010 & 0.990 & 0.000 & 0.010 \\
\hline Mixed sludge, Q7 (ALL) & 0.940 & 0.000 & 0.060 & 0.940 & 0.015 & 0.045 \\
\hline Slurry from anaerobic digestion, Q8 (ALL) & 0.940 & 0.000 & 0.060 & 0.940 & 0.015 & 0.045 \\
\hline Stabilized sludge, Q9 (ALL) & 0.100 & 0.000 & 0.900 & 0.100 & 0.225 & 0.675 \\
\hline Recycle digestate, Q10 (ALL) & 0.866 & 0.000 & 0.134 & 0.907 & 0.000 & 0.093 \\
\hline Treated effluent, Q11 (OZ, UV, GAC) & 0.995 & 0.000 & 0.005 & NA & NA & NA \\
\hline $\begin{array}{l}\text { From algae cultivation to } \\
\text { Autoflocculation, Q11 (Algae) }\end{array}$ & NA & NA & NA & 0.999 & 0.001 & 0.000 \\
\hline Feed to reverse osmosis module, Q11 (RO) & 0.995 & 0.000 & 0.005 & NA & NA & NA \\
\hline Autoflocculation solids, Q12 (Algae) & NA & NA & NA & 0.990 & 0.010 & 0.000 \\
\hline Retentate/Reject, Q12 (RO) & 1.000 & 0.000 & 0.000 & NA & NA & NA \\
\hline Treated effluent, Q13 (RO) & 1.000 & 0.000 & 0.000 & NA & NA & NA \\
\hline Autoflocculation water, Q13(Algae) & NA & NA & NA & 1.000 & 0.000 & 0.000 \\
\hline $\begin{array}{l}\text { Recycle algae sludge/Thickening } \\
\text { Solids, Q14 (Algae) }\end{array}$ & NA & NA & NA & 0.900 & 0.100 & 0.000 \\
\hline Thickening water, Q15 (Algae) & NA & NA & NA & 1.000 & 0.000 & 0.000 \\
\hline Treated effluent, Q16 (Algae) & NA & NA & NA & 1.000 & 0.000 & 0.000 \\
\hline Evaporation, Q17 (Algae) & NA & NA & NA & 1.000 & 0.000 & 0.000 \\
\hline
\end{tabular}

\subsubsection{Calculation of Reported LCA Metrics}

Two principal LCA metrics were computed for the WWTP + algae system and its four conventional benchmark systems, including energy return on investment (EROI), and estrogenicity removal per volume of treated wastewater. EROI calculations are summarized in Section 3.3.7.1 of Chapter 3. Total estrogenicity removal was computed and reported using units of "nanograms estradiol equivalent per liter", ng EEQ/L for E2, E1, and EE2. The concentrations of these chemicals were multiplied by their relative estrogenic potencies (Table 5.13), and these quantities were summed together to compute overall estrogenic toxicity for the WWTP influent 
and effluent. Decreases in the concentration of E2, E1, or EE2 from influent to effluent are thus associated with a corresponding decrease in estrogenic toxicity.

Table 5.13. Empirical estrogenic potency factors for the three eEDCs evaluated in this study. Note that E2 is assigned an estrogenic potency factor of $1 \mathrm{ng}$ estradiol-equivalent (EEQ) per $\mathrm{ng}$ $\mathrm{E} 2$ because $\mathrm{E} 2$ is the prototypical estrogen and all other eEDC potencies are expressed relative to its potency.

\begin{tabular}{lcccc}
\hline \multicolumn{1}{c}{ Parameter } & Modeled Distribution & $\begin{array}{c}\text { Likeliest Value for } \\
\text { Estrogenic Potency Factor } \\
\text { (ng EEQ/ng eEDC) }\end{array}$ & Standard Error & Source \\
\hline $17-\beta$ estradiol (E2) & Lognormal & 1.0 & 0.001 & A-C \\
Estrone (E1) & Lognormal & 0.5 & 0.05 & A-C \\
Ethinylestradiol (EE2) & Lognormal & 1.35 & 0.135 & A, D \\
\hline
\end{tabular}

A. Khanal et al. (2006); B. Ternes, Joss and Siegrist (2004); C. Sumpter and Johnson (2005); D. Westerhoff et al. (2005).

\subsubsection{LCA Impact Fators}

LCA impact factors from the industry-standard ecoinvent database (Weidema, 2008) were used to assess materials and energy inputs associated with components of each LCA model, for the WWTP + algae system and its four selected benchmarks. Pertinent LCA impact factors are summarized in Table 5.14.

Table 5.14. Life cycle impact factors for materials and energy inputs used in LCA models for the selected tertiary treatment methods (algae, ozonation, UV irradiation, reverse osmosis, or adsorption onto GAC). Values are shown $\mu / \sigma$ notation in each column, where $\mu$ is mean value and $\sigma$ is standard deviation. All data were from ecoinvent v. 2.0 (Weidema, 2008).

\begin{tabular}{|c|c|c|c|c|}
\hline Item & Unit Basis & Energy Use (MJ) & Water Use $\left(\mathrm{m}^{3}\right)$ & $\begin{array}{r}\mathrm{GHG}\left(\mathrm{kg} \mathrm{CO} \mathrm{CO}_{2}\right. \\
\text { eq) }\end{array}$ \\
\hline Aggregates & $1 \mathrm{~kg}$ gravel & $0.04 / 0.007$ & $0.04 / 0.007$ & $0.003 / 0.0004$ \\
\hline Carbon Dioxide & $1 \mathrm{~kg} \mathrm{CO} 2$ & $8.3 / 2.0$ & $2.2 / 0.6$ & $0.8 / 0.1$ \\
\hline Concrete & $1 \mathrm{~m}^{3}$ & $1,180.0 / 836.0$ & $561.0 / 87.1$ & $265.0 / 47.7$ \\
\hline Electricity & $1 \mathrm{kWh}$ from US grid & $12.5 / 10.0$ & $0.8 / 0.1$ & $0.2 / 0.01$ \\
\hline Fertilizer $-\mathrm{N}_{2} \mathrm{H}_{4} \mathrm{CO}$ & $1 \mathrm{~kg}$ as $\mathrm{N}$ & $62.1 / 11.8$ & $4.0 / 1.3$ & $3.4 / 0.3$ \\
\hline Fertilizer $-\mathrm{H}_{12} \mathrm{~N}_{3} \mathrm{O}_{4} \mathrm{P}$ & $1 \mathrm{~kg} \mathrm{P}_{2} \mathrm{O}_{5}$ & $37.5 / 5.4$ & $0.7 / 0.1$ & $0.8 / 0.1$ \\
\hline Fertilizer - $\mathrm{CaH}_{2} \mathrm{P}_{2} \mathrm{O}_{8}$ & $1 \mathrm{~kg} \mathrm{P}_{2} \mathrm{O}_{5}$ & $33.8 / 14.5$ & $12.4 / 2.4$ & $2.8 / 0.5$ \\
\hline Heating Oil (Light) & $1 \mathrm{MJ}$ from light heating oil & $1.3 / 0.2$ & $0.03 / 0.004$ & $0.1 / 0.01$ \\
\hline Polypropylene & $1 \mathrm{~kg}\left(\mathrm{C}_{3} \mathrm{H}_{6}\right)_{\mathrm{n}}$ & 70.7/0.01 & $0.05 / 0.0008$ & $2.0 / 0.0007$ \\
\hline Polyvinyl chloride & $1 \mathrm{~kg}\left(\mathrm{C}_{2} \mathrm{H}_{3} \mathrm{Cl}\right)_{\mathrm{n}}$ & $47.2 / 3.6$ & $0.5 / 0.04$ & $2.0 / 0.1$ \\
\hline Steel & $1 \mathrm{~kg}$ steel $(>10.5 \% \mathrm{Cr})$ & $62.3 / 19.9$ & $59.3 / 3.1$ & $5.2 / 0.3$ \\
\hline
\end{tabular}




\subsection{Results and Discussion}

\subsubsection{Phototrophic Algae Cultivation}

Figure 5.14 depicts the growth curve for S. scenedesmus cultivated in synthetic wastewater effluent (See Appendix A) spiked with E2 at $5 \mathrm{ng} / \mathrm{L}$. Algae cell concentrations were measured using optical density at $662 \mathrm{~nm}$ (See Appendix B). The growth curve is superimposed with E2 removal (Section 5.4.2) to show that, as cell concentration increases, E2 concentration decreases. Although the metabolites were not tested in this study, previous work has shown that some algae are able to transform E2 into E1, which is less potently estrogenic than the parent compound (Lai, Scrimshaw and Lester, 2002; Khanal et al., 2006).

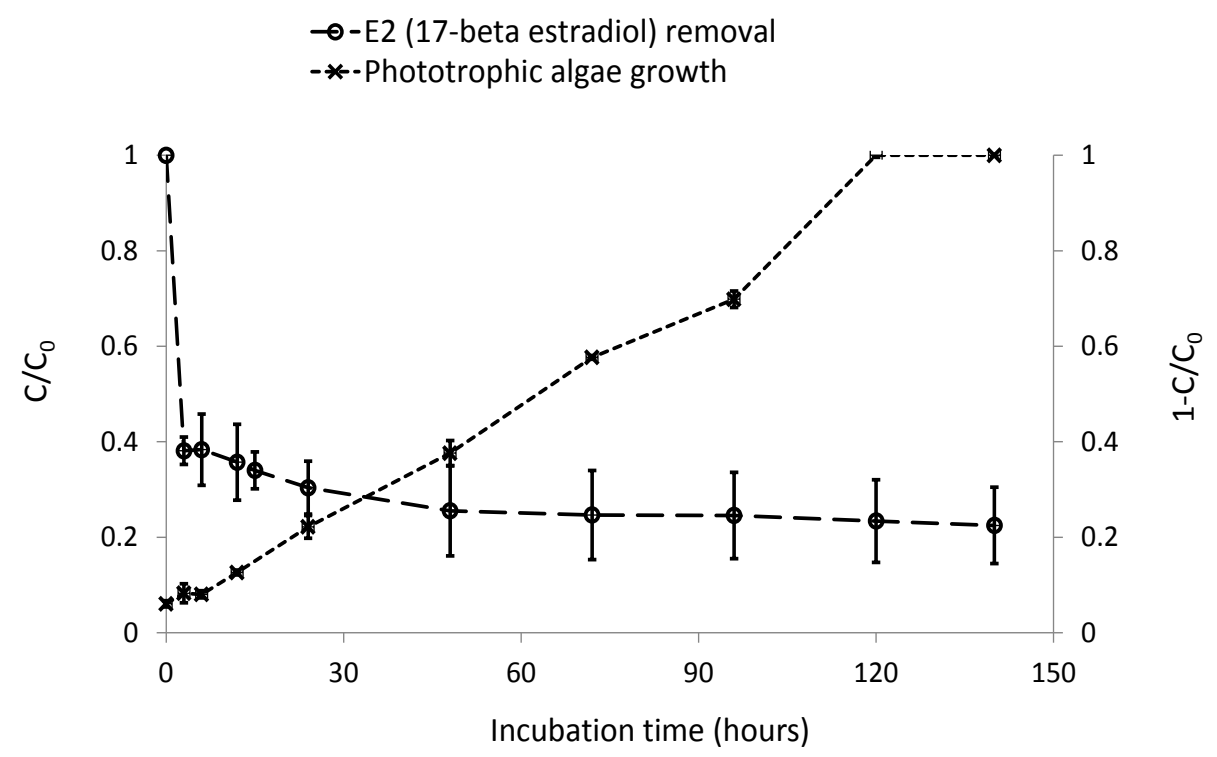

Figure 5.14. Growth curve for $S$. dimorphus pure culture over 150 hours (right axis). Concentration of 17- $\beta$ estradiol (E2) over time (left axis) is superimposed to show the relationship between both parameters. Sample points represent median values from $(\mathrm{n}=2$ replicates). Eror bars represent minimum and maximum values for each sampling.

The algae growth medium becomes increasingly turbid as cultivation progresses, and the algae themselves appear to "floc" together as they approach stationary growth ( $>5$ days). It is presumed that, as time progresses, the algae produce and emit so-called "algal organic matter" 
(AOM). AOM was not measured in this study, but it has been well-documented in other previous studies (Sychrová et al., 2012; Gattullo et al., 2012).

\subsubsection{Algae-Mediated E2 Removal in Batch Tests}

Batch experiments were performed to test the removal of E2 by an axenic culture of the freshwater diatom Scenedesmus dimorphus. This algae strain was selected because it is commonly found in the Mid-Atlantic region throughout most of the year and it has high growth rate (University of Texas Culture Collection of Algae, 2012). Thus, it was expected that the

perofrmance of $S$. dimorphus would be representative of actual algae cultivation in low-salinity WWTPs scenarios. E2 was used as model eEDC because it is the prototpyical steroid hormone, and, as such, the estrogenic potencies of all estrogenic compounds are reported using units of “nanograms E2 equivalents" ("ng EEQ).

Figure 5.15 presents E2 removal as a function of time during bench-scale experiments using four types of reactors: experimental reactors, in which we expect E2 removal to proceed via some combination of photolysis, biosorption, and algae-mediated biotransformation; an autoclaved algae light control, to isolate $\mathrm{E} 2$ removal by biosorption and photolysis in the absence of algaemediated biotransformation; a light positive control, to futher isolate E2 photolysis in the absence of biosprotion or algae-mediated biotransformation; and a dark positive control, to rule out any E2 removal that occurs by reactions other than photolysis, biosorption or algae-mediated biotransformation. Samples from the experimental reactors were collected in duplicates, each from either of the three reactors. 


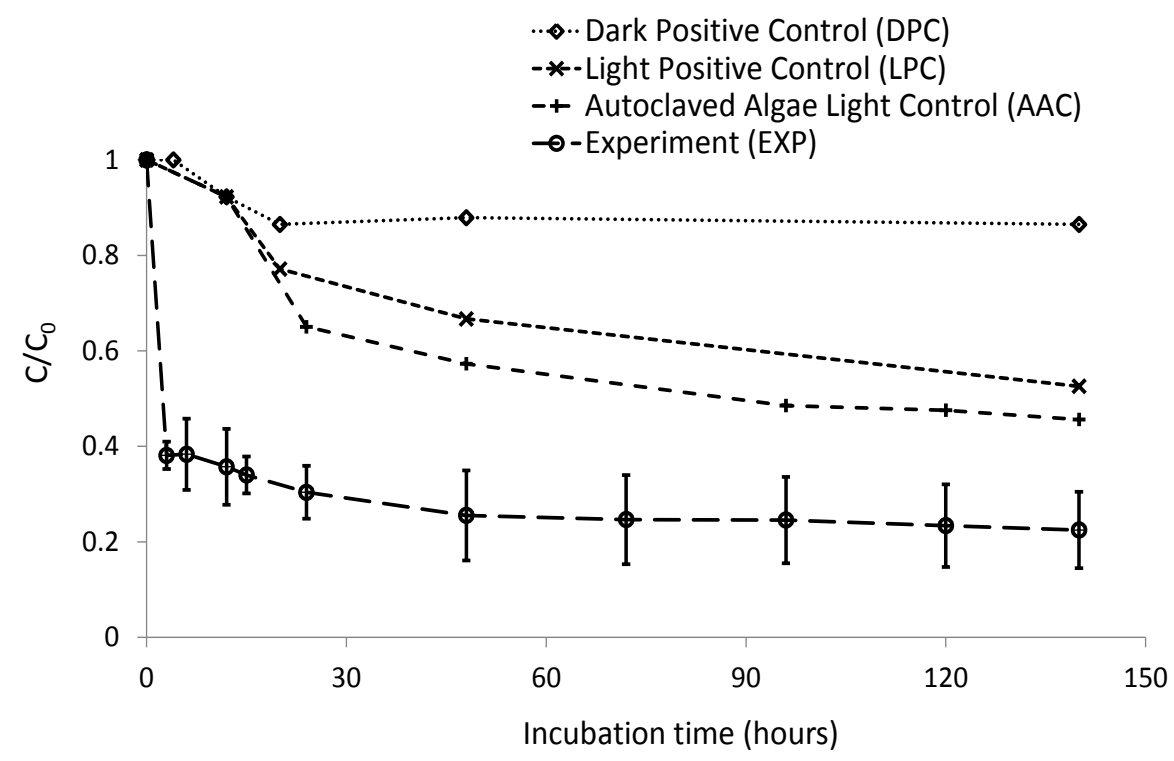

Figure 5.15. Concentrations of $17-\beta$ estradiol (E2) over time during cultivation of $S$. dimorphus exhibiting exponential growth. Sample points for EXP represent median values $(n=2$ replicates) and error bars represent minimum and maximum values for each sampling. The EXP data are replotted from Figure 5.14.

From Figure 5.15, approximately $78 \%$ of the initial E2 concentration was removed from the aqueous phase after 6 days $(140 \mathrm{~h})$. Most of this removal occurred very rapidly, whereby the initial concentration dropped by $62 \%$ within the first $3 \mathrm{~h}$ and $70 \%$ within the first $24 \mathrm{~h}$. The remaining removal ( $8 \%)$ occurred slowly over the next 6 days. When the apparent removal of E2 in the so-called "experimental" reactors is fit to first-order rate model, the $\mathrm{R}^{2}$ coefficient is $94.3 \%$ and the rate constant is $\mathrm{k}=-0.0681 / \mathrm{h}$. This indicates good consistency with other studies of biotransformation of E2 by algae or activated sludge (Lai, Scrimshaw and Lester, 2002; Shi et al., 2010; Weber et al., 2005).

One goal of the experiments giving rise to Figure 5.15 was assessing the relative contributions of the three expected E2 removal mechanisms: photolysis, biosorption, and algae-mediated biotransformation. Table 5.15 summarizes E2 removal during the first 12 hours of darkness and at steady-state, taking into account data from the various controls. 
Table 5.15. E2 removal within the first 12 hours of dark and after $24 \mathrm{~h}$ and $48 \mathrm{~h}$. Experimental batches are as follows: dark positive control, DPC; light positive control, LPC; autoclaved algae light control, AAC; and experiment, EXP. Relevant removal operations were identified corresponding to each experimental batch for each light regime.

\begin{tabular}{|c|c|c|c|c|c|c|}
\hline Batch (Flask) & $\begin{array}{c}\text { E2 Removal } \\
\text { Mechanism } \\
(12 \mathrm{~h})\end{array}$ & $\begin{array}{c}\text { Percent E2 } \\
\text { Removed } \\
(12)\end{array}$ & $\begin{array}{c}\text { E2 Removal } \\
\text { Mechanism } \\
(24 \mathrm{~h})\end{array}$ & $\begin{array}{c}\text { Percent E2 } \\
\text { Removal } \\
(24 \mathrm{~h})\end{array}$ & $\begin{array}{c}\text { E2 Removal } \\
\text { Mechanism } \\
(>48 \mathrm{~h})\end{array}$ & $\begin{array}{c}\text { Percent E2 } \\
\text { Removal } \\
(>48 \mathrm{~h})\end{array}$ \\
\hline DPC & NA & $8 \%$ & NA & $8 \%$ & Base & $14 \%$ \\
\hline LPC & NA (Dark) & $8 \%$ & Photolysis & $33 \%$ & Photolysis & $47 \%$ \\
\hline AAC & Biosorption & $8 \%$ & $\begin{array}{c}\text { Photolysis }+ \\
\text { Biosorption }\end{array}$ & $43 \%$ & $\begin{array}{c}\text { Photolysis }+ \\
\text { Biosorption }\end{array}$ & $54 \%$ \\
\hline EXP & $\begin{array}{c}\text { Biosorption }+ \\
\text { Biodegradation }\end{array}$ & $64 \%$ & $\begin{array}{c}\text { Photolysis }+ \\
\text { Biosorption }+ \\
\text { Biodegradation }\end{array}$ & $74 \%$ & $\begin{array}{c}\text { Photolysis }+ \\
\text { Biosorption }+ \\
\text { Biodegradation }\end{array}$ & $78 \%$ \\
\hline
\end{tabular}

The results presented in Table 5.15 highlight the contributions of each removal mechanism to the total E2 removal. The dark positive control (DPC) was expected to exhibit no significant E2 removal, because it is not exposed to light and it did not contain any algae biomass. As expected, E2 removal was minimal in the dark positive control, ranging from $8-14 \%$ over 6 d. Because the first portion of this experiment was performed in the dark, the DPC and the light positive control (LPC) should be identical for the first $12 \mathrm{~h}$ of the experiment. Thereafter, the LPC should exhibit greater E2 removal than the DPC, because the LPC is subject to photolysis. From Table 5.15, the LPC does exhibit the expected performances for the first $12 \mathrm{~h}$ (dark) and the subsequent period. This indicates that photolysis constitutes appreciable removal during the lighted portion of the first 24-h period $(t=12 \mathrm{~h}$ through $\mathrm{t}=24 \mathrm{~h})$. From the LPC data for $\mathrm{t}>48 \mathrm{~h}$, photolysis accounts for roughly $33 \%$ of overall E2 removal.

The autoclaved algae light control (AAC) was intended to assess the contribution of biosorption separate from biotransformation because the autoclaved algae cells are completely inactivated. Somewhat surprisingly, the AAC exhibited no E2 removal in the first $12 \mathrm{~h}$ beyond what was also observed for the DPC. At longer intervals ( $48 \mathrm{~h},>48 \mathrm{~h}$ ), the AAC exhibits roughly $35-40 \%$ greater E2 removal than the DPC and $\sim 10 \%$ greater E2 removal than the LPC. This suggests that 
the algae biomass is capable of removing E2 via biosorption, but that this reactor occurs much more slowly than E2 photolysis.

Finally, the experimental (EXP) reactors were expected to exhibit contributions of all three postulated E2 removal mechanisms. This expectation is consistent with observations from Table 5.15. After $12 \mathrm{~h}$ of darkness, the EXP reactors exhibit $56 \%$ greater E2 removal than the AAC. This indicates that biotransformation can occur in the dark. For later samples, the difference in E2 removal between the AAC and EXP decreases but still persists (31\% for $48 \mathrm{~h}$ and $24 \%$ for $>48$ h). This could reflect the increasing impact of slow biosorption over time. From the EXP samples for $\mathrm{t}>48 \mathrm{~h}$, the relative contributions of the three observed removal mechanisms are as follows: biosorption $<$ biotransformation $\leq$ photolysis.

The extent to which photolysis contributes to E2 removal during batch studies is interesting and perhaps somewhat unexpected. Moreover, it remains unclear whether this photolytic removal proceeds via direct photolysis or indirect photolysis. "Direct photolysis" occurs when the contaminant of interest (here, E2) is itself able to absorb UV energy, and as a result, undergoes some photo-induced transformation reaction. This type of photolysis tends be less significant than "indirect photolysis", whereby some dissolved "photosensitizing agent" absorbs the UV energy, initiating a series of radical reactions with water and other dissolved materials, ultimately transforming the contaminant of interest (Chowdhury, Charpentier and Ray, 2011). Because AOM was not directly measured in this study, it is impossible to determine the extent to which direct and indirect photolysis contribute to photolytic E2 removal in the light positive control (LPC) and the experimental reactors (EXP). Though, it is worth pointing out that algae-mediated tertiary treatment leverages essentially "free" solar-induced photolysis in a way that conventional treatments cannot, because they required closed, covered reactors. 


\subsubsection{Algae Cultivation versus Conventional Tertiary Treatment Method: Moore's Creek WWTP Case Study}

The experiments performed in this study show that algae are capable of providing a critical ecosystem service, namely estrogenicity removal, even if they are being cultivated for some other purpose (i.e., bioenergy production). This observation, in conjunction with the good suitability of digestion for conversion of algae biomass into usable energy, makes municipal WWTPs seemingly good locations for "test-driving" algae-derived energy production in the near term. Additionally, it should not be overlooked that environmental engineers and WWTP operators possess decades or experience that could be brought to bear for effective algae cultivation, including: operating large-scale, engineered biological systems; managing large volumes of dilute slurries comprising microbial organisms in water; dewatering and managing the dewatered solids; and, safely and efficiently digesting biosolids to produce usable bioelectricity. To further articulate the proposed benefits of an integrated WWTP + algae cultivation system, a life cycle model was built for an existing mid-sized WWTP in Charlottesville, Virginia, U.S.A., the Moore's Creek WWTP. In particular, this system was evaluated using three metrics: estrogenicity removal per $F U$, energy use per $F U$, and greenhouse gas emissions per $F U$. Results from this analysis were then compared to conventional tertiary wastewater treatment systems, for benchmarking purposes.

To reiterate from the Methodology section, hydraulic retention time (HRT) is a key design parameter for all of the tertiary treatments evaluated in this study. For the WWTP + algae system, there is a tradeoff between two pertinent HRTs: (1) the HRT associated with some desired level of eEDC removal; and (2) the HRT associated with maximum algae cell concentration, to optimize downstream energy production. The optimal HRT value for this study best balances the trade-off between estrogenicity removal and energy production as dual objectives for this system. From Figure 5.14, this optimum HRT is roughly 1.7 days (41 h), which is the point of intersection 
for the algae growth (increasing) and E2 concentration (decreasing). This HRT corresponds to roughly $70 \%$ eEDC removal.

\subsubsection{Overview of Key Model Outputs}

The results of LCA analyses for all evaluated systems (algae, ozonation, UV irradiation, reverse osmosis, and adsorption on granular activated carbon) are presented in Table 5.16. One interesting point of comparison is between energy use and tertiary treatment land use. Although algae requires a significantly larger footprint (25 1-ha ponds) than the conventional tertiary treatment systems, it uses much less energy and emits very little greenhouse gas (GHG) per unit volume of wastewater treated. The normalized energy use data, which accounts for energy use per quantity of estrogenicity removed, are particularly for algae relative to the other systems. Thus, this data seems to support the use of algae for removal of estrogenicity in municipal WWTPs.

Table 5.16. Summary of key model outputs for treatment of one functional unit $\left(5.94 \times 10^{7}\right.$ L/day) in five evaluated WWTP + tertiary treatment systems. Outputs represent median values from their respective empirical distributions.

\begin{tabular}{|l|c|c|c|c|c|}
\hline \multicolumn{1}{|c|}{ Impact/Ecosystem Service } & $\begin{array}{c}\text { Ozonation } \\
(\mathrm{OZ})\end{array}$ & $\begin{array}{c}\text { UV } \\
\text { Irradiation } \\
\text { (UV) }\end{array}$ & $\begin{array}{c}\text { Reverse } \\
\text { Osmosis } \\
\text { (RO) }\end{array}$ & $\begin{array}{c}\text { Adsorption on } \\
\text { (GAC) }\end{array}$ & Algae \\
\hline Energy use per unit volume WW treated (MJ/L) & 516,130 & 514,895 & 189,822 & 911,581 & 234 \\
\hline $\begin{array}{l}\text { Greenhouse gas emissions per unit volume WW } \\
\text { treated (kg CO } 2 \text { equivalents/L) }\end{array}$ & 20,500 & 20,451 & 7,545 & 36,198 & 20 \\
\hline $\begin{array}{l}\text { Estrogenicity removal per unit volume WW } \\
\text { treated (mg EEQ/L) }\end{array}$ & 8.5 & 6.3 & 9.0 & 7.1 & 5.7 \\
\hline $\begin{array}{l}\text { Energy use per unit estrogenicity removed } \\
\text { (MJ/ng EEQ) }\end{array}$ & 61 & 82 & 21 & 128 & 0.04 \\
\hline Likeliest tertiary treatment HRT (days) & 0.01 & 0.02 & 0.13 & 0.02 & 1.7 \\
\hline Tertiary treatment land use (ha) & 0.009 & 0.035 & 0.144 & 0.016 & 25 \\
\hline
\end{tabular}

\subsubsection{Energy and Estrogenicity Removal Analysis}

From Table 5.16, energy use for the WWTP + algae system is three orders of magnitude less than in the conventional tertiary systems. This occurs in two ways. First, 25\% more digestible biomass is fed to the anaerobic digester in algae systems relative to conventional systems. This increases 
the amount of bioenergy that can be produced by the WWTP by a small amount. Second, the unit operations required for algae cultivation consume considerably less electricity than those required for conventional tertiary treatment methods. From Table 5.16, the order of energy use in treating $1 \mathrm{~L}$ of wastewater is: algae $<<<\mathrm{RO}<\mathrm{UV} \approx \mathrm{OZ}<\mathrm{GAC}$. This trend is not surprising considering that open pond algae systems require only minimal amounts of electricity, mostly for low-speed paddle wheel mixing and liquid pumping at low velocities.

Figure 5.16 presents the results of the energy analysis for all systems: (1) total energy input $\left(\mathrm{E}_{\mathrm{IN}}\right)$ (left), (2) total energy output $\left(\mathrm{E}_{\mathrm{OUT}}\right)$ (middle) and EROI (EROI $\left.=\mathrm{E}_{\mathrm{OUT}} / \mathrm{E}_{\mathrm{IN}}\right)($ right $)$. All systems have roughly the same amount of energy output, which constitutes bioelectricity produced from digestion biogas. As in Table 5.16, there is significant variation in the energy inputs required per FU, whereby the algae system requires far less energy input than the other systems. This makes it such that algae system offers much greater EROI than any of the other systems. 


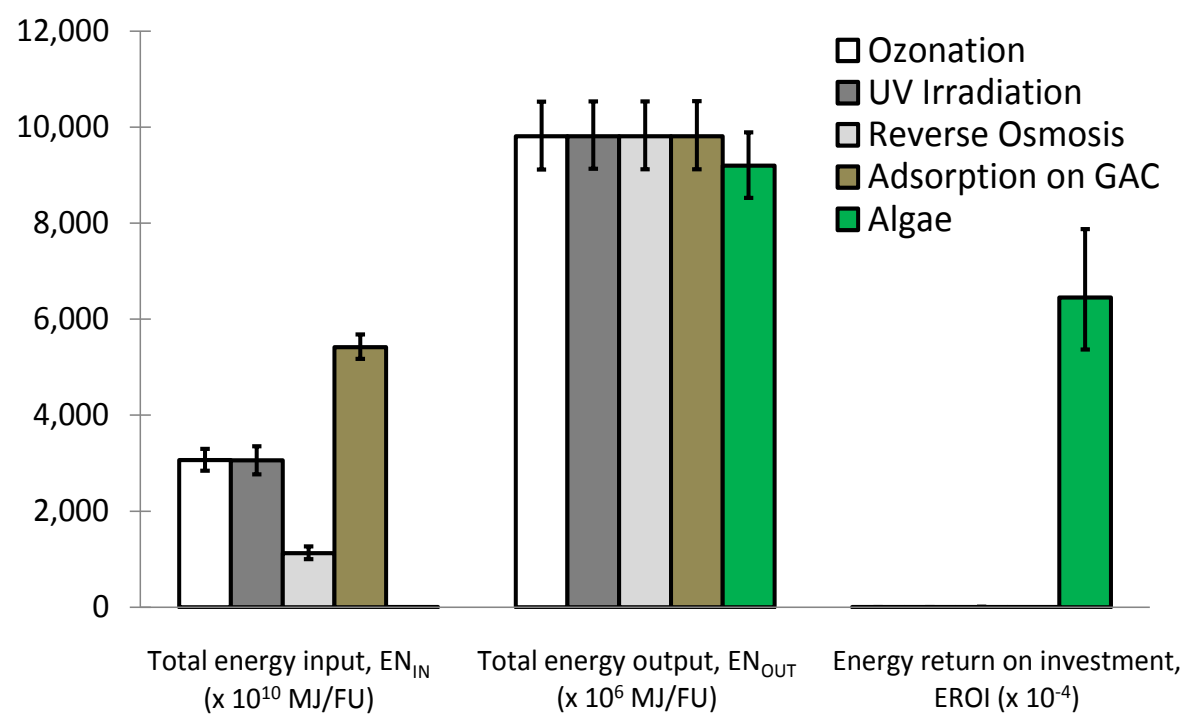

Figure 5.16. Total energy input $\left(\mathrm{EN}_{\mathrm{IN}}\right)$, total energy output $\left(\mathrm{EN}_{\mathrm{OUT}}\right)$, and energy return on investment $\left(\mathrm{EROI}=\mathrm{EN}_{\mathrm{OUT}} / \mathrm{EN}_{\mathrm{IN}}\right)$ for production of one functional unit $\left(5.94 \times 10^{7} \mathrm{~L} /\right.$ day $)$ in five evaluated WWTP + tertiary treatment systems. EROI median values are: $3.0 \times 10^{-4}$ for ozonation; $2.8 \times 10^{-4}$ for UV irradiation; $6.6 \times 10^{-4}$ for reverse osmosis; $1.6 \times 10^{-4}$ for adsorption on granular activated carbon; and 0.64 for algae. Error bars represent $25^{\text {th }}-75^{\text {th }}$ percentiles from empirical output distributions.

Energy use data, together with quantitative information about two ecosystem services, nutrients removal and estrogenicity removal, provides a comprehensive decision-making set in evaluating the purported benefits of establishing an integrated WWTP + tertiary treatment system. All WWTPs in the U.S. employing some sort of conventional tertiary treatment have set nutrient removal efficiencies that allow them to abide with stringent federal and state nutrients standards and address eutrophication concerns. Removal efficiencies for total nitrogen and total phosphorus using any of the conventional tertiary treatment method were between $85-99 \%$ (Stalter et al., 2010). In the case of algae, nutrient uptake efficiencies were lower: $72-78 \%$ for total nitrogen (Menger-Krug, Niederste-Hollenberg and Hillenbrand, 2012) and 80\% for total phosphorus (Shi et al., 2007). However, unlike nutrients, eEDCs are currently unregulated. If it were somehow possible for an integrated WWTP + tertiary treatment system to concomitantly reduce/eliminate 
estrogenicity and produce energy, then the environmental sustainability of such system would have been improved. Results presented in Table 5.16 assess this energy-estrogenicity relationship.

All of the WWTP + tertiary treatment systems evaluated in this study require energy input from the grid (i.e., not produce more energy than they consume), but the algae system is by far lessenergy deficient than the conventional tertiary treatment benchmarks. On the downside, the algae system offers less efficient removal of nutrients and estrogenic compounds than the selected benchmarks. The normalized metrics offer some insight into the efficiency of estrogenicity removal; whereby, the conventional systems remove larger quantities of eEDCs but use larger quantities of energy to do so. From Table 5.16, the order of increasing cost of removing estrogenicity from a CAS effluent is as follows: algae $<<<$ reverse osmosis $<\mathrm{UV} \approx \mathrm{OZ}<\mathrm{GAC}$. Thus, evaluating each system on either an energy analysis sense or a combined energyestrogenicity removal perspective portrays algae as a more environmentally preferable method of removing estrogenicity from WWTP effluents.

\subsubsection{Greenhouse Gas Analysis}

Figure 5.17 presents the results of greenhouse gas balances. The components of the graph are: (1) GHG emissions (left), (2) GHG offsets (middle) and (3) "net GHG ratios" (i.e., NGR = $\left.\mathrm{GHG}_{\mathrm{EMISSIONS}} / \mathrm{GHG}_{\mathrm{OFFSETS}}\right)$. Note that the components of Figure 5.17 are plotted using different orders of magnitude as indicated in the axes. This graph is very similar to the energy balance plotted in Figure 5.16. Algae has tremendously lower GHG emissions than any of the conventional tertiary treatment benchmarks, and it has a significantly lower "net greenhouse gases ratio" than the benchmarks (right). This is not surprising since systems that consume more energy are likely to emit more GHG. 
The middle cluster exhibits more favorable environmental performance for algae compared to the selected benchmarks: larger GHG offsets. There are two types of offsets: direct and indirect. The direct impact of algae production on GHG offset arises from the mass of $\mathrm{CO}_{2}$ taken up during algae photosynthesis. Only the WWTP + algae system engenders direct GHG offset, making its total GHG offset four times as high as that of the benchmarks. This accounted for roughly $75 \%$ of the total WWTP + algae system GHG offset. The indirect GHG impact in all five systems is accounted for by the emissions that would otherwise accrue without use of post-digestate solids to supplant chemical fertilizers. Total TSS fed to the digester is slightly higher in WWTP + algae $\left(1.304 \times 10^{6} \mathrm{Mg} / \mathrm{yr} * \mathrm{FU}\right)$ than the benchmarks $\left(1.302 \times 10^{6} \mathrm{Mg} / \mathrm{yr} * \mathrm{FU}\right)$; as a results, algae has higher total GHG offset $\left(1.46 \times 10^{8} \mathrm{~kg} \mathrm{CO}_{2} / \mathrm{FU}^{*} \mathrm{yr}\right)$ than the benchmarks $\left(3.72 \times 10^{7} \mathrm{~kg}\right.$ $\left.\mathrm{CO}_{2} / \mathrm{FU}^{*} \mathrm{yr}\right)$.

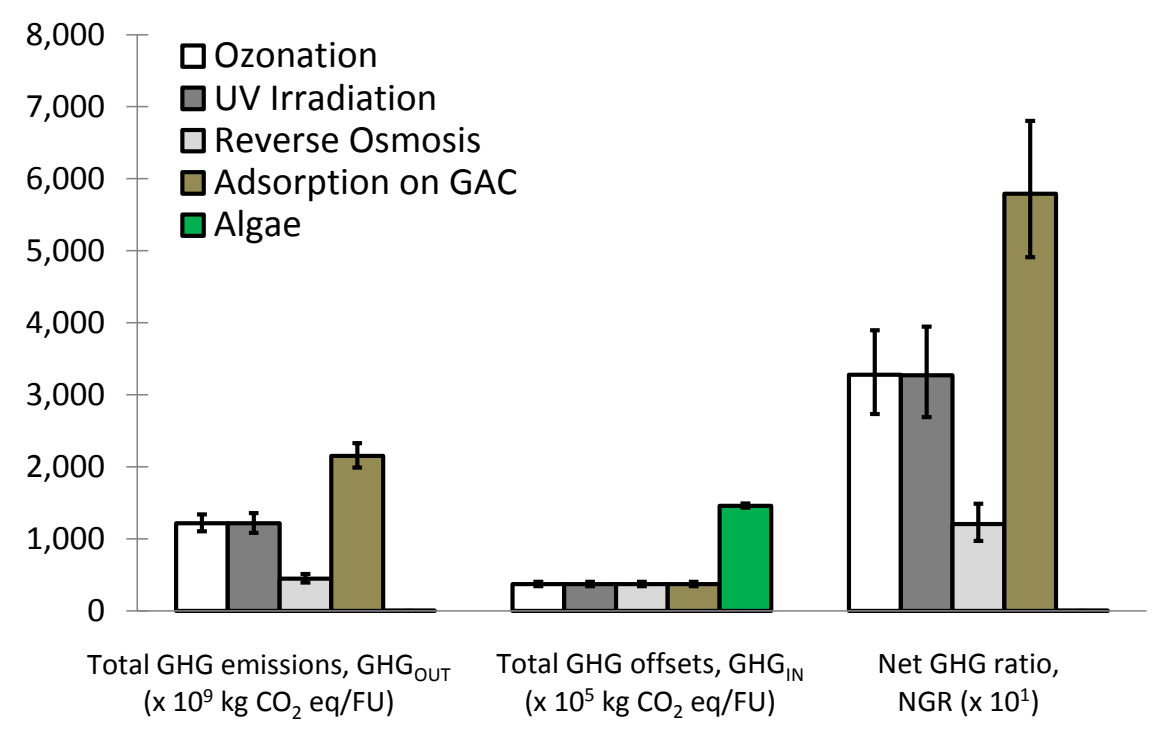

Figure 5.17. Total greenhouse gas emissions $\left(\mathrm{GHG}_{\mathrm{OUT}}\right)$, total greenhouse gas offsets $\left(\mathrm{GHG}_{\mathrm{IN}}\right)$ and net greenhouse gas ratio $\left(\mathrm{NGR}=\mathrm{GHG}_{\mathrm{OUT}} / \mathrm{GHG}_{\mathrm{IN}}\right)$ for production of one functional unit $\left(5.94 \times 10^{7} \mathrm{~L} /\right.$ day $)$ in five evaluated WWTP + tertiary treatment systems. NGR median values are: 32,791 for ozonation; 32,712 for UV irradiation; 12,069 for reverse osmosis; 57,901 for adsorption on granular activated carbon; and 8 for algae. Error bars represent $25^{\text {th }}-75^{\text {th }}$ percentiles from empirical output distributions. 


\subsection{Conclusions}

This study evaluated five WWTP + tertiary treatment systems (ozonation, UV irradiation, reverse osmosis, adsorption on granular activated carbon, and algae). Batch experiment was performed in the lab to determine the optimum hydraulic residence time (HRT) (1.7 days) that captures both desired eEDC removal (i.e., 70\% E2 removal) and optimum algae growth. Utilizing the HRT in all five model frameworks, energy use, energy per unit estrogenicity removed, and greenhouse gas emissions were obtained for each system. Results indicate WWTP + algae perform favorably relative to the WWTP + conventional tertiary treatment benchmarks, but that there are clear tradeoffs among various pertinent metrics.

\section{$5.6 \quad$ References}

Al-Bastaki, N. M., Abbas, A. "Modeling an Industrial Reverse Osmosis Unit." Desalination 126 (1999): 33-39.

Alum, A., Yoon, Y., Westerhoff, P., Abbaszadegan, M. "Oxidation of Bisphenol A, 17ßEstradiol, and 17 $\alpha$-Ethynyl Estradiol and Byproduct Estrogenicity." Environmental Toxicology 19, no. 3 (2004): 257-264.

Alturki, A. A., Tadkaew, N., McDonald, J. A., Khan, S. J., Price, W. E. “Combining MBR and NF/RO Membrane Filtration for the Removal of Trace Organics in Indirect Potable Water Reuse Applications.” Journal of Membrane Science 365, no. 1-2 (2010): 206-215.

Anasruron, D. F. D., Bade, O., Korner, I. "Nitrogen Recovery from Biogas Plant Digestates via Solid-Liquid Separation and Stripping. In Ramiran 2010 - Treatment and Use of Organic Residues in Agriculture, FAO European Cooperative: Lisbon, 2010.

Atkinson, S. K., Marlatt, V. L., Kimpe, L. E., Lean, D. R. S., Trudeau, V. L., Blais, J. M. "Environmental Factors Affecting Ultraviolet Photodegradation Rates and Estrogenicity of Estrone and Ethinylestradiol in Natural Waters." Archives of Environmental Contamination and Toxicology 60 (2011): 1-7.

Benemann, J., Oswald, W. "Systems and Economic Analysis of Microalgae Ponds for Conversion of $\mathrm{CO}_{2}$ to Biomass - Final Report." U.S. Department of Energy: Pittsburgh, 1996, 201.

Benotti, M. J., Stanford, B. D., Wert, E. C., Snyder, S. A. "Evaluation of a Photocatalytic Reactor Membrane Pilot System of Pharmaceuticals and Endocrine Disrupting Compounds from Water." Water Research 43 (2009): 1513-1522. 
Bodzek, M., Dudziak, M. "Elimination of Steroidal Sex Hormones by Conventional Water Treatment and Membrane Processes." Desalination 198 (2006): 24-32.

Borowski, S., Szopa, J. S. "Experiences with the Dual Digestion of Municipal Sewage Sludge." Bioresource Technology 98, no 6 (2007): 1199-1207.

Campbell, C. G., Borglin, S. E., Green, F. B., Grayson, A., Wozei, E., Stringfellow, W. T. "Biologically Directed Environmental Monitoring, Fate, and Transport of Estrogenic Endocrine Disrupting Compounds in Water: A Review." Chemosphere 65 (2006): 1265-1280.

Canonica, S., Meunier, L. Von Gunten, U. "Phototransformation of Selected Pharmaceuticals During UV Treatment of Drinking Water.” Water Research 42 (2008): 121-128.

Carey, R., Migliaccio, K. "Contribution of Wastewater Treatment Plant Effluents to Nutrient Dynamics in Aquatic Systems: A Review.” Environmental Management 44, no. 2 (2009): 205217.

Caupos, E., Mazellier, P., Croue, J. P. "Photodegradation of Estrone Enhanced by Dissolved Organic Matter Under Simulated Sunlight.” Water Research 45 (2011): 3341-3350.

Chowdhury, R. R., Charpentier, P. A., Ray, M. B. "Photodegradation of 17- $\beta$ Estradiol in Aquatic Solution Under Solar Irradiation: Kinetics and Influencing Water Parameters." Journal of Photochemistry and Photobiology A: Chemistry 219 (2011): 67-75.

Coleman, H. M., Routledge, E. J., Sumpter, J. P., Eggins, B. R., Byrne, J. A. "Rapid Loss of Estrogenicity of Steroid Estrogens by UVA Photolysis and Photocatalysis over an Immobilised Titanium Dioxide Catalyst.” Water Research 38 (2004): 3233-3240.

Deborde, M. Rabouan, S., Duguet, J., Legube, B. "Kinetics of Aqueous Ozone-Induced Oxidation of Some Endocrine Disruptors." Environmental Science and Technology 39, no. 16 (2005): 60866092.

Desbrow, C., Routledge, E. J., Brighty, G. C., Sumpter, J. P., Waldock, M. "Identification of Estrogenic Chemicals in STW Effluent 1: Chemical Fractionation and In-Vitro Biological Screening." Environmental Science and Technology 32, no. 11 (1998): 1549-1558.

Dodd, M. C., Zuleeg, S., Von Gunten, U., Pronk, W. "Ozonation of Source-Separated Urine for Resource Recovery and Waste Minimization: Process Modeling, Reaction Chemistry and Operational Considerations." Environmental Science and Technology 42 no. 24 (2008): 93299337.

Eckenfelder, E. W. "Industrial Water Pollution Control." McGraw-Hill Companies, Inc.: New York, N.Y., 1989.

Feliz World. http://www.felizworld.com/products-lamps.html (accessed August 2011).

Filby, A. L., Shears, J. A., Drage, B. E., Churchley, J. H., Tyler, C. R. "Effects of Advanced Treatments of Wastewater Effluents on Estrogenic and Reproductive Health Impacts in Fish." Environmental Science and Technology 44, no. 11 (2010): 4348-4354. 
Fisher Scientific, Inc.

http://www.fishersci.com/ecomm/servlet/cmstatic?storeId=10652\&ddkey=http:fsproductdetail (accessed February 2012).

Fuerhacker, M., Dürauer, A., Jungbauer, A. "Adsorption Isotherms of 17- $\beta$ Estradiol on Granular Activated Carbon (GAC).” Chemosphere 44 (2001): 1573-1579.

Gattullo, C. E., Bährs, H., Steinberg, C. E. W., Loffredo, E. "Removal of Bisphenol A by the Freshwater Green Alga Monoraphidium Braunii and the Role of Natural Organic Matter." Science of the Total Environment 416 (2012): 501-506.

Gehringer, P., Fiedler, H. "Design of a Combined Ozone/Electron Beam Process for Waste Water and Economic Feasibility of the Process." Radiation Physical Chemistry 52, no. 1 (1998): 345349.

Golueke, C. G. “Anaerobic Digestion of Algae.” American Society for Microbiology, 1957.

Harris, G. D., Dean-Adams, V., Sorensen, D. L., Dupont, R. R. "The Influence of Photoreactivation and Water Quality on Ultraviolet Disinfection of Secondary Municipal Wastewater." Water Environment Federation 59, no. 8 (1987): 781-787.

Harrison, R., Xue, D., Henry, C., Cole, D. W. "Long-term Effects of Heavy Applications of Biosolids on Organic Matter and Nutrient Content of a Coarse-Textured Forest Soil." Forest Ecology and Management 66, no. 1-3 (1994): 165-177.

Huang, C., Sedlak, D. L. "Analysis of Estrogenic Hormones in Municipal Wastewater Effluent and Surface Water Using Enzyme-Linked Immunosorbent Assay and Gas Chromatography/Tandem Spectrometry." Environmental Toxicology and Chemistry 20, no. 1 (2000): 133-139.

Jones, O. A. H., Green, P. G., Voulvoulis, N., Lester, J. N. "Questioning the Excessive Use of Advanced Treatment to Remove Organic Micropollutants from Wastewater." Environmental Science and Technology 41, no. 14 (2007): 5085-5089.

Khanal, S. K., Xie, B., Thompson, M. L., Sung, S., Ong, S., van Leeuwen, J. H. "Fate, Transport and Biodegradation of Natural Estrogens in the Environment and Engineered Systems." Environmental Science and Technology 40, no. 21 (2006): 6537-6546.

Khunjar, W. O., Mackintosh, S. A., Skotnicka-Pitak, J., Baik, S., Aga, D. S., Love, N. G. "Elucidating the Relative Roles of Ammonia Oxidizing and Heterotrophic Bacteria During the Biotransformation of $17 \alpha$-Ethinylestradiol and Trimethoprim." Environmental Science and Technology 45, no. 8 (2011): 3605-3612.

Kolpin, D. W., Furlong, E. T., Meyer, M. T., Thurman, E. M., Zaugg, S. D., Barber, L. B., Buxton, H. T. "Pharmaceuticals, Hormones, and Other Organic Wastewater Contaminants in U.S. Streams, 1999-2000: A National Reconnaissance." Environmental Science and Technology 36, no. 6 (2002): 1202-1211.

Kumar, A. K., Mohan, S. V. "Endocrine Disruptive Synthetic Estrogen (17- $\alpha$ Ethinylestradiol Removal from Aqueous Phase through Batch and Column Sorption Studies: Mechanistic and Kinetic Analysis." Desalination 276, no. 1-3 (2011): 66-74. 
Lai, K. M., Scrimshaw, M. D., Lester, J. N. "Biotransformation and Bioconcentration of Steroid Estrogens by Chlorella vulgaris." Applied and Environmental Microbiology 68, no. 2 (2002): 859-864.

Leech, D. M., Snyder, M. T., Wetzel, R. G. "Natural Organic Matter and Sunlight Accelerate the Degradation of 17- $\beta$ Estradiol in Water." Science of the Total Environment 407 (2009): 20872092.

Li, Y., Park, S. Y., Zhu, J. "Solid-State Anaerobic Digestion for Methane Production from Organic Waste." Renewable and Sustainable Energy Reviews 15, no. 1 (2011): 821-826.

Lin, A. Y. C., Reinhard, M. "Photodegradation of Common Environmental Pharmaceuticals and Estrogens in River Water." Environmental Toxicology and Chemistry 24, no. 6 (2005): 13031309.

Linden, K. G., Rosenfeldt, E. J., Kullman, S. W. "UV/ $\mathrm{H}_{2} \mathrm{O}_{2}$ Degradation of Endocrine-Disrupting Chemicals in Water Evaluated via Toxicity Assays." Water Science Technology 55 (2007): 313319.

Liu, B., Liu, X. "Direct Photolysis of Estrogens in Aqueous Solutions." Science of the Total Environment 320 (2004): 269-274.

Menger-Krug, E., Niederste-Hollenberg, J., Hillenbrand, T., Hiessl, H. "Integration of Microalgae Systems at Municipal Wastewater Treatment Plants: Implications for Energy and Emission Balances.” Environmental Science and Technology 46, no. 21 (2012): 11505-11514.

Maier, R. M., Pepper, I. L., Gerba, C. P. “Environmental Microbiology, $2^{\text {nd }}$ Edition.” Elsevier, Inc.: London, U.K., 2009.

Masayuki, H., Murata, H., Nakata, Y. "Geomechanics and Geotechnics of Particulate Media." Taylor and Francis/Balkema: London, U.K., 2006.

Metcalf and Eddy, Inc. "Wastewater Engineering: Treatment and Reuse, $4^{\text {th }}$ Edition." Tchobanoglous, G., Burton, F. L., Stensel, D., ed. McGraw-Hill Companies, Inc.: New York, N.Y., 2003.

Mukherjee, P. S., Ray, A. K. "Major Challenges in the Design of a Large-Scale Photocatalytic Reactor for Water Treatment." Chemical Engineering Technology 22, no. 3 (1999): 253-260.

Nakada N., Shinohara H., Murata A., Kiri K., Managaki S., Sato N. "Removal of Selected Pharmaceuticals and Personal Care Products (PPCPs) and Endocrine-Disrupting Chemicals (EDCs) during Sand Filtration and Ozonation at a Municipal Sewage Treatment Plant." Water Research 41 (2007): 4373-4382.

Nakagawa, S., Kenmochi, Y., Tutumi, K., Tanaka, T., Hirasawa, I. "A Study on the Degradation of Endocrine Disruptors and Dioxins by Ozonation and Advanced Oxidation Processes." Journal of Chemical Engineering Japan 35, no. 9 (2002): 840-847.

Nghiem, L. D., Manis, A., Soldenhoff, K., Schäfer, A. I. "Estrogenic Hormone Removal from Wastewater Using NF/RO Membranes.” Journal of Membrane Science 242 (2004): 37-45. 
NREL, National Solar Radiation Database Update (1991-2005). In National Renewable Energy Laboratory, 2005.

Ottmar, K. J., Colosi, L. M., Smith, J. A. "Fate and Transport of Atorvastatin and Simvastatin Drugs during Conventional Wastewater Treatment." Chemosphere 88, no. 10 (2012): 1184-1189.

Pagsuyoin, S.A., Lung, W., Colosi, L. M. "Predicting EDC Concentrations in a River Mixing Zone." Chemosphere 87 (2012): 1111-1118.

Perry, R. H., Green, D. W. "Perry's Chemical Engineers' Handbook, 7th Edition.” McGrawHill: 1997.

Rajagopal, C., Kapoor, J. C. "Development of Adsorptive Removal Process for Treatment of Explosives Contaminated Wastewater Using Activated Carbon." Journal of Hazardous Materials B87 (2001): 73-98.

Ren, Y., Nakano, K., Nomura, M., Chiba, N., Nishimura, O. "Effects of Bacterial Activity on Estrogen Removal in Nitrifying Activated Sludge." Water Research 41, no. 14 (2007): 30893096 .

Rakness, K. L., Stover, E. L., Krenek, D. L. "Design, Start-Up, and Operation of an Ozone Disinfection Unit." Journal of Water Pollution Control Federation 56, no. 11 (1984): 1152-1159.

Redfield, A. C. "The Biological Control of Chemical Factors in the Environment." American Scientist 64 (1958), 205-221.

Rivanna Water and Sewer Authority, "Moore's Creek WWTP: Nutrient Removal Preliminary Engineering Report." Hazen and Sawyer Environmental Engineers and Scientist, 2007.

Rosenfeldt, E. J., Chen, P. J., Kullman, S., Linden, K. G. "Destruction of Estrogenic Activity in Water Using UV Advanced Oxidation.” Science of the Total Environment 377 (2007): 105-113.

Samson, R., Leduy, A. "Influence of Mechanical and Thermochemical Pretreatments on Anaerobic Digestion of Spirulina maxima Algal Biomass." Biotechnology Letters 5, no. 10 (1983): 671-676.

Sanchez-Hernandez, E. P., Travieso-Curdoba, L. "Anaerobic Digestion of Chlorella vulgaris for Energy Production.” Resources, Conservation and Recycling 9, no. 1-2 (1993): 127-132.

Schäfer, A. I., Nghiem, L. D., Waite, T. D. "Removal of the Natural Hormone Estrone from Aqueous Solutions Using Nanofiltration and Reverse Osmosis." Environmental Science and Technology 37 (2003): 182-188.

Shi, W., Wang, L., Rousseau, D. P. L., Lens, P. N. L. "Removal of Estrone, 17- $\alpha$ Ethinylestradiol, and 17- $\beta$ Estradiol in Algae and Duckweed-Based Wastewater Treatment Systems." Environmental Science Pollution Research 17 (2010): 824-833.

Sialve, B., Bernet, N., Bernard, O. "Anaerobic Digestion of Microalgae as a Necessary Step to Make Microalgal Biodiesel Sustainable.” Biotechnology Advances 27, no. 4 (2009): 409-416.

Sigma Aldrich, Inc. http://www.sigmaaldrich.com/united-states.html (accessed February 2012). 
Sosnowski, P., Wieczorek, A., Ledakowicz, S. "Anaerobic Co-digestion of Sewage Sludge and Organic Fraction of Municipal Solid Wastes." Advances in Environmental Research 7, no. 3 (2003): 609-616.

Spilling, K., Seppälä, J., Tamminen, T. "Inducing Autoflocculation in the Diatom Phaeodactylum tricornutum through $\mathrm{CO}_{2}$ Regulation.” Journal of Applied Phycology (2010): 1-8.

Stalter, D., Magdeburg, A., Weil, M., Knacker, T., Oehlmann, J. "Toxication or Detoxication? In Vivo Toxicity Assessment of Ozonation as Advanced Wastewater Treatment with the Rainbow Trout." Water Research 44, no. 2 (2010): 439-448.

Sukenik, A., Shelef, G. "Algal Autoflocculation - Verification and Proposed Mechanism." Biotechnology and Bioengineering 26, no. 2 (1984): 142-147.

Sumpter, J. P., Johnson, A. C. "Lessons from Endocrine Disruption and Their Application to Other Issues Concerning Trace Organics in the Aquatic Environment." Environmental Science and Technology 39, no. 12 (2005): 4321-4332.

Sundstrom, D. W., Klei, H. E. "Wastewater Treatment.” Prentice-Hall: Englewood Cliffs, N.J., 1979.

Sychrová, E., Štěpánková, T., Nováková, K., Bláha, L., Giesy, J. P., Hilscherová, K. "Estrogenic Activity in Extracts and Exudates of Cyanobacteia and Green Algae." Environment International 39 (2012): 134-140.

Ternes, T. A., Stuber, J., Herrmann, N., McDowell, D., Ried, A., Kampmann, M., Teiser, B. "Ozonation: A Tool for Removal of Pharmaceuticals, Contrast Media and Musk Fragrances from Wastewater?" Water Research 37 (2003): 1976-1982.

Ternes, T. A., Joss, A., Siegrist, H. "Scrutinizing Pharmaceuticals and Personal Care Products in Watswater Treatment." Environmental Science and Technology 38, no. 20 (2004): 392A-399A.

University of Texas Culture Collection of Algae. http://web.biosci.utexas.edu/utex/ (accessed June 2012).

Virginia Sewage Collection and Treatment Regulations, 2007:

http://lis.virginia.gov/000/reg/TOC09025.HTM (accessed January 2013).

Warman, P. R., Termeer, W. C. "Evaluation of Sewage Sludge, Septic Waste and Sludge Compost Applications to Corn and Forage: Yields and N, P and K Content of Crops and Soils." Bioresource Technology 96, no. 8 (2005): 955-961.

Weidema, B. "Ecoinvent Data v2.0.” http://www.ecoinvent.org/ (accessed September 2008).

Weber, S., Leuschner, P., Kämpfer, P., Dott, W., Hollender, J. "Degradation of Estradiol and Ethinylestradiol by Activated Sludge and by a Defined Mixed Culture." Applied Microbiology Biotechnology 67 (2005): 106-112. 
Westerhoff, P., Yoon, Y., Snyder, S., Wert, E. "Fate of Endocrine-Disruptor, Pharmaceutical, and Personal Care Product Chemicals During Simulated Drinking Water Treatment Processes." Environmental Science and Technology 39, no. 17 (2005): 6649-6663.

Wild, D., Kisliakova, A., Siegrist, H. "Prediction of Recycle Phosphorus Loads from Anaerobic Digestion.” Water Research 31, no. 9 (1997): 2300-2308.

Yen, H., Brune, D. E. “Anaerobic Co-Digestion of Algal Sludge and Waste Paper to Produce Methane.” Bioresource Technology 98, no. 1 (2007): 130-134.

Yoon, Y., Westerhoff, P., Snyder, S. A., Esparza, M. "HPLC-Fluorescence Detection and Adsorption of Bisphenol A, 17- $\beta$ Estradiol, and 17- $\alpha$ Ethinylestradiol on Powdered Activated Carbon." Water Research 37 (2003): 3530-3537.

Zhang, H., Yamada, H., Tsuno, H. "Removal of Endocrine-Disrupting Chemicals during Ozonation of Municipal Sewage with Brominated Byproducts Control." Environmental Science and Technology 42, no. 9 (2008): 3375-3380.

Zhang, Y., Zhou, J. L. "Removal of Estrone and 17-ßEstradiol from Water by Adsorption." Water Research 39 (2005): 3991-4003.

Zidouri, H. "Desalination in Morocco and Presentation of Design and Operation of the Laayoune Seawater Reverse Osmosis Plant.” Desalination 131 (2000): 137-145.

Zorita, S., Martensson, L., Mathiasson, L. "Occurrence and Removal of Pharmaceuticals in a Municipal Sewage Treatment System in the South of Sweden." Science of the Total Environment 407, no. 8 (2009): 2760-2770. 


\section{Chapter 6 \\ Conclusions and Directions for Future Work}

This dissertation investigated the synergies between municipal wastewater treatment and algae cultivation in terms of energy production, nutrient recycling, and removal of estrogenic endocrine disrupting compounds (eEDCs). Life cycle assessment (LCA) and laboratory experiments were used to assess the environmental sustainability of algae-to-bioenergy system, algae-derived energy carriers, algae cultivation configurations, and synergies between algae cultivation and wastewater treatment using both conventional environmental impacts (land use, energy use, water use, etc.) and eEDC removal. Relevant findings of the research are as follows:

1. Algae's life cycle cultivation impacts are highly dependent upon the availability of nutrients and carbon dioxide. The conversion processes downstream used to produce energy carriers are much smaller than the cultivation impacts (Chapter 2);

2. Algae can deliver more vehicle kilometers traveled (VKT) per hectare than the selected benchmark crops but at the same time create larger environmental burdens on a per-km basis. Economic drivers are likely to be more important in the decision to deploy biodiesel or bioelectricity (Chapter 3);

3. Open-pond (OP) algae-to-bioenergy systems are more environmentally and economically preferable than photobioreactors (PBRs) in delivering transportation energy, either as bioelectricity or biodiesel (Chapter 4); and 
4. The performance of wastewater treatment plant (WWTP) + algae system is better in an environmental sense (lower energy use) and ecosystem service perspective (lower cost per unit estrogenicity removed) than conventional activated sludge WWTPs.

\section{Future Work}

This work can be extended in a few important ways. Future work will be generally focused on the expansion of the current WWTP + tertiary treatment process to include full economic assessment of each alternative using life cycle costing (LCC) analysis (profitability, payback, etc.) and refinement to the experimental protocol. These experimental modifications will allow for a more accurate determination of algae hydraulic retention time (HRT) that includes:

1. Performance of a batch experiment for eEDC removal employing a much longer reaction time (> 6 days) to fully quantify the increasing effect of biosorption over time;

2. Performance of a batch experiment for eEDC removal employing mixed solution of eEDCs (E2, estrone (E1), and 17- $\alpha$ ethinylestradiol (EE2)) to investigate potential metabolites interaction;

3. Conduct of a large-scale biosorption experiment using large quantities of algae slurry. This promotes the accurate evaluation of the extent of biosorption in an industrial set-up appropriate for a WWTP.

Since national and statewide adaptation of an integrated WWTP + algae system depends on land availability, a reconnaissance of all existing and operational WWTPs in the U.S. must be conducted using appropriate GIS databases. This will determine social acceptability, economic implications, and further improvements of an algae pond in a wastewater treatment facility. 
Anaerobic digestion, a promising method of producing bioelectricity, can be further enhanced by exploring other sources of digester inputs. The conduct of bench-scale co-digestion experiments using multiple biomass feeds, in addition to algae and wastewater sludge, will assess improvements in digestate production and methane yield. Environmental impacts and financial feasibility assessment of other algae biomass conversion processes such as thermochemical liquefaction and pyrolysis can also be performed. This will increase the number of conversion pathway and bioenergy carrier (i.e., bioorganics) alternatives that can be used in performing comparative LCA + LCC.

Finally, algae-mediated wastewater treatment can be extended to include other contaminants such as pharmaceuticals, organic compounds, and heavy metals. The use of high performance liquid chromatography (HLPC), UV-vis spectrophotometry, and microscopy enables accurate determination of these wastewater pollutants after lab-scale batch tests using single freshwater algae species. In the future, improved pollutant quantitation can be achieved if a more sophisticated instrument is used, particularly liquid chromatography-mass spectrometry (LCMS). The use of LCMS will be especially relevant if experiments are done using mixed algae culture or perhaps other organic substrates. 


\section{Appendices}

\section{Appendix A. Media Formulation}

\section{Table A.1. Protease Medium ${ }^{\mathrm{A}}$ Formulation}

\begin{tabular}{lccc}
\multicolumn{1}{c}{ Component } & Amount & $\begin{array}{c}\text { Stock Solution } \\
\text { Concentration }\end{array}$ & $\begin{array}{c}\text { Final } \\
\text { Concentration }\end{array}$ \\
\hline Bristol Medium & $1 \mathrm{~L}$ & $\mathrm{NA}^{\mathrm{B}}$ & NA \\
Protease Peptone & $1 \mathrm{~g} / \mathrm{L}$ & $\mathrm{NA}$ & NA \\
\hline
\end{tabular}
A. For $1 \mathrm{~L}$ total, $\mathrm{pH} \sim 6.8$ (University of Texas Culture Collection of Algae, 2012):
1. Add Proteose Peptone to Bristol medium.
2. Cover and autoclave medium.
B. $\mathrm{NA}=$ non-applicable.

\section{Table A.2. Bristol Medium ${ }^{\mathrm{A}}$ Formulation}

\begin{tabular}{lccc}
\hline \multicolumn{1}{c}{ Component } & Amount & $\begin{array}{c}\text { Stock Solution } \\
\text { Concentration }\end{array}$ & $\begin{array}{c}\text { Final } \\
\text { Concentration }\end{array}$ \\
\hline $\mathrm{NaNO}_{3}$ & $10 \mathrm{~mL} / \mathrm{L}$ & $10 \mathrm{~g} / 400 \mathrm{~mL} \mathrm{dH} 2 \mathrm{O}$ & $2.94 \mathrm{mM}$ \\
$\mathrm{CaCl}_{2} \cdot 2 \mathrm{H}_{2} \mathrm{O}$ & $10 \mathrm{~mL} / \mathrm{L}$ & $1 \mathrm{~g} / 400 \mathrm{~mL} \mathrm{dH} 2 \mathrm{O}$ & $0.17 \mathrm{mM}$ \\
$\mathrm{MgSO}_{4} \cdot 7 \mathrm{H}_{2} \mathrm{O}$ & $10 \mathrm{~mL} / \mathrm{L}$ & $3 \mathrm{~g} / 400 \mathrm{~mL} \mathrm{dH} 2 \mathrm{O}$ & $0.30 \mathrm{mM}$ \\
$\mathrm{K}_{2} \mathrm{HPO}_{4}$ & $10 \mathrm{~mL} / \mathrm{L}$ & $3 \mathrm{~g} / 400 \mathrm{~mL} \mathrm{dH} 2 \mathrm{O}$ & $0.43 \mathrm{mM}$ \\
$\mathrm{KH}_{2} \mathrm{PO}_{4}$ & $10 \mathrm{~mL} / \mathrm{L}$ & $7 \mathrm{~g} / 400 \mathrm{~mL} \mathrm{dH} 2 \mathrm{O}$ & $1.29 \mathrm{mM}$ \\
$\mathrm{NaCl}$ & $10 \mathrm{~mL} / \mathrm{L}$ & $1 \mathrm{~g} / 400 \mathrm{~mL} \mathrm{dH} 2 \mathrm{O}$ & $0.43 \mathrm{mM}$ \\
\hline
\end{tabular}

A. For $1 \mathrm{~L}$ total (University of Texas Culture Collection of Algae, 2012):

1. To approximately $900 \mathrm{~mL}$ of $\mathrm{dH}_{2} \mathrm{O}$, add each of the components in the order specified while stirring continuously.

2. Cover and autoclave medium.

3. Store at refrigerator temperature.

Table A.3. Modified Bold 3N Medium ${ }^{\mathrm{A}}$ Formulation

\begin{tabular}{|c|c|c|c|}
\hline Component & Amount & $\begin{array}{l}\text { Stock Solution } \\
\text { Concentration }\end{array}$ & $\begin{array}{c}\text { Final } \\
\text { Concentration }\end{array}$ \\
\hline $\mathrm{NaNO}_{3}$ & $30 \mathrm{~mL} / \mathrm{L}$ & $10 \mathrm{~g} / 400 \mathrm{~mL} d \mathrm{H} 2 \mathrm{O}$ & $8.82 \mathrm{mM}$ \\
\hline $\mathrm{CaCl}_{2} \cdot 2 \mathrm{H}_{2} \mathrm{O}$ & $10 \mathrm{~mL} / \mathrm{L}$ & $1 \mathrm{~g} / 400 \mathrm{~mL} \mathrm{dH} 2 \mathrm{O}$ & $0.17 \mathrm{mM}$ \\
\hline $\mathrm{MgSO}_{4} \cdot 7 \mathrm{H}_{2} \mathrm{O}$ & $10 \mathrm{~mL} / \mathrm{L}$ & $3 \mathrm{~g} / 400 \mathrm{~mL} d \mathrm{H} 2 \mathrm{O}$ & $0.30 \mathrm{mM}$ \\
\hline $\mathrm{K}_{2} \mathrm{HPO}_{4}$ & $10 \mathrm{~mL} / \mathrm{L}$ & $3 \mathrm{~g} / 400 \mathrm{~mL} d \mathrm{H} 2 \mathrm{O}$ & $0.43 \mathrm{mM}$ \\
\hline $\mathrm{KH}_{2} \mathrm{PO}_{4}$ & $10 \mathrm{~mL} / \mathrm{L}$ & $7 \mathrm{~g} / 400 \mathrm{~mL} d \mathrm{H} 2 \mathrm{O}$ & $1.29 \mathrm{mM}$ \\
\hline $\mathrm{NaCl}$ & $10 \mathrm{~mL} / \mathrm{L}$ & $1 \mathrm{~g} / 400 \mathrm{~mL} d \mathrm{H} 2 \mathrm{O}$ & $0.43 \mathrm{mM}$ \\
\hline P-IV Metal Solution & $6 \mathrm{~mL} / \mathrm{L}$ & NA & NA \\
\hline Soilwater: GR+ Medium & $40 \mathrm{~mL} / \mathrm{L}$ & NA & NA \\
\hline Vitamin B12 Solution & $1 \mathrm{~mL} / \mathrm{L}$ & NA & NA \\
\hline Biotin Vitamin Solution & $1 \mathrm{~mL} / \mathrm{L}$ & NA & NA \\
\hline Thiamine Vitamin Solution & $1 \mathrm{~mL} / \mathrm{L}$ & NA & NA \\
\hline
\end{tabular}

A. For 1 L total, $\mathrm{pH} \sim 6.2$ (University of Texas Culture Collection of Algae, 2012):

1. To approximately $850 \mathrm{~mL}$ of $\mathrm{dH}_{2} \mathrm{O}$, add each of the components in the order specified (except vitamins) while stirring continuously. 
2. Bring the total volume to $1 \mathrm{~L}$ with $\mathrm{dH}_{2} \mathrm{O}$.

3. Cover and autoclave medium.

4. When cooled add vitamins.

5. Store at refrigerator temperature.

B. $\mathrm{NA}=$ non-applicable.

\section{Table A.4. P-IV Metal Solution ${ }^{\mathrm{A}}$ Formulation}

\begin{tabular}{lccc}
\multicolumn{1}{c}{ Component } & Amount & $\begin{array}{c}\text { Stock Solution } \\
\text { Concentration }\end{array}$ & $\begin{array}{c}\text { Final } \\
\text { Concentration }\end{array}$ \\
\hline $\mathrm{Na}_{2} \mathrm{EDTA} \cdot 2 \mathrm{H}_{2} \mathrm{O}$ & $0.750 \mathrm{~g} / \mathrm{L}$ & $\mathrm{NA}^{\mathrm{B}}$ & $2.0000 \mathrm{mM}$ \\
$\mathrm{FeCl}_{3} \cdot 6 \mathrm{H}_{2} \mathrm{O}$ & $0.097 \mathrm{~g} / \mathrm{L}$ & $\mathrm{NA}$ & $0.3600 \mathrm{mM}$ \\
$\mathrm{MnCl}_{2} \cdot 4 \mathrm{H}_{2} \mathrm{O}$ & $0.041 \mathrm{~g} / \mathrm{L}$ & $\mathrm{NA}$ & $0.2100 \mathrm{mM}$ \\
$\mathrm{ZnCl}_{2}$ & $0.005 \mathrm{~g} / \mathrm{L}$ & $\mathrm{NA}$ & $0.0370 \mathrm{mM}$ \\
$\mathrm{CoCl}_{2} \cdot 6 \mathrm{H}_{2} \mathrm{O}$ & $0.002 \mathrm{~g} / \mathrm{L}$ & $\mathrm{NA}$ & $0.0084 \mathrm{mM}$ \\
$\mathrm{Na}_{2} \mathrm{MoO}_{4} \cdot 2 \mathrm{H}_{2} \mathrm{O}$ & $0.004 \mathrm{~g} / \mathrm{L}$ & $\mathrm{NA}$ & $0.0170 \mathrm{mM}$ \\
\hline
\end{tabular}

A. For $1 \mathrm{~L}$ total (University of Texas Culture Collection of Algae, 2012):

1. To approximately $950 \mathrm{~mL}$ of $\mathrm{dH}_{2} \mathrm{O}$, add the nutrients in the order listed while stirring continuously. Note: The $\mathrm{Na}_{2}$ EDTA should be fully dissolved before adding other components.

2. Bring total volume to $1 \mathrm{~L}$ with $\mathrm{dH}_{2} \mathrm{O}$.

3. Store at refrigerator temperature.

B. $\mathrm{NA}=$ non-applicable.

\section{Table A.5. Soilwater: GR+ Medium ${ }^{\mathrm{A}}$ Formulation}

\begin{tabular}{lccc}
\multicolumn{1}{c}{ Component } & Amount & $\begin{array}{c}\text { Stock Solution } \\
\text { Concentration }\end{array}$ & $\begin{array}{c}\text { Final } \\
\text { Concentration }\end{array}$ \\
\hline Green House Soil $^{\mathrm{B}}$ & $1 \mathrm{tsp} / 200 \mathrm{~mL} \mathrm{dH}{ }_{2} \mathrm{O}$ & $\mathrm{NA}^{\mathrm{C}}$ & $\mathrm{NA}$ \\
$\mathrm{CaCO}_{3}$ (optional) & $1 \mathrm{mg} / 200 \mathrm{~mL} \mathrm{dH}{ }_{2} \mathrm{O}$ & $\mathrm{NA}$ & $0.05 \mathrm{mM}$ \\
\hline
\end{tabular}

A. For $200 \mathrm{~mL}$ total (University of Texas Culture Collection of Algae, 2012):

1. Combine all components listed.

2. Cover the medium container and steam for 2 consecutive days, 3 hours on each day. Pasteurization is a gradual rising of temperature to approximately $95^{\circ} \mathrm{C}$ in 15 minutes. Increase just over $98^{\circ} \mathrm{C}$ for the 3 -hour duration. Cooling occurs gradually at room temperature.

3. Refrigerate for 24 hours or more and bring to room temperature before using.

B. Prior to its use in soil-water media, treat soil in batches by placing it in a heat-resistant pan lined with aluminum foil, fill the soil to a so depth of $1 / 4$ inch, and bake at $150^{\circ} \mathrm{C}$ for 2 hours. After it cools, cover the pan with aluminum foil and store in darkness at room temperature. Avoid excessive moisture during storage.

1. The soil should be loam, with a mixture of particle sizes (sand, silt, clay).

2. It should contain a moderate amount (15-20\%) of well-decomposed organic matter.

3. It must not contain pesticides, especially herbicides.

4. It should be soil that has been aged (preferably for 6 months or more) under moist conditions and not, for example, fresh potting soil, soil that contains fresh manure, or soil to which a commercial fertilizer was recently applied.

5. A slightly acidic soil derived from granite or other igneous rock is preferable to soil obtained from calcareous soils. Calcium carbonate can be added to the soilwater medium when it is prepared if a slightly alkaline medium is required.

6. Particulate matter in the soil such as gravel, perlite, or vermiculite are not necessarily damaging but can be of considerable nuisance when wishing to quantitate the amount of soil used in the medium or when handling algae that are physically associated with the soil. Particulate organic matter, such as compost that is only partially degraded, should be avoided altogether.

C. $\mathrm{NA}=$ non-applicable. 
Table A.6. Vitamin B12 Solution ${ }^{\mathrm{A}}$ Formulation

\begin{tabular}{lccc}
\multicolumn{1}{c}{ Component } & Amount & $\begin{array}{c}\text { Stock Solution } \\
\text { Concentration }\end{array}$ & $\begin{array}{c}\text { Final } \\
\text { Concentration }\end{array}$ \\
\hline HEPES buffer, $\mathrm{pH} 7.8$ & $2.400 \mathrm{~g} / 200 \mathrm{~mL} \mathrm{dH} \mathrm{H}_{2} \mathrm{O}$ & $\mathrm{NA}^{\mathrm{B}}$ & $50 \mathrm{mM}$ \\
Vitamin B12 (Cyanocobalamin) & $0.027 \mathrm{~g} / 200 \mathrm{~mL} \mathrm{dH}{ }_{2} \mathrm{O}$ & $\mathrm{NA}$ & $0.1 \mathrm{mM}$ \\
\hline
\end{tabular}

A. For $200 \mathrm{~mL}$ total (University of Texas Culture Collection of Algae, 2012):

1. Prepare $200 \mathrm{~mL}$ of HEPES buffer $(50 \mathrm{mM})$.

2. Adjust the $\mathrm{pH}$ to 7.8 .

3. Add Vitamin B12 (0.1 mM). Wait until fully dissolved.

4. Sterilize using $0.45-\mu \mathrm{m}$ Millipore filter. Store in a dark place at freezer temperature.

Note: The amount of vitamins added can vary from medium to medium so the final concentration is not listed.

B. NA = non-applicable.

\section{Table A.7. Biotin Vitamin Solution ${ }^{\mathrm{A}}$ Formulation}

\begin{tabular}{lccc}
\hline \multicolumn{1}{c}{ Component } & Amount & $\begin{array}{c}\text { Stock Solution } \\
\text { Concentration }\end{array}$ & $\begin{array}{c}\text { Final } \\
\text { Concentration }\end{array}$ \\
\hline HEPES buffer, $\mathrm{pH} \mathrm{7.8}$ & $2.400 \mathrm{~g} / 200 \mathrm{~mL} \mathrm{dH} \mathrm{H}_{2} \mathrm{O}$ & $\mathrm{NA}^{\mathrm{B}}$ & $50 \mathrm{mM}$ \\
Biotin & $0.005 \mathrm{~g} / 200 \mathrm{~mL} \mathrm{dH} \mathrm{m}_{2} \mathrm{O}$ & $\mathrm{NA}$ & $0.1 \mathrm{mM}$ \\
\hline
\end{tabular}

A. For $200 \mathrm{~mL}$ total (University of Texas Culture Collection of Algae, 2012):

1. Prepare $200 \mathrm{~mL}$ of HEPES buffer $(50 \mathrm{mM})$.

2. Adjust the $\mathrm{pH}$ to 7.8 .

3. Add Biotin (0.1 mM). Wait until fully dissolved.

4. Sterilize using $0.45-\mu \mathrm{m}$ Millipore filter. Store in a dark place at freezer temperature.

Note: The amount of vitamins added can vary from medium to medium so the final concentration is not listed.

B. $\mathrm{NA}=$ non-applicable.

\section{Table A.8. Thiamine Vitamin Solution ${ }^{\mathrm{A}}$ Formulation}

\begin{tabular}{lccc}
\multicolumn{1}{c}{ Component } & Amount & $\begin{array}{c}\text { Stock Solution } \\
\text { Concentration }\end{array}$ & $\begin{array}{c}\text { Final } \\
\text { Concentration }\end{array}$ \\
\hline HEPES buffer, $\mathrm{pH} 7.8$ & $1.20 \mathrm{~g} / 200 \mathrm{~mL} \mathrm{dH}_{2} \mathrm{O}$ & $\mathrm{NA}^{\mathrm{B}}$ & $50 \mathrm{mM}$ \\
Thiamine & $0.11 \mathrm{~g} / 200 \mathrm{~mL} \mathrm{dH} \mathrm{H}_{2} \mathrm{O}$ & $\mathrm{NA}$ & $6.5 \mathrm{mM}$ \\
\hline
\end{tabular}

A. For $50 \mathrm{~mL}$ total (University of Texas Culture Collection of Algae, 2012):

1. Prepare $50 \mathrm{~mL}$ of HEPES buffer $(50 \mathrm{mM})$.

2. Adjust the $\mathrm{pH}$ to 7.8 .

3. Add Biotin (6.5 mM). Wait until fully dissolved.

4. Sterilize using $0.45-\mu \mathrm{m}$ Millipore filter. Store in a dark place at freezer temperature.

Note: The amount of vitamins added can vary from medium to medium so the final concentration is not listed.

B. $\mathrm{NA}=$ non-applicable. 


\section{Appendix B. Standard Calibration Curves}

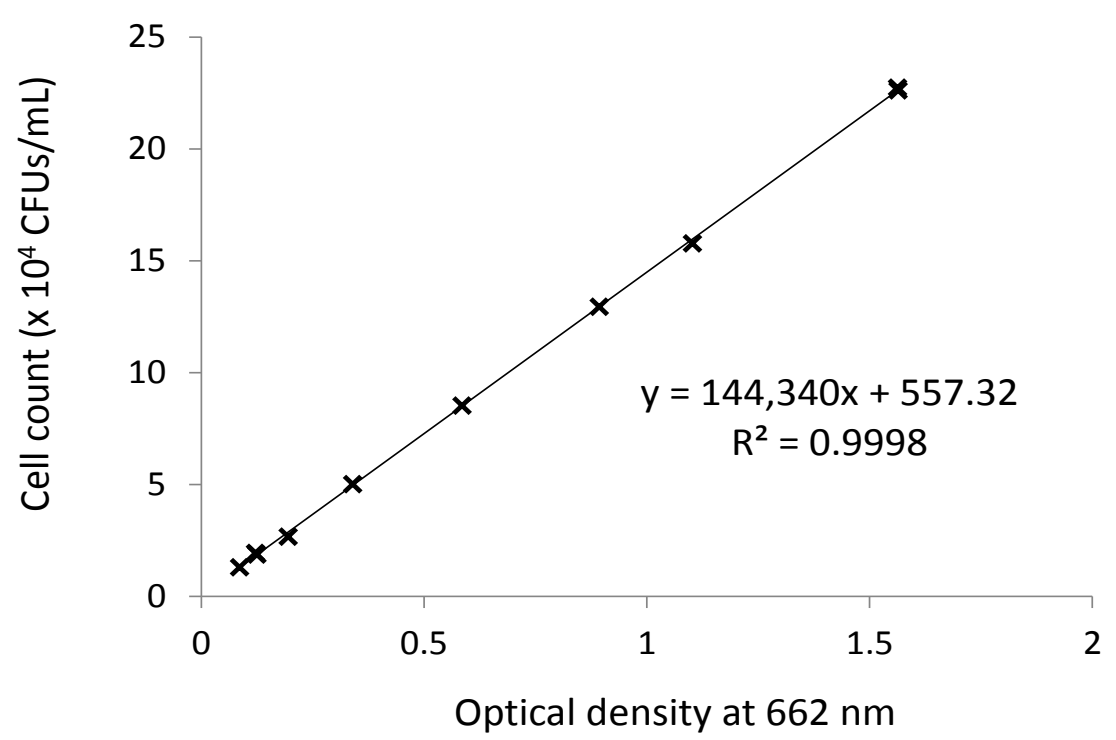

Figure B.1. Standard calibration curve for algae cell count using optical density (OD) at $662 \mathrm{~nm}$. Markers are actual cell count from hemocytometer readings and OD from UV-spectrophotometer readings. Solid line is regression line.

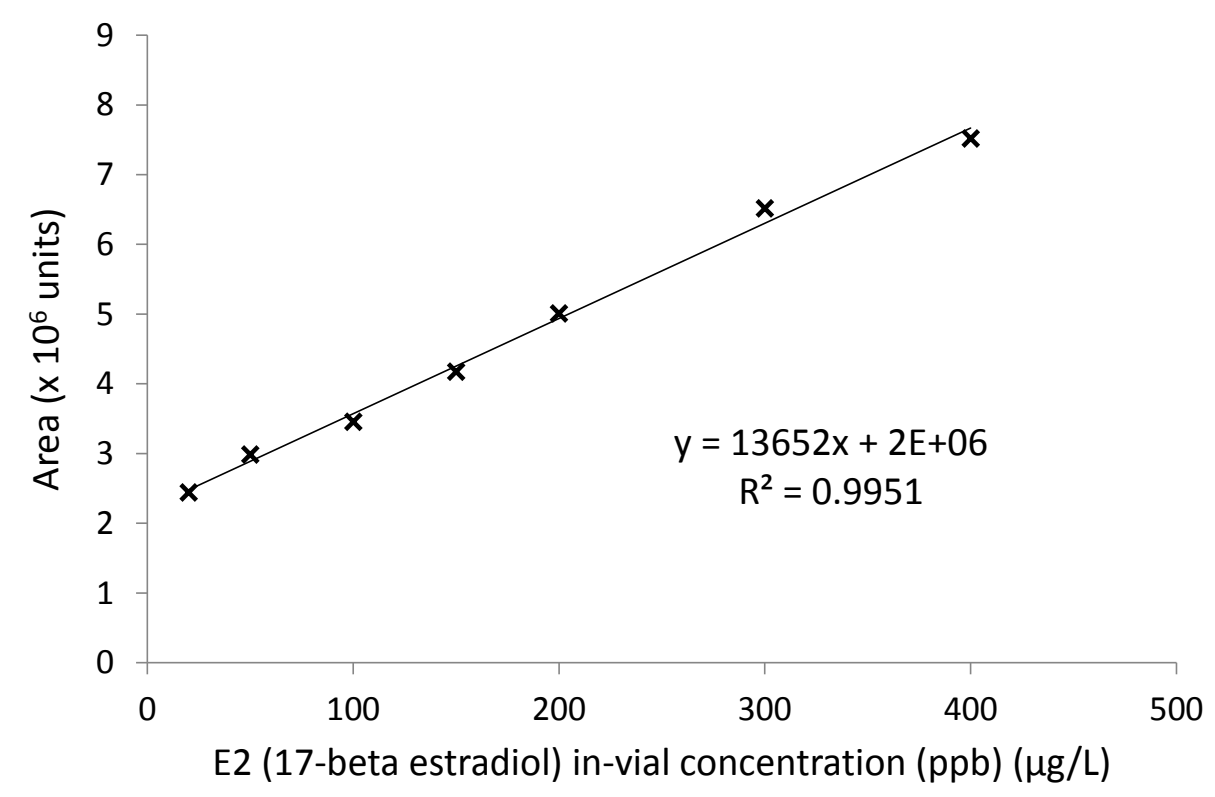

Figure B.2. Standard calibration curve for $17-\beta$ estradiol (E2). Markers are actual HPLC measurements. Solid line is regression line. 


\section{Appendix C. Chromatographs for Standards}

Method for Figures C.1-C.9 (linear range $=20-400 \mathrm{ppb}$ ):

Equipment: Shimadzu Prominence 20A-series chromatograph equipped with UV-Vis and fluorescence detectors.

Detector: Fluorescence detector at excitation wavelength $=280 \mathrm{~nm}$ and emission wavelength $=$ $310 \mathrm{~nm}$.

Column: Restek $^{\circledR}$ reverse-phase biphenyl column $(150 \mathrm{~mm} \times 2.1 \mathrm{~mm} \times 5 \mu \mathrm{m})$.

Mobile phase: $25 \mathrm{mM} \mathrm{H}_{3} \mathrm{PO}_{4}(\mathrm{~A})$ and HPLC-grade acetonitrile $(\mathrm{ACN})(\mathrm{B})$.

Flowrate: $0.75 \mathrm{~mL} / \mathrm{min}$.

Injection volume: $100 \mu \mathrm{L}$.

Gradient: $0-0.01 \mathrm{~min}$ (Start); 0.01-15 minutes (30\% B); $15-23$ minutes (30-40\% B); 23-26 minutes (40\% B); 26-27 minutes (40-10\% B); 27-32 minutes (10-30\% B); 32-40 minutes (30\% B); 40-40.10 min (Stop).

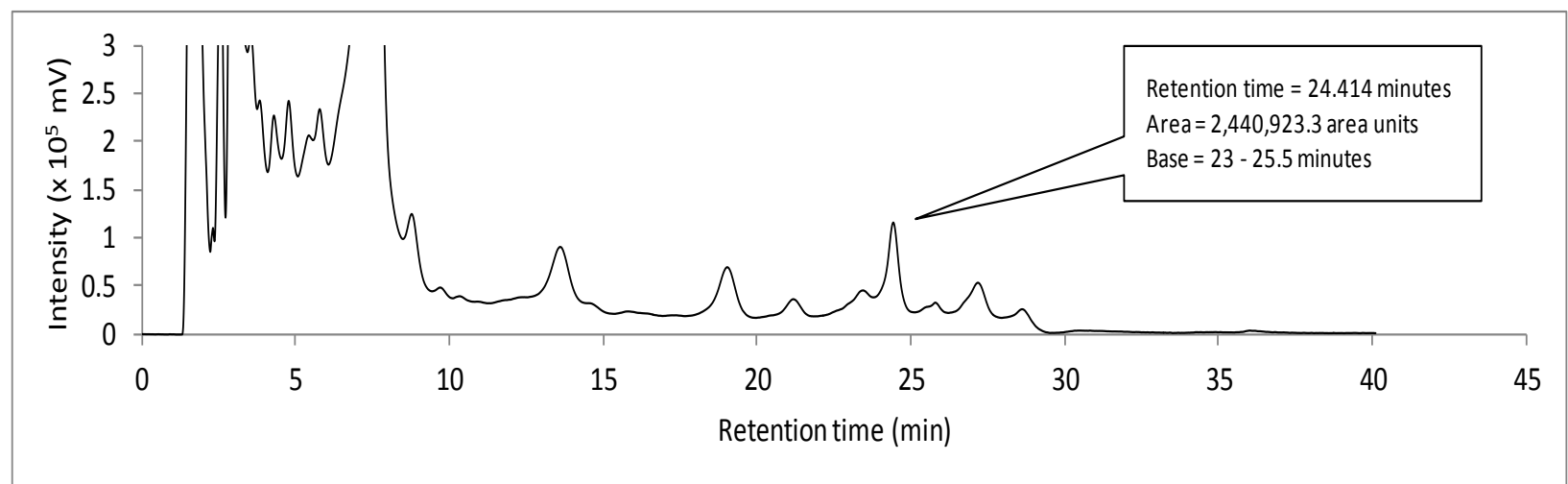

Figure C.1. Chromatogram for $20 \mathrm{ppb}(\mu \mathrm{g} / \mathrm{L}) \mathrm{E} 2$ (17-beta estradiol) in algal organic matter.

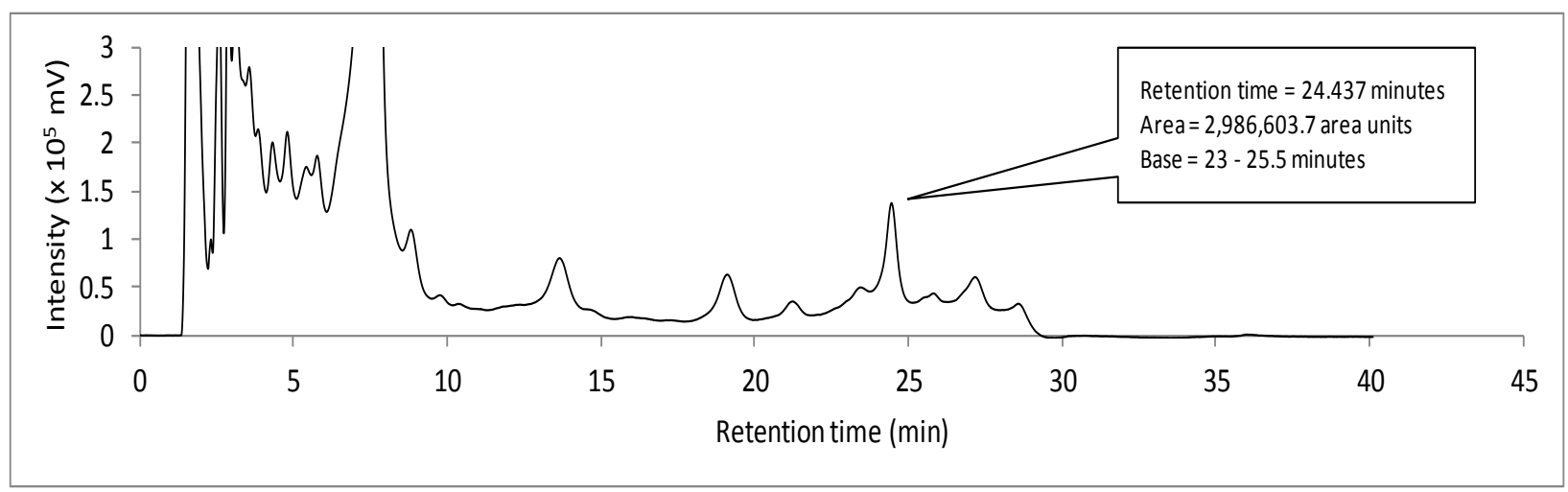

Figure C.2. Chromatogram for $50 \mathrm{ppb}(\mu \mathrm{g} / \mathrm{L})$ E2 (17-beta estradiol) in algal organic matter. 


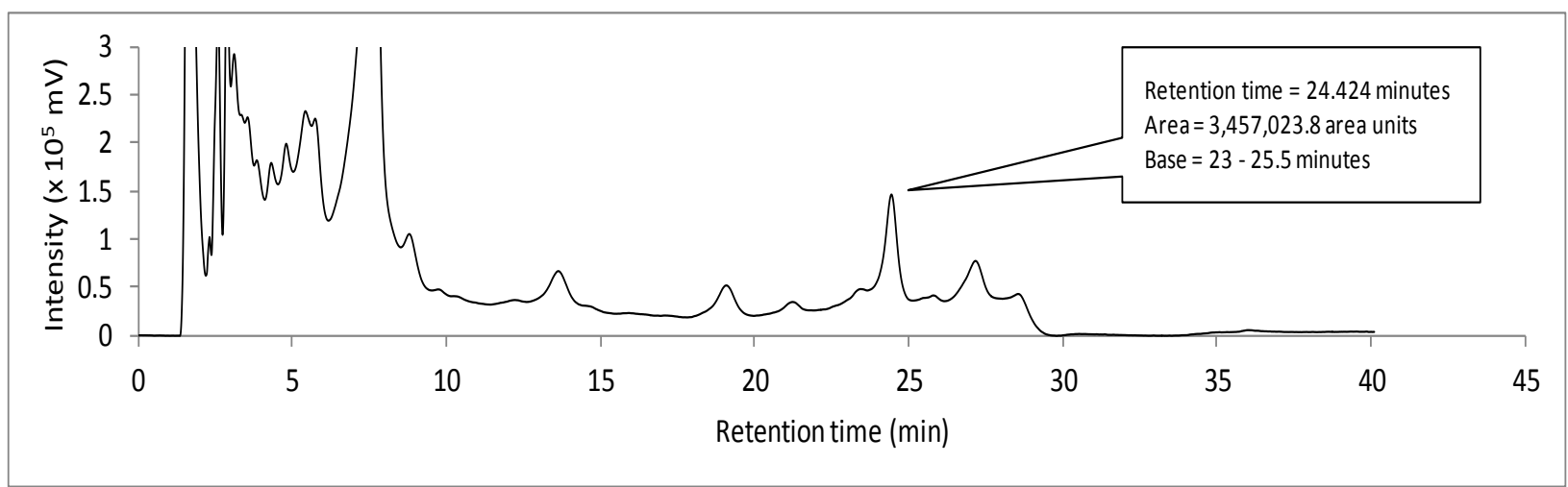

Figure C.3. Chromatogram for $100 \mathrm{ppb}(\mu \mathrm{g} / \mathrm{L})$ E2 (17-beta estradiol) in algal organic matter.

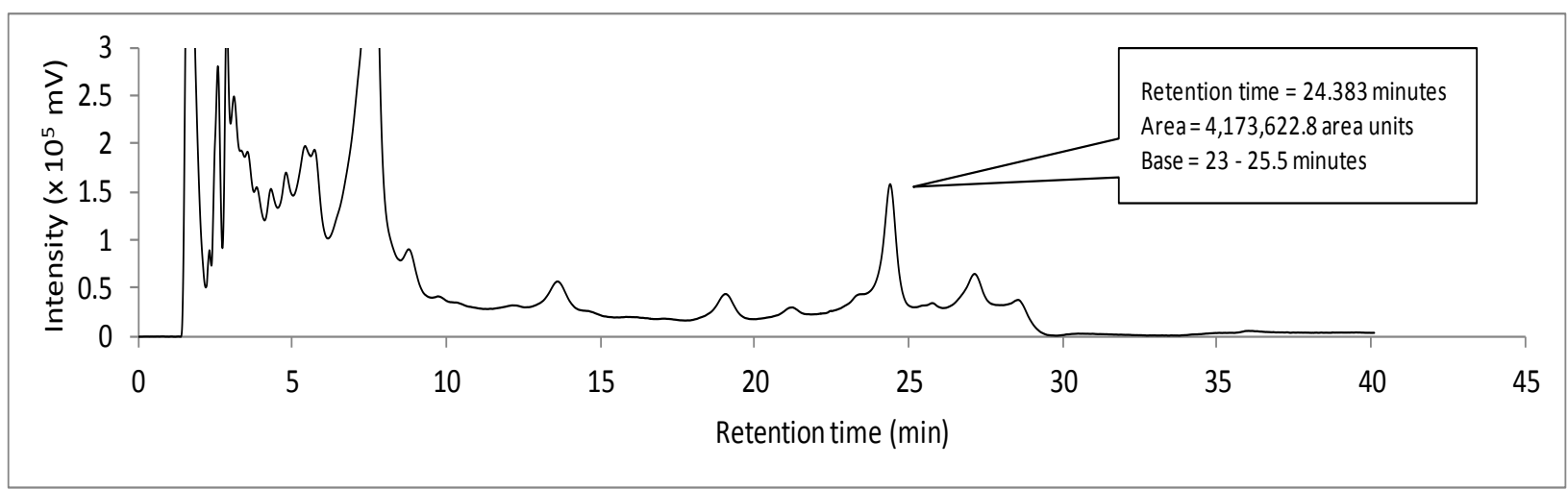

Figure C.4. Chromatogram for $150 \mathrm{ppb}(\mu \mathrm{g} / \mathrm{L}) \mathrm{E} 2$ (17-beta estradiol) in algal organic matter.

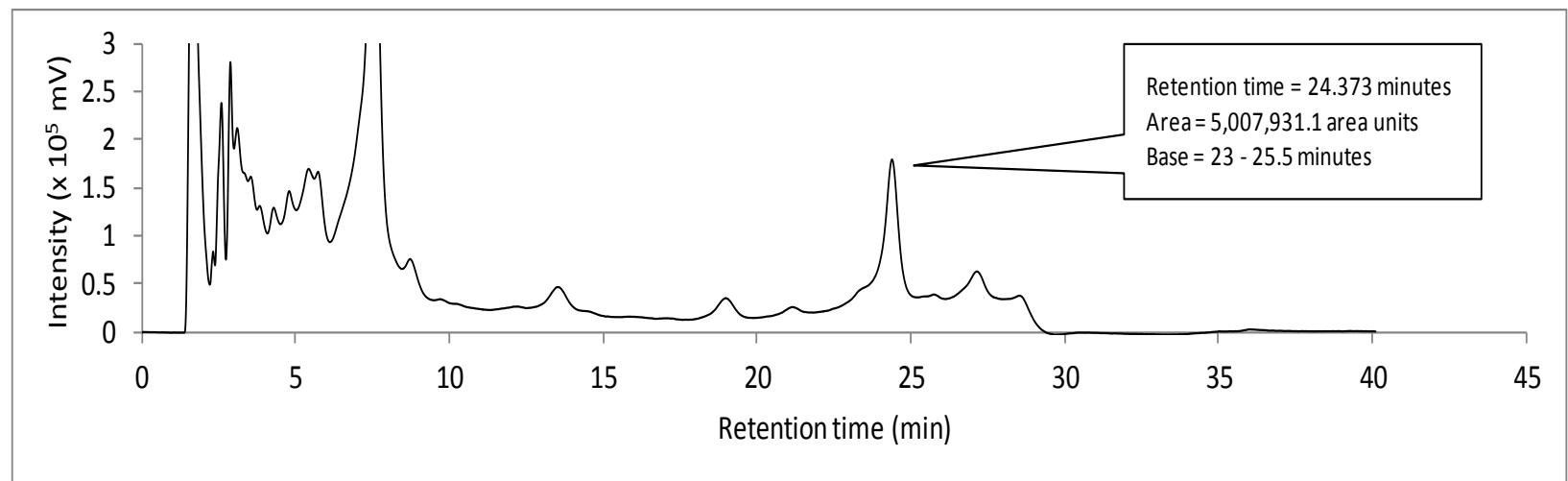

Figure C.5. Chromatogram for $200 \mathrm{ppb}(\mu \mathrm{g} / \mathrm{L})$ E2 (17-beta estradiol) in algal organic matter. 


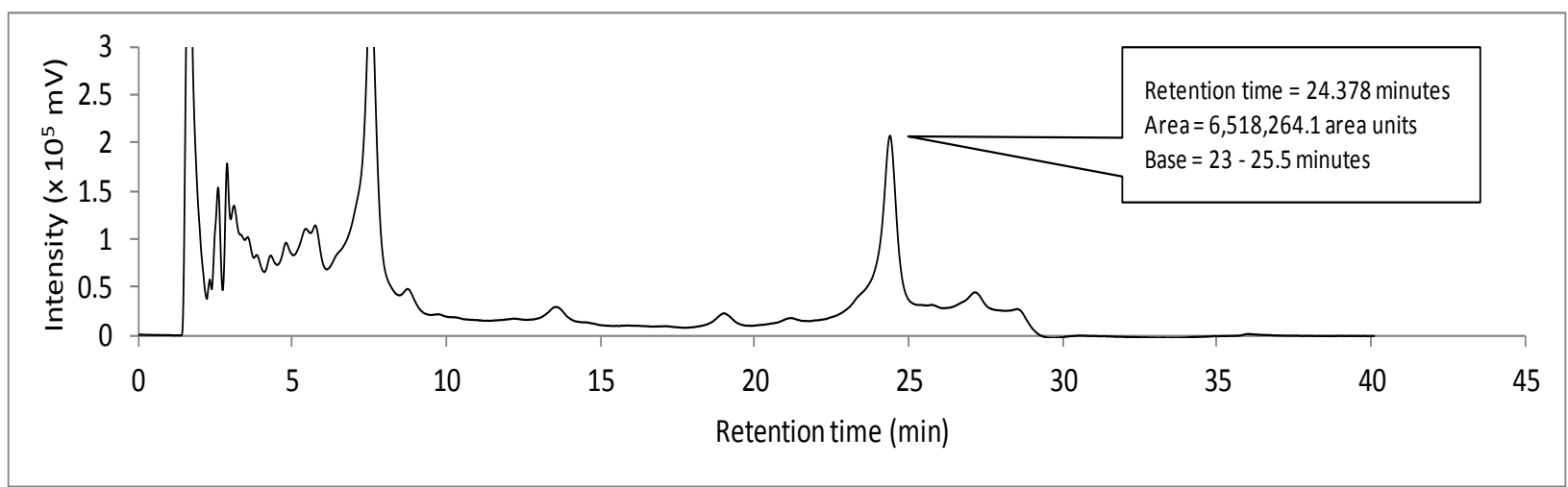

Figure C.6. Chromatogram for $300 \mathrm{ppb}(\mu \mathrm{g} / \mathrm{L})$ E2 (17-beta estradiol) in algal organic matter.

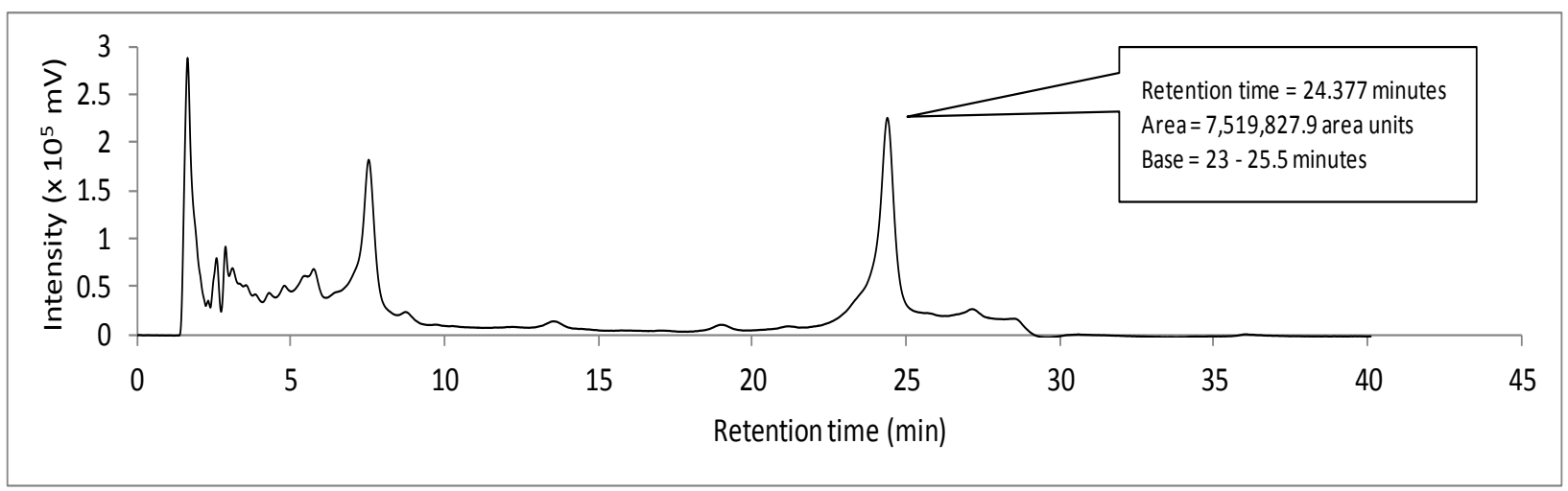

Figure C.7. Chromatogram for $400 \mathrm{ppb}(\mu \mathrm{g} / \mathrm{L})$ E2 (17-beta estradiol) in algal organic matter. 